\title{
MEFLOQUINE DREAMS: EXPLORING THE SUBJECTIVE \\ EXPERIENCE OF RISK AND SAFETY AND ITS ROLE IN THE \\ REGULATION OF PHARMACEUTICAL DRUGS IN CANADA
}

\author{
by \\ KIMBERLY-ANNE FORD, M.A. \\ A thesis submitted to \\ the Faculty of Graduate Studies and Research \\ in partial fulfillment of the requirements for the degree of \\ Doctor of Philosophy
}

Department of Sociology and Anthropology
Carleton University
Ottawa, Ontario

September 19, 2006

(C) copyright 2006 by

Kimberly-Anne Ford 


$\begin{array}{ll}\begin{array}{l}\text { Library and } \\ \text { Archives Canada }\end{array} & \begin{array}{l}\text { Bibliothèque et } \\ \text { Archives Canada }\end{array} \\ \begin{array}{l}\text { Published Heritage } \\ \text { Branch }\end{array} & \begin{array}{l}\text { Direction du } \\ \text { Patrimoine de l'édition }\end{array} \\ \begin{array}{l}\text { 395 Wellington Street } \\ \text { Ottawa ON K1A ON4 }\end{array} & \begin{array}{l}\text { 395, rue Wellington } \\ \text { Ottawa ON K1A ON4 } \\ \text { Canada }\end{array}\end{array}$

Your file Votre référence ISBN: 978-0-494-18218-5 Our file Notre référence ISBN: 978-0-494-18218-5

NOTICE:

The author has granted a nonexclusive license allowing Library and Archives Canada to reproduce, publish, archive, preserve, conserve, communicate to the public by telecommunication or on the Internet, loan, distribute and sell theses worldwide, for commercial or noncommercial purposes, in microform, paper, electronic and/or any other formats.

The author retains copyright ownership and moral rights in this thesis. Neither the thesis nor substantial extracts from it may be printed or otherwise reproduced without the author's permission.
AVIS:

L'auteur a accordé une licence non exclusive permettant à la Bibliothèque et Archives Canada de reproduire, publier, archiver, sauvegarder, conserver, transmettre au public par télécommunication ou par l'Internet, prêter, distribuer et vendre des thèses partout dans le monde, à des fins commerciales ou autres, sur support microforme, papier, électronique et/ou autres formats.

L'auteur conserve la propriété du droit d'auteur et des droits moraux qui protège cette thèse. $\mathrm{Ni}$ la thèse ni des extraits substantiels de celle-ci ne doivent être imprimés ou autrement reproduits sans son autorisation.
In compliance with the Canadian

Privacy Act some supporting forms may have been removed from this thesis.

While these forms may be included in the document page count, their removal does not represent any loss of content from the thesis.
Conformément à la loi canadienne sur la protection de la vie privée, quelques formulaires secondaires ont été enlevés de cette thèse.

Bien que ces formulaires aient inclus dans la pagination, il n'y aura aucun contenu manquant.

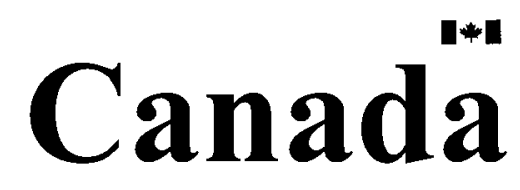




\section{Abstract}

Mefloquine is a controversial anti-malarial drug. Health Canada, the Canadian military, and travel medicine providers (TMPs) across the country affirm that it is safe and effective. However, government reports, radio and television investigations, questions raised in the House of Commons, and testimonial by travellers challenge this claim, pointing to the potential of serious neuro-psychiatric side effects. This thesis employs a case study of mefloquine to answer the question: With specific reference to the prevention and treatment of malaria, what role do/could alternative epistemologiesbased upon subjective experience-play in the construction of medical knowledge and understandings of risk and safety? This question is broken down into two sub-questions: What is the present state of knowledge on malaria and mefloquine? and How does/could subjective experience influence the regulation of drug safety and the creation of public health knowledge (in particular anti-malarial campaigns)?

A three-pronged theoretical framework is informed by three stages in the history of medicine: First, medicalisation refers to an epistemological shift towards positivism and a growing tendency for behaviours to be scrutinised by the 'medical gaze'. In the second stage-governmentality—individuals are encouraged to govern themselves according to 'truths' about what constitutes the good of society. In the third stagereflexivity - there is a demand for greater involvement of laypeople in the creation and reproduction of medical knowledge.

A multi-method approach, including in-depth interviews, surveys, and analyses of weblogs, government documents, and the Health Canada adverse reactions database, is 
adopted. The methodology was guided by the principles of participatory action research, reflexive ethnography, stakeholder analysis and genealogy.

While statements by interview respondents and 'bloggers' cited in the study illustrate that health advocacy is frequently born of personal experience, TMPs tend to denigrate the role of personal experience in the health care process. Subjective experience-in the form of medical symptoms, reports of illnesses and/or psychotic episodes, and recovery information - allows the system of drug regulation to function. A more proactive role for subjective knowledge-wherein it aligns scientific and technical developments with general social needs and interests-is discussed in the conclusion.

KEYWORDS: Advocacy, Auto-Ethnography, Department of National Defence, Health Canada, Genealogy, Governmentality, Malaria, Medicalisation, Mefloquine, Medical Sociology, Participatory Action Research, Pharmaceutical Drug Regulation, Reflexivity, Risk, Stakeholder Analysis, Subjective Knowledge, Travel Medicine, Weblog. 


\section{Acknowledgements}

Putting together a Ph.D. thesis committee can be quite challenging. I really struck gold with this team! My co-supervisors, Florence Kellner and Louise de la Gorgendière, provided enthusiastic supervision and sustained encouragement. My work has improved considerably thanks to their expertise and advice, and from their detailed and considerate feedback throughout the research process. They have been mentors to me, in every sense of the word. As an undergraduate at Concordia University, Anthony Synnott's 'Social Problems' course influenced my decision to switch from a Major in French Literature to an Honours Degree in Sociology. I have since then benefited from his creative teaching and firm commitment to his students' wellbeing. Finally, I was inspired early on in my Ph.D. studies by Edward T. Jackson's writings on Participatory Action Research. His input has driven me to be a more ethical researcher. I cannot overstate my gratitude to these four members of my thesis committee. I also wish to thank my external examiners, William Shaffir and Aviva Freedman, for their insightful comments during the examination.

I am grateful to have been included in Steve Flemming's Perstempo and the Human Dimensions of Deployment research team, in which I learned much about the realities of field research and the Canadian military. The Directorates of Quality of Life and of Strategic Human Resources in the Canadian Department of National Defence provided financial support over the course of my Ph.D. studies.

This thesis would not have been possible without the contributions of all of the research participants. I want to highlight the work of Lariam Action U.S.A. and to thank 
Susan Rose for sharing her extensive knowledge about mefloquine. I am also indebted to individuals working in the Access to Information Directorates of Health Canada and DND.

My fellow graduate students have motivated me during the course of my studies. Members of the Wellington Ph.D.-mothers' support group-Sara Kindon, Jayne Krisjanous, Jennifer Solomon, and Nicole Voles—offered a stimulating environment for academic discussions and advice on balancing parenting with academia. Tanya Bergevin has offered her wisdom since we met in the fifth grade.

As is the case with so many important endeavours, this was a family affair. My husband, William Hipwell, lovingly supplied me with encouragement, sound advice, inspiration, a critical eye, hours of computer assistance and inspiring conversation, throughout this process. His philosophical and theoretical insights tremendously improved my work, and I could not have managed without his support. My extended family-my grandmother, aunts, uncles, cousins and brother Jason-believed in me and offered their assistance whenever possible. My step-daughter Tao-Lynn Hipwell, PHD (patient helpful daughter), was always understanding of the demands that a doctorate can place on a household and ready to lend a hand. My son, Leon Richard Hipwell, inspired me to get through the writing, quickly! Lastly, and most importantly, my mom and dad, Richard and Diane Ford, raised me to value education, and to believe in my abilities. Throughout my schooling they provided the love, support, nurturing, discipline, encouragement and resources that I needed to achieve my goals, and never for one minute allowed me to think that I might give up! It is an honour to finally thank all of the people who helped to make this thesis possible. 


\section{Dedication}

I'd like to dedicate this thesis to three inspiring travellers-

My grandma, Maria Duquette, who still has a suitcase packed and under her bed, ready to go just about anywhere;

My husband, Bill Hipwell, who helped me through the 'mefloquine madness' and consistently offered love and support in the pursuit of my 'mefloquine dream', and with whom I can reach the seemingly unattainable; and

My son, Leon Richard Hipwell, who has toddled through ten countries before the age of two (Oh, the Places You'll Go...), and who was so proud to say, on the day of my defence: "Mummy's all done the school". 


\section{Table of Contents}

ABSTRACT $\quad$....................................................................................................... II

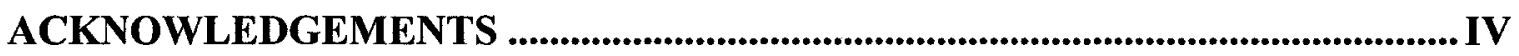

DEDICATION .................................................................................................................

TABLE OF CONTENTS .........................................................................................................VII

LIST OF TABLES .....................................................................................................................XII

LIST OF FIGURES ..............................................................................................

LIST OF APPENDICES ..................................................................................... XIV

Preface - From Mefloquine Madness to Mefloquine Dreams ........................................... Xv

CHAPTER 1 AN INTRODUCTION TO 'MEFLOQUINE DREAMS' .................1

1.1 A ROLE FOR SOCIOLOGISTS IN THE 'RISK SOCIETY' .................................................. 4

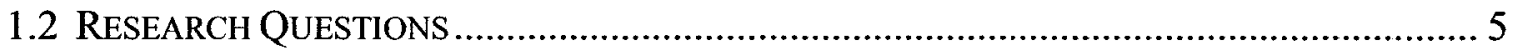

1.3 Situating the Study Within the Sociology of Scientific KnOWLedge ............. 6

1.4 Chapter Summary and Discussion of Following Chapters ………………........ 8

Personal Narrative \#1 - Eritrea Journal Entry …………................................................ 11

CHAPTER 2 MEDICALISATION, GOVERNMENTALITY AND RISK: A THREE-FACETED THEORETICAL FRAMEWORK FOR THE

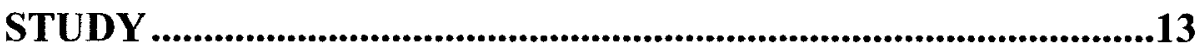

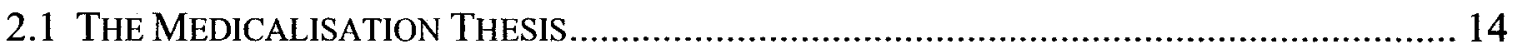

2.1.1. Pointillism, Intuition AND SubJeCtive KNowledge IN SCIENCE........................ 21

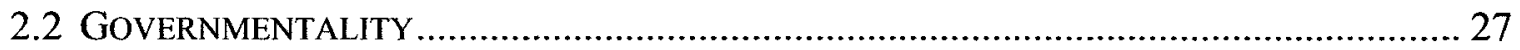

2.2.1. SUBJeCtIVITY AND THE Governing PROCESS.................................................... 33

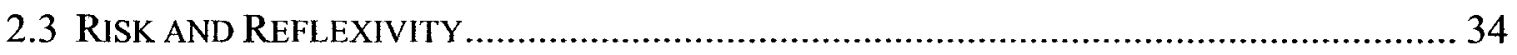

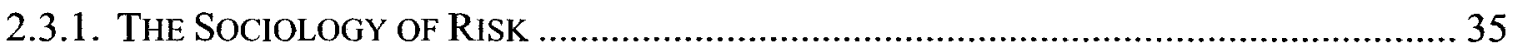

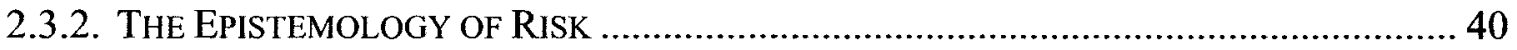

vii 


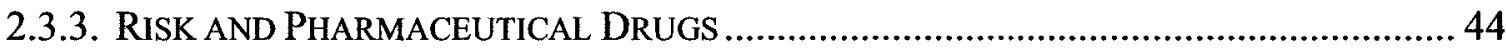

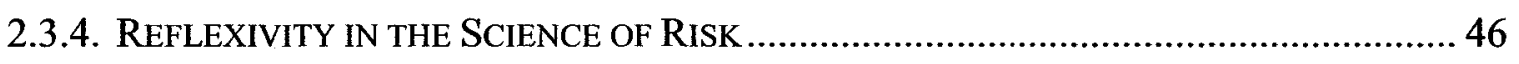

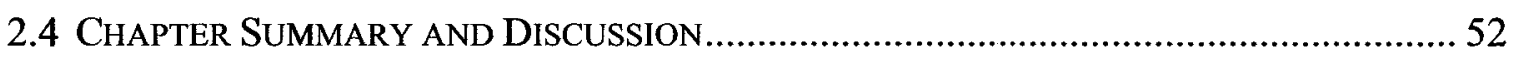

Personal Narrative \#2 - The Ministry of Health 'Form 42' ............................................56

CHAPTER 3 METHODOLOGY: INVESTIGATING THE SUBJECTIVE EXPERIENCE OF RISK ...................................................................58

3.1 ReSEARCh Methods, Data Collection and ANalysis .......................................... 59

3.1.1 INTERVIEWS WITH SUbJeCt MATTER EXPERTS ………........................................ 59

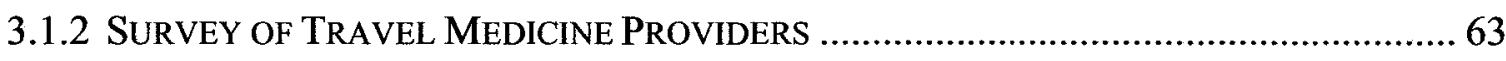

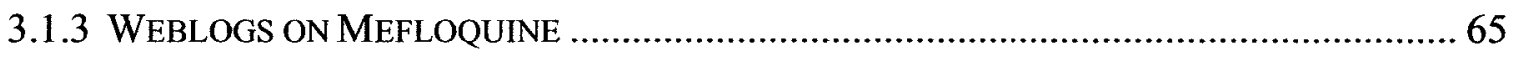

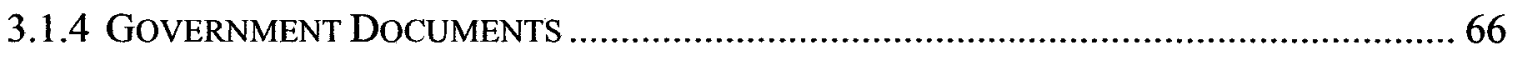

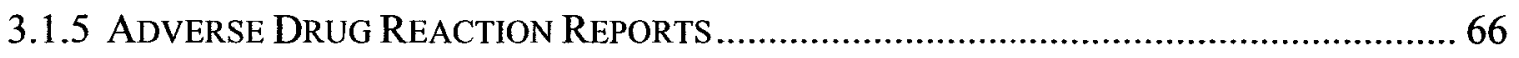

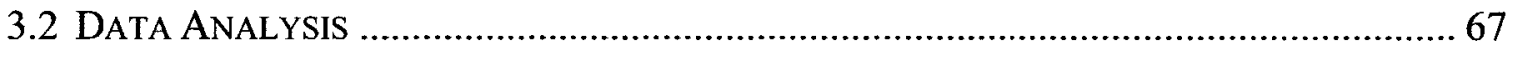

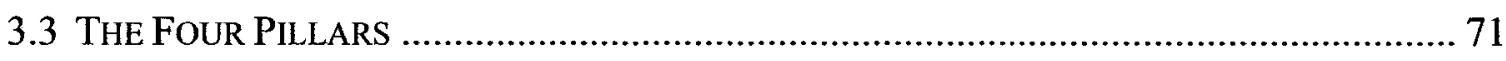

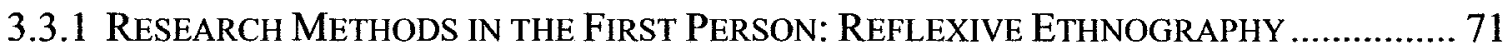

3.3.2 Participatory ACtion ReSearch and the SubJective Volce............................. 72

3.3.3 A Genealogy of Malaria Risk and MEfloquine Safety ................................. 76

3.3.4 Stakeholder ANALYSIS To UnCover PoWer Dynamics ...................................... 77

3.4 ChaPTER Summary AND DiSCUSSION.................................................................. 77

Personal Narrative \#3 - Client Orientation Information ................................................. 79

CHAPTER 4 A GENEALOGY OF KNOWLEDGE ON MALARIA AND MEFLOQUINE................................................................................80

4.1 The PreSent Danger: Malaria Today ………................................................ 82

4.1.1 CONTEMPORARY KNOWLEDGE ON DiSEASE TRANSMISSION ……............................. 84

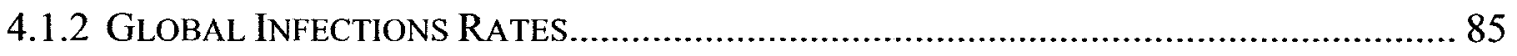

viii 
4.1.3 Disease OF THE (SUB)-TROPICS VERSUS 'IMPORTED MALARIA' 87

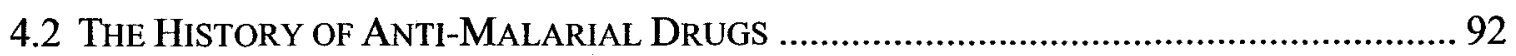

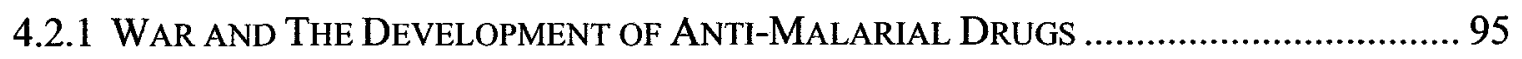

4.2.2 MEFLoQuine AND THE AMERICAN MiLITARY ................................................. 98

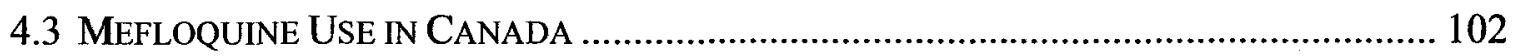

4.3.1 SAFETY INFORMATION ON MEFLOQUINE ...................................................... 107

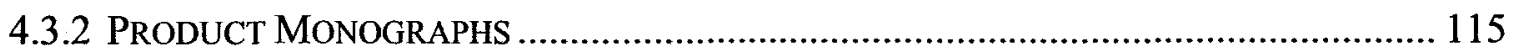

4.3.3 The Mefloquine Safety Evaluation Study 1990-1993 ............................ 119

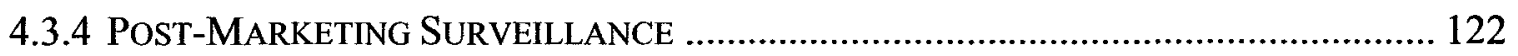

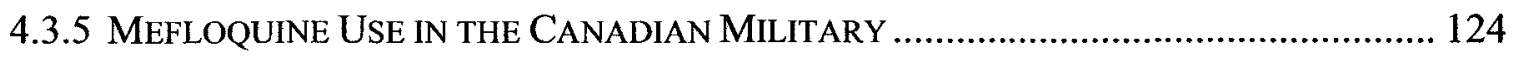

4.3.6 THE TRIALS AND TRIBULATIONS OF MEFLOQUINE USE.................................... 132

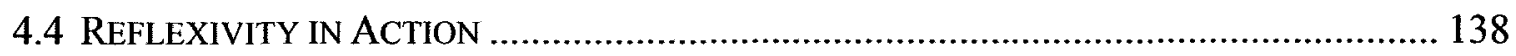

4.5 CHAPTER SUMMARY AND DiSCUSSION....................................................... 142

Personal Narrative \#4 - Workplace Safety Insurance Board Documentation................ 145

CHAPTER 5 A CACOPHONY OF VOICES................................................147

5.1 INTERVIEW Participants. .. Who ARE THEY? ............................................ 148

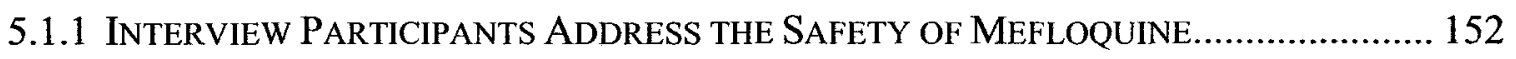

5.1.2 INTERVIEW PARTICIPANTS DESCRIBE DRUG REGULATION................................ 159

5.1.2 a) Non/Government Factors in Drug Regulation......................................... 163

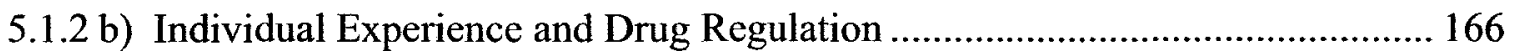

5.1 .2 c) Controversy and Advocacy in the Regulatory Process................................. 168

5.1.2 d) The Role of the Public in the Regulatory Process ..................................... 172

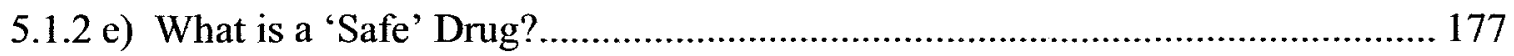

5.1.3 INTERVIEW PARTICIPANTS DISCUSS NON-EXPERT KNOWLEDGE ...................... 179 ix 
5.1.3 a) The Availability of Health Information ............................................................ 179

5.1.3 b) The Subjective Experience of Risk ………………...................................... 182

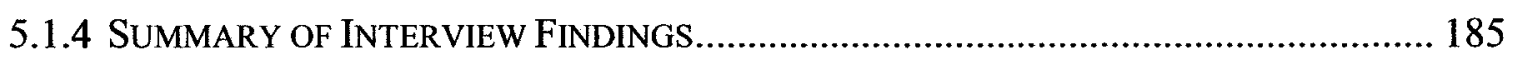

5.2 SURVEY RESPONDENTS (TMPS). . . WHO ARE THEY? ............................................. 186

5.2.1 TMPS ADDRESS THE SAFETY OF MEFLOQUINE ................................................... 186

5.2.2 TMPs DESCRIBE Drug REgULATION ............................................................ 192

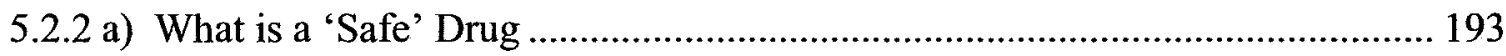

5.2.3 TMPS DISCUSS NON-EXPERT KNOWLEDGE AND EXPERIENCE................................. 194

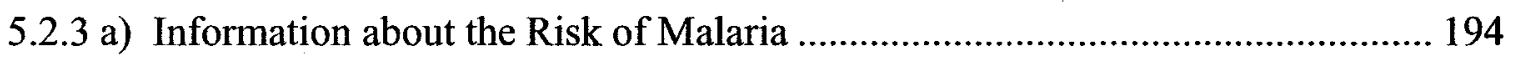

5.2.3 b) The Availability of Adequate Health Information .......................................... 196

5.2 .3 c) Clients' / Patients' Knowledge ........................................................................... 201

5.2.3 d) The Subjective Experience of Risk ............................................................ 203

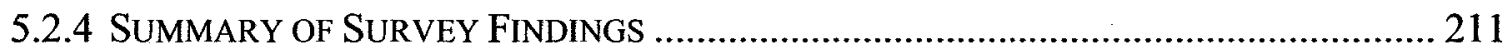

5.3 'BLOGGERS' ... WHO ARE THEY? ...................................................................... 212

5.3.1 BlogGers' EXPERIENCES AND THE AdVERSE REACTIONS DATABASE ................... 219

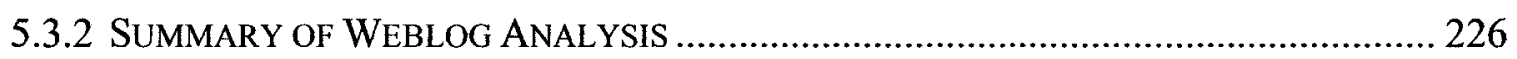

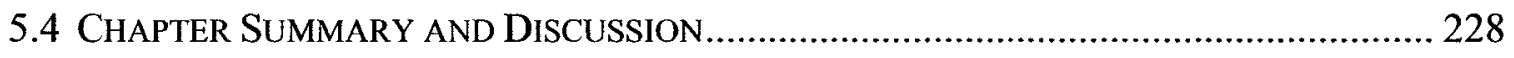

Personal Narrative \#5 - Medical Doctors Confirm the Diagnosis .................................... 231

CHAPTER 6 POWER/KNOWLEDGE IN THE PREVENTION OF MALARIA AND THE REGULATION OF ANTI-MALARIAL DRUGS .....232

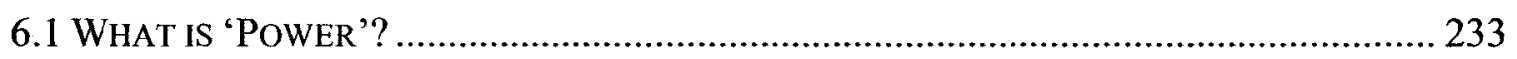

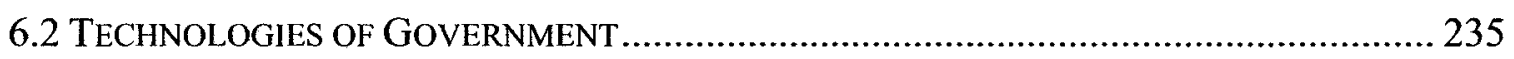

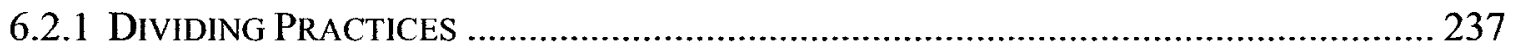

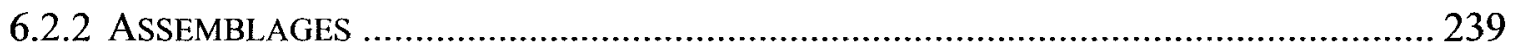




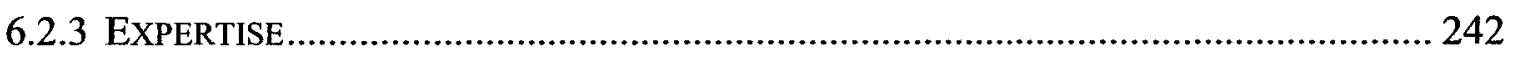

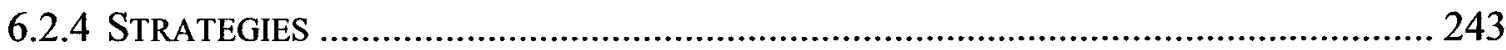

6.3 StAKEHOLdER ANALYSIS: A LENS to EXPOSE PoWER DYNAMICS ....................... 247

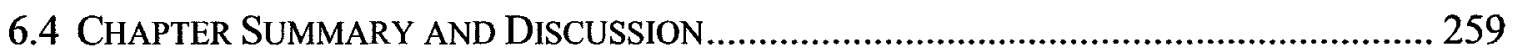

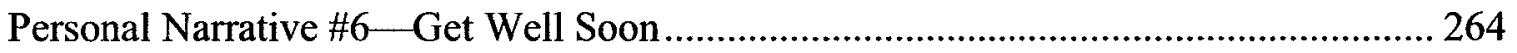

\section{CHAPTER 7 CONCLUSION: FROM MEFLOQUINE MADNESS TO} MEFLOQUINE DREAMS ..................................................265

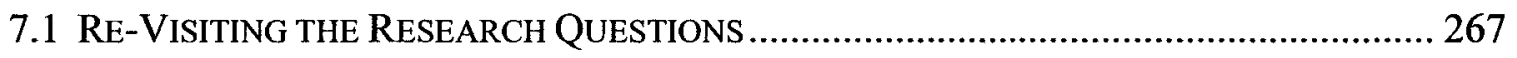

7.1.1 The Universal and the Particular - or The “Lies of the State”............... 2270

7.2 Social AND Political Interests AND THE Citizen's VoicE........................... 271

7.3 RefleXive Modernisation -- ARE We There Yet? ...................................... 276

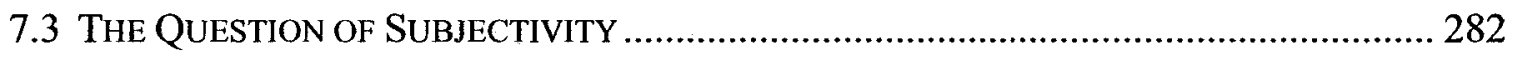

7.4 Auto-Ethnography: the Personal Narrative and the Research Process .. 286

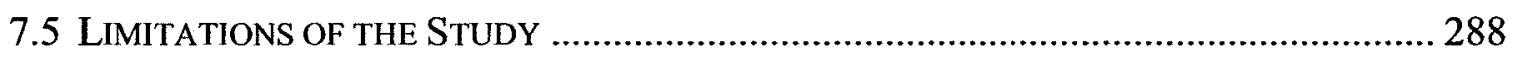

7.6 Future Directions... More Mefloquine Dreams.......................................... 289

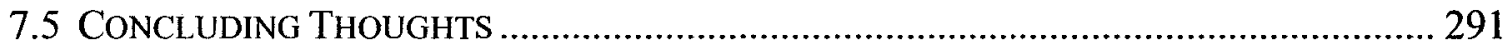

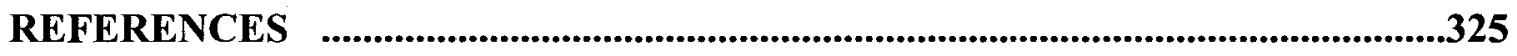




\section{List of Tables}

Table 3.1 Overview of Primary and Secondary Data ..............................................59

Table 5.1 Do People 'Overestimate', 'Properly Evaluate', or 'Underestimate' the Risk of Experiencing a Side-effect and the Risk of Getting Malaria? Interview Respondents' Views

Table 5.2 The Most-Commonly Prescribed Anti-Malarial Drug(s) According to TMPs

Table 5.3 TMPs Rate the Relevance of Various Sources of Information for Individuals who are Planning Travel to a Malaria- Endemic Country

Table 5.4 Do People 'Overestimate', 'Properly Evaluate', or 'Underestimate' the Risk of Experiencing a Side-effect and the Risk of Getting Malaria? TMPs' Views

Table 6.1 Stakeholder Position Vis-à-vis the Objective of Improving Drug Safety by Incorporating Subjective Experience into the Regulatory Process

Table 6.2 Stakeholders' Interests, Power, Legitimacy and Types of Knowledge Used 


\section{List of Figures}

Figure 4.1 Global Malaria-Endemic Zones .............................................................89

Figure 4.2 Mefloquine in Canada: Timeline ..........................................................105

Figure 5.1 Sample Health Canada Adverse Reaction Report ....................................220

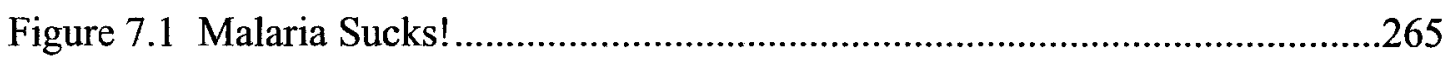




\section{List of Appendices}

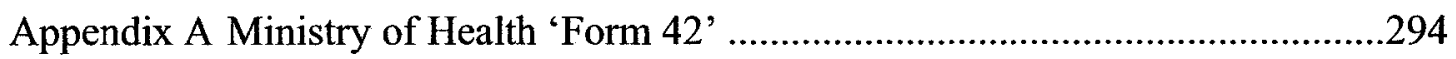

Appendix B Ottawa Hospital Dept. of Psychiatry Orientation Pamphlet ................296

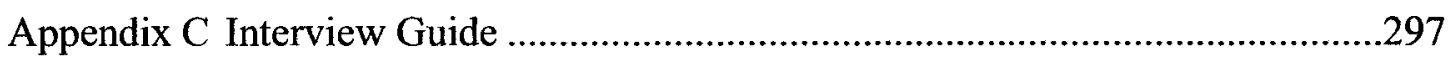

Appendix D Survey of Travel Medicine Providers ..............................................306

Appendix E Instruction Letter for Interview Participants..................................311

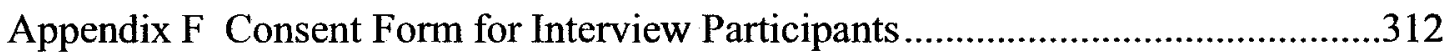

Appendix G Waiver of Anonymity Form for Interview Participants.......................314

Appendix H Letter of Information for Survey Participants....................................315

Appendix I Letter to the Workplace Safety Insurance Board ..............................317

Appendix J Excerpt from the Product Information Sheet (2004) and Full Mefloquine and Product Insert (1997) and Pharmacy Print-Out.........................319

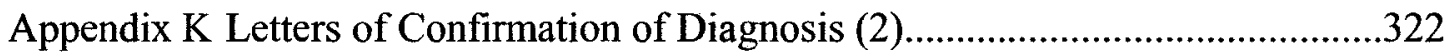

Appendix L Characteristics of Canadian Mefloquine Bloggers …..........................324 


\section{Preface - From Mefloquine Madness to Mefloquine Dreams}

This study begins with an account of my subjective experience of risk. I took mefloquine in 2001, when I was sent to Eritrea to interview Canadian Peacekeepers, as part of my job with the Canadian Department of National Defence. In preparation for the trip, I was immunised and prescribed mefloquine as a malaria prophylaxis. I had heard that the drug could cause serious psychiatric side-effects. When I voiced some concerns to the military medical officer, I was told that the prevalence of mefloquine side-effects was negligible and that no other alternatives were possible. The pharmacy printout about mefloquine only listed mild reactions, including stomach upset, vomiting, dizziness or vision problems. It further stated that rash or difficulty breathing should be reported to health officials. The product insert indicated more serious potential unwanted side-effects, which might occur "in rarer cases" such as: abnormal heartbeat, convulsions, changes in mood, and sleep disturbances. It further added that these events usually subside within a short period after cessation of the drug administration and that the consequences of malaria are cause for far greater concern. ${ }^{I}$ So, I followed the directions and took the mefloquine as prescribed.

My research in Eritrea had nothing to do with malaria or mefloquine, however several individuals spoke to me about vivid dreams and sleepless nights, which they attributed to mefloquine. They were curious as to whether or not I was having any

'Hoffmann-La Roche (1998), "Information for the Consumer", Mississauga, Ontario. It should be noted that later product inserts include a more detailed list of 'rarer unwanted reactions', including suicidal ideation, and state that use of mefloquine should be discontinued if they occur because they could be indications of a more serious reaction to follow. 
'weird reactions'. I told them that I had only taken two pills, and had experienced nothing but bizarre dreams and a slightly upset stomach.

Upon returning home to Canada, I was instructed to continue taking mefloquine once a week for three more weeks. After taking the third dose, almost overnight, my mental health deteriorated to such a degree that my husband brought me to the Ottawa Civic hospital. I was then involuntarily committed to a psychiatric ward, where I spent four days, was administered anti-schizophrenic drugs and heavily tranquillised. Luckily, on my second day in hospital, my husband acted on a hunch and wrote on my patient chart "my wife has been taking mefloquine". The treating physician saw this and stopped his treatment. Once enough of the mefloquine had left my body, my psychotic symptoms subsided and I was released from the hospital.

I remained shaken by this event for months after stopping the mefloquine and being released from the hospital: my self-esteem was weakened; I had trouble concentrating; I heard loud ringing in my ears; I was very depressed. My family physician and a psychiatrist both confirmed that I had suffered from 'an acute psychotic episode as a result of mefloquine' and prescribed extended convalescence.

In part, this thesis tells my story. In italics, at the end of each chapter, there is a fragment of the tale of my own experience with mefloquine and its relationship to the research project. I speak in the first person in these 'personal narratives' and connect the dots between fragments of my experience with mefloquine, and the research process on the whole. 


\section{Chapter 1 An Introduction to 'Mefloquine Dreams'}

The one thing I remember most is that often times, one or two days after taking [mefloquine], I would have these bizarre, vivid dreams-dreams that seemed so real that even after I woke up it took me several minutes to convince myself that it was actually a dream. It wasn't unusual to look around the mess hall on Tuesday or Wednesday morning (we took the pills on Monday-easy to remember mefloquine Monday or malaria pill Monday) and to see other soldiers just staring vacantly into the distance with the "300 yard stare"-you just knew it was because they were still "coming down" from their mefloquine dreams... I've always thought that "Mefloquine Dreams" would make a great book title. ${ }^{2}$

Does our society have appropriate measures in place to allow for the interpenetration of subjective and objective knowledge within systems of health regulation? Are citizens who resist mainstream medical treatment submitted to systems of social control and coerced to adopt a 'sick role' (Parsons, 1951: 431; Wheale, 1984: 110 ), or is there space for the system to grow from such resistance? In probing these kinds of questions about regulation, health, and society, this thesis argues for greater inclusion of subjective knowledge in systems that govern health in contemporary society. As shown in the preface, the study was inspired by a subjective experience. As such, it can be seen as the author's way of rebelling against the 'sick role' and inserting her own voice into the regulatory machine, of which allopathic medicine is a central part. The

\footnotetext{
2 This quote taken from: Sgt. Stryker's daily Briefing http://www.sgtstryker.com/weblog/archives/001054.php (last accessed 24 July 2006).
} 
thesis was prefaced by a subjective account, and a first person narrative is intertwined within the research process and its write-up. The central focus is to elucidate the impact of such subjective accounts on the "cacophony of voices" (Fine et al. 2000:119) that are at play in the regulation of pharmaceutical products; the formulation of health knowledge; and the creation of common understandings of risk in Canada.

Broadly speaking, the thesis is a post-structural exploration of the creation and circulation of knowledge on risk and danger. Knowledge about the risk of malaria for Canadian travellers who are heading to a malaria endemic region, and about the safety of the anti-malarial drug mefloquine, are used as a case study to explore the problematic of health regulation and risk management. Mefloquine is a controversial drug, because it has been associated with severe side-effects; however, it remains widely used by North Americans who are travelling to malaria-endemic parts of the world. In fact, it is rare that the history of a pharmaceutical product produces a tale as intriguing, as controversial, and as political as that of mefloquine. In Canada, alone, the drug has been the subject of numerous investigations and reports: Auditor General's report (Auditor General of Canada, 1999); Standing Committee on Public Accounts (SCOPA) hearing (Maria, 1999); Standing Committee on Defence and Veterans Affairs (SCONDVA) hearing; numerous inquiries in the House of Commons (Cummins, 1999b; Cummins, 1999c; Cummins, 2002a; Cummins, 2002b; Cummins, 2002c; Cummins, 2004), countless briefing notes to Members of Parliament and Ministers, Memoranda to cabinet and various official reports (e.g. Gadd, 1997; Gadd, 1998; Hall, 2002; Jones, 2002a; Jones, 2002b; Jones, 2002c; Jones, 2002d; Juckett, 1999; Kavanagh, 2002a; Kavanagh, 2002b; Kinsman, 1998; National Defence Canada (DND), 1997; National Defence 
Canada (DND), 2002a; National Defence Canada (DND), 2002b; Salisbury, 1997; Scott, 2002a; Scott, 2002b; Seck, 1999). Since 1990, mefloquine has figured in no less than seven in-depth television and radio reports (Canadian Broadcasting Corporation (CBC), 1998; Canadian Broadcasting Corporation (CBC), 2003; Canadian Television Network (CTV), 1997; Fekete, 2002; Gartner, 2002; Renaldo, 1997; Tremanti, 2004). Internationally, mefloquine is the subject of a documentary movie entitled Taken as Directed. ${ }^{3}$ It was also the at the heart of a plot line in a television episode of Law and Order Special Victims Unit, in which two officers returning from Afghanistan shot their wives. ${ }^{4}$ Moreover, several class action suits have been launched in Europe and the U.S.A. against the makers of mefloquine. ${ }^{5}$

Mefloquine, therefore, is an appropriate case for exploring how the sub-politics of knowledge play themselves out in the domain of health regulation and in the creation of new knowledge on risk. In the official public health literature in North America, mefloquine is said to be an effective anti-malaria drug-in fact it is often called the "drug of choice"-with only rare instances of serious adverse effects reported (Health Canada, 1995; Health Canada, 2001; Health Canada and (CATMAT), 2000). Conversely, advocacy groups and a growing proportion of individuals who have taken the drug beg to differ, and speak out publicly against the official reports and statistics. These lay-experts

${ }^{3}$ Taken As Directed, http://www.taken-as-directed.com/html (last accessed 17 November 2005).

${ }^{4}$ This plot line was taken from years of media research that was conducted by Dan Olmsted and Mark Benjamin. See

http://www.salon.com/ent/tv/review/2005/05/25/lo_svu/ (last accessed 24 July 2006) for further information.

${ }^{5}$ For more information on these class action suits and other international information on mefloquine, see: www.lariaminfo.org (last accessed on 24 July 2006). 
argue that mefloquine is, in fact, much more dangerous than suggested by Health Canada and Travel medicine providers (Benjamin and Olmsted, 2002b; Benjamin and Olmsted, 2003; Cummins, 1999a; Cummins, 2002c; Holder, 2003).

\subsection{A Role for Sociologists in the 'Risk Society'}

Ulrich Beck's $(1992 ; 1999)$ thesis on the 'risk society' (discussed in Chapter Two) delineates a clear role for sociologists who are involved in the study of popular critique of scientific knowledge: to create possibilities for the sub-politics of knowledge to exert influence; to open up institutional space for dialogue on risk and uncertainty. $\mathrm{He}$ argues that along with many scientific advances, industrial civilisation brought with it numerous risks. He calls for science to become more 'reflexive', in other words, for scientific development to grow out of a critique of science. He theorises that a new division of labour must take place, wherein critique is embraced within all aspects of science and technology development. He is hopeful in asking the question:

Behind the facades of good old industrial society that are still being propped up, could it be that, alongside the many risks and dangers, forms of [a] new division of labour and power between politics and sub-politics are already beginning to stand out and be practiced today? (Beck, 1992: 235)

He believes that criticism of technological risks and risk management should be part of the systems that create these risks in the first place. This thesis posits that, on the contrary, while lay experts are voicing their concerns in the field of science and risk, criticism is not yet afforded the central role that it occupies in Beck's theory of 'reflexive 
modernisation'. However, taking its lead from Beck, it does postulate how democratisation in the sciences with respect to the case study might be facilitated.

\subsection{Research Questions}

The safety of mefloquine and the risk of malaria are used in a case study that addresses the following over-arching research question:

With specific reference to the prevention and treatment of malaria, what role do/could alternative epistemologies, based upon subjective experience, play in the construction of medical knowledge and understandings of risk and safety?

This question is broken down into two sub-questions:

1. What is the present state of knowledge on malaria and mefloquine? Specifically, what types of knowledge claims do various stakeholder groups put forth regarding mefloquine, and how do these claims come together in discourses of safety and danger regarding malaria and mefloquine?

2. How could or how does subjective experience influence the regulation of drug safety and the creation of public health knowledge (in particular anti-malarial campaigns)?

Discourses of risk are proliferating at an unprecedented pace; this is, in part, due to the ever-increasing availability of health information and communication technologies. We live in a 'culture of risk' in which "safety has become the fundamental value" (Furedi, 1997: 1). Everyday we learn of new risks that confront us, and are bombarded by often conflicting or competing information on the various ways to safeguard ourselves against them. Theories of the 'Risk Society' (Beck, 1992; Beck, 1999; Giddens, 1999) 
implore that while science may offer the solution to a number of risks, it might also be the source of these and other risks. Moreover, within the science of risk, we often find that, "... an overly narrow focus on technical matters le[ads] to the exclusion of lay concerns" (Ali, 2002: 29). With respect to health risks, are the needs of individuals being met, or are they usurped in favour of some other societal or political interests? Herein lies the object of study in the proposed thesis, which seeks to examine the power dynamics that shape information and technologies of risk management.

\subsection{Situating the Study Within the Sociology of Scientific Knowledge}

Theoretically and epistemologically, this thesis figures in the area of the sociology of scientific knowledge (or SSK for short), a domain of sociological inquiry that developed in the early 1970s in the U.K. (Pickering, 1992). More specifically, it figures within the "strong programme" of SSK -"Proponents of the 'strong program', many of them associated with the University of Edinburgh, argued that knowledge is to be construed, in science as elsewhere, as accepted (and not as true) belief' (McMullin, 1992: 18). The central premise of this body of literature is that: “... science has to be seen, not as the transparent representation of nature, but rather as knowledge relative to a particular culture, with this relativity specified through a sociological conception of interest" (Pickering, 1992: 5). On SSK as a whole, Ian Hacking (1992) writes: 
The unity of the sciences was once a battle cry, but today it is the fashion to emphasise the disunities among the sciences. I am right up there on the bandwagon [...]. Some suggest that there is nothing in general to be said about science unless it be the message of Latour (1987) that everything in the world and our knowledge of it is to be understood as a model for politics, or maybe is politics.

In adopting a post-structuralist analysis of the power dynamics that shape the creation and circulation of health knowledge within the case study, this thesis jumps on board Hacking's and Latour's bandwagon! Moreover, by adopting a post-structural outlook on the relationship between science and society, the constructivist debate about society and technology (which asks to what degree does society shape technology and/or vice-versa) is eschewed in favour of a 'seamless web' perspective. This perspective views society and technology as self-constituents and "resists the notion that division between the social and the technical should be taken for granted" (Bijker and Law, 1992: 201). Bruno Latour's (1987) 'actor network theory' of the development of science and technology is founded on this seamless web perspective.

Starting with this vision of science as representing a politically malleable view of the natural world, two core sociological concepts are at the root of this thesis: epistemic reflexivity and social interest. First, the notion of 'reflexivity' (as discussed, for example, in Beck, 1999; Bourdieu, 2004; Ellis and Bochner, 2000; Knuutila, 2002; Latour, 1987) is of particular relevance to this study, because, on the surface, it is itself epistemologically reflexive (Bourdieu, 2004). It is also concerned with the notion of 'reflexive modernisation' (Beck, 1992; Beck, 1999; Giddens, 1999), and investigates the ways in 
which, and conditions under which, public criticism of science and technology acts as an impetus for, or guides, future developments in science and technology. In exploring the 'seamless web' between society and technology, it examines the degree to which health advocates; individuals who have taken mefloquine; and other non-scientific actors influence knowledge-building and regulatory processes in society. Meanwhile, drawing from the advances of the 'strong programme' in science and technology studies, which, as noted above, argues that "the content of science should be amenable to social study" (Woolgar, 1981), the thesis examines the social and political interests that shape science and technology, and the interests at play in resolving scientific controversy. It has been said that: "how science handles controversies is an important aspect of how science actually works" (Bridgstock, 1998: 83). This project postulates that how social actors handle scientific controversy is an important aspect of how society actually works.

\subsection{Chapter Summary and Discussion of Following Chapters}

The thesis materials are organised into seven chapters, the first of which is the present introduction. The second chapter outlines the theoretical framework and important philosophical concepts. It sketches out a three-faceted theoretical framework, which corresponds roughly to three phases in the history of medicine (medicalisation, governmentality and reflexivity), and discusses how intuition and subjective knowledge became subjugated with the rise of allopathic (or conventional 'Western') medicine. The third chapter presents the methods used, as well as the methodological principles that underlie, this project. The research was guided by a 'participatory' approach to knowledge creation (Park, 1993), in which researchers and participants are both supposed 
to be empowered by the research process. However, this is not a participatory action research project per se. Chapter Four begins with a précis of knowledge and information on the global malaria pandemic and various prevention methods that are available. It then draws primarily from Health Canada and Department of National Defence documents that were obtained under the Access to Information Act (1985), to sketch out the history of mefloquine use in Canada along with contemporary debates about the drug. Chapter Five presents a synopsis of findings from interviews and surveys. It then delves into an analysis of weblogs (or 'blogs') posted on the Internet by Canadians who have consumed mefloquine; or who want information about mefloquine; or else who have family members who have suffered from an adverse reaction to mefloquine. The Health Canada adverse reactions database is also explored in this chapter. Chapter Six presents a post-structuralist stakeholder analysis. Post-structuralist understandings of power (Foucault, 1980) are defined in the introductory paragraphs. Findings that were raised in Chapters Four and Five are then applied to a 'stakeholder analysis' (Chevalier, 2001) in order to consider the power dynamics between stakeholder groups. Finally, an analysis of the 'dividing practices', 'assemblages', 'technologies of power' and 'strategies' employed in the regulation of pharmaceutical drugs and production of travel health campaigns is conducted (Rose, 1994; Rose and Miller, 1992). The final chapter, Chapter Seven, recapitulates the key issues and conclusions raised throughout the thesis. Interspersed between these chapters, is a personal narrative recounting fragments of the author's experience with mefloquine that are related to the research process and have become important in writing up the results of the study. 
To sum up, the thesis investigates how political power is deployed in contemporary society, using a case study in the area of public health. It examines the intricacies of the struggle to insert subjective knowledge into the coextensive processes of drug safety and malaria prevention. This exploration of local struggles or instances of resistance aims to elucidate the nature of political power and its deployment throughout contemporary society.

It should be underscored that this is not medical research, but research in the $\underline{\text { social studies of medicine; }}$ as such it will not provide an assessment of one malaria prevention method over another, nor will it assert any conclusions about the safety of mefloquine. Instead, the thesis will examine how information regarding the prevention of malaria and the safety of mefloquine is socially and politically constructed and transmitted, in order to shed insight on the role of subjectivity in the governance of risk. 


\section{Personal Narrative \#1 - Eritrea Journal Entry}

I found the following entry in my Eritrea journal...

Yesterday I went to get my 'kit' at the National Defence Headquarters. I was given: a kit bag; helmet; flack jacket; sleeping bag; liner; mosquito net; insect repellent; sun hat; boots; socks. The whole thing was so heavy that I had trouble carrying it to the car. How am I going to carry it, and my personal belongings, through military camps in Africa? I also did a weapons familiarisation course that taught me how to assemble and disassemble an M16, how to aim and shoot, and what to do if I should come across such a weapon lying around on the ground. Last night I took my first mefloquine tablet. When I got to work this morning, Sergeant $D^{*}$. asked me if I was feeling any weird symptoms. He told me that he'd heard people talking about 'Mefloquine Mondays' or 'Mad Mondays' in reference to the day that they take their anti-malarial drugs. He joked that mine would be 'Whacky Wednesdays' for the next little while. All I've felt so far is a slightly upset stomach. Let's hope things stay that way...

Looking back over those words, I am struck by the ways in which risk prevention can take place in institutional and informal ways. The potential risks associated with finding a loaded weapon and needing to disarm it, or to shoot, are dealt with formally and at an institutional level. Every civilian scientist who is sent into a Canadian military operational theatre is given the same course and provided with the same information. Meanwhile, the potential risk of going mad because of a drug seems to be dealt with in an informal manner and dismissed, if not silenced altogether institutionally. Although the

\footnotetext{
* All names have been omitted to safeguard the identity of those involved.
} 
'whacky Wednesday' comment did shake me momentarily, I let it slip by without a further thought. I had already been convinced by the mainstream voice that I would not be one of the very few people who go mad on mefloquine! 


\section{Chapter 2 Medicalisation, Governmentality and Risk: A Three-Faceted Theoretical Framework for the Study}

This chapter provides a three-faceted theoretical framework for the study: medicalisation, governmentality and risk. These three facets of the theoretical framework also represent three phases in the history of medical knowledge. The medicalisation facet looks at the transformation from classical to contemporary medicine, which occurred on the heels of the more general rise of positivism in the human sciences in Europe. This transformation in science discredited local knowledge, in particular subjective experience about one's health, in favour of a clinical epistemology that favours a probabilistic determination of health risks by medical experts. This first sub-section includes a discussion of the epistemological implications of this transformation, which set the stage for the following two phases in medicine and for present day knowledge on malaria and anti-malarial drugs. The second facet of the theoretical framework is the 'governmentality' thesis. This thesis elucidates how transformations in medicine in the eighteenth and nineteenth century have played themselves out politically in post World War II, industrialised, neo-liberal states. Since then medicine has come to play an increasingly important political role in today's society. This section of the chapter explores the notion that political power is wielded less through political institutions and more through the daily conduct of citizens who are encouraged to govern themselves according to discourses of power. Medical professionals and medical knowledge play an increasingly important role in the governance of everyday life. These last two phases in 
medicine: medicalisation and governmentality, it is argued, have shaped contemporary risk management, and have contributed to our understandings of risk and safety with respect to pharmaceutical drugs. An overview of contemporary sociological theories of risk and research on pharmaceutical drugs is presented in the final sub-section of the chapter. This last final facet of the theoretical framework -risk and reflexivity- explores the role of lay expertise in science and the need for a revitalisation of public dialogue on science and risk, or what some authors have called 'reflexivity' in science (Beck, 1992; Beck, 1999; Bourdieu, 2004; Latour, 1987; Latour, 2004b; Latour and Bastide, 1986). These three facets of the theoretical framework - medicalisation, governmentality and risk- which can roughly be seen as three phases in medicine, provide an epistemological context for the development of medical knowledge about malaria and anti-malarial drugs.

\subsection{The Medicalisation Thesis}

The term 'medicalisation' as it is used in the 'social studies of medicine' literature, designates both an epistemological shift and a critique of contemporary medical power. It indicates an epistemological shift, in that it refers to a period in history in which medical knowledge went from being grounded in a cosmological order, to being steeped in clinical rationality. It is also associated with a critique of contemporary medical power, because the term 'medicalisation' has come to be associated with a political tendency in which everyday behaviours are increasingly scrutinised with a medical gaze. The notion of medicalisation has become a prolific area of inquiry in the literature. Sociologists have shown how every aspect of daily life, from mothering (Murphy, 2003; Singh, 2004) to physical activity (Wheatley, 2005); from shopping (Lee, 
2004) to sex (Potts, 2004) has been 'medicalised'. This study does not present an account of the medicalisation of travel (for one such account, see Hacking, 1998, on the first clinically diagnosed transient). It does, however, focus on present day implications of the rise of positivism and the biomedical model. It also adopts a critical look at Western medicine, which is pervasive in this literature. As Lupton (1997) notes, proponents of the medicalisation thesis are usually critical of medical power, and allege that Western medicine is ineffective in treating a wide range of effects and is often the cause of iatrogenic side-effects (Lupton, 1997: 55).

While Michel Foucault never used the word 'medicalisation' (Lupton, 1997: 58), his entire oeuvre can be seen as presenting a history of medical knowledge and this political phenomenon. Foucault (1965)'s work on the history of madness in the age of reason is his first work to describe how the professionalisation of medicine, and the branching-out of psychiatry as a specialisation, is tied to the rise of positivism in the eighteenth century. He shows how positivism and normative thinking produces a conception of 'the madman'. It is also the first of Foucault's works to analyse the doctorpatient relationship and its role in the production of clinical epistemologies. Finally, it is also his first, in a long line of works, that presents the connection between the medical gaze and the wielding of political power, through a medicalised notion of morality that is further and further from every-day ways of knowing. He writes: 
This psychiatric practice, mysterious even to those who used it, is very important in the situation of the madman within the medical world... [T]hose most eager to discover the origin of madness in organic causes or heredity dispositions would not be able to avoid this style-[ [to] increasingly confine themselves in positivism. ... As positivism imposes itself upon medicine and psychiatry, this practice becomes more and more obscure. (Foucault, 1965: 275)

Foucault's next major work (1970), addresses the emergence of the concept of 'man' as the subject of 'scientific' knowledge in the human sciences in the eighteenth century. He demonstrates historically that the social sciences emerged due to the requirements of particular social problems. For example, new norms imposed upon man by industrial civilisation were in place before the discipline of psychology could be considered a science. He explains:

The human sciences are not, then, an analysis of what man is by nature; but rather an analysis that extends from what man is in his positivity (living, speaking, labouring being) to what enables this same being to know (or seek to know) what life is, in what the essence of labour and its laws consist, and in what way he is able to speak. (Foucault, 1970: 353)

In The Archaeology of Knowledge, Foucault (1972) presents his history of the discursive formation of knowledge. It is in this work that readers glean a preliminary understanding of an emerging conception of 'medicalisation', meaning the segregation, relations and professionalisation of various elements of medical practice, all operating in 
alignment with and feeding into an overarching rational and positivist discourse. He writes:

[C]linical medicine must not be regarded as the result of a new technique of observation ... but as the establishment of a relation, in medical discourse, between a number of distinct elements, some of which concerned the status of doctors, others the institutional and technical site from which they spoke, others their position as subjects perceiving, observing, describing, teaching, etc. It can be said that this relationship between different elements (some of which are new, while others were already in existence) is affected by clinical discourse: it is this, as a practice that establishes between them all a system of relations that is not 'really' given a priori. (Foucault, 1972: 53)

It is in his analysis of clinical medicine, which is expanded in his The Birth of a Clinic (1973), that Foucault provides a detailed history of clinical epistemology. He shows that clinical epistemology is a way of articulating and practicing the laws of positivism, stating: "The clinic is both a new way of 'carving up' things and the principle of their verbalisation in a form which we have been accustomed to recognising as the language of a 'positive science'..." (Foucault, 1973: xviii).

Foucault shifted directions in his oeuvre after writing The Birth of a Clinic, moving away from analyses of 'archaeologies of knowledge' to producing 'genealogies of power', such as in his famous examination of disciplinary society in Discipline and Punish (Foucault, 1977). Two philosophical premises from this book are particularly relevant to the medicalisation thesis. First, that power is not repressive, but rather a creative force that produces knowledge. Second, that discipline is exercised not on 
bodies, but on souls. These two premises are further articulated in Foucault's first three volumes on the History of Sexuality (Foucault, 1978; Foucault, 1985; Foucault, 1988). The notion of subjectification and the idea of the self-governing individual will be dealt with in at length in the sub-section of this chapter on governmentality. They are introduced at this point because they are relevant to the medicalisation thesis in that, despite all the writing about medicine and sanitation as forms of social control in the nineteenth century (and in some contemporary works of medical sociology - as noted above) the practice of medicine should not be seen as purely repressive, but rather as the creation and actualisation of knowledge and medical discourse. Secondly, while medicine can be seen as the exercise of power on the bodies of subjects, individuals must believe in medical knowledge in order to comply with medical practice. As such, the exercise of medical power is directed at the patients' will. ${ }^{6}$

It is useful at this point to present the historical and epistemological foundations of the phenomenon of medicalisation, because it is this history that has resulted in the marginalisation of subjective experience in medicine that is pertinent to this study on risk and the safety of pharmaceutical drugs. Hacking (1990) theorised on the rise of positivism in the human sciences in his book The Taming of Chance. He notes that prior to 1829 , there were no health statistics, no known laws of morbidity. In fact, it was during that year, that the chief actuary for the National Debt Office proclaimed in the British House of Commons, that: "life and death are subjected to a known law of nature,

\footnotetext{
${ }^{6}$ This statement leads to a further philosophical discussion about the Cartesian model and mind body dualism. This distinction between power as being exercised on body versus soul is meaningless when one holds a more unified conception of self as both physical and mental.
} 
but sickness is not" (cited in Hacking, 1990: 47). This, according to Hacking, led to an avalanche of statistics and social laws classifying people by sex, location, disease and occupation, in the periodicals in 1840 . He qualifies this period in the history of statistics as follows:

Numerical regularities about disease, unknown in 1820 , were commonplace by 1840. They were called laws, laws of the human body and its ailments. . medical men [sic.] were able to claim new expertise in matters moral and mental. (Hacking, 1990: 55)

Most relevant to the medicalisation thesis, is his account of how the 'average man' was conceptualised by applying the normal curve to biological phenomena. However, when it comes to biological and social phenomena, as Hacking explains, the mean in this case is not really a real quantity. Nonetheless, mathematician Adolphe Quetelet applied the normal curve to these phenomena:

Whether we think of the Normal distribution as an error curve or as the limit of a binomial coin-tossing game, we are concerned with what we think of as real quantities. The coin has a real objective propensity (so we suppose) to fall heads in a certain portion of tosses. The celestial position being measured is a real point in space, and the distribution of errors, we suppose, is an objective feature of the measuring device and the measurer. Quetelet changed the game. He applied the same curve to biological and social phenomena where the mean is not a real quantity at all, or rather: he transformed the mean into a real quantity. . . in a series of works he gave us the 'average man'. (Hacking, 1990: 107) 
This had important conceptual consequences, but it also had political implications, because the conceptualisation of the 'average man' related to the characteristics of a people, or a nation, or a racial type, led to both a new kind of information about populations and a new conception of how to control them. Abstract notions such as average height, for example, began to be seen as a real, or ideal, feature of the population (Hacking, 1990: 107-108). Hacking notes that it was the next step, by Quetelet, that had the most far-reaching implications in terms of social control:

He transformed the theory of measuring unknown physical qualities, with a definite probable error, into the theory of measuring ideal or abstract properties in a population. Because these could be subjected to the same formal techniques, they became real quantities. This is the crucial step in the taming of chance. It began to turn statistical laws that were merely descriptive of large-scale regularities into laws of nature and society that dealt in underlying truths and causes. (Hacking, 1990: 108)

It is through this conception of the 'average man' that the positivist epistemology of medicine was born. Philosophically, it is this "taming of chance", i.e., the translation of statistical laws (abstracts) into laws of nature (truths), that is the epistemological foundation for the present study. It carries with it two important philosophical implications, which will be discussed in the following paragraphs: the mis-representation of reality through pointillism and the subjugation of intuitive and subjective thought in medical practice. 


\subsubsection{Pointillism, Intuition and Subjective Knowledge in Science}

The rise of positivism has meant that Western science became equated with normative thinking and pointillist epistemology, a scientific vision that perceives the world in terms of discrete bits. In allopathic or conventional medicine, for example, the body is conceived of in terms of discrete 'tissues', 'cells', and 'organs', for instance. Little attention is paid to the space between these, the body's energy or life-force, or the flux that each discreet entity goes through over a life-course. ${ }^{7}$ Hipwell (2001) defined pointillism as follows:

Simply put, pointillism is the belief that reality can be broken down and reduced to discrete "atoms" or "points" or "identities." For Deleuze, these static forms are dangerous illusions: the real world is by contrast always fluid and mobile; reality is characterised by underlying continuity and constant change. (Hipwell, 2001: 40)

This mis-representation of reality by pointillist thought is at the heart of intellect-based knowledge; holistic views of reality are by contrast both intellectual and intuitive:

${ }^{7}$ This is in stark contrast to Chinese medicine, for instance, which is far more holistic, and emphasizes the role of chi energy. 
The intellect by its very nature must break down reality into atomistic identities that can be calculated rationally. By contrast, intuition may bring the intellect to recognise that life does not quite go into the category of the many nor yet that of the one; that neither mechanical causality nor finality can find a sufficient interpretation of the vital process. The very act of knowing with our heads destroys the most fundamental and important aspect of that which we are trying to know: the fact that nothing is discrete. Only the intuition can sense this. Gilles Deleuze calls such intuitive knowledge "wisdom of the body". (Ford and Hipwell, 2001: 18)

In contrast to Western pointillist modes of thought, French philosopher Henri Bergson (1911) calls for an epistemology that is both intuitive and intellectual:

[I]ntuition may enable us to grasp what it is that intelligence fails to give us, and indicate the means of supplementing it. . . intuition may bring the intellect to recognise that life does not quite go into the category of the many nor yet into that of the one; that neither mechanical causality nor finality can find a sufficient interpretation of the vital process. (p. 195)

Any complete theory of knowledge in the life sciences must take into account these two ways of knowing - intellectual and intuitive. For Bergson, human life is not reducible to matter; therefore scientific laws fall short when applied to the body or to the totality of living beings (Deleuze, 1991: 29). From Bergson's writings on intellectual and intuitive ways of knowing, it can be reasoned that science's instruments of calculation and prediction can aptly describe the exterior (or the shape and function) of bodily parts, 
tissues, etc., but have trouble deciphering the interior, such as consciousness, the interplay between body parts, and energies. He argued that science deforms the interior, because, for example, scientific reasoning isolates one psychological state-one pleasure, one hurt-from other in the conscious mind. This, to Bergson, is an illegitimate abstraction, since conscious states, for instance, are co-extensive and fluid.

Given Bergson's intuitive epistemology, it is possible that scientific knowledge about medicine and risk marginalises the interior and the subjective, because it lacks the means to access and process it. Bergson argued that the intellect could only grasp bounded concepts and solids. However, the reality of sickness and health, like the reality of life itself, is fluid and transient. Creative evolution is occurring in the microbial, parasitic world. We know that viruses do not behave in a totally predictable manner. Resistance occur, tissues stop responding to treatments, spontaneity is at play. Scientists understand this, yet they continue to use probabilistic models based on purely intellectual epistemologies, to address life (both human and parasitic). Intellect-based understandings of 'risk,' 'disease' and 'epidemic' must therefore be complemented by intuitive, subjective epistemologies.

Along with the subjugation of intuitive knowledge, comes the marginalisation of subjective experience. Foucault (1980) understands two things by 'subjugated knowledge': first, the historical mass of knowledge that as been buried by functionalist systematisation; and second, disqualified, low ranking or naïve knowledge. This is the knowledge of political struggles. Following Foucault's advice, it is through the insurrection of these subjugated knowledges that formal medical and risk-management systems can be critically examined. He affirms: 
I also believe that it is through the re-emergence of these low-ranking knowledges, these unqualified, even directly disqualified knowledges . . . and what involve what I would call popular knowledge (le savoir des gens)... that criticism performs its work. (Foucault, 1980: 82)

This philosophical/academic process also had important political consequences. The "avalanche of numbers of the 1820-1840s" and the "taming of chance", as discussed above, were immediately put to political ends, as the rationale for the social control of 'unruly' beings. It is seen as a means to improve health and to improve morality, whereby individuals of unruly classes are governed by numbers. Hacking remarks that statistics became a rationalisation for social control, stating:

Statistical laws do apply to classes. It is the laws about 'them', about the other, that are to be determined, to be analysed, and to be the basis for legislation. The classes in question are not abstract entities but social realities. Inevitably it is the labouring, or criminal, or colonial classes that are the chief objects to be changed, for their own good. (Hacking, 1990: 120)

These laws are then applied to the social control, or treatment, of unruly beings, supposedly, for their own good. This is a crucial element of the disciplinary society that is described in Foucault's genealogical work (Foucault, 1977; Foucault, 1978; Foucault, 1985; Foucault, 1988), and throughout much of the contemporary medicalisation literature. Like most theorists addressing medicalisation, Szasz (2004) is highly critical of this notion, and shows that it is also a dominant literary theme, citing, among others, C.S. Lewis, who wrote: 
Of all the tyrannies, the tyranny sincerely exercised for the good of the victim may be the most oppressive... To be 'cured' against one's will and to be cured of states which we may not even regard as disease is to be put on a level with those who have not yet reached the age of reason and those who never will; to be classified with infants, imbeciles and domestic animals. (as cited in Szasz, 2004:

\section{5)}

Bryan Turner (2000) refers to this era of medicine as a time of great struggle between 'allopathic' and 'social' medicine, writing:

Although the nineteenth century is seen in official histories of medicine as the great triumph of the scientific revolution, it also disguised a profound struggle between individualistic allopathic medicine and social medicine. At the core of this debate was, on the one hand, the great successes in scientific responses to infection through such techniques as vaccination, and on the other the great social need of the urban population. (Turner, 2000: 16)

In an earlier work, Turner (1987) explains that it was during this era of the rise of rationality and positivism that doctors began to replace members of the clergy as agents of social organisation and control. He situates medicalisation within a larger process of secularisation of social relations, in which medicine came to supplant religion as the source of the doctrine of 'normal' behaviours: 
The medicalisation of society involves therefore a regularisation and management of populations and bodies in the interest of a discourse which identifies and controls that which is normal... The medical profession has replaced the clergy as that group in society which manages normal social relations. (Turner, 1987: 219)

Newtonian physics was paired with Cartesian mind-body dualism to create mathematical laws of the human body, these laws were then used to govern society.

This highly individualistic, rational, experimental ethos took shape at the expense of, or through the silencing of, a more communitarian, holistic and traditional practice of medicine. In an anthropological exploration of the history of the biomedical model and its effect on medical practice, Commelles (2000) shows how the subjugation of subjective experience, as discussed philosophically above, occurs concretely in medical practice. He shows that the process of medicalisation that took place in Europe led to the marginalisation of personal contact, ethnographic accounts and local knowledge, which characterised classical medicine, in favour of the individualism, mercantilism and pragmatic efficacy of the biomedical model. Thus a partial rupture in the role and social function of medical practitioners took place; in his words:

Medicalisation represents a new development, a break with prior structures of medical practice and ideology and a substantial change in the intellectual position of doctors in the contemporary state. Once considered social engineers... they became legitimators and defenders of individualized risk management.

(Comelles, 2000: 54) 
He concludes that the abandonment of ethnographical practice in medicine resulted in two related developments: the hegemony of clinical epistemology and the depoliticisation of physicians' commitment to their patients. It also led to the view of sickness as transgression (Comelles, 2000: 55).

To summarise this sub-section of the chapter, medicalisation, as a historical transformation in medicine, began in the seventeenth century, and continued on until the end of the nineteenth century. This process took place in conjunction with the rise of positivism and the dominance of rationality in the Western world. As such, it was part of a broader academic and scientific movement, which denigrates intuitive and subjective modes of perception in favour of intellectual and positivist rationality. With this transformation, the profession of medicine increasingly broke down into smaller specialisations, and the clinic gained tremendous importance as the site for indoctrinating medical professionals and creating and transmitting medical knowledge. Medicine gained increasing political influence, since medical discourse supplanted religious doctrine as the source of knowledge on 'normal' human behaviour and ways of being. The following sub-section expands on the political significance of this transformation in medicine.

\subsection{Governmentality}

Bryan Turner (1987) has written the following about the three dimensions (or stages) of western rationality: 
The growth of western rationality can be approached in terms of different dimensions. First, there has been a general secularisation of culture, whereby religious symbols and beliefs have come to lose their public dominance... Secondly, there is a corresponding intellectualising of the mundane world, whereby scientific procedures and beliefs become the criteria for action. Thirdly, rationalisation involves the increasing importance of systems of individual discipline and regulation by bureaucratic agencies related to the nation-state. (Turner, 1987: 37)

His first two stages together make-up medicalisation, as described in the previous subsection of this chapter. His third stage, with its increasing reliance on systems of individual discipline and regulation by bureaucratic agencies, is equated with the notion of governmentality, which is discussed in this sub-section of the chapter.

Although the genesis of the governmentality literature is usually attributed to Foucault's later work (Foucault, 1991; Foucault, 1997), psychiatrist Thomas Szasz (2004) was dealing with the same issues as early as 1974 . He writes:

I first proposed the term "pharmacracy" in 1974, to complete a triad of phases to identify that we are in the process of a profound cultural transformation... [in which] our system of social controls has become increasingly dependant on the principles of a politicised medicine, and has been legitimised and enforced by a complex state apparatus that co-mingles the principles and practices of paternalistic "therapy," punitive psychiatry, collectivist public health and the criminal justice system. (Szasz, 2004:54) 
The social and political role of medicine and medical discourse was a central element of post-war sociological thought. It was in this era that Parsons (1951) wrote the following about the "sick role", for instance:

...illness is a state of disturbance in the "normal" functioning of the total human individual, including both the state of the organism as a biological system and of his personal and social adjustments. It is thus partly biologically and partly socially defined. Participation in the social system is always potentially relevant to the state of illness, to its aetiology and to the conditions of successful therapy, as well as to other things. (Parsons, 1951: 431)

Health and illness can thus be seen as organising principles and elements of control in society. Foucault theorised the rationale behind this social and political organisation in his writings on 'governmentality'. In his essay entitled “Governmentality", Foucault (1991) states that by 'governmentality', he means three things: first, the “. . . ensemble formed by institutions, procedures, analyses and reflections, the calculations and tactics ..." that allow the exercise of political power on populations; second, the tendency of this form of power, which results in " ... the formation of a whole series of specific governmental apparatuses ..." and " ... the development of a whole complex of savoirs ..." to dominate over all others (e.g. sovereignty and discipline) throughout the West; and third, the set of processes “. . through which the state of justice in the Middle Ages, transformed into the administrative state during the fifteenth and sixteenth centuries, gradually becomes 'governmentalised"' (Foucault, 1991: 102-103). This mode of governing has as its purpose: “ . . the welfare 
of the population, the improvement of its condition, the increase of its wealth, longevity, health, etc. ..." Moreover,

[T] he means that the government uses to attain these ends are themselves all in some sense immanent to the population; it is the population itself on which government will act either directly through large-scale campaigns, or indirectly through techniques that will make possible, without full awareness of the people, the stimulation of birth rates, the directing of the flow of populations into certain regions or activities, etc.. (Foucault, 1991: 100)

This rationalisation of political power as being 'in the interest of populations' is reminiscent to that which transpired from the "avalanche of numbers" or the proliferation of statistics on population's health (as discussed above): the idea of social control in 'society's best interest'. However, what slowly takes place through the process of governmentality, as Foucault explains, is the creation of new sets of techniques, whereby individuals are 'socialised' (although Foucault never used such a word) to become aware of themselves and aware of others and to govern themselves accordingly.

These technologies of power rely on individual freedom to operate. In his work on "the Birth of Biopolitics", Foucault (1997) looks to the rise of early liberalism, beginning in the $18^{\text {th }}$ century, to understand how problems of populations-longevity, birthrates, health, sanitation, etc., became rationalised and managed as problems of government, in a system of rule that was " ... anxious to have the respect of legal subjects and to ensure the free enterprise of individuals ..." (Foucault, 1997: 73). Foucault, as well as scholars such as Mitchell Dean (1994), Colin Gordon (1991) and Nicholas Rose $(1993 ; 1994)$ have argued that this type of power operates through free 
citizens who govern themselves along the lines established in discourses of power. More simply put, it is argued that political power is less based upon coercion or brute force and more enmeshed in the common understandings and norms that guide everyday behaviour. As Colin Gordon notes in his "Introduction to Governmental Rationality", this is a form of governing that “ . . economises on its own costs: a greater effort of technique aimed at accomplishing more through a lesser extension of force and authority"(Gordon, 1991: 24). Rose (1993: 299) also advances this point, stating:

Whilst welfare sought to govern through society, advanced liberalism asks whether it is possible to govern without governing society, that is to say, to govern through the regulated and accountable choices of autonomous agents - citizens, consumers, parents, employees, managers, investors. (emphasis in original).

This mode of governing is efficient and effective and much simpler than we might think. It is based upon: "ideas that go without saying, which make possible existing practices and our existing conceptions of ourselves". These, according to Gordon, “... may be more contingent, recent and modifiable that we think" (Gordon, 1991: 48). Gordon concludes that:

$[\mathrm{G}]$ overnment is a 'conduct of conduct': because the relation between government and the governed passes, to a perhaps ever-increasing extent, through the manner in which governed individuals are willing to exist as subjects ... to the extent that the governed are engaged, in their individuality, by the propositions and provisions of government, government makes its own rationality intimately their affair: politics becomes, in a new sense, answerable to ethics. (Gordon, 1991: 48) 
Nicholas Rose (1993) argues that we should not, therefore, come to understand our freedom as a sham, but rather should be cognizant that what we have come to understand as freedom is crafted by the tension between liberty and government (Rose, 1993: 299). He expands on this point in a later work, stating:

We are required to be flexible, to be in continuous training, to participate in lifelong learning and perpetual assessment; we are faced with continual incitement to buy and improve ourselves, urged to engage in constant monitoring of our health and never-ending risk management ... The ambition for this new technology of governing the self is the restoration of continual long-term maintenance of the free individual, obliged to choose and take responsibility for his or her life as if it were the outcome of acts of choice. (Rose, 2003: 430)

Rose (1994) has theorised the role of medicine in this form of government, arguing that it has displaced the rule of law in the exercise of political power, because power, today, is very much about expertise and the delineation of what is 'true' and what is 'good' for society and for the self. Medical authority extends beyond the clinic, to society and life as a whole, or in Rose's words: “. . . the remit of medicine extends beyond the dimension of illness and cure, and into the management of normality itself' (Rose, 1994: 67). He explains:

If, in our present times, medicine has come to play such an important role within this ethical complex, it is in part because it has come to link the ethical question of how we should behave to the scientific question of who we truly are and what our nature is as human beings, as life forms in a living system, as simultaneously unique individuals and constituents of a population. (Rose, 1994: 68) 
The medical gaze is even more far reaching in the twenty-first century, argues Rose (2003), because of the growing potential of pharmaceutical drugs to reshape human life. Rose contends:

The power to reshape life by drugs seems to extend way beyond what we previously understood as illness .... The capitalisation of the power to treat intensifies the redefinition of that which is amenable to correction or modification. This process is not simply blurring the borders between normalcy and pathology or widening the net of pathology. We are seeing an enhancement in our capacities to adjust and readjust our somatic existence according to the exigencies of the life to which we aspire. These capacities for enhancement involve the co-production of a drug, the condition it will treat, and the desire and demand for it. (Rose, 2003: 433)

Therefore, he argues that the focus of sociology of health and illness should shift from the study of biopolitics (in the Foucaultian sense) to bioethics, because “. . . human capital is now to be understood in a rather literal sense, in terms of the new linkages between the politics and economics of life itself" (Rose, 2003: 433). This study takes up Rose's challenge, acknowledging the centrality of medicine in the governing process and examining the linkages between politics and the economics of the vital realm.

\subsubsection{Subjectivity and the Governing Process}

If governance is equated with a form of regulated freedom, whereby individuals internalise discourses of power, then one can assume that individual experience or subjective knowledge is necessary for the fulfilment of this process. In order for public 
health discourse to be actualised, for example, individuals must not only accept the knowledge offered by public health institutions, but they must also share their personal experiences with the medical establishment. From this sharing of personal knowledge and experience, statistics on disease prevalence and drug side-effects are coded and recorded. Foucault $(1980 ; 1973)$ posits that this is at the heart of the power of clinical discourses-the power to recuperate subjectivity. As he explains:

In fact, those unitary discourses, which at first disqualified and then ignored [subjugated knowledges] when they made their appearance, are, it seems, quite ready to take them back within the fold of their own discourse and to invest them with everything this implies in terms of their effects of knowledge and power.

(Foucault, 1980: 86)

The following sub-section of the chapter theorises the reflexive phase of medicine, wherein individuals who are concerned with the uncertainties attached to medical and scientific technologies are becoming increasingly involved in the coproduction of knowledge, and whereby science is self-critical of its own products.

\subsection{Risk and Reflexivity}

This third transformation in medicine, which includes all of the elements noted above, has not only led to diversification and specialisation of medical knowledge, but also to increased lay-awareness and lay involvement in its shaping. We can see this, for 
example, in the work of advocacy groups and political lobbyists. ${ }^{8}$ Uncertainty is acknowledged in this stage of medicine, and 'risk management thinking' (i.e., a probabilistic accounting of the costs and benefits of particular hazards) increasingly enters into medical discourse. Meanwhile, risk management thinking reveals itself to be of limited value when addressing elements of health that are in constant ebb and flow, as discussed above. In light of the uncertainties regarding health and illness, and of growing doubt about sciences' abilities to cure all ills, expertise is multiplied. As a result, there are a greater number of specialisations within medicine and a growing faction of citizens who form patient advocacy groups, or find other ways to insert their voices into the creation of knowledge on health and illness.

It is necessary, at this point, to present an overview of theories of risk, because 'risk thinking'-i.e., a probabilistic approach to dealing with potential harm or dangerhas begun to permeate contemporary Western approaches to medicine. Reflexivity is then offered up as a potential way to cope with the limitations of risk thinking in medicine and to address the increasing importance of lay expertise in medicine.

\subsubsection{The Sociology of Risk}

What is risk? When and how did the concept of risk arise in our everyday vocabulary? How is risk different from danger? Mary Douglas has written extensively about this. In her work, Purity and Danger (1966), she writes that culture, or power, has always strived to impose order over anomalous events. This was traditionally done by

\footnotetext{
${ }^{8}$ Consider, for example, the work of AIDS activists in the 1990, who successfully lobbied the Food and Drug Administration to speed up the approval of several HIV drugs. Cindy Patton (1996) speaks of this in Fatal Advice: How Safe Sex Education Went Wrong, Duke University Press.
} 
settling upon one definition and interpretation of anomalies; by physically controlling individuals and coercing them to avoid anomalies; by devising rules for avoiding anomalous events; by labelling anomalous events as dangerous and enforcing conformity; and by using symbols to represent the unified patterns of danger. She asserts that definitions of danger and prescription of ways to avoid it, are expressions of social and political culture and power, and states that " ... dangers are better interpreted as symbols of the relation between parts of society, as mirroring designs of hierarchy or symmetry which apply to the larger social system" (Douglas, 1966: 4-5). In Risk and Blame (1992) she also explains that in pre-modern times, understandings of risk and danger were tied to spirituality and taboo, and notes that methods of pollution control were called upon to minimise the dangers associated with impurity, and the gods were placated in a variety of ways, to prevent disasters. Death and illness, she argues, present an arena in which to define blameworthiness. A social contract is thus borne by understandings of danger and blame. She calls this “... social solidarity through misfortune” (Douglas, 1992: 7). In many ways, she shows that modern technology changed all of this. First, because technology, and not cosmology, became the primary means to evaluate and divert dangers, and most dangers remain unpredictable. Second, because technology itself gave rise to further danger. Hence, today, the spectre of uncertainty is pervasive.

The concept of risk, as we now understand it, grew out of the acknowledgement of this uncertainty of danger. It is based on probability and insurance. It is statistical and not natural, or cosmological, in its essence. According to David Garland (2003), a danger is "something that is liable to cause harm, injury, or adversity of some kind", whereas a risk is "the possibility of some kind of loss or injury". He further explains: 
Risk is a measure of exposure to danger, of the likelihood and the extent of loss.

So the ideas of risk and danger are closely connected, but clearly distinguishable.

'Danger' (or its synonyms, 'peril' or 'hazard') is the potential for harm that inheres in a thing a person or a situation. Risk is a measure of that potential's likelihood and extent. Put at its simplest, risks are estimates of the likely impact of dangers. (Garland, 2003: 50)

According to German sociologist Ulrich Beck, author of The Risk Society (Beck, 1992) and World Risk Society (Beck, 1999), the notion of risk is a systematic way of addressing the hazards and insecurities induced by modernisation itself. His focus is on the threats that are " ... spreading within the globalisation of high risk industries, whether for warfare or welfare purposes", and he notes that the unintended consequences of modernisation now dominate history and society, stating that: "[a]long with the growing capacity of technical options ... grows the incalculability of their consequences" (Beck, 1992: 22). Beck thus ties risk to modernisation and the globalisation of doubt.

Postmodern risk is thus in part irrational, incalculable, and uncertain, due to the globalisation of doubt brought by the modern industrial project. This project brings with it a slew of technologies to assess, measure and interpret the risks associated with it. In postmodernity, science is reflexive, this is its raison d'etre, its self-fulfilling prophecy. Hence, as the science of risk encounters itself: "Science is one of the causes, the medium of definition and the source of solutions of risk, and by virtue of that very fact, it opens up new markets for the scientization of itself' (Beck, 1992: 155; emphasis in original). 
Beck underscores the political element of having the power to define risk, or to put parameters around potential catastrophes, in his words: "[W]hat thus emerges in risk society is the political potential of catastrophes. Averting and managing these can include a reorganization of power and authority" (Beck, 1992: 24). Consequently, according to Beck, society becomes a risk-analysis laboratory, and the public are its subjects. He writes:

It is not that one could not know how the toxic rations affect people individually or in total. One does not want to know it. People are supposed to find that out for themselves. A permanent experiment is being conducted, so to speak, in which people serving as laboratory animals in a self-help movement have to collect and report data on their own toxic symptoms against the experts sitting there with their deeply furrowed brows. Even the already published statistics on such things as diseases or dying forests apparently do not appear eloquent enough to the acceptable-levels magicians. (Beck, 1992: 69; emphasis in original)

Anthony Giddens (1999) also emphasises that the source of contemporary anxiety surrounding risk is bound up with the progression of Western knowledge. For Giddens, 'risk' is a modern construct that has not lived up to its potential of averting catastrophes, in his words:

Risk was supposed to be a way of regulating the future, of normalising it and bringing it under our dominion. Things haven't turned out that way. Our very attempts to control the future tend to rebound upon us, forcing us to look for different ways of relating to uncertainty. (Giddens, 1999: 1) 
He identifies two kinds of risk: 'external risk' comes from the natural world, while 'manufactured risk' is a by-product of scientific development. This later understanding of risk is at the root of post-modern anxiety about technological progress and the distrust of scientific experts. As Giddens argues:

At a certain point, however - very recently in historical terms - we started worrying less about what nature can do to us, and more about what we have done to nature. This marks the transition from the predominance of external risk to that of manufactured risk. (Giddens, 1999: 2)

It is possible to take his point a step further: even more recently, we have begun to worry about what the things we do to protect ourselves from the things we have done to nature, can themselves do to us! Risk, and the perception thereof, is clearly proliferating at an ever-increasing pace. ${ }^{9}$

In present day risk management, that which counts as valid knowledge or expertise is multiplied. As such, one can no longer count on "... one definition and interpretation of anomalies ..."; a single set of " ... rules of avoiding anomalous events ..." or conformity to those rules; or any "... unified patterns of danger", as in the society described in Douglas' (1966: 4) early work. Instead, as Hunt (2003: 169-170) argues, the management of risk in everyday life, today, is characterised by a proliferation of conflicting forms of expertise and distrust in expert knowledge.

\footnotetext{
${ }^{9}$ For more information on the risk of adverse drug reactions, see "Faint Warning" a CBC investigative report on the tracking of adverse reactions in Canada.

http://www.cbc.ca/news/adr/ (last accessed on 24 July 2006).
} 


\subsubsection{The Epistemology of Risk}

How do we know what we know about risk? What forms of knowledge are used in risk management? How is knowledge about risk constructed? What defines a 'risk'? The following paragraphs grapple with these epistemological queries regarding the nature of risk.

Contemporary risk management is grounded in a calculative, probabilistic, perception of reality. As a science, contemporary risk management is actuarial and is based on the concept of insurance, or in Hacking (2003)'s words, a "calculating concept that modulates the relationship between fear and harm." He further notes that: "calculation [first] began to dominate instinct, tradition and collective wisdom, in a measured way, only in seventeenth century Europe" (Hacking, 2003: 27), as was discussed in depth in the previous pages of this chapter.

For Francois Ewald (1991) and Daniel Defert (1991), this actuarial and positivist approach to risk becomes translated into insurance practices that transform the social sphere into a complex process of accounting and compensating for the eventuality of risk. Ewald states that:

Insurance is linked to 'the geometry of hazard' or 'the algebra of chance' . ...

Risk, in the meaning of insurance, has three great characteristics: it is calculable, it is collective and it is a capital ... each person is a factor of risk .... Insurance assigns a new mode of existence to previously dreaded events: it creates value. (Ewald, 1991: 200-201)

He further asserts: " . . from these three characteristics of risk as the actual value of possible damage in a determined unit of time, one can deduce a definition of insurance as 
the compensation of effects of chance according to the laws of statistics" (Ewald, 1991: 205). So, the pre-modern conception of blame and social contract is replaced with a probabilistic model that spreads risk out over the entire populace. On this note, Daniel Defert (1991) asserts that: "Social insurance has the effect of completely marginalising the old territories of working-class solidarity, and of re-organising them around a novel set of political notions" (Defert, 1991: 212).

Medical definitions of risk take a positivist approach and often discredit subjective experience. According to Health Canada researchers, Vertinsky and Wehrung (1990), the intuitive risk judgements that people make when they evaluate hazards (also called 'public risk perceptions') often differ from the judgements made by regulators based on scientific evidence. These 'public risk perceptions' are said to: "influence the regulatory process in unproductive ways, and may distort socially efficient market processes" (Vertinsky and Wehrung, 1990: 1; emphasis added). This kind of official denigration of subjective knowledge is common.

The sociological study of risk often adopts a similar positivist approach, which denigrates the role of subjective knowledge. For Kevin Haggerty (2003), risk is statistical, rational and probabilistic. This conception of risk assumes it as a static and given reality. Haggerty posits that the neo-liberal subject becomes responsible for risk, and must therefore adopt a "calculative approach to life management" (Haggerty, 2003: 197). However, he states that subjects are rarely knowledgeable regarding probabilities and therefore erroneously inflate their risk, applying a precautionary approach to riskmanagement that is based upon fear and angst, and not grounded in reality. He supports this thesis by referring to the exploding market in home security technologies. 
What role does subjective experience play in the modern-day conception of risk? Does the individual subject necessarily inflate risk on the basis of "irrational fear and angst" alone, or is the reality that the technologies and mechanisms in place to account for risk and its management are ill-equipped to deal with subjective experience? Ulrich Beck's (1992) theory of risk runs counter to much of the contemporary sociological literature on risk as 'real' and 'calculable', since he emphasises uncertainty and the subjective nature of risk, arguing, for example:

Risks originate after all in knowledge and norms, and they can thus be enlarged or reduced in knowledge and norms, or simply displaced from the screen of consciousness. What food is for hunger, eliminating risks, or interpreting them away, is for the consciousness of risks. (Beck, 1992: 75; emphasis in original)

According to Beck, public criticism plays an integral role to the development of science "the publicly transmitted criticism of the previous development becomes the motor of expansion" (Beck, 1992: 161). He argues that this should also be the case with respect to the science of risk.

One of Beck's greatest contributions to theories on risk is his understanding of the "reflexivity" of science in the risk society. He explains that modern industrial development brought with it many hazards, most notably the danger of the atomic bomb; meanwhile, it also provided an assortment of technologies to assess, measure and interpret the risks associated with it. Hence within contemporary risk management, science encounters itself, and is a driving factor in its own expansion. As Beck clearly puts it: "science is one of the causes, the medium of definition and the source of solutions of risk, and by virtue of that very fact, it opens up new markets for the scientisation of 
itself" (Beck, 1992: 155). Furthermore, "the publicly transmitted criticism of the previous development becomes the motor of expansion" (Beck, 1992: 161). Knowledge gains political significance in the risk society; in Beck's own words: "What thus emerges in risk society is the political potential of catastrophes. Averting and managing these can include a reorganisation of power and authority" (Beck, 1992: 23-24). In the reflexive stage, the expansion of science includes a critique of itself. This has some important consequences, including: "a de-monopolisation of scientific knowledge claims, which comes about as science becomes more and more necessary, but at the same time, less and less sufficient for the socially necessary, binding definitions of truth" (Beck, 1992: 157158).

Nicholas Luhmann (1993) does not define the reality of risk, but rather emphasises the subjective experience of risk, or 'subjective negotiation'. He writes:

We can speak of risk only if we presuppose that the person who perceives a risk and eventually assumes it draws certain distinctions, namely the distinction between the good and bad results; advantages and disadvantages; profits and losses; and the distinction between the probability and the improbability of their occurrence... only then can we really speak of risk awareness. (Luhmann, 1993: 219)

It is this subjective experience of risk that lies at the heart of the present study. 


\subsubsection{Risk and Pharmaceutical Drugs}

Measures to safeguard populations from various risks permeate many aspects of society. The following pages zero in on the prevention of risk with regard to pharmaceutical products.

Recently, the Canadian Broadcasting Corporation (C.B.C., 2004a) publicly attested to the shortcomings of the system by which Canada ensures drug safety in an investigative report entitled "Faint Warning: From Coloured Tabs to Computerized Signals: How Canada Tracks Dangerous Drugs”. They state that only between one and $10 \%$ of adverse reactions to pharmaceutical products are recorded in the national drug monitoring system. Joel Lexchin (e.g. 1998; 2003; 2004) has written extensively on risk management within the pharmaceutical industry in Canada. In an article entitled "Drug Makers and Drug Regulators: Too Close for comfort" (1998), he shows that major loopholes that jeopardise the health and safety of patients are systemic, and exist due to the collegial relationship and crossovers between the Canadian drug regulation agency and Canadian drug makers. In a later article, Lexchin shows that confidentiality laws favour drug producers at the risk of endangering Canadians who want information about drug safety. He writes: 
In Canada, the information used to approve new drugs is deemed commercially sensitive and hence confidential under the Access to Information Act, and the Therapeutic Products Directorate (TPD) will not release such information without the manufacturer's approval. As a consequence, safety and efficacy information contained in unpublished trials submitted to the TPD is generally unavailable to researchers, physicians and patients, a situation that can potentially lead to the inappropriate prescribing and use of medications (Lexchin and Mintzes, 2004: 1503).

When it comes to technical matters involving the health of citizens, risk management involves calculation and prediction, on the one hand, and risk communication, on the other. In order for risk management to proceed in a transparent manner, all stages of the processes should be open to public scrutiny and informed citizens should have ample opportunity to have their voices heard. However, the bureaucratic and institutional settings rarely leave room for citizen input. In an exploration of the Walkerton E. Coli situation, in which citizens became ill and died when the water supply was contaminated, Ali $(2002 ; 2004)$ examined the interaction between the government, environmental activists, scientists, and citizens. He found that "an overly narrow focus on technical matters led to the exclusion of lay concerns based on cultural rationality" (Ali, 2002: 24), thereby resulting in tragedy. This case showed that a lack of transparency can lead to unnecessary deaths.

Health Canada, has been shown to respond very unfavourably when anyone, even its own scientists, express concerns over the safety of health products. The recent dismissal of Shiv Chopra, Margaret Haydon and Gerard Lambert, three Health Canada 
scientists who criticised Monsanto corporation's bovine growth hormone and spoke out against the use of antibiotics in farm animals, is a case in point to support the notion that Health Canada is unreceptive to criticism from the inside (Canadian Broadcasting Corporation (CBC), 2004b). On this point, Lexchin (1998) concludes his study of the relationship between drug makers and drug regulations by stating that: "[u]nfortunately for the Canadian public, democratisation in the field of drug policy seems a long way off' (Lexchin, 1998: 495). The following section presents the work of theorists who have elucidated how this democratisation in science and risk management might take place.

\subsubsection{Reflexivity in the Science of Risk}

In a recent article in Harpers magazine, Bruno Latour (2004a) called into question the work that he and his colleagues have advanced in the sociology of scientific knowledge, stating that they might have gone too far with their critiques. He asks:

Do you see why I am worried? I myself have spent some time in the past trying to show the lack of scientific certainty inherent in the construction of facts... Perhaps the danger no longer stems from ideological arguments posturing as matters of fact -which we have learned to combat so efficiently- but from an excessive distrust of good matters of fact disguised as bad ideological biases. (Latour, 2004a: 15)

He goes on to suggest that the critique of science should, from now on, be associated “. . . with more, not with less; with multiplication, not with subtraction" (Latour, 2004a: 20). This sub-section of the chapter begins with this quote by Bruno Latour, to show that what is needed to cope with today's hazards is an increase in dialogue on risk, or a 
revitalisation of the science of risk. This revitalisation will occur with the synthesis of a variety of knowledges from various sources of expertise. As Bourdieu (2004) noted, reflexivity is meant to underwrite not to undermine science.

Reflexivity beckons the insertion of multiple voices into the critique of science. When reflexive, science grows from critique; critique is part of science. In his study of the search for a Guelph landfill site, Ali (1999), shows that the changing character of contemporary risk has led to a rapprochement between those who make decisions about risk and those who face the consequences of risk. As such, the science of risk must become de-monopolised. He explains:

For Beck (1992) as well as Giddens (1990), the changed character of the risks we now face... has led to the emergence of a new dynamic in which both institutional and individual actors are forced to adapt to the newly emerging characteristics of the risk society... It is my contention that this development has led to changes in the treatment of environmental risk, including such changes as the demonopolization of technical knowledge, changes in the opportunity structure for lay involvement in risk matters, and the opening of technical work to social standards of relevance. (Ali, 1999: 5)

He argues that this takes place through 'reflexive scientization': 
The new mode of scientific activity is not a linear 'rule altering' process but a 'reflexive scientization' -when counter expertise is institutionalized, scientific dissent about what constitutes scientific fact is made public, as is the inability of scientific research to guarantee certainty ... competing claims raise lay awareness of technical errors, which in turn highlight the inherently uncertain character of the science of environmental risk assessment and management. (Ali, 1999: 11)

He also suggests that in order to institutionalise public involvement in scientific knowledge production, interest groups must be transformed into advisory groups, thus increasing social relevance of scientific knowledge production, increasing communication between lay people, the scientific community and decision-makers, and increasing accountability in regard to technical decision making (Ali, 1999: 16).

Giddens (1999) speaks of the democratisation of knowledge on risk. To quell the post-modern anxiety regarding external risks, he calls for a 'public democracy' in which everyday experience can inform public policy and democratic regulation; in which a dialogue between the public and regulators is based on principles of openness, engagement, and transparency; or, in Gidden's words, in which "everyday culture which will be complementary to and add to democracy in the public sphere ... based on active trust, based on the capability of respecting other people's opinions" (Giddens, 1999: 4).

As noted above, Ulrich Beck $(1992 ; 1999)$ has theorised that post-modernity and post-Enlightenment thinking can be characterised by a unique production of knowledge and discourse on risk. In his writings on the 'risk society,' he argues that 'reflexive modernisation' - a process of critique of and self-criticism within science-can create a social dialogue on the many uncertainties that are by-products of the modernising 
process. Modernisation and technological advancement bring with them many risks and uncertainties, including the side-effects caused by pharmaceutical drugs. Reflexivity can keep the 'unintended consequences' of this modernising process in check, and as Beck affirms: "even in the most technical risk arenas, therefore, there is important sociological work to be done" (Beck, 1992: 5). This is because, as Beck argues, those who have power usually want to uphold the dichotomous view that "science 'determines risk' and the population 'perceives risk"' (Beck, 1992: 57). In Beck's view, this division between the 'experts' and 'non-experts' creates a general perception of the public as ignorant, but well-intentioned. Moreover, it encourages the belief that "protests, fears, criticism or resistance in the public sphere are pure problems of information, [in other words] if the public knew what the technical people know, they would be at ease- otherwise they are just hopelessly irrational" (Beck, 1992: 58). As such, in order to maintain a position of power, the 'experts' or those who claim sole access to 'expert knowledge', often disparage individual experience, common sense and/or community viewpoints.

Beck (1992; 1999) does not speak of post-modernity, but rather of 'reflexive modernisation.' His thesis on the risk society moves us beyond post-modern doubt, and delineates a noble pursuit for sociologists: to open up certain possibilities wherein the sub-politics of knowledge can exert an influence on knowledge building. To some degree, discourse on risk and discourse on modernisation are conflated in the risk society. Resistance to the discourse of modernisation and a dialogue on 'manufactured uncertainty' are what enable 'reflexive modernisation' to take place. It is through resistance to discourse on risk that "'we' deal with our unawareness (or inability to know) [and] decide in and between manufactured uncertainties" (Beck, 1999: 132). A critical 
role for sociologists in the risk society is to re-build public institutions that open up a space for dialogue on risk and uncertainty. These institutions would protect "alternative evaluations, alternative professional practice, discussion within organizations and professions of the consequences of their own development and repressed scepticism" (Beck, 1992: 234). It is only once criticism is embraced from within dominant institutions as a positive force, that society can begin to cope with uncertainty. In Beck's words:

Only when medicine opposes medicine, nuclear physics opposes nuclear physics, human genetics opposes human genetics or information technology opposes information technology can the future that is being brewed up in the test-tube become intelligible and evaluable for the outside world. Enabling self-criticism in all its forms is not some sort of danger, but probably the only way that the mistakes that would sooner or later destroy our world can be detected in advance. (Beck, 1992: 234; emphasis in original)

Science is a political process, and " $[i] \mathrm{t}$ is no longer accepted that there is a universal taxonomy of disease or that medical practices are neutral" (Turner, 2000: 22). Bruno Latour, alone $(1983 ; 1990 ; 1994)$ and in his work with Bastide $(1986)$, has looked critically at the scientific process, seeing it as a textual construction of reality in which every new development is based on a succession of the last. He calls this the process the 'inscriptive method' and asks his readers the following question: "Does a scientific text tell a story like other kinds of texts?" to which he responds: 
No, because it stacks the traces in such a way that each one is a transformation of the last. So does it therefore constantly repeat itself. ... No, because it adds something each time, which is not really shown but is not really unfound either. The text puts together its elements as if they were stones in a primitive arch. Each one is supported by the last but leans into the void. . . [the strength of the construction] depends upon the negotiations which guide the way in which each stone is balanced upon the last. (Latour and Bastide, 1986: 59)

Latour has also contributed extensively to the growing body of literature of reflexivity in science. For Latour (1987), science is always "science in action", and we are never confronted with technology and science, but with a gamut of "stronger and weaker associations". This means, "irrationality is always an accusation made by someone building a network over someone else who stands in the way; thus there is no great divide between minds but only longer or shorter networks" (Latour, 1987: 259).

The notion of reflexivity underscores the political nature of science. There is no doubt that healthcare and medicine are political. This study explores the many avenues that citizens are finding to insert their voices into the political processes of medical practice and health care. Free trade and the Internet have provided, for better or for worse, numerous possibilities for individuals to bypass state policies and take their health into their own hands.

Public involvement and scrutiny of the sciences also call into question the 'knowledge interests' that underlie the production of scientific knowledge. Cramer et al. (1987) note that scientific interests must be aligned with general societal needs, and that reflexive scientization allows this: 
[The] analysis of the link between public interest and the production of scientific knowledge has received increasing attention over the past decades ... That science and technology can possibly have negative effects on society is a relatively new idea, which is perhaps best symbolized by the destructive potential of the atom bomb and of nuclear weapons in general. Such negative effects of scientific knowledge production have made more people aware of the necessity of aligning scientific and technical developments with general social needs. (Cramer, Eyerman, and Jamison, 1987: 89)

Perhaps, this potential for revealing the knowledge interests behind scientific knowledge production, is the reason why efforts aimed to promote reflexivity are often quelled.

Western discourse on anti-malarial drugs appears to be stuck in what Beck calls the "developmental logic of the first phase" (Beck, 1992: 162), in which scientific claims are spared from self-criticism and internal scepticism. External forces, such as advocacy groups, can and do challenge statistics on the prevalence of adverse reactions; and layexperts who have first hand experience on the drug can and do publicise their reactions to it, however the dominant message remains the same: mefloquine is a safe drug. This message is repeated in the absence of further investigation of the claim.

\subsection{Chapter Summary and Discussion}

Some authors contend that there has been another important transformation in medicine, calling it by different names: bio-cultural model, bio-medicine, and biomedicalisation (Clarke et. al. 2003; Hess, 2004; Morris, 1998). The prefix 'bio' meaning life, implies a broader vision of medicine, one that outstretches the limits of the physical 
human body, in terms of organs and pathogens, to incorporate elements of lifestyle and environment. Moreover, 'bio' entails the wider network of life, and thus implies a medicine that brings together human and non-human elements of the living earth. Key aspects of this transformation include the emergence of genetics and other life-science technologies, globalisation, critique of science, risk management rationality and lay expertise. This premise is presented in the conclusion to this chapter, because it represents the synthesis of the three phases in medicine that are described above. According to Morris (1998), we find ourselves in an era when the biomedical model has revealed its inherent limitations, but when the bio-cultural model has not yet proven its power to constitute a replacement. He argues that:

The value of a bio-cultural model lies not only in its power to dismantle a mechanistic view of life but also in its power to subsume the knowledge generated by mechanistic assumptions within a more comprehensive vision. . . A twenty-first century bio-cultural medicine attuned to the influence of mind, emotion and culture can help greatly in addressing illnesses that. . . involve not only the life cycle of a virus or pathogen, but also issues of personal behaviour and public health. . . cultural activities like the destruction of rain forests. . . It can offer knowledge about the social and iatrogenic sources of illness. (Morris, 1998: 276)

In order for this transformation to materialise, lay knowledge must make its way into scientific texts.

To sum up, this chapter has outlined a three-staged transformation in medicine: In the first stage, it was shown that the genesis of positivism and the growing dominance 
of rationality in the West, gave rise to understandings of the "average man" -an abstract concept that was taken as real and used as a rationale of social control. Medicalisation refers both to this epistemological transformation in medicine and the growing area of society that falls under the medical gaze. In the second stage, governmentality, individuals are encouraged to govern themselves according to "truths" about what constitutes the good of society; medical authority usually defines these truths. In the third stage, reflexivity, the increase in bio-technology and growing interest in the larger biotic community has led to a demand for greater involvement from the community, in the creation and reproduction of medical knowledge. These three stages in the history of medicine also make up the three-facet theoretical framework for the present study. The study begins where this chapter ends, with an examination of reflexivity at play. It examines reflexivity on two levels, first and foremost, politically-as it takes place through the actions of various actors who are all playing their part in shaping knowledge about malaria and anti-malarial drugs. It is also reflexive on a different levelepistemologically - in that the study itself is born of, and grounded in, subjective experience.

In his book, Illness and Culture in the Postmodern Age, David Morris (1998: 277) remarks: "Our life takes shape at the crossroads of biology and culture." What is the role for sociologists at this juncture? With respect to the safety of anti-malarial products, the role of the sociologist is not to evaluate the safety of a pharmaceutical product or to make recommendations about strategies for the prevention of malaria. A sociologist can, however, examine the discourses that define risk and safety and try to determine whether the sub-politics of knowledge have an influence over the production and promulgation of 
these discourses. Moreover, given Beck's notion of reflexivity, a sociologist can evaluate whether the public institutions that produce and circulate discourses of safety and danger do in fact accommodate the insertion of local and subjective knowledge, grow from conflict and contestation, and embrace criticism and scepticism. A sociologist can ask: what uncertainties are left unspoken or silenced?

This thesis focuses on the role of subjective knowledge in the construction of medical knowledge. What has been the place of subjectivity in each of the phases of medicine? During the course of medicalisation, the role of subjective knowledge in medicine was eroded in favour of a clinical, positivist rationality. In the era of governmentality, subjectivity, through free choices, is how political power is wielded and also how it is delineated (as discussed in greater depth in Chapter Six). Subjecting oneself to a norm or a rule or to some form of common sense, however it may be defined at the time, is what actualises the governing process. It is in the reflexive stage that subjective knowledge has the potential to perform the greatest effect on medical knowledge: criticism born of subjective experience, in this phase, is what guides future knowledge. Whether or not, or how, this plays itself out and become actualised in the contemporary fields of medicine and risk management is an object of inquiry in this study. 


\section{Personal Narrative \#2 - The Ministry of Health 'Form 42'}

I have a folder of papers related to my reaction to mefloquine; I call it my "crazy time file”. It includes official documents such as my 'Form 42 '(see Appendix A), which reads:

This is to inform you that Dr D. H. examined you on April $8^{\text {th }} 2001$ and has made an application for you to have a psychiatric assessment. That physician has certified that he/she has reasonable cause to believe that you have: Shown or are showing a lack of competence to care for yourself; and that you are suffering from a mental disorder of a nature or quality that likely will result in: serious bodily harm to yourself; and serious physical impairment. That physician has certified that he/she has reasonable cause to believe that you have been found incapable, within the meaning of the Health Care Consent Act, 1996, of consenting to your treatment in a psychiatric facility and the consent of your substitute decision-maker has been obtained; and you are not suitable for admission or continuation as an informal or voluntary patient. The application is sufficient authority to hold you in custody in this hospital for up to 72 hours. You have the right to retain and instruct a lawyer without delay.

This thesis concentrates on discursive, interactive, non-coercive, non-physical means of exercising one's will and applying political power. However, my own experience reminds me that the state still has many physical and coercive means of exerting force. The 'Form 42' and my committal to a psychiatric ward can be seen as one example of such. When I re-read this form today, I am struck by the memory of the immediate 
silencing and loss of agency that I experienced, first, by losing my mental faculties, second, by my committal into the state's custody, and third, by the medical treatmentheavy sedation-that I received during my hospitalisation. This one artefact, the Form 42, illustrates the fact that coercive, physical power is still very much a part of our social and political landscape. This is also an example of society's power to act in coercive or repressive ways for its subjects' own good. As discussed in Chapter Two, this type of coercive power (for the subject's own good) is the most insidious type of power born of the medicalisation of society.

By writing this narrative I am trying to navigate from the subjective experience of being rendered insane by a pharmaceutical product, to then being medically objectified, and finally to reclaiming my voice. It remains to be seen whether or not, and if so how, that subjective experience will be recuperated by power and re-inscribed into the regulatory system. 


\section{Chapter 3 Methodology: Investigating the Subjective Experience of Risk}

This chapter provides an overview of the methods of data collection and analysis used in this study. Part ethnographic in its quest for 'thick description' (Geertz, 1973) and contextualised understanding of the subjective experience risk and safety, and part 'grounded theory' (Glaser and Strauss, 1967) in its attempt to uncover the bureaucratic process by which safety and danger are defined and governed, the completed thesis presents a case study of the social and political processes involved in the creation and recreation of knowledge on risk and the regulation of safety in Canadian society.

The study's methodological framework rests on four pillars, which are described in detail following the account of the specific methods employed. First, reflexiveethnography is central to the research, because the author's own experience of an adverse reaction to mefloquine inspired the study. Second, Participatory Action Research (PAR), a research orientation that values individual experience and aims to empower participants, greatly influenced the overall methodological approach. Third, the genealogy was a valuable tool used to uncover the knowledge interests that factor into the construction of knowledge on mefloquine. Fourth, in order to shed light on the power dynamics at play in the regulation of safety and danger, a post-structural stakeholder analysis was undertaken. 


\subsection{Research Methods, Data Collection and Analysis}

This study adopts a multi-method approach. Primary data include: semistructured interviews and a survey. In addition, aside from the bibliographic research undertaken for the review of the literature, three sources of secondary qualitative data were collected: weblogs, government documents on mefloquine, and adverse drug reaction reports. These data, which are described in detail in the following pages, are summarised in the following table.

Table 3.1 Overview of Primary and Secondary Data

\begin{tabular}{|c|c|c|}
\hline & Type of Data & $\mathrm{N}=$ \\
\hline \multirow[t]{2}{*}{ Primary } & Interviews & 8 Participants \\
\hline & Surveys & 28 Participants \\
\hline \multirow[t]{3}{*}{ Secondary } & Weblogs & 50 Blogs by Canadians \\
\hline & Government Documents & Approximately 1,200 Pages \\
\hline & Adverse Reaction Reports & 88 Cases between $1990-2006$ \\
\hline
\end{tabular}

\subsubsection{Interviews with Subject Matter Experts}

Semi-structured interviews with eight subject matter experts were used to gain information about mefloquine and the process of pharmaceutical drug regulation. In an attempt to reach a variety of individuals living and working in different parts of Canada 
and the U.S., various methods of interviewing were adopted. In three cases, the interviews were conducted by telephone and lasted one-hour-and-a-half to two hours. In two cases, the interviews were conducted face-to-face, and took place at the participants' places of work. One of these lasted four hours and the other lasted two hours. In two other cases, the interviews took place through e-mail exchanges, whereby a list of questions and answers were sent back and forth between the participant and the researcher. Finally, in one case, communication took place via e-mail and telephone, and consisted of several interactions. (See Appendix C for Interview Questions.)

Word-of-mouth (or snowball sampling) and Internet research were the two ways of making contact with potential interview candidates. ${ }^{10}$ Interview participants came from varied professional backgrounds; their experience with mefloquine was also varied, and included: people linked to the organisation 'Lariam Action U.S.A.'; ex-military personnel; advisors to Health Canada; academics in the fields of public health and biotechnology; representatives of the Canadian Parliament; individuals working in nongovernmental organisations; and medical doctors. Three of these participants had some professional experience working with or within the pharmaceutical industry. For instance, one worked on two marketing projects that were funded by Syntex (now part of

\footnotetext{
${ }^{10}$ Although 'snowball sampling' is widely used throughout the social sciences, questions regarding its impact on the anonymity of respondents have arisen in the literature (see for example Van Den Hoonnard, 2002). Snyder (2002) addresses the particular difficulty of safeguarding the anonymity of public figures. It should, therefore, be noted that individuals who suggest future participants will not be made aware as to whether or not their suggestions are acted upon; moreover, they will not receive information on the identity of any other participants. Finally, it is important to remember that participants can refuse to participate and can choose to opt out of the research at any time. In sum, while 'snowball sampling' may have a minor impact on respondents' anonymity, the confidentiality of their input in the research process will be safeguarded.
} 
Hoffmann-La Roche). Two others conducted research related to clinical trials (not on mefloquine, but on other drugs).

All research participants received letters of information about the study. Interview respondents also received, filled out and signed informed consent forms, and were offered the option of signing a 'waiver of anonymity' form, if they did not wish to remain anonymous. Some of the subject matter experts did not chose to remain anonymous, while others did. For the sake of consistency, and in order to protect the identity of those who did want to remain anonymous, throughout the thesis, interview respondents are identified only by a respondent number, followed by a gender and a professional category, as follows: (Interview Respondent \#1.1; female; director of an NGO). In some cases, individuals fell into more than one professional category. In these cases, they were identified by their primary occupation, according to self-reports. (See Appendices E, F, G, and $\mathrm{H}$ for letters of information, consent forms and a waiver of anonymity form.)

Detailed notes were taken during telephone interviews. These were typed up and saved in Microsoft Word ${ }^{\mathrm{TM}}$ (MSWord) documents. Interview respondents had the opportunity to review these typed interview notes, to expand on points, make omissions or corrections, and/or to withdraw from the study, if they so desired. While each respondent did take the opportunity to add and amend elements of the transcript, no one withdrew from the study. The transcript was then sent to them a second time for approval, which was given in all cases. Quotes from the interviews were taken verbatim from the transcripts, aside for minor grammatical editing, in all instances except for one. 
The one notable exception is interview \#5.2, which was conducted in French. Therefore, quotes from this interview were translated, and appear in italics.

Aside from the formal interviews that are discussed above, a series of more succinct conversations took place with public relations personnel and management from Health Canada and from the pharmaceutical company Hoffmann-La Roche. In some cases, notes, which served as preliminary research, were taken during these telephone exchanges. These notes were not ultimately used in the thesis, because these informants did not agree to take part in the study. They did, however, assist in identifying the types of documents that should be requested through the Access to Information Program (as described below). After four months of unreturned telephone calls and unanswered emails, it became apparent that it would be impossible to interview representatives from Health Canada and Hoffmann-La Roche.

The interview sample size was, in part, determined using the principle of 'interpretive sufficiency':

Interpretive sufficiency means taking seriously that lives are loaded with multiple interpretations and grounded in cultural complexity ... interpretive discourse is authentically sufficient when it fulfils three conditions: represents multiple voices, enhances moral discernment, and promotes social transformation. (Christians, 2000: 145)

In this case, interpretive sufficiency meant taking seriously the notion that certain people might be compromising their professional situations by speaking out about mefloquine. While 'multiple voices' were represented through the diverse professional backgrounds of the interview participants, it quickly became clear that certain individuals and groups 
would not speak openly about mefloquine, and, therefore, that certain perspectives would not be captured in interview data. The lack of participation from Health Canada and Hoffmann-La Roche, for example, explains the small sample size of interviews. Given the widespread news of the dismissal of two scientists from Health Canada for speaking out against bovine growth hormones, it is no surprise that people (especially researchers from Health Canada) might be reluctant to come forth to speak about a controversial drug like mefloquine (Bueckert, 2004). At least ten individuals who were approached for the study, refused to sign consent forms or to speak 'officially' on the topic of mefloquine. The dearth of interview data was addressed in two ways: through official requests to government departments for documentation on mefloquine and through Internet research on Hoffman-La Roche and its products. The difficulty of recruiting interview participants also led to the decision to conduct a survey of travel medicine providers, which is discussed next.

\subsubsection{Survey of Travel Medicine Providers}

A detailed questionnaire was distributed by mail to 142 travel medicine providers (TMPs) from across Canada, who were identified from the Health Canada website. ${ }^{1}$ This survey, which was meant to elicit more detailed information on the safety of mefloquine and the prevention of malaria among Canadian travellers, consisted of 35 open- and closed-ended questions (See Appendix D for survey questions). Out of the 142 that were sent out, 33 surveys were returned (23\%), of which 5 were returned blank, leaving $28(20 \%)$ that were retained as usable surveys. Given the length of the

\footnotetext{
${ }^{11} \mathrm{http} / / / \mathrm{www} . h \mathrm{hc}-\mathrm{sc} \cdot \mathrm{gc} . \mathrm{ca} / \mathrm{pphb}$-dgspsp/tmp-pmv/travel/clinic_e.html (last accessed 01 October 2003). This website is meant to provide an exhaustive list of TMPs working across Canada.
} 
questionnaire and the amount of detail requested, and based on the literature (e.g. Dilman, 2000; Kiernan, 2005), this response rate fell within the $19 \%$ and $27 \%$ that could be expected. ${ }^{12}$

It was possible to determine the province of origin of the completed surveys in two ways: first, survey respondents were asked if they wish to be notified upon completion of the thesis. In 9 out of 28 cases they did, and included their business card with their answers, for this purpose. Second, since Canada Post stamps the postal code of origin on all of its mail, it was possible to retrace the city or province of origin of returned surveys, using the 'reverse postal code search' feature on the Canada Post website. ${ }^{13}$ It was thereby determined that there was representation from Eastern, Central and Western Canada, with the majority of respondents practising in Ontario: 12 respondents are from Ontario, three from Nova Scotia, one from Saskatchewan, five from Alberta, three from Quebec, two from Newfoundland and two are of unknown origin, since the postal code was not visible. Given the small sample sizes, however, it is impossible to make any generalisations about regional variations between survey respondents.

The travel medicine survey data were coded and transferred to MSWord files, basic descriptive statistics were computed, and open-ended questions were transcribed and coded. Travel medicine providers who are quoted in the study are referred to by a respondent number, in this manner: (TMP \#23).

\footnotetext{
${ }^{12}$ Kiernan (2005) suggests a way to improve response rates for mail surveys, using a series of reminder cards. Due to time and financial constrains, it was not possible to follow her advice in this study. However, Kiernan's methodology should be utilized whenever possible to improve response rates for mail surveys.

${ }^{13}$ www.canadapost.com (last accessed on 24 July 2006).
} 


\subsubsection{Weblogs on Mefloquine}

Weblogs or "blogs" on the use of mefloquine were downloaded from the Internet. ${ }^{14}$ In total, 284 pages of text, or $2,481 \mathrm{~KB}$ of data were saved in MSWord files. These weblogs were found through the Google ${ }^{\mathrm{TM}}$ search engine, using the terms 'lariam' or 'mefloquine' and 'weblog', or 'story'. It should be noted that a large proportion of the 'blogs' came from one specific web site that was constructed by someone who suffered a reaction to mefloquine, and now wants to provide information on the topic and to offer a virtual sounding board for people taking the drug. ${ }^{15}$ On this site, participants were asked whether or not they had experienced a mefloquine side-effect, and to provide their country and city of origin, e-mail address, and comments. As such, it was possible to extract postings by Canadians, from the mass of weblog data found. This proved to be an excellent resource for this study, because it was possible to triangulate these data with the Health Canada adverse reactions database (as discussed below). In total, between 1998 and 2004, 50 Canadians posted messages regarding mefloquine on this website. These Canadians were contacted by e-mail in order to ask, for example, if they had experienced

\footnotetext{
${ }^{14}$ A weblog is defined as: "a Web site of personal or non-commercial origin that uses a dated $\log$ format that is updated on a daily or very frequent basis with new information about a particular subject or range of subjects. The information can be written by the site owner, gleaned from other Web sites or other sources, or contributed by users. A weblog often has the quality of being a kind of "log of our times" from a particular point-of-view. Generally, weblogs are devoted to one or several subjects or themes, usually of topical interest, and, in general, can be thought of as developing commentaries, individual or collective on their particular themes" from What is http://whatis.techtarget.com/definition/0,,sid9_gci213547,00.html (last accessed 24 July 2006).

${ }^{15}$ From Melfoquine (Lariam) Links, http://www.geocities.com/TheTropics/6913/lariamlinksf.htm (last accessed 24 July 2006).
} 
a reaction to mefloquine, and whether or not they reported this to a Canadian medical doctor. (See Appendix G for a summary of characteristics of Canadian 'bloggers'.)

\subsubsection{Government Documents}

A request through the Access to Information Act yielded approximately 1,200 pages of internal Health Canada and Department of National Defence documents pertaining to mefloquine. ${ }^{16}$ These documents were reviewed for content concerning the safety of mefloquine, its use by military members, reports of adverse reactions by military members or members of the public, and official debate about the drug.

\subsubsection{Adverse Drug Reaction Reports}

Health Canada maintains a database of adverse reactions to all pharmaceutical products sold in Canada. Medical doctors, manufacturers and/or individual patients report "serious" or "unexpected" reactions to "The Marketed Health Products Directorate' of Health Canada, which are then input into the database. The reporting system is largely voluntary; only drug manufacturers are required by law to report all reactions to their products, as soon as they become aware of them. A such, the database reportedly only captures between one and 10 percent of the actual occurrences of adverse drug reactions (CBC, 2004c). It should be noted that any change in the status of mefloquine as a "safe drug", or any warnings to be added to the product insert, depends on "red flags" raised in this system.

Until February of 2004, this database was not accessible to the public. It was only after five years of resistance by Health Canada, that the Canadian Broadcasting

\footnotetext{
${ }^{16}$ For more information on the Act, see Access to Information and Privacy, http://canada.justice.gc.ca/en/ps/atip/ (last accessed 24 July 2006).
} 
Corporation (CBC) was finally able to access the database through the Access to Information Act. Once it succeeded in doing so, the $\mathrm{CBC}$ made the database public by posting it on its website, and produced an in-depth report on adverse reactions in Canada (CBC, 2004a). Following this, public pressure about the need to make adverse reactions known to the general public was heeded, and Health Canada uploaded the entire database, in searchable form, onto the Internet in 2006 (Health Canada, 2006). The Health Canada database of adverse reactions to pharmaceutical drugs was analysed, and 88 records of adverse reactions to mefloquine were found for the period between 1990 and 2006 (Health Canada, 2006).

The preceding paragraphs describe a multi-method approach that is characteristic of PAR (as discussed, for example, in Greenwood and Levin, 2000: 93). What follows is an outline of the various steps taken for the analysis.

\subsection{Data Analysis}

As identified in Chapter One, the over-arching research question is: With specific reference to the prevention and treatment of malaria, what role do and/or could alternative epistemologies — based upon subjective experience-play in the construction of medical knowledge and understandings of risk and safety? This question is broken down into two sub-questions:

1. What is the present state of knowledge on malaria and mefloquine? Specifically, what types of knowledge claims do various stakeholder groups put forth regarding 
mefloquine, and how do these claims come together in discourses of safety and danger regarding malaria and mefloquine?

2. How could or how does subjective knowledge affect the regulation of drug safety?

In an effort to answer these questions, the research project is organised according to three main tasks. First, an objective of the thesis was to produce a genealogy of knowledge on malaria and a history of mefloquine use in Canada. This was achieved through bibliographical research and discourse analysis of malaria prevention campaigns, which are used to answer basic epidemiological questions such as: what are the other methods of malaria prevention available to travellers to malarial zones; what are the rates of malaria infection among Canadian travellers to malarial countries; and what are the rates of side-effects experienced by mefloquine users. These findings are presented in Chapter Four.

A second objective was to examine the mechanisms that govern pharmaceutical drug safety. The interview, survey and secondary data sources, described above, were used to accomplish this task. Moreover, the CBC (2004) in-depth report, Faint Warning, From Coloured Tabs to Computerized Signals: How Health Canada Monitors Adverse Reactions, was particularly useful in this regard.

Finally, a third objective was to investigate the subjective experience of risk and to examine how it influences the process of pharmaceutical drug regulation in Canada. To meet this objective, individuals' experiences with mefloquine, as reported in weblogs and interviews, were compared with the 'official' medical knowledge, in particular 
reports of adverse drugs reactions that are recorded in the Health Canada database, as discussed above.

All forms of primary and secondary qualitative data were read through in their entirety and analysed for content (as defined by Ryan and Bernard, 2000: 769-783). Peter Jackson's (2001) warnings were heeded, in particular, the need to avoid "cherry picking" (or selective quotation) by being thorough and systematic. The data were organised under thematic headings, which were originally created during questionnaire design and preliminary research, and expanded upon during data analysis. A list of keywords, which follows, was generated for each of the central themes.

- 'Traveller's Awareness': information, knowledge, risk of malaria, website, Health Canada, Travel Medicine Clinic, Travel Medicine provider, tropical, family physician, WHO, World Health Organization, myth, beliefs, science, CDC, Centre for Disease Control, travel agent.

- Citizenship and Health: Responsibility, shared decision, imported malaria, sideeffects, experience, invincible, report, adverse reaction, doctor, body, advocate, public, accountability, democracy, cover-up, Thalidomide, immigrants, education, deet.

- Knowledge/Discourse about Malaria: malaria zone, strategies, prevention, climate, season, geography, resistance, anti-malarial drugs, mefloquine, chloroquine, doxycyclen, malarone, net, repellent, risk, endemic.

- Safety of Pharmaceutical Products: safety, regulation, serious, side-effect, Health Canada, Department of National Defence, unexpected, purple sheet, report, 
doctor, post-marketing, surveillance, clinical study, clinical trials, monitoring, data, evidence, personal experience, market, pharmaceutical company (ies), Hoffmann-La Roche, government, controversy, media, myths, risk, approval, testing, consumers, advocacy groups, thalidomide, tasmar, dangerous drug, safe drug, danger, precaution.

- Use and Safety of Mefloquine and Other Anti-Malarial Drugs: status, product insert, FDA, warning, contra-indications, media, psych*, mental, Internet, suicide, tolerance, compliance, neuro-psych*, dreams, nightmares, advocacy groups, activism.

- Subjective Experience of Risk: dreams, nightmares, rash, symptoms, thought, fear, afraid, danger*,

- Health Canada: 'Lariam Safety Monitoring Study', accountability, transparency, database, [reaction terms], serious, unexpected.

- Mefloquine and the Canadian Military: Somalia, military, Canadian Forces, Department of National Defence, Fort Bragg, Navy, Airborne, McClatchy, D'Allaire.

These themes and keywords were used to guide the analysis as well as the final write-up of the results.

Glaser and Strauss's (1967) 'constant comparative method' was used throughout the process of reading through, coding, analysing and summarising the data. This approach was useful to make comparisons that sought to reveal similarities and differences within and between the different sources of data, and to generate theories about the construction of knowledge on mefloquine. 


\subsection{The Four Pillars}

An overarching methodological framework that rests on four 'pillars' - reflexive ethnography, participatory action research, genealogy, and stakeholder analysis — guided the methods that are presented above. These 'pillars' are described in the following pages.

\subsubsection{Research Methods in the First Person: Reflexive Ethnography}

This thesis can be seen as falling somewhere in the middle of Ellis and Bochner (2000)'s continuum of 'reflexive ethnography':

In reflexive ethnography, the researcher's personal experience becomes important primarily in how it illuminates the culture under study. Reflexive ethnographies range along a continuum from starting research from one's own experience ... to confessional tales where the researcher's experience of doing the study becomes the focus of investigation. (Ellis and Bochner, 2000: 740)

In attempting to make sense of my own experience of a serious reaction to mefloquine, I began to ask myself how it compared to that of the broader community of travellers to malaria-endemic countries. Preliminary informal investigations revealed that my reaction to mefloquine was not uncommon. For example, a quick Internet search using the Google ${ }^{\mathrm{TM}}$ search engine (www.google.com) on the word "mefloquine", undertaken in November of 2003, uncovered approximately 29,900 hits; the majority of these include narrative accounts and/or blogs of adverse reaction to mefloquine. I became aware of numerous individual and group efforts to inform travellers of the potential dangers associated with this drug. I then began to question how an individual's experience taking 
a drug, especially if it leads to a severe reaction, factors into the mechanisms that ensure the safety of pharmaceutical drugs. This research project has thereby allowed me to explore the relevance of my own experience to broader social and regulatory processes. Furthermore, it provided fertile ground upon which to interrogate the notion of the research 'subject' and 'object' divide that is characteristic of mainstream research methodologies.

\subsubsection{Participatory Action Research and the Subjective Voice}

The methodology was greatly influenced by the principles of Participatory Action Research (PAR) (as defined, for example, in Park, 1993). ${ }^{17}$ PAR is a three-pronged approach that is aimed at effecting social change, while fulfilling pragmatic data collection needs. First and foremost, a research methodology is said to be participatory when it forges a reciprocal exchange with the people who would otherwise be considered 'research subjects' in traditional methods of inquiry. In PAR, participants have input into the research design, in varying degrees, from the identification of key issues through to the construction of research instruments.

Second, the action component of PAR denotes a commitment to social action and change. As such, PAR is an empowerment tool for all parties involved. Often, the action

\footnotetext{
${ }^{17}$ It became clear through the research process that true PAR, i.e., full partnership with an organization or social group, would not fulfill the thesis objectives, since a number of stakeholders play an important role in the process of pharmaceutical drug regulation, and because there are so many conflicting viewpoints regarding the safety of mefloquine. It was determined early on that a PAR project might not yield the fullest and most accurate 'thick' description of the creation of knowledge on mefloquine. However, as explained in the chapter, the thesis did adhere to some of the principles of PAR, for example remaining in contact with organizations like 'Lariam Action' and sharing the results of the research. Hopefully, this thesis will be used by various organizations to fulfill their objectives.
} 
component of PAR centres on education, but can also include other forms of social or political action, and/or the creation or expansion of social support networks between participants.

Third, the research component situates PAR within the larger academic or intellectual tradition of generating knowledge. PAR developed as a response to the dissatisfaction of many scholars with the separation of the academy from society at large. On this point, Vidich and Lyman (2000) state that:

The sociologist-ethnographer will not merely observe that history; he or she will participate in its everlasting quest for freedom, and be a partner in and a reporter on the pains, the agonies, the emotional experiences, the small and large victories, the traumas, the fears, the anxieties, the dreams, fantasies and the hopes of the lives of the peoples. These constitute this era's ethnographies-true tales of the field. (Vidich and Lyman, 2000: 61)

Similarly, Greenwood and Levin (2000) dispute the use of many standard premises of academic discourse — such as distinctions between 'applied' versus 'pure' and 'qualitative' versus 'quantitative' research-and argue that "[these dichotomies] . . are insufficient as guiding concepts for the practice of social research" (Greenwood and Levin, 2000: 85).

PAR usually employs multiple methods to elucidate multiple versions of social reality. Fine et al. (2000), for instance, write: 
Following a poststructuralist emphasis on contradiction, heterogeneity, and multiplicity, we produced a quilt of stories and a cacophony of voices speaking to each other in dispute, dissonance, support, dialogue, contention and/or contradiction. (Fine et al 2000: 119)

The objective, therefore, of a multi-method approach in PAR, is not to produce a more rigorous yet homogeneous view of reality, but, rather, to find solutions to local problems and to inform community action. So, while the sociological notion of validity rests upon positivist and consensual assumptions-i.e., a measure is valid if it measures what it sets out to measure, or something is valid if everyone agrees upon it - a participatory definition of validity rests on its usefulness for social action. As Greenwood and Levin (2000) explain:

Credibility, validity, and reliability in action research are measured by the willingness of local stakeholders to act on the results of the action research, thereby risking their welfare on the 'validity' of their ideas and the degree to which the outcomes meet their expectations .... The core validity claim centres on the workability of the actual social change, and the test is whether or not the actual solution to a problem arrived at solves the problem. (Greenwood and Levin, 2000: 97)

PAR is particularly relevant to the social study of science, because citizens often have difficulty influencing scientific inquiry. Increasing specialisation in science and medicine has marginalised subjective experience. PAR, meanwhile, gives voice to people's experiences of health, broadens access to information and knowledge, and can 
foster a cooperative relationship between laypersons and scientists to produce a more holistic approach to human health. Merrifield (1993) suggests how the gap between laypersons and experts can be bridged through PAR. In her words:

[W]hat we need to do now is break the link between scientific knowledge and elite forms of inquiry, and devise new approaches that combine essential elements of scientific research-the rigorous rules of proof, for example-with a process that is accountable to people. (Merrifield, 1993: 84)

The Institute for Health Promotion of the University of British Columbia (1995) has published a list of guidelines against which PAR projects can be evaluated. Overall, according to these guidelines, this study did adhere to most of the central principles of PAR. For example, all participants have a concern about, or experience with, the issue at hand; participants contributed their intellectual and/or physical resources to the project; careful attention was paid to the barriers that would potentially block participation in the research process; participant input was sought in the planning stage and during the data collection stage of the research process; the project attempts to facilitate the sharing of knowledge and learning among all participants. However, due to academic and time constraints, the project falls short of true PAR, in some respects. For instance, the researcher alone conducted the data analysis and owns the data.

Most importantly, the thesis attempts to forge the kind of relationship between the researcher and participants as advocated by PAR. Jacques Rheaume (1982) explains that: 
[PAR] represents less a new research method in the social sciences than a new type of relationship between researchers and social groups engaged in the dynamics of action. ... [It] is not a research methodology, per se, in terms of distinguishing between quantitative or qualitative approaches, or empirical research versus theoretical elaboration. In some cases, it brings about new techniques, for example, feed back inquiry, but overall, it relies on a variety of social science research methodologies, including: surveys, content analyses, interviews, participant observation, etc. (Rheaume, 1982: 50-51)

Every effort was made to demystify the research process and will be made to enable participants to utilise the results as tools for empowerment.

\subsubsection{A Genealogy of Malaria Risk and Mefloquine Safety}

Foucault (1980) suggests using a genealogical approach to examine the " . . the effects of the centralising powers that are linked to the institution and functioning of an organised scientific discourse within a society such as ours." He adds: “. . it is really against the effects of the power of a discourse that is considered to be scientific that the genealogy must wage its struggle" (Foucault, 1980: 84). An important part of this study involves the production of a comprehensive review of the medical knowledge and information about mefloquine that has been produced since the drug's creation in the 1970s. The study also attempts to isolate power differentials or driving forces that may have led mefloquine to become such a commonly used anti-malarial drug. 'Official' knowledge is then compared with, and supplemented by, subjugated knowledge. 


\subsubsection{Stakeholder Analysis to Uncover Power Dynamics}

A post-structuralist stakeholder analysis is conducted to explore the power dynamics that shape information regarding the risk of malaria and the safety of mefloquine, and analyse the power differentials that obstruct or withhold pertinent information from various stakeholders. ${ }^{18}$ A post-structuralist conception of power, as articulated in Foucault (1980), along with the technologies of government that are discussed, in Rose and Miller (1992), for instance, are incorporated into an analysis of each stakeholder group's power. The resulting post-structuralist stakeholder analysis reveals how each stakeholder group acts upon its interests, utilises its networks, and appeals to various sources of legitimacy, in order to actualise its power.

\subsection{Chapter Summary and Discussion}

Everything is post these days, as if we're all just a footnote to something earlier that was real enough to have a name of its own. (Atwood, 1990: 86)

This chapter presented the methods of data collection and analysis used in this study. It also described the study's overarching methodological framework, which was heavily influenced by reflexive ethnography, PAR, stakeholder analysis and genealogy. The 'crisis in representation' informed the approach taken in this study. The metanarratives of class conflict, functionalism, social cohesion, structuralism, and feminism, on their own, do not explain why subjective experience is marginalised from medical

\footnotetext{
${ }^{18}$ For an overview of the theory and methods associated with stakeholder research, see Chevalier, 2001. "Stakeholder Analysis and Natural Resource Management" http://www.aiatsis.gov.au/rsrch/ntru/ifamp/practice/pdfs/Chevalier_2001.pdf (last accessed 24 July 2006).
} 
knowledge and the governance of health in Canadian society. Instead, at the heart of this thesis is a dilemma that is characteristic of our postmodern condition and permeates the discipline of sociology on the whole: the "... unending tension between the one and the many, the universal and the particular, as a permanent feature of human society" (Wallerstein, 1994: 77). Through its investigation of the role of subjective knowledge in the creation of medical knowledge and the governance of health, this study specifically exposes this tension. 


\section{Personal Narrative \#3 - Client Orientation Information}

I remember being informed of my new 'privileges' in the psychiatric ward, in a pamphlet entitled: 'Ottawa Civic Hospital Department of Psychiatry Client Orientation' (see Appendix B). I went from being a 'I to I' patient, which meant that I had to remain “in P.J.'s... in the room at all times other than walks on Unit Q, for 1 hour, if condition allows it”, to being a patient requiring 'Close Observation'. My new privilege list: I could remain in pyjamas (no jogging suits) and remain on the ward unless accompanied by a staff member, but I could wear my own clothes. Arguably, this new status brought with it more freedom than before, so I should have been happy. But that was the moment when I first realised my situation: I was stuck in this 'Total Institution'-to use Goffman's term-and I couldn't leave. I went to lunch in the cafeteria for the first time. A man who thought that he was Jesus befriended me and sat with me. A nurse went from table to table and gave everyone some pills. I got mine and thought about not taking them, but in the end I did. I needed the escape. I returned to my room to sleep; to drown out the knowledge that I could not go home.

Funny, how I slipped between the military and the medical (or the mental ward). .

. I know that am not the first person to have navigated the subjective space between these two institutions. 


\section{Chapter 4 A Genealogy of Knowledge on Malaria and Mefloquine}

Nature is not a faithful ally of man; she seems always quite as deeply interested in the success of the parasite and of the mosquito. (Hackett, 1947: 267)

This chapter presents a 'history of the present' or 'genealogy' (Dreyfus and Rabinow, 1983; Foucault, 1980; Rose, 1994; Sheridan, 1994) of North American and European-based knowledge on malaria. By examining the political and social circumstances that led North American and European countries to become interested in the problem of tropical malaria, it is possible to critically examine the root of knowledge on anti-malarial drugs that proliferates in these countries today. This chapter shows that knowledge on malaria is in flux and can be politically driven. It also demonstrates that specific societal interests - namely those attuned to colonial drives and military imperatives - are served by, and uphold, the development of knowledge on malaria and the discovery of technologies to control the parasite in the Western industrial countries of Europe and North America.

A genealogy, or a 'history of the present', is a detailed account of the politics or power dynamics that incite and uphold the creation of knowledge. Its starting point is the present, so, more aptly put, a genealogy involves writing a history of the past in terms of the present. Genealogies are not positivistic returns to a more careful or more exact form of science. They do not produce more truthful or more accurate accounts of history than those commonly told. Instead, they are precisely anti-sciences. As Foucault (1980: 84) writes, they are opposed to "the centralising powers that are linked to the institution and 
functioning of an organised scientific discourse within a society such as ours... [I]t is really against the effects of the power of a discourse that is considered to be scientific that the genealogy must wage its struggle". Following the advice of Foucauldian scholars, this chapter adopts a "critical attitude to the past and its relation to the present" (Dreyfus and Rabinow, 1983: 118), and aims to "dig out a whole mass of discourse that has accumulated under one's feet. ... and like a Nietzchean philosopher, take a hammer to it" (Sheridan, 1994: 197). As such, the genealogical method is very much in line with the poststructuralist emphasis on contradictions, and the following pages will discursively initiate the cacophony of voices which, according to Fine et al. (2000), is characteristic of poststructuralist research.

This chapter does not present an exhaustive account of the history of malaria and its prevention, for such an endeavour would not be a sociological exercise, but rather a painstaking work of medical history. Moreover, it may well be impossible to write a definitive history of knowledge on malaria. Speaking about his own history of malaria, written half a century ago, Russell (1955) explains:

The story of the development of malaria prophylaxis merits the pen of a master historian. Antiquity of backgrounds, drama of episodes, brilliance of personalities, immense social connotations of failures and successes, provide substantial and ornate materials for a superb narrative. But this cannot be a definitive history. (Russell, 1955: 123)

Instead, as Russell aptly puts it, his “is an attempt to whet appetites, to illuminate for retrospect a few of the many facets... of man's [sic.] attempt to protect himself from the intermittent fevers" (Russell, 1955:123). Russell's words hold true in this case as well. 
The main focus is the development of knowledge on malaria and technologies of control that have been used and developed in North America. The first sub-section provides readers with a summary on disease transmission and an overview of global infections rates, as well as a brief discussion of the WHO's effort to halt the spread of the disease. This is followed by a discussion of the term "imported malaria", its use in public health discourse today and epidemiological data from the United Kingdom, Canada and the United States of America (U.S.A.). The genealogical gaze is then directed towards the production of knowledge on malaria by Western industrialised countries. The second sub-section focuses on knowledge that was developed during the Second World War era in the U.S.A.. A brief historical account of the development of mefloquine is provided. The chapter comes full circle in the third sub-section, back to a discussion of the present, this time with a focus on history of mefloquine use in Canada. The last sub-section of the chapter presents an overview of the contested knowledge regarding the safety of mefloquine.

\subsection{The Present Danger: Malaria Today}

Knowledge on malaria has changed over time, and such knowledge does not represent a final stable reality regarding the parasite at any given time. Instead, such knowledge is constructed, based in part, upon political and societal interests of the day. Consider the contradiction between the two following comments concerning the control of malaria: 
The verb 'to master' does not imply an end to matter: rather it suggests that having prevailed over an opposing force one has assumed moral responsibility for keeping it under control. The point is that malaria, after centuries of effort, is now universally controllable. Techniques are available and for most communities, even those least developed, the cost of malaria control is not beyond local means . ... Malaria is retreating with spectacular acceleration. Man [sic.] is indeed master at last. (Russell, 1955: viii)

Today malaria is found throughout the tropical and sub-tropical regions of the world and causes more than 300 million acute illnesses and at least one million deaths annually. (WHO, 2002)

The first quote is from a speech to the Rockefeller foundation in the early 1950 s, when malaria was considered to have been defeated. Through its use of military rhetoric (such as 'opposing forces', 'master', 'retreat', 'control') this quote can be seen within a more pervasive discourse of conquest and victory that permeated public discourse during the post World War II era in the U.S.A.. The speech also situates malaria control efforts within military objectives, which has been the case from pre World War I up to today. Meanwhile, as illustrated in the second quote, today, the malaria parasite is deemed stronger than ever. We now know that while the war-time effort of malaria control-i.e., the development of chloroquine and the widespread use of DDT at home and abroadled to some progress in controlling malaria on a global scale, these methods eventually began to fail. In both cases, the parasite developed resistance to the method of control. Meanwhile, the widespread use of DDT has had disastrous ecological consequences, leading to the poisoning of wildlife and loss of habitat for numerous species (Speth, 
2004). The second quote, by the World Health Organization (WHO), indicates that the parasite is indeed "master" again. One can situate the second quote within discourses of danger that paint tropical and sub-tropical regions as dark and dangerous places, or places in need of 'rescuing' by Western industrial nations. ${ }^{19}$

\subsubsection{Contemporary Knowledge on Disease Transmission}

Malaria -in Latin, mal-aria- was originally attributed to bad air. It is now known to be:

[A] vector-borne disease (one carried by an intermediary, in this case a mosquito) that is caused by four protozoan parasites in the genus Plasmodium. The malaria parasite is a highly complex organism that goes through four distinct stages in its lifecycle that cannot be completed without access to both a mosquito and a mammal. (Platt McGinn, 2003: 73)

According to the Centre for Disease Control (CDC), there are approximately "156 named species of Plasmodium which infect various species of vertebrates, of these, four are known to infect humans: P. falciparum, $P$. vivax , $P$. ovale and $P$. malariae" (CDC, 2003). Falciparum malaria is the most dangerous type to humans today, in part because it has become resistant to the most widely available anti-malarial drug, chloroquine. Regarding the devastation caused by the disease on the human population, it is commonly believed that: "no other disease in the course of human history has had as profound an

${ }^{19}$ Much has been written, for example of Africa as the "dark continent". For example, see The Coming Anarchy, in which Kaplan (1994) provides one such account. 
effect on human development and well-being as malaria" (Platt McGinn, 2003: 62). This statement is evidenced in the following section on infection rates.

\subsubsection{Global Infections Rates}

According to the WHO, this is the decade to 'roll back malaria'-a reference to an international initiative aimed at reducing the global malaria burden by 50 percent by $2010 .{ }^{20}$ However, in spite of this global initiative, "some experts foresee as much as a $20 \%$ annual increase in Africa's rate of malaria-related illness and death" (Malaria Foundation International, 1999). Indeed, the Malaria Foundation International (MFI) has summed up the magnitude of malaria as a global health issue as follows:

Malaria is the most common and deadly parasitic disease in the world... environmental disturbance, malnutrition and the failure of drugs once used to control the disease have conspired to make malaria as serious a problem now as it was during the first half of the twentieth century. (Malaria Foundation International, 1999)

Despite having acquired detailed knowledge of the patterns of disease transmission, and in the face of the progress made in the areas of prevention and eradication over the past decade, malaria remains the deadliest disease to humans. The WHO notes that: "Malaria, either alone or in combination with other diseases, is

\footnotetext{
${ }^{20}$ Roll Back Malaria (RBM) is a global partnership founded in 1998 by the World Health Organization (WHO), the United Nations Development Programme (UNDP), the United Nations Children's Fund (UNICEF) and the World Bank. For more information on this initiative, see:

http://www.who.int/rbm/ (last accessed 16 June 2003).
} 
estimated to kill between 1.1 and 2.7 million people worldwide each year, and over 2,400 million remain at risk" (WHO, 2000: 71).

The disease is most hard-hitting in Sub-Saharan Africa, where 90 percent of malarial deaths occur, and where the disease wreaks the greatest havoc on infants, children and pregnant women:

Malaria kills an African child every 30 seconds. Many children who survive an episode of severe malaria may suffer from learning impairments or brain damage. Pregnant women and their unborn children are also particularly vulnerable to malaria, which is a major cause of peri-natal mortality, low birth weight and maternal anaemia. (WHO, 2002: 1)

It is also noted in the same publication, that malaria "disproportionately affects rural populations living in housing without screens and doors" (WHO, 2002: 2).

Writing about globalisation and health, Gutierrez and Kendall (2000: 86) note that most medical breakthroughs, with respect to malaria, are financially out of the reach of those who need them most. Moreover, the authors explain how Western methods of malaria control have contributed to a rise in infection rates:

Treatment has, in fact, played a role in the new threat it poses. In many places, mass chemoprophylaxis led to the presumptive treatment of all fevers with chloroquine, the biological effect of which has likely played a great role in the doubly deleterious effect of promoting resistance to chloroquine and reducing naturally gained immunity in populations. Population movement further enhances this process. (Gutierrez and Kendall, 2000: 86) 
This is certainly the case also with mefloquine. Robert Kaplan has noted, for instance, that

Visitors to malaria-afflicted parts of the planet are protected by a new drug, mefloquine, a side-effect of which is vivid, even violent dreams. But a strain of cerebral malaria resistant to mefloquine is now on the offensive. Consequently, defending oneself against malaria in Africa is becoming more and more like defending oneself against violent crime. You engage in 'behaviour modification': not going out at dusk, wearing mosquito repellent all the time (Kaplan, 2000: 17).

Brown (1997) contends that the role of 'human' factors-social and culturalsuch as population migration and poor drug compliance have long been ignored, and that this may have contributed to the current resurgence. He emphasises the role of human agency on the spread of the disease and states that:

[T]he scientific and political discussion about emerging and resurging infections has emphasized the disease pathogens, has deemphasized the role of human behavior in creating these new epidemiological trends, and has underemphasized human empowerment to improve health conditions. (Brown, 1997)

This thesis pays close attention to such human agency, by examining the role of subjective experience in the creation of knowledge regarding malaria and prevention methods.

\subsubsection{Disease of the (Sub)-Tropics Versus 'Imported Malaria'}

How the disease is envisaged in scientific discourse implies much about the ideology that supports the development of methods to treat and prevent it. Public health 
discourses on malaria can provide some insight as to why infection rates continue to rise, even in the face of global campaigns to stop its spread.

Malaria is largely a disease of the tropics and sub-tropics. Figure 4.1 illustrates present-day global malaria transmission zones. ${ }^{21}$ Disease mapping, as represented in Figure 4.1 (below) is an illustration of 'pointillist epistemology', as discussed in Chapter two, because it masks the variability that is characteristic of the risk of malaria transmission. In other words, figures like these homogenise the risk of malaria within state boundaries and do not represent the variability in infection rates that exists across geographical regions, seasons, and weather conditions. ${ }^{22}$

${ }^{21}$ This map was selected for clarity and because it was the most recently updated map of malaria endemic zones found using the Google Images ${ }^{\mathrm{TM}}$ search engine, http://www.anlis.gov.ar/consulta/infecciosas/malaria/malaria.htm (last accessed 26 July 2006). It should, however, be noted that many similar maps exist, including some produced by the Centre for Disease Control and the World Health Organization, among others, that depict the same transmission areas, with only slight variations.

${ }^{22}$ For example, when travelling through Kat Tien National Park in Vietnam, researchers in the park were able to state with confidence that there was a risk of malaria $x$ number of kilometres away. 
Figure 4.1 Global Malaria-Endemic Zones

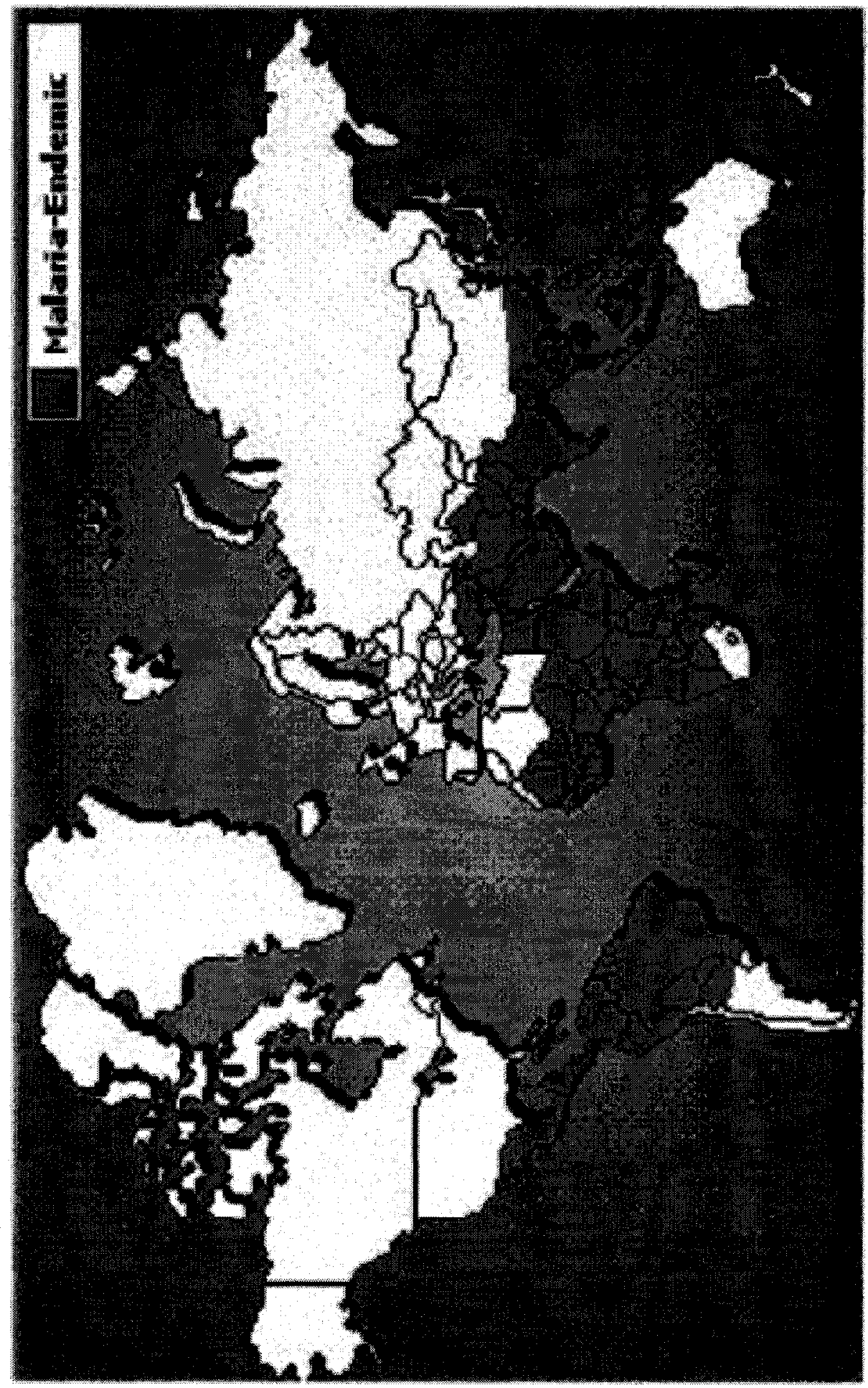

(Adapted from Administracion Nationales de Laboratorios e Intitutos de Salud, 2005) 
Non-endemic countries--in particular in North America and Europe-are becoming increasingly concerned with growing rates of "imported malaria", or cases of malaria that are 'brought back home' by travellers returning from tropical malarial countries (Health and Canada, 2001; Rowlands, 2000). In 1999, the CDC received 1,227 reports of malaria cases with onset of symptoms in 1998 among persons in the United States and its territories; 98 percent of these cases were classified as "imported", primarily from Africa (60\%), Asia (20\%), and the Americas (19.1\%) (CDC, 2001).

Remarkably, Canada's rate of 'imported malaria', which peaked to 1,036 in 1997, is 3 to 10 times higher than that of the U.S.A., per capita. It is unclear, however, whether this substantial difference is based on a reporting artefact (Health Canada, 2000). The supposed growing rates of 'imported malaria' have driven Health Canada to promote the risk of malaria, the use of anti-malarial drugs, and the value of travel medicine providers to Canadian travellers. Malaria was the cause of seven Canadian deaths from 1997 to 1999 (Health Canada, 2000). Non-compliance, or failure to use appropriate chemoprophylactic agents altogether, delay in diagnosis and treatment, and incorrect therapy once a diagnosis had been reached, are said to be factors in these deaths.

In the United Kingdom, 2500 cases of imported malaria were recorded in 1997. This is the highest annual total for that country for the past 25 years; almost all cases involved visits to Africa and 64 per cent of individuals affected took no form of prophylaxis (Abraham et. al., 1998). Again, failure to use appropriate drugs, or poor compliance, was blamed for this high rate of infection, and the "anticipated side-effects" was one factor that contributed negatively to the intention to follow through with prophylaxis regiment. 
What does all the "hype" about 'imported malaria' among public health institutions indicate? First, it clearly situates malaria as a problem that comes from the outside to compromise the health of Western industrialised nations; a problem of 'them' versus 'us'. The main concern, of course, is the protection of Canadians, Americans and Europeans. Second, it places the responsibility for safeguarding oneself, and, by extension, one's fellow citizens, on the backs of individual travellers. This is not a global problem to be solved through cooperative efforts aimed at eradication of tropical malaria; it is a domestic public health concern, and each traveller is responsible to quell it.

Hunt (2003) argues that risk discourse is always a moralising discourse, and claims that "the proliferation of risk discourses has expanded the range of social situations in which individuals can become responsibilized" (Hunt, 2003: 183). The use of terms like 'imported malaria' throughout the public health literature inflates the public perception of the risk of malaria. This is, perhaps, part of a moralising discourse that calls upon individuals to take action to protect, not only themselves, but also their homelands. It distorts the reality that if the aim is, indeed, to halt the global spread of malaria, then public health resources would be better spent attacking the problem at its source rather than curbing rates of 'importation' to non-endemic countries. Finally, the term evokes colonial discourses of purity, wherein "our" countries are seen to be "contaminated" by disease from foreign lands. This last statement is ironic when one considers the fact that it was the introduction of Western modes of agriculture such as 'slash and burn', that caused the Anopheles Gambiae mosquito (which feeds by preference on human blood) to supplant other species of mosquito, thereby increasing the 
toll of human malaria. This brought malaria to epidemic intensity in Western Africa in the first place (McNeill, 1976: 41-42).

Detailed information on the mechanisms of malaria transmission from mosquitoto-human-to-mosquito is known. Moreover, the Plasmodium falciparum parasite has been genetically mapped..$^{23}$ Despite a growing body of medical knowledge on malaria, and despite the WHO's plan to "roll back malaria", global infection rates are on the rise and malaria is still the deadliest disease to humans, reaping the greatest havoc on the peoples of Sub-Saharan Africa. In response to the problem of malaria, Western industrialised countries of the world seem to have focussed their attention on managing rates of 'imported malaria' by informing travellers of the risk and prescribing various forms of prophylactic drugs. One of these in particular - mefloquine-has been associated with severe side-effects. What follows is an account of the history of antimalarial drugs, with a focus on the military impetus for research on malaria and ways of preventing it.

\subsection{The History of Anti-Malarial Drugs}

Peoples of the tropics and scientists from around the world have been searching for malaria remedies since ancient times. Chinese and Hindu physicians and priests, followed by Hippocrates, spoke of the 'intermittent fevers', and sought a cure (Williams, 1969). Prior to the seventeenth century, healers appealed to supernatural forces, and

\footnotetext{
${ }^{23}$ For more information on the mapping project, see "NIH Scientists Create First Detailed Genetic Map of Malaria Parasite, http://www2.niaid.nih.gov/newsroom/releases/malariagen.htm (last accessed 24 July 2006).
} 
made use of purging, bleeding, administering sundry herbs, rest, massage, and diet to treat malaria. Many curious ancient remedies can be found in medical archives, including a number of charms and rituals used to expulse the "fever demons". In fact, one ancient remedy against the intermittent fevers was a gentle purgative and cooling drink made of cucumber, camphor, sorrel and other substances; from this came the expression "cool as a cucumber" (Russell, 1955-89). According to historical documents, cinchona bark (which is the basis for quinine) has been successfully used to treat malaria since the $1600 \mathrm{~s}$.

The term 'malaria' was coined in Italy in the Middle Ages. Italian physicians and country folk alike usually referred to bad air-mal aria-as the source intermittent fevers. Some time during the Middle Ages, the two words were joined as one word to refer not to the disease, but to the inciting causes (as explained in Hackett, 1947; Icke, 2000; Jones, 1909; Prothero, 1965; Russell, 1955; Williams, 1969). In the early 1800s the term came to be used in the English language, in particular, in the British Naval service, and by 1841 it was included in the American Dictionary of the English Language, with the following definition:

Malaria, N./mal and aria, bad air, Ital. Bad air; that species of air which produces or tends to produce disease.

This definition persisted until the 1910 edition, which then included a second definition:

Med. a febrile disease supposed to be due to poisonous exhalations from the soil, but now known to be due to the presence of the red blood corpuscles of animal parasites of the genus Plasmodium. (as cited in Russell, 1955: 19-21) 
In 1898, Ronald Ross, an English general stationed in India, discovered that the female mosquito transmitted the plasmodium parasite that causes malaria, and was able to demonstrate the life cycle of the parasite (Bate and Tren, 2001). This discovery and the mapping of the parasite's life cycle hastened experimental research to discover a cure for the disease.

The first attempt to manufacture an anti-malarial drug in a laboratory was made by Dr. Paul Ehrlich in 1891. He studied the properties of methylene blue for fourteen years. When administered to a patient with malaria, it seemed to produce a therapeutic benefit. This is said to be the "first in which a medicinal drug of any sort, natural or synthetic, was appraised for curative powers derived from direct action on an infecting organism. In other words, it was the first 'chemotherapy' as the word was used by Ehrlich" (Russell, 1955: 105).

What is most striking about the history of the development of anti-malarial drugs in Western industrialised countries of North America and Europe, is that it can be written in parallel with major development projects, colonialism, exploitation, and wars. For example, the inability to control malaria epidemics is what caused the French to abandon their attempts to construct the Panama Canal in the early 1800 s. A decade later, in 1914, the U.S.A. was able to complete the project as a result of the discovery and widespread use of pyrethrum spray (Bate and Tren, 2001). Similarly, the development of 'Paris green' -a larvicide- enabled the construction of railways in South Africa. In general, most attempts to control malaria in Africa, where the disease is most hard-hitting, were 
devised for Western exploitation of the continent. ${ }^{24}$ This was clearly illustrated, for example, in a speech at the first meeting of the WHO in 1948. Bate and Tren (2001) write:

Speaking at the Third Session of a joint WHO FAO meeting in 1948, Missiroli of Italy noted that the prosperity of Europe depended on the possibility of exploiting Africa. He said, "Africa cannot be fully exploited because of the danger of flies and mosquitoes; if we can control them, the prosperity of Europe will be enhanced. (Bate and Tren, 2001: 40-41)

While it might seem that it is industrial development and colonialism that drove early efforts to eradicate malaria, the American military's effort to control the parasite during the second World War is perhaps unparalleled in the history of medicine, in terms of their experimentation with, and synthesis of, numerous chemical compounds. This segment of medical history is described in the following sub-section.

\subsubsection{War and The Development of Anti-Malarial Drugs}

As shown in the following quotes, the period of the Second World War was critical to the development of anti-malarial drugs:

\footnotetext{
${ }^{24}$ Speaking at a plenary session of the annual meeting of the Congress of the Humanities and Social Sciences in Winnipeg in June, 2001, the High Commissioner of Uganda, made the point that malaria pills that are distributed throughout Africa by Western companies cost $\$ 7$ per dose. This is an unaffordable prevention measure to combat the disease in Africa. Moreover, in Migrants and Malaria in Africa, Prothero (1965) demonstrates that malaria control through prophylactic drugs is a Western approach for Western use, and that this approach to malaria control has not yet achieved any noteworthy successes in Africa.
} 
In many [military] engagements, malaria accounted for more casualties than combat. This was true not only in the South Pacific and Far East, but in the Sicilians' campaigna and at the air bases in West Africa. (Williams, 1969: 151)

Ninety percent of the world's usual sources of quinine were denied to the Allies when the Japanese occupied Indonesia ... In the absence of an effective antimalarial drug, troops cannot operate successfully where malaria is highly endemic, the loss of Java's cinchona created a real problem because Allied troops were heavily committed in some of the most malarious regions of the world. (Russell, 1955: 109)

American military officials took serious action to cope with the shortage of quinine. By military order, they: restricted all use of cinchona alkaloids to the treatment of malaria in the military; made persuasive appeals to all owners of alkaloid supplies to send them to the War Production Board and large supplies of quinine and other cinchona alkaloids were built up and stored in reserve for possible military needs; and, transported seeds from Mindanao in the Philippines to the Washington Department of Agriculture for analysis and germination in various locations in the American tropics (Russell, 1955: 110-111).

The dwindling supply of quinine also led to the creation of an extensive, multinational research programme on the chemotherapy of malaria. In the U.S.A., this involved close cooperation between scientific institutions, pharmaceutical firms, private individuals, the Army, Navy, and Public Health Service, and led to many advances in research and development in the area of malaria control. Moreover, it yielded a number of drugs that are still in use today. This laboratory research to identify potential anti- 
malarial compounds was supplemented by large-scale clinical trials, usually performed on soldiers, students, prisoners or other large pools of male 'volunteers'. The military imperative to control malaria led to unparalleled medical research in the field. It is stated that: "All in all, the Japanese invasion of Indonesia resulted in a ten-year programme of intensive investigation of anti-malarials that, in scope and results, is unequalled in the history of chemotherapy" (Russell, 1955: 116).

It is largely British and American military might, then, that shaped the knowledge interests behind the drive to technologically control malaria on a global scale. Modern day malaria prevention methods sprang from the wartime effort to develop quinine-based malaria chemo-prophylactics. Some argue that the militaristic ideology underpinning the development of malaria control measures is at the root of the global resurgence in infection rates. William Leiss (1972), for instance, contends that the ideology of a battle for dominion over nature underpins efforts to control malaria globally (Leiss, 1972). Medical anthropologist, Peter Brown, further argues that 'ideological resistance' is now playing a key role in the resurgence of malaria (1997). He argues that "the public health community became trapped in the military metaphor of the postwar eradication era, and when victory became impossible ... ministries of health throughout the world abandoned, or at least neglected, anti-malaria activities" (Brown, 1997: 122).

The following section looks at the controversy surrounding mefloquine, a drug that was created to quell a malaria epidemic among American troops serving in the Vietnam War. 


\subsubsection{Mefloquine and the American Military}

Mefloquine has a long history of military use. The drug was developed at the Walter Reed Army Medical Centre in the U.S.A., in the 1960s, initially for use as a treatment for soldiers who were infected with a chloroquine-resistant strain of malaria during the Vietnam War. The Federation of American Scientists (F.A.S.) explains that the development of mefloquine is a classic example of military-industrial cooperation in the U.S.A.:

The development of mefloquine is a classic example of an early cooperative effort between the Army and industry, which predates the Federal Technology Transfer Act. Each party funded its own pre-clinical and clinical studies with its own unique resources and shared and consolidated the data. The Army medical research and development program over the past decades has fostered thousands of cooperative relationships with academia and industry. (F.A.S., 1998: 1)

In other words, this is a classic example of Eisenhower (1961)'s Military Industrial Complex, which proclaims the need for an immense military establishment and a large arms industry that will be interconnected by economic, political and spiritual spheres of society. C. Wright Mills (1956) foresaw this trend, and wrote apprehensively about this 'military ascendancy' in the United States, affirming: 
[American warlords] are now more powerful than they ever have been in the history of the American elite; they now have more means of exercising power in many areas of American life which were previously civilian domains; they now have more connections; and they are now operating in a nation whose elite and whose underlying population have accepted what can only be called a military definition of reality. (Mills, 1956: 198)

He noted important changes in the social structure of American society after World War II. Most notably, he remarked upon increased traffic between the military, corporate and scientific realms, and observed that beginning during the wartime period of emergency, but far outlasting the crisis, "the general direction of pure scientific research has been set by military considerations, its major finances are from military funds, and very few of those engaged in basic scientific research are not working under military direction" (Mills, 1956: 216).

Mefloquine, which was initially developed for treatment of malaria, was quickly put to use as a preventative in Europe and the U.S.A. in the 1980s. There was a demand (primarily from the Canadian military) for it to be made available as a preventative in Canada as well. Health Canada agreed to let the manufacturer, Hoffmann-La Roche, begin to market the drug through the auspices of the 'Mefloquine Safety Evaluation Protocol' a clinical study to evaluate the safety of mefloquine, in 1991. This clinical study, as well as the use of mefloquine by the Canadian military, will be discussed at length in the following pages on the history of mefloquine use in Canada.

While the American and Canadian militaries generally stand behind their evaluation of mefloquine as a safe and effective anti-malarial drug, this view has been 
challenged 'on the ground', by military personnel who have taken it and their family members. For example, it has been argued that mefloquine failed to protect American troops in Liberia, in August of 2003. Brown (2003: 1) found that: "most of the more than 200 marines who spent time ashore in Liberia [in August, 2003] contracted malaria, with about 43 of them ill enough to be hospitalized." He further asserts that "this is the most intensive outbreak of malaria in the U.S.A. armed services in recent memory and the largest number of cases among marines since the deployment to Somalia a decade ago" (Brown, 2003: 1). These marines were all taking mefloquine. The reasons given for the outbreak included: inadequate absorption of the drug into the blood; low drug compliance; poor drug quality; and potential drug resistance.

Some military personnel who have experienced negative reactions to mefloquine have publicly (though often anonymously) criticised the drug. Examples of these criticisms can be found in 'weblogs' such as the following:

My sleep is still filled with violent and disturbing dreams. Repeatedly through the night I [bolt] upright in bed. I no longer sleep with a round in the chamber of my pistol. The other night Harding woke me in the middle of a dream by poking me with the barrel of his rifle. When I came to my senses, my pistol was out, finger on the trigger. It is happening to everyone. You can tell when you wake them or by listening during the night, but no-one talks about it. ${ }^{25}$

However, openly voicing complaints about the drug can swiftly put an end to a military career. Reporters Benjamin and Olmsted (2003), of the United Press

\footnotetext{
${ }^{25}$ From The Canadian Airborne Regiment in Somalia-A Soldier's Journals http://www.commando.org/somalia.php?page=newcamp.txt (last accessed 24 July 2006).
} 
International, have alleged that there is a potential Navy cover-up regarding possible mefloquine side-effects. They describe the case of Commander William Manofsky of the American Navy, who took the drug while serving in Kuwait. Manofsky suffered a serious case of mefloquine toxicity, his symptoms included shaking hands and legs (to the point that he could not walk for a prolonged period of time), speech pathology, violent rage, and suicidal ideation. Today, there is apparently no longer any indication in his medical file of him ever having taken mefloquine. After raising concerns about the drug, he has been discharged from the Navy. Lori Manofsky, William Manofsky's wife, alleges a Navy cover-up and has in her possession a photocopy of her husband's medical file, which includes all of the pages that state that he once took mefloquine. She argues:

The military created the drug... There is a lot of money involved in the drug. I think there are a lot of careers at stake. Anything that shows a problem with Lariam ${ }^{\circledR}$ has to be hidden or covered up somehow by the military. If all these people came back and it was clearly Lariam ${ }^{\circledR}$, there would be lawsuits up the kazoo! (as cited in Benjamin and Olmsted, 2003)

The Navy refused to comment on this case.

The American military was forced to publicly investigate the link between mefloquine and serious psychiatric events in 2003 , when three military members shot their wives and subsequently shot themselves soon after returning back to Fort Bragg, North Carolina, after having served in Afghanistan. Two other murders were included in the Fort Bragg investigation. However, in these last two cases, the perpetrators had not taken mefloquine. The military thus concluded that mefloquine could not be linked to any of the murders that occurred in Fort Bragg (Benjamin and Olmsted, 2003; Lese et. 
al., 2005). ${ }^{26}$ The following sub-section of the chapter provides a description of the history of mefloquine use in Canada.

\subsection{Mefloquine Use in Canada}

It is difficult to imagine that writing the history of a pharmaceutical drug in Canada could be so turbulent. Indeed, as noted in the introduction, this tale is marred by allegations of drug-induced violence by, and suicide of, Canadian military personnel. Mefloquine safety experiments are punctuated by cases of disappearing pills. The public debate about mefloquine has been captured in Parliamentary hearings, an auditor general inquiry, and countless briefing notes, ministerial inquiries and questions raised in the House of Commons. Throughout this tumultuous history, which has been unfolding since 1990 and continues on in the present day, the 'official voices' of Health Canada and the Department of National Defence, publicly affirm that mefloquine is a safe and effective prophylactic. Meanwhile, certain commanding officers and military medical officers who have witnessed mefloquine in use in operational theatres, along with some Canadian media reporters and Members of Parliament, have repeatedly come forth to express concerns that mefloquine might be not be as safe as presumed; moreover, they argue that the safety of mefloquine was not adequately examined prior to being marketed in Canada and used in military operations.

${ }^{26}$ This is an example of the logical fallacy of the illicit minor term, which argues: some $\mathrm{Xs}$ are not Ys, so no Xs are Ys. Based on the fallacious argument that because two out of five murderers did not take mefloquine, mefloquine was not a contributing factor in any of the murders, and therefore no further investigation was conducted. 
Drawing from over 1,200 pages of government documents, this sub-section of Chapter four recounts the history of mefloquine use in Canada. ${ }^{27}$ The following timeline is an up-dated and amended version of a timeline that was produced by Health Canada (author and date unknown). It visually represents some of the key events in the history of mefloquine use in Canada. One of the most striking features of the timeline, is the fact that mefloquine was released onto the Canadian market (in April of 1993) before Health Canada received the safety data analysis from the manufacturer (in March of 1994). The timeline also highlights other controversial and in some cases unethical events and circumstances surrounding the Mefloquine Safety Evaluation Protocol, namely, the administration of mefloquine as an experimental drug, without proper consent, to Canadian military personnel, and the loss of lack of any safety data on the mefloquine that was administered during the Canadian Forces deployment in Somalia. The controversy surrounding the pre-market testing of mefloquine was hotly debated in the Standing Committee on Public Accounts (SCOPA) hearing, and is discussed at length in the following pages. All of the major stages of mefloquine safety trials, public hearings, military events, and media reports on mefloquine figure in the timeline. The pages that follow the timeline address five major themes in the history of mefloquine use in Canada.

${ }^{27}$ About one quarter of the documents acquired from Health Canada through the ATIP contain no reference information. Furthermore, there were a large number of duplicates, and reports with pages missing. Documents released through the ATIP are usually released as a set, beginning with previously released documentation. This, in part, explains why there were so many duplicates. However there are also some clear omissions. For example, in some cases the existence of certain documents was confirmed through personal communication with individuals who work at Health Canada and/or the Department of National Defence. However, an official request of these documents, by title or subject, was returned null and void. It was thus impossible to locate or acquire these documents without identifying individuals (who refused to go "on the record") who had spoken of them in the first place. 
These themes figure prominently in the above timeline: an overview of current information on the safety of mefloquine (including changes to the Canadian product monograph effected between 1990 and today); the mefloquine safety evaluation protocol, mefloquine use in the Canadian military (in general); mefloquine use by the Canadian military in Somalia; and finally the public trials and debates about mefloquine in the Canadian Parliament and investigative reports in the Canadian media. 
Figure 4.2 Mefloquine in Canada: Timeline

Aug. 1990: The Mefloquine Safety

Evaluation Protocol (MSEP), submitted to Health Canada by Hoffmann-La Roche, is approved. The manufacturer is therefore free to initiate the study.
Nov. 1990: First MSEP shipments are sent out.
March 25 1991: Dr. Tepper (of DND) signs on as co-investigator in the MSEP.
Between March 1991 and Feb. 1992: DND receives 3,500 mefloquine tablets under the auspices of the MSEP.

\section{2}

Between Sept. $9^{\text {th }}$ and Oct. $6^{\text {th }} 1992: 1,380$ bottles of mefloquine, each one containing 50 tablets, are sent to Petawawa. These bottles are never accounted for in the MSEP reports.

\section{3}

March $16^{\text {th }} 1993$ A Somali prisoner is tortured and killed. Clayton Matchee and other members of the Airborne are charged. Mefloquine is implicated but not conclusively linked to the events.
March 1993: Last MSEP shipments of mefloquine were sent out to various parties.

April 01 1993: Mefloquine is introduced into the Canadian market.

\section{4}

\begin{tabular}{|c|c|}
\hline $\begin{array}{l}\text { March } 01 \text { 1994: Health Canada receives } \\
\text { MSEP safety analysis from the manufacturer. }\end{array}$ & $\begin{array}{l}\text { April 1994: A Member of Parliament contacts } \\
\text { Health Canada to raise concerns about the } \\
\text { safety of mefloquine. }\end{array}$ \\
\hline $\begin{array}{l}\text { Oct } 5^{\text {th }} 1994: \text { The mefloquine product } \\
\text { monograph is revised to include a warning } \\
\text { about concomitant use of alcohol. }\end{array}$ & $\begin{array}{l}\text { December } 24^{\text {th }} 1994: \text { Corporal Scott Smith } \\
\text { commits suicide. Mefloquine is implicated but } \\
\text { not conclusively linked to this event. }\end{array}$ \\
\hline
\end{tabular}

\section{5}

Jan 10 1995: The 'Information to the Consumer' section of the product monograph is revised to include a warning about concomitant use of alcohol.

March 1996: A military psychiatrist sends a memo to the Director General of Health Services regarding the neuro-psychiatric difficulties associated with mefloquine, exnerienced bv militarv nersonnel in Rwanda.

(continued on next page) 
Mefloquine in Canada: Timeline (continued)

\section{7}

May 7 1997: The "Report of the Somalia Commission of Inquiry on the Mefloquine Issue" is published by DND. Mefloquine is still not officially linked with the events in Somalia.
Oct. 14 1997: A televisions series, W5, entitled "Mefloquine Nightmare" showcases some of the problems with mefloquine use among military personnel.

\section{8}
January 10 1998: Patrick Ryan is arrested for a robbery in Calgary. He claims that mefloquine caused a "Jekyll and Hyde" transformation in his personality.

\section{9}

January to May 1999: Questions are raised in the House of Commons about the MSEP, the link between mefloquine and the events in Somalia, and between mefloquine and Corporal Smith's suicide.
Nov 18 1999: The "Auditor General's Report on Mefloquine", stating that DND did not comply with the MSFP. is nublished.

Nov 18: 1999 The Standing Committee on Public Accounts hearing on mefloquine and the MSEP takes place. It is publicly stated that DND did not comply with the MSEP.

\section{0}

2001

2002

July 2002: The media reports that three soldiers returned from Afghanistan and murdered their wives and later committed suicide. These soldiers were taking mefloquine.
Oct $16^{\text {th }} 2002:$ The Fifth Estate television broadcast entitled: "The Nightmare Drug", about adverse reactions to mefloquine, including violence and suicide. is aired.

\section{3}

\begin{tabular}{|l|l|}
\hline $\begin{array}{l}\text { April 14 } 4^{\text {th }} \text { 2004: CBC Radio The Current } \\
\text { airs a broadcast entitled: "Lariam and } \\
\text { Suicide Among Soldiers". }\end{array}$ & $\begin{array}{l}\text { April 22 } 2004 \text { : Patrick Ryan is granted full } \\
\text { parole after spending 6 years in jail for robbery. } \\
\text { corrections Canada ruled that side-effects from } \\
\text { mefloquine contributed to his criminal } \\
\text { behaviour. }\end{array}$ \\
\hline
\end{tabular}




\subsubsection{Safety Information on Mefloquine}

Canadian travelers to malarial countries are strongly cautioned about the risk of malaria and advised to take some form of anti-malarial prophylactic for the duration of their journey abroad. As a general rule, travel medicine providers (TMPs) in Canada and the U.S.A. prescribe travellers with one, or a combination, of the following prophylactic drugs: chloroquine, doxyclyline, primaquine, mefloquine (sold under the brand name Lariam $\left(\right.$ ) , atovaquone plus proguanil (sold as Malarone ${ }^{\mathrm{TM}}$ ). Because the parasite has developed resistance to the most commonly used anti-malarial prophylaxis and treatment - chloroquine-Health Canada advises people to take mefloquine as a malaria prophylaxis when travelling through 69 malarial countries (Health Canada, 1995), and, therefore, most travel medicine providers across Canada make the same recommendation. In fact, mefloquine (Lariam $\left.{ }^{\circledR}\right)$, is the most widely prescribed anti-malarial drug in North America today; it has been prescribed to more than 22 million people worldwide since 1985 and is now prescribed by doctors in the U.S.A. 1000 times every day (Benjamin and Olmsted, 2002b: 1). Moreover, mefloquine is deemed the "drug of choice" by Health Canada and the Canadian military (Health Canada, 1995; Health Canada, 2000; Mackenzie, 1996; Scott, 2002a).

For a traveller who is preparing to visit a country where there is a risk of malaria, the available information on mefloquine (in particular, that which can be found on the Internet) is confusing and at times contradictory. The WHO and most of the 'official' sources of information that are produced by North American national health agencies (such as Health Canada, and the Centre for Disease Control) argue that mefloquine is safe and effective, and that the risk of experiencing a side-effect is negligible. Health Canada, 
a main source of information for Canadian travellers, lists very few potential side-effects on its website, citing only: "dizziness, nausea, diarrhoea, headache, insomnia, strange dreams" as common side-effects (Health Canada, 1995). No mention of 'rare' or 'occasional' side-effects for Mefloquine is made, while it does list several of these types of side-effects for the other available anti-malarial drugs.

In The Compendium of Pharmaceuticals and Specialities, the Canadian Pharmacists Association (CPA, 2002) the following contraindications regarding mefloquine use are noted: "Patients with a history of psychiatric disturbances (including depression) should not be prescribed mefloquine prophylactically since mefloquine may precipitate these conditions." The following precautions are offered:

Caution should be exercised with regard to driving, piloting airplanes, operating machines, deep sea diving or any activity requiring alertness and fine motor coordination, as dizziness, a disturbed sense of balance and other disorders of the central and peripheral nervous system have been reported during and up to three weeks after the use of mefloquine ... During prophylactic use, if signs of unexplained anxiety, depression, restlessness, or confusion are noticed, these may be considered prodromal to a more serious event. In these cases, the drug must be discontinued and an alternative prophylactic agent should be recommended. (C.P.A., 2002: 876-877) ${ }^{28}$

Adverse reactions to mefloquine are classified according to the likelihood of their occurrence. The less frequently reported adverse effects are grouped into five categories:

\footnotetext{
${ }^{28}$ Note that caution is recommended for all things required for being a soldier!
} 
neuropsychiatric, cardiovascular, musculoskeletal, skin and other. The CPA further notes that: "In the literature, the incidence of serious neuropsychiatric adverse drug reactions (e.g., seizures, psychotic reactions) with mefloquine has been reported at $1 / 13000$ following prophylactic use" (CPA, 2002: 876-877). It is interesting to note here, that the British Medical Association situates an acceptable level of risk as falling somewhere between one to 100 deaths per million (BMA 1993: 228; as cited in De La Gorgendière, 2005: 172).

The statement: ' 1 in 13,000 will experience a serious neuro-psychiatric reaction to mefloquine', is the most frequently cited statistic of the incidents of adverse reactions to mefloquine in the public health literature (i.e., the literature that is made public by Health Canada, the Department of National Defence and other international health agencies). However, internal Health Canada and Department of National Defence documentation on mefloquine contains a significant variation in the rates of incidence. For example, in April of 1996, a memorandum for the Minister of Health was drafted in preparation for the following question, which was to be raised in the House of Commons: "Is Health Canada aware that the antimalarial drug mefloquine has been associated with neuropsychiatric side-effects?" The proposed response included many phrases about the value of mefloquine and the risk of malaria and the following statement:

The Department is following the adverse reaction profile of this drug. Current information indicates that the incidence of severe neuropsychiatric reactions is [one] in 10,000 to [one] in 13,000 when used to prevent contracting the disease. (Gadd, 1996: 3) 
When the same question was raised the following year in the House of Commons, the response included the following: "Current information indicates that the incidence of serious neuropychiatric effects (seizures, psychotic episodes) is 1 in 13,000 to 1 in 50,00 when used for prevention" (Gadd, 1997: 3). As is the case in many (perhaps most) public health documents pertaining to mefloquine, it is unclear where these figures come from, because no references are included.

Such statistics on the incidence of serious adverse reactions to mefloquine are challenged in three different ways: First, this commonly cited statistic is not based on controlled double blind studies, but on spontaneous reports of adverse reactions made by consumers or doctors to the manufacturer or to a health agency (such as the WHO, Health Canada or other). One unpublished report by the World Health Organization, for instance, measures the incidence rates of adverse reactions between 1985 and 1990, using data of spontaneous reports from Hoffman-La Roche. These adverse events are then compared with an estimate of the number of mefloquine users during that time period, based on sales data. The WHO assumes that $50 \%$ of those who suffered from adverse reactions reported their experiences, and then extrapolates that the incidence rate is 1:10000 for serious events. The report cites a number of personal communications and anonymous reports as further support for this incidence rate. ${ }^{29}$ This is extremely problematic because we do not know that all those included in the estimate of mefloquine users actually took the mefloquine; so the estimated denominators might actually be much smaller, and therefore the proportion of those experiencing side-effects much larger. Also, we can never be certain that spontaneous reports represent the actual

${ }^{29}$ This report is available on the Internet: 
numbers of people who experience adverse reactions. In one of Health Canada's reports on the adverse reactions reporting program, for example, it is clearly stated that "only a small proportion of suspected adverse reactions are reported to the programme, consequently this information must not be used to estimate the incidence of adverse reactions" (Health Canada, 1994: 2).$^{30}$ Elsewhere, the incidents of spontaneous reports has been estimated at less than 10\% (Canadian Broadcasting Corporation (CBC), 2004a: 1). Yet, this report is a main source, if not the only source, of support for the commonlycited statistic that 1 in 10,000 to 1 in 13,000 suffer serious adverse reactions to mefloquine. Even more remarkable is the fact that it concludes by stating that the causes of psychiatric and neurological impairment associated with mefloquine use are unknown, and calls for further research on mefloquine toxicity. However, as confirmed by Susan Rose, co-director of 'Lariam Action U.S.A.', these studies were never conducted (based on a personal communication).

A second way that the commonly cited incidence rate can be criticised, is by looking at the definition of 'serious' that is used. The WHO and Health Canada define a 'serious' reaction as one that causes prolonged hospitalisation, severe disability or death (e.g., Health Canada, 2000b). However, many authors have argued that this definition is too restrictive when dealing with a preventative drug. Croft et al. (2002) and Overbosch et al. (2001), for example, use the term 'severe reaction', which is defined as one in which a person is unable to carry out their daily activities, one that requires medical

http://whqlibdoc.who.int/malaria/WHO_MAL_91.1063.pdf (last accessed 31 July 2006), and www.lariaminfo.org/information/labeling.shtml (last accessed 11 September, 2006). ${ }^{30}$ It is based on these types of studies that Hoffmann La Roche convinced Health Canada to fast track their new drug submission for mefloquine and got the "Lariam Safety Evaluation Protocol" approved. This point is pursued further on in the chapter. 
advice, or one that necessitates cessation of the drug, as a measure of the drug's tolerability. Not surprisingly, these authors find much higher prevalence of 'severe reactions'. For example, one study by the British-based Medical Advisory Service for Travellers Abroad (MASTA) found that one in 140 travellers taking mefloquine could expect to have a neuro-psychiatric adverse event unpleasant enough to temporarily prevent them from carrying out their day-to-day activities (Barrett, Emmins, Clarke, and Bradley, 1996: 525).

Third, the incidence rate is disputed in small-scale studies and by 'lay experts' who claim that the prevalence of adverse reactions is, in fact, much higher than 1 in 10,000. However, since large-scale clinical trials have not been conducted, and since different clinical definitions are used, it is impossible to state with confidence what the actual rates of neuro-psychiatric side-effects are. Nonetheless, there are small-scale accounts that seem to contradict the overall assumption that serious side-effects are rare. For example, in 1993, Dr. Claire Franklin, then acting director of the bureau of Human Prescriptions Drugs, Health and Welfare Canada, received a letter from a development coordinator who brought a group of 20 volunteers to the Solomon Islands. He describes the group's experiences with mefloquine as follows: " $50 \%$ of us had severe reactions to mefloquine and subsequently switched to chloroquine... one of our group members was mentally unstable and had suicidal tendencies... I contracted malaria...". He concludes his letter by stating: 
I would strongly oppose any recommendation by physicians at Canadian travel clinics to prescribe mefloquine for malaria prophylaxis. I feel that it would be better to contract malaria and be treated for it than to take mefloquine for prophylaxis .... I hope that these comments will be seriously considered and that the approval of mefloquine will be rescinded. (Venkatacharya, 1993: 2)

This letter is particularly noteworthy since it was received during the Mefloquine Safety Evaluation Protocol when mefloquine was still considered an 'experimental' drug in Canada. Recent double-blind studies also indicate that the incidence of moderate to severe adverse reactions is much higher than 1 in 10,000. For example, in a controlled double-blind study, Schlagenhauf et al. (2003) found that 42 per cent of mefloquine users experienced moderate to severe adverse reactions. Likewise, Overbosch et al. (2001) found that the frequency of adverse events attributed to mefloquine was around 42 per cent. Furthermore, they state that:

$[\mathrm{N}]$ europsychiatric events were reported by a significantly larger proportion of subjects who received mefloquine, compared with those who received atovaquone-proguanil ... which provides convincing evidence that such events are causally related to mefloquine in some people (Overbosch et al. 2001: 1020).

In a response to the aforementioned study, Croft and Herxheimer (2002: 1278) emphasise that: six per cent of participants who received mefloquine experienced a severe adverse event (defined as requiring medical advice), and noted: 
The most common category of unwanted effects in the mefloquine treatment arm were neuropsychiatric adverse effects, which were reported by one-third of all mefloquine users. (Croft and Herxheimer, 2002: 1278)

Most recently, in another controlled double blind study, VanRiemsdijk and her colleagues (2005) pegged the risk of experiencing a 'psychiatric event' (operationally defined as all psychiatric syndromes included in the International Classification of Diseases, Ninth Edition, 2003) at 35 per cent and found that mefloquine use was associated with significantly higher scores on scales for depression, anger, and fatigue and lower scores for vigour, than prophylactic use of atovaquone plus chloroguanide (Malarone).

It seems, however, that these clinical studies and small-scale observations are simply dismissed by governing bodies. For instance, Canadian health authorities stand firm on their endorsement of mefloquine as the drug of choice for malaria prevention in chloroquine-resistant areas. In an Appendix to the "2000 Recommendations for the Treatment and Prevention of Malaria" (last updated in September of 2005), for example, Health Canada (2002c) affirms the following: 
Myth: Most people who take mefloquine have serious side-effects. Fact: For travellers to high-risk areas, the risk of acquiring malaria and dying is significantly greater than the risk of experiencing a serious side-effect from mefloquine. Over 11 million travellers have used mefloquine prophylaxis, and severe reactions (seizure, psychosis) to this drug are rare (reported from [one] in 10,000 to [one] in 13,000 users). The great majority of mefloquine users (9599\%) have either no side-effects or only mild and temporary ones. Occasionally, a traveller will experience a less severe but still troublesome neuropsychological reaction (e.g. anxiety, mood change) to mefloquine ([one] in 250 to 500 users) requiring a change to an alternative drug. These reactions are almost always reversible. Death from malaria, however, is not. (Health Canada, 2002c)

This study examines how cases of severe reaction to mefloquine are recorded. Concretely, it investigates the proportion of cases of reactions to mefloquine requiring prolonged hospitalisation, or resulting in injury or death, that are accounted for in the official statistics. On a more abstract level, it considers what the commonly held understandings of what might constitute a 'serious reactions' are, and what level of risk various stakeholder groups are willing to take when it comes to a drug that is to be used as a method of prevention for a potential disease.

\subsubsection{Product Monographs}

Product inserts (or "information for the consumer") are the main way that the manufacturer communicates safety information about its products directly to its clients. These vary from country to country, even when accompanying the same drug. So, the product insert that accompanies mefloquine in Canada contains different information 
from the product insert that accompanies mefloquine when it is sold in another country (See Appendix $\mathbf{J}$ for the Lariam ${ }^{\circledR}$ Product Information Sheet, the Product insert as well as a pharmacy printout on mefloquine).

The 1997 Canadian product insert for mefloquine stated the following:

The following unwanted effects have been reported to occur with [mefloquine]: nausea, vomiting, dizziness, light-headedness, loss of balance, headache, sleepiness, inability to sleep, abnormal dreams, loose stools or diarrhoea, and abdominal pain. In rarer cases, loss of appetite, abnormal heartbeat, itching of the skin or skin rash, hair loss, eyesight problems, muscle pains, convulsions, and disturbances of mood (depressed mood, mental confusion, anxiety states) may occur. (Hoffman La Roche, 1997)

It further added: "If these adverse events are not severe in nature and are tolerable, it is in your best interest to continue 'Lariam' prophylaxis since the consequences of contracting malaria are cause for greater concern." The 2002 (most recent) Canadian product insert has been amended. It now asserts that more 'severe' reactions may persist after mefloquine has been stopped, and warns about the potential risk of suicide:

People taking 'Lariam' occasionally experience severe anxiety, feelings that people are against them, hallucinations (seeing or hearing things that are not there for example), depression, unusual behaviour, or feeling disoriented. There have been reports that in some patients these side-effects continue after 'Lariam' is stopped. Some patients taking 'Lariam' think about killing themselves, and there have been rare reports of suicides. It is not known whether 'Lariam' was responsible for these suicides. (Hoffmann-La Roche, 2003) 
Moreover, patients are now warned to discontinue use of mefloquine if neuro-psychiatric side-effects occur, as these may be signs of more serious problems to come:

If you use 'Lariam' to prevent malaria and you develop a sudden onset of unexplained anxiety, depression, restlessness or irritability, or confusion (possible signs of more serious mental problems), or you develop other serious side-effects, including a persistently abnormal heart beat or palpitations, contact a doctor or health care provider. It may be necessary to stop taking 'Lariam' and use another malaria prevention medicine instead. If you can't get another medicine, leave the malaria area .... (Hoffmann-La Roche, 2003)

This recent set of changes is likely associated with a series of changes to the product monograph in the U.S.A.. In 2002, the Food and Drug Administration (FDA) required four changes to the product insert over a period of 13 months. The most recent product label states:

Occasionally, more severe neuropsychiatric disorders have been reported such as: sensory and motor neuropathies (including paresthesia, tremor and ataxia), convulsions, agitation or restlessness, anxiety, depression, mood changes, panic attacks, forgetfulness, confusion, hallucinations, aggression, psychotic or paranoid reactions and encephalopathy. Rare cases of suicidal ideation and suicide have been reported though no relationship to drug administration has been confirmed.

(F.D.A., 2002)

This much more detailed product monograph and the mention of suicide and suicidal ideation are the result of an FDA investigation into allegations that mefloquine was 
leading to cases of suicide among military members serving in Afghanistan and Iraq. The four murder-suicides in Fort Bragg, by military members returning from Afghanistan, also raised alarms that mefloquine was linked to these events. The FDA responded by calling for the aforementioned changes to the product insert. Moreover, the FDA has since then allowed the makers of Malarone ${ }^{\circledR}$ to market it as the 'safer antimalarial drug' in the U.S.A., and to state that it has a better safety profile than mefloquine (GlaxoSmithKline, 2002). This series of investigations and changes to the product insert in the U.S.A. led to amendments to the "information to the patient" section of the Canadian product monograph, as follows:

The Information for the Patient section of the Canadian Product Monograph for Lariam ${ }^{\circledR}$ (mefloquine) advises patients to stop taking their Lariam ${ }^{\circledR}$ and immediately consult a physician if they experience unexplained anxiety, depression, restlessness, or irritability, or confusion. (Leitch, 2003: 3)

A "Dear Health Care Professional" and "Dear Pharmacist" letter was also issued to remind prescribers of mefloquine of their obligation to provide patients with a medication guide. This only occurred after a large quantity of mefloquine was sold without any product information, leading to a class action suit in the U.S.A. (Holder, personal communication). 


\subsubsection{The Mefloquine Safety Evaluation Study $1990-1993^{31}$}

In 1990, Hoffmann-La Roche made a submission to Health Canada requesting that mefloquine be marketed to the Canadian public. The drug was already being sold for this purpose in other countries and was deemed safe by the WHO. Health Canada approved the Mefloquine Safety Evaluation Protocol (MSEP), and allowed the manufacturer to conduct the safety monitoring study. The first shipments of mefloquine were sent out to participating investigators in November of 1991 . With regard to Health Canada's role in drug safety studies, it should be noted that "a safety monitoring study", such as this one, "follows patients more closely and requires informed consent prior to administration of the drug." ... [However], "Health Canada's mandate does not extend to being involved with, or overseeing all aspects of research on new drugs"; this is the manufacturer's responsibility (Health Canada, 1999: 4). When a safety monitoring study such as this one is being conducted, medical practitioners are asked to join the study, and if they do so, they agree to follow their patients who take the experimental drug, compiling safety data and reports of adverse reactions, which they submit to the manufacturer.

Questions on the MSEP arose in the House of Commons when it was revealed that, although a DND medical practitioner had joined the study, there was no accounting

\footnotetext{
${ }^{31}$ Details of the Mefloquine Safety Evaluation Protocol are difficult to acquire. Although hundreds of pages on the issue were supplied through the ATIP, much of the information was suppressed due to rules about trade secrets and manufacturer's confidentiality. Many of these pages contain large sections of text that have been struck out. In particular, data, such as numbers of patients who participated in the study, and numbers of adverse reactions reported, are all suppressed. The ATIP documents pertaining to the Mefloquine Safety Evaluation Study do provide useful information on the unfolding of the study, as well as information about drug safety protocols in general.
} 
for the mefloquine that was used in Somalia in 1992. Military members who were administered the drug at that time did not give their informed consent to participate in a drug trial for mefloquine, and safety data were not submitted to the manufacturer. In light of the events that took place during and after the deployment to Somalia (the torture and murder of a Somali, the disbanding of the Airborne regiment, the subsequent suicide of a corporal who had served in Somalia), and given the allegation that these events were linked to mefloquine, which was an experimental drug in Canada at that time, this became a very public interrogation of the Ministers of National Defence and Health Canada. The Department of National Defence purported to have acquired the mefloquine from the manufacturer, outside of the auspices of the study. Health Canada denied having any knowledge of the provenance of the mefloquine used in Somalia. When asked to comment on this, the manufacturer stated they were "unsuccessful in obtaining from the DND any information regarding the usage of the 'Lariam ${ }^{\circledR}$ ' supplied in September and October 1992" (Biondi, 1994: 3). Moreover, they emphasised that they did not provide mefloquine to DND outside of the auspices of the drug study (as DND has maintained).

The study's shortcomings were noted in a memorandum from Dr. McDonald (reviewer in the MSEP) to Dr. Gadd (then Assistant Chief of the Infection and Immunology Division Health Canada). This memo included the following quote from the manufacturer, which clearly shows that the MSEP was a flawed study in many ways: 
Unfortunately many investigators have failed to return their completed case record forms to Hoffmann-La Roche. This indicates that the safety data from the Canadian study is incomplete. In addition, since the majority of the investigators collected their safety data by means of passive surveillance, the data is less useful than that collected by active surveillance. (McDonald, 1992: 3)

Despite these shortcomings, and despite never having received data on the military personnel who took mefloquine in Somalia, Health Canada released mefloquine onto the Canadian market in April of 1993, eleven months before receiving Hoffmann-La Roche's final report on the MSEP. It was later noted in the Standing Committee On Public Accounts (SCOPA) hearing that "only $65.1 \%$ of the patients who took the drug were accounted for" (Maria, 1999: 32).

In sum, the above discussion leaves this social scientist seeing a gaping hole where the safety data should be. The new drug submission for mefloquine was approved by Health Canada, based largely on the fact that mefloquine was already being used as an anti-malarial drug elsewhere in the world and was deemed 'safe' (through spontaneous reports to the manufacturer compared with estimated sales figures). Since it was still considered an experimental drug in Canada, a safety protocol for the evaluation of new drugs had to be approved and followed. However, many of the 'subjects' that were given mefloquine as part of this study were not followed and no data were reported to the manufacturer. Meanwhile, Health Canada released mefloquine onto the Canadian market before seeing the manufacturer's final analysis. Unfortunately, it was impossible to get a clearer picture, or to fill in some of these gaps, because the numerous attempts made to 
solicit input and clarification from anyone at Health Canada and/or Hoffmann-La Roche during the eight-month period of data collection, were all rebuffed.

\subsubsection{Post-Marketing Surveillance}

The Canadian Adverse Drug Reaction Monitoring Newsletter, which is prepared by the Therapeutic Products Directorate of Health Canada, begins with the following statement:

A voluntary reporting system thrives on intuition, lateral thinking and openmindedness [sic.]. For these reasons, most adverse drug reactions (ADRs) can be considered only to be suspicious, for which a proven causal association has not been established. Because there is gross underreporting of ADRs and because a definite causal association cannot be determined, this information cannot be used to estimate the incidence of adverse reactions. (Health Canada, 2002a: 1)

This statement is interesting for a number of reasons. In the context of the present study, it underscores the value of intuition in scientific knowledge building, and it is a primary objective of this study to examine the role of subjective knowledge in such processes. It is also noteworthy because, although it urges the contrary, it is precisely this type of information that is used to confirm the incidence of adverse reactions to.

Once approved for sale in Canada, Health Canada ensures the safety of pharmaceutical products by maintaining a database of adverse reactions. This system of post-marketing surveillance relies on doctors, pharmaceutical corporations and the public to report all serious adverse reactions to Health Canada. Pharmaceutical corporations are obliged, under the Canada Health Act (1984), to report any and all spontaneous adverse 
reactions to their products, of which they become aware. Apart from that, the system is voluntary and is thus plagued by chronic under-reporting. In fact, the Canadian Broadcasting Corporation (CBC, 2004) and Lexchin and Minztes $(2003 ; 2004)$ show that the Canadian adverse reaction database merely captures between 1 and 10 percent of actual adverse reactions. In an interview with the $\mathrm{CBC}$, Mintzes explained that medical doctors are actually dissuaded from reporting adverse drug reactions, exclaiming: "We're not even getting the tip of the iceberg of what's going on . .", and adding:

There's underreporting for a range of reasons. One reason is that there's, if anything, a financial disincentive for doctors to report. If a doctor is working on a fee-for-service basis, they're paid for their consultations with their patient, but they're not paid for the time they take to fill out a form and report. (Canadian Broadcasting Corporation (CBC), 2004c: 1)

The following chapter compares Health Canada data with primary and secondary data collected for this study. As noted elsewhere in this chapter, Health Canada does not have adequate resources to ensure that pharmaceutical products are safe, and thus relies largely on the manufacturer to perform this task. For instance, it is the manufacturer who must follow up on "signals" that a drug might be unsafe. This was explained in a memorandum to the Minister of Health, which states: 
[I]t should be noted that Health Canada does not conduct investigations of each adverse event report, rather, adverse reaction reports are analysed to discover potential health product safety signals. A signal is considered to be the preliminary indication of a product-related issue. The identification of a signal is not by itself the proof of the association of an adverse reaction to the health product, but it triggers the need to further investigate a potential association as well as establish appropriate risk management measures. There is an expectation that follow-up information should be sought by the manufacturer... as part of the manufacturer's safety monitoring responsibilities. (Gorman, 2002: 2)

So, ultimately, the responsibility for ensuring the safety of a product rests with the manufacturers of that product. The manufacturers are, it seems, also responsible for determining the best risk management strategies when it comes to addressing potential safety signals. This is a clear example of what Joel Lexchin (1998) means when he says and that 'safety loopholes' in the drug regulation process are not accidental, but systematic - in this case, those who profit from the sale of a drug are often entrusted with the responsibility of ensuring the safety of those very products. This point is further expanded upon in the discussion of the SCOPA hearings (below).

\subsubsection{Mefloquine Use in the Canadian Military}

The Canadian Forces adopted mefloquine as a malaria prophylaxis in their deployment to Somalia in 1992. Since it is cheap, must only be taken once per week, and is effective in areas were the malaria parasite has become resistant to chloroquine, mefloquine remains the anti-malarial "drug of choice" in the Canadian Forces today. According to one internal DND document, a minimum total of 2,250 members of the 
Canadian Forces have taken mefloquine on international deployments to Somalia, Rwanda, Ethiopia, Eritrea, East Timor, and Afghanistan (DND, 2002a: 6). ${ }^{32}$ Another internal DND document identified other countries in which mefloquine was used, stating that "mefloquine has been used by the CF in parts of the world where malaria has developed a resistance to chloroquine-for example Cambodia and Africa (Angola, Nigeria, Zaire, Somalia)" (Vaillancourt, 1997: 1). Regardless of variations in the accounting of mefloquine use operationally, the Department of National Defence (DND, 2002b) stands behind its endorsement of mefloquine, stating that it has been prescribed to at least 15 million people worldwide. In Colonel Ken Scott's words:

Mefloquine remains the antimalarial drug of choice for travelers deploying to areas endemic for Chloroquine Resistant Plasmodium Falciparum (CRPF). Multiple international expert panels, including the Centers for Disease Control and Prevention (CDC), have reached this conclusion after reviewing all the evidence available. These expert panels have noted that mefloquine's unsalutary reputation has been driven by two factors: UK malaria experts and travel clinics preferred a combination of chloroquine and proguanil for prophylaxis. . [ [and] the drug has side-effects in some people that include nausea, dizziness, vertigo, lightheadedness (described as an inability to concentrate), bad dreams, seizures and psychosis. (Scott, 2002a)

\footnotetext{
32 Oddly enough, in that same document, on the next page, it is indicated that mefloquine has also been used by the CF in Kenya. This is just one of the many inconsistencies found in the ATIP documents.
} 
However, one internal DND document calls into question the notion that mefloquine should remain the CF "drug of choice". In a tabulation of the pros and cons (or "pluses" and "minuses") for doxycyclen or malarone as alternatives to mefloquine, the "pluses" given for both Malarone and doxycyclen are simply stated as follows: “it ain't MEF [referring to mefloquine]!" (DND, 2002c: 8). There are also numerous references in the internal documents to the fact that one military psychiatrist who conducted stress debriefings in Rwanda expressed grave concerns about mefloquine -without consulting with the chain of command-- and outlined neuropsychiatric difficulties, which he and four members of his team were privy to and experienced (Cameron, 2001). Although these discreet criticisms of mefloquine are present in the internal DND documentation, mefloquine nonetheless remains the $\mathrm{CF}$ drug of choice.

A number of military personnel have argued the need for a study of mefloquine among military personnel. In 1997, a briefing note was prepared for the Minister of National Defence and the Chief of the Defence Staff. The purpose of this note was to inform them about the military use of mefloquine and of the present status of a study of mefloquine side-effects. It also mentions a study of mefloquine side-effects in the Canadian Forces, and states that: 
In order to document the potential adverse effects of mefloquine on human function, a study was planned in the $\mathrm{CF}$, in conjunction with the chairman of CATMAT (Health Canada's Committee to Advise on Tropical Medicine and Travel), to undertake neuro-psychiatric testing of individuals required to take mefloquine because of their travel plans. Funding was approved by the Medical Services Research Board... [and] to date, the study, which has been proceeding at a low level for the past two years, has been limited to civilians because there has been no valid requirement for the use of mefloquine among military members. (MacKenzie, 1997: 1-2)

Later, internal DND documents stated that a study of mefloquine side-effects was not planned and that, to date, none has been carried out because there has not been a large enough deployment that required the use of mefloquine. Since then, there has been one deployment— to Afghanistan-in which large enough numbers of military and civilian personnel have been given mefloquine, nonetheless, the study has not been carried out.

There seems to be some reticence by DND to documenting adverse reactions to mefloquine. In an internal memorandum, for example, one post-deployment health specialist at the National Defence Medical Centre states that encouraging people to use the Adverse Drug Reaction reporting system for mefloquine concerns is a good idea, "despite the inherent risks". He goes on to say that:

We have to have a way to investigate those who come forward. Treating these people with the interest, attention, respect and concern they deserve (as soon as possible) may be the single most important thing we have to offer them. (Reference omitted for confidentiality of the author - endnote record \# 626) 
Canadians were shocked when it was reported in the media that members of the Canadian Forces' Airborne regiment had tortured and murdered a Somali boy in 1992. There were allegations that mefloquine was connected to these atrocities. One news story began as follows:

Psycho Tuesday, wacky Wednesday, freaky Friday ... they were the names our troops had in Somalia for the days they were given pills to fight off malaria .... Mefloquine's bizarre side-effects became the talk of the camp .... The Airborne . . c called their violent dreams 'meflomares'. (CTV, 1997)

Mefloquine use by the Canadian military in Somalia is of unique importance for two reasons: first, although mefloquine was only available through the mefloquine safety evaluation study in 1992, DND officials claimed that the pills used on the deployment in Somalia were purchased directly from the manufacturer, outside of the auspices of the study. As such, DND did not take all of the necessary steps required when administering an experimental drug, as discussed above. Meanwhile, the manufacturer claims that it did not provide any mefloquine to DND outside of the auspices of the mefloquine safety evaluation study. This issue remains unresolved to this day. Second, mefloquine was implicated in the event described above and in the later suicide of Corporal Scott Smith (in 1994) who had served in Somalia.

The Somalia Commission of Inquiry was struck to investigate how to account for the violent behaviour of certain members of the Airborne regiment who were deployed in Somalia. One hypothesis was that either mefloquine was a cause or a contributing factor. What follows is a lengthy excerpt from the Report of The Somalia Commission of Inquiry on the Mefloquine Issue (DND, 1997). The report states: 
If mefloquine did in fact cause or contribute to some of the misbehaviour that is the subject of this Inquiry, CF personnel who were influenced by the drug might be partly or totally excused for their behaviour. However ... we are not able to reach a final conclusion on this issue. We can offer only general observations about the decision to prescribe mefloquine for personnel deployed to Somalia: 1 . DND's decision in 1992 to prescribe mefloquine for CF personnel deployed to Somalia appears to be consistent with the medical practice at the time... We cannot say, however, whether DND took adequate precautions to ensure that persons susceptible to severe psychiatric disorders did not receive mefloquine, since even in 1992 it was known that mefloquine should not be prescribed to such individuals. 2. At the time of the deployment, there seems to have been no strong evidence that mefloquine might interact with alcohol to produce or increase the risk of abnormal behaviour or to magnify such behaviour. The possible adverse effects of mixing alcohol with mefloquine were analysed in detail in the medical literature only after the Somalia deployment. DND, therefore, cannot be faulted for failing to relate the consumption of alcohol to the use of mefloquine. 3. More recent medical information suggests that severe adverse effects from mefloquine used as a prophylactic are not as rare as first thought, but views on this point conflict, and further investigation may be necessary. 4. Mefloquine use could have been a factor in the abnormal behaviour of some troops in Somalia. ... It is evident that further investigation is warranted before any firm conclusions about the role of mefloquine can be drawn. (DND, 1997: 7-8) 
This report is quite insightful on the process of ascribing blame and defining accountability within large bureaucratic institutions. The following points should be emphasised: first, if DND officials had followed the mefloquine safety evaluation protocol when administering mefloquine to personnel deploying to Somalia, as they were supposed to do, the Commission would have known for certain whether or not persons with a predisposition for neuro-psychiatric reactions were given mefloquine in Somalia. Second, nowhere else in all of the documents received from DND through Access to Information, is the notion that severe adverse effects from mefloquine are not as rare as first thought. This very critical point is mentioned only once, without reference to any literature. Third, no firm conclusions on the role of mefloquine in the Somalia events were ever reached. However, in terms of accountability for, and repercussions of, the events, eight military members were charged in connection with the Somali boy, Shidane Arone's death. One of these, Clayton Matchee, tried to commit suicide and suffered permanent brain damage and is now committed to a mental institution for life, as a result. Another, Corporal Scott Smith, committed suicide in Rwanda, on Christmas Eve. A Briefing Note was prepared for the Minister of National Defence on the Report of The Somalia Commission of Inquiry on the Mefloquine Issue (1998). The author at once mentions, then quickly dismisses the need for further research by DND, stating: "Further investigation is warranted before any firm conclusions about the role of mefloquine in Somalia can be drawn", but adding: "Internationally recognized experts . . . have, however, stated that from what is published and known regarding the side-effects of mefloquine, the drug could have accounted for only a small proportion of the observed behaviour" (Kinsman, 1998: 2). There is no further mention elsewhere in the internal 
DND documents of any follow-up studies on the connection between mefloquine use and the events that took place in Somalia.

DND leaders seem more apt to blame the mission than the drug, for what transpired in Somalia. For example, Colonel Ken Scott states:

The Canadian mission to Somalia was a flawed one. There were members of the Airborne who developed side-effects related to mefloquine and the drug received a bad reputation amongst members of this group, being blamed for multiple problems. Some Canadian medical personnel on that mission alleged that mefloquine was responsible for impaired judgement in the Airborne personnel, that ultimately led to the killings of Somali citizens by Canadian military personnel. The allegation was that this drug produced subtle neuropsychiatric disturbances. These claims were not supported by the available literature. (Scott, 2002: 1)

It should be underscored that DND went from a position that further investigation was needed to understand mefloquine's role in the tragic events, to dismissing the role of mefloquine, altogether, without actually conducting any further investigation. DND was asked to account for the fact that the MSEP was not followed when mefloquine was used in the deployment to Somalia. One spokesperson explained: 
DND had participated in the mefloquine Safety Monitoring Study since 1991. In September 1992, because of the operational requirements and with the risk of contracting malaria outweighing the potential side-effects of mefloquine, DHPP (the Surgeon General Branch directorate responsible for establishing immunization and preventative medicine policy for the CF) authorized the use of mefloquine in Somalia without obtaining the written consent of members and therefore outside the parameters of the Safety Monitoring Study. In doing so, it was the belief of the Surgeon General's staff that Health Canada was aware of the procedure. (Vaillancourt, 1997: 3)

However, as noted above, Hoffmann-La Roche and Health Canada both vow that DND was not supplied mefloquine outside of the auspices of the study at that time. The 1999 Report of the Auditor General affirms that the Department of National Defence did not comply with the conditions of the study, and that this was a case of inadequate monitoring with respect to a pre-licensed drug (Auditor General of Canada, 1999).

\subsubsection{The Trials and Tribulations of Mefloquine Use}

This sub-section looks in depth at the Canadian controversy surrounding mefloquine. Specifically, it gleans over information from reports of Canadian public hearings about mefloquine, questions raised in the House of Commons, and media reports on the drug.

Mefloquine was the subject of three major public inquiries: the Somalia Commission of Inquiry (DND, 1997), the Auditor General Report (Auditor General of Canada, 1999), which were both discussed above, and lastly, the Standing Committee on Public Accounts Hearing (Maria, 1999). This last public hearing, some of the transcripts 
of which will be presented below, dealt specifically with the pre- licensing use of mefloquine by DND and Health Canada. It exposes the difficulty of defining risks and benefits when it comes to pharmaceutical drugs, and provides example of the avoidance of blame in bureaucracies.

It is stated in the opening remarks of the hearing:

DND officials told [the court] that the reason they did not follow the protocol was that they believed that they had received authorization from Health Canada to follow a different set of procedures ... However this was not the case. No such approval had been sought or obtained by National Defence. (Maria, 1999: 2)

The transcript of the hearing is fraught with finger pointing and filibusters, with very little accountability or admission of any wrongdoing. At one point during the trial, a high ranking representative of DND (a Brigadier General) was asked to comment on the fact that Corporal Scott Smith was forced to take mefloquine in Rwanda, despite having complained of neuro-psychiatric troubles when he took it in Somalia. In response, the Brigadier General stated: "I have to admit that I'm not aware of the detail of the person or the member that you are referring to. So I regret that I cannot really comment on that". While this Brigadier General asserts that he does not know the details of this case, it is very hard to believe that such a high-ranking official would not have heard some details of one of the most public cases of suicide in the Canadian military!

Two issues are raised in the SCOPA hearing transcript that are tangential to the trial at hand, but central to this study. The first important revelation is that there is no clear definition of, or formula for, undertaking a risk-benefit analysis when it comes to 
the safety of a pharmaceutical drug. The following dialogue between a Member of Parliament (M.P.) and a representative of Health Canada (H.C.) clearly shows this:

M.P. Could you tell us how you decide in Health Canada what the value is of a risk and how you determine this? [...]

H.C. We require a significant submission from someone who wishes to market a drug that contains the results of many scientific studies; studies for the safety of the drug but also the clinical trial data. We review it. The review process takes many months and sometimes longer. What we are attempting to determine is that the product conveys a benefit of some type and that the risks that taking the product present are not greater than the benefit.

M.P. Okay, so $51 \%$ of the people are affected in a positive way. .. and $49 \%$ in a negative way. .. that drug's approved?

H.C. I'm not sure that wouldn't be just a little too close [...]

M.P. I'd like to know approximately what risk? How do you determine what the risk level is? You said the risk on this one is good enough. ... So tell me, how you decide that.

H.C. It would be a case of determining the statistics that were involved in what the benefit was. . against the probability of there being side-effects or serious side-effects within it. ...

M.P. But you're not willing to give me any figures of what this ratio is. What was it with this drug, then? 
H.C. I don't have the data . . we could put together a paper that would lay out in this particular case ... the probability of contracting malaria in a particular situation against the probability of the side-effects that might arise. It's compounded, if you like, by whether or not there are other drugs that might be used in similar situations ... It also depends on what the diseases are .... So, it's very difficult to answer your question in general because it depends. (Maria, 1999: 21-22)

The Chair cut off the discussion, because it had surpassed the allotted eight minutes. The second revelation is that there are no standardised procedures for monitoring clinical trials at Health Canada. One representative of Health Canada states that its mandate is to oversee clinical trials. By this, he means that Health Canada requires that all adverse reactions occurring in the context of a clinical trial must be reported to them, and that they have the power to stop a trial if they see problems arising. But they do not systematically make sure that this takes place, nor do they have any systematic way of auditing the trials, as avowed in the following quote by a representative from Health Canada: 
We do not have in place now and did not have in place then a system to audit clinical trials. ... What is being suggested I think by the auditor general's office is that we ought to have in place a standard audit process where on a regular basis we follow up, perhaps on a random percentage, the clinical trials which are taking place. So you're moving from a situation where we would act if we knew that a problem had arisen to a situation where we act on a continuous basis, whether there is an indication of problem or not. Perhaps we should have been auditing clinical trials in the past. The problem is one of resources and priorities. (Maria, 1999: 26)

It seems obvious that auditing clinical trials would be one way of achieving the Health Products and Food Branch's first mandate, which is “minimizing health risk factors to Canadians while maximizing the safety provided by the regulatory system for health products and food". ${ }^{33}$

In sum, the Somalia Commission of Inquiry, the Auditor General Inquiry and the Standing Committee on Public Accounts Hearing all concluded that, although DND was a partner in the clinical study of mefloquine, they failed to meet the requirements of the study. However, there was no accountability on the part of DND, nor any attempt to make amends (i.e., by following through with the study of mefloquine that was planned). In a broad sense, these trials highlight how difficult it is to define accountability when dealing with the safety of a pharmaceutical drug. They also highlight the impersonal, yet

\footnotetext{
${ }^{33}$ Health Canada, Health Products and Food Branch, http://www.hc-sc.gc.ca/ahcasc/branch-dirgen/hpfb-dgpsa/index_e.html (last accessed September 22, 2005).
} 
rational and effective way, that human tragedy can be dismissed in a bureaucratic context. This is also dismissive of the risk factor for the general population.

Mefloquine was also the subject of a number of in-depth investigative reports in Canada (e.g., Canadian Broadcasting Corporation (CBC), 1998; Canadian Broadcasting Corporation (CBC), 2003; Canadian Television Network (CTV), 1997; Gartner, 2002; Pugliese, 2002; Tremanti, 2004). These reports dealt with a number of mefloquinerelated issues, such as: the events that took place in Somalia; the safety of mefloquine, in general; cases of suicide among military personnel; and adverse reactions among military members. They often coincided temporally with major public hearings and inquiries. As noted elsewhere in this study, mefloquine also figured prominently in the media in the U.S.A.. Two investigative journalists, Dan Olmsted and Mark Benjamin, of the United Press International (UPI), were actively involved in research on mefloquine for the past five years. Their work, for instance, demonstrates that the connection between mefloquine and suicide is well documented in the FDA files (Benjamin and Olmsted, 2002a: 1). Moreover, their research shows that quinolone drugs, of which mefloquine is one, can cause homicidal or suicidal rage (Benjamin and Olmsted, 2002a: 1). Benjamin and Olmsted also produced reports on the connection between mefloquine use and the murders of three women in Fort Bragg, North Carolina, by military personnel who had returned from Afghanistan and had been given mefloquine (Benjamin and Olmsted, 2003).

Mefloquine was the subject of a documentary film entitled Taken as Directed (Lese, Gregory, and Rose, 2005). The film identifies numerous individuals who have committed suicide while on mefloquine, and provides an in-depth look at five cases of 
individuals suffering from 'Lariam toxicity', a blanket term used when discussing the long term effects of mefloquine, such as vestibular damage (balance problems, shaking hands, ringing in the ears), psychological problems (such as hallucinations, anxiety, rage, depression and suicidal ideation or suicide attempts). A number of important points are raised about mefloquine in the film. The mother of a teenager who is suffering from mefloquine toxicity mentioned a very serious and important point. She said that after much perseverance on her part, Hoffmann-La Roche did finally admit that mefloquine could cause "serious neurological events" (she recommends that they should call this what it is: brain damage). However, they cannot tell her how to cure or reverse these problems, nor can they give her any answer as to how long these problems will likely last. This is in stark contrast to the affirmation on the product monograph (as discussed above) that serious reactions are usually short lived.

As noted above, mefloquine was also the topic of the season finale of the television drama Law and Order Special Victims Unit, in which the central character returns from Afghanistan, brutalises and kills his wife and then commits suicide. The show's premise is that the anti-malarial drug that this character had been required to take while serving abroad was the cause of the violence and suicide. This episode of Law and Order appears to have been taken directly from Olmsted and Benjamin's investigative journalism reports.

\subsection{Reflexivity in Action}

Unofficial information about mefloquine has proliferated over the Internet since the early 1990s. Much of the alternative information about mefloquine-i.e., small-scale 
clinical studies; symptoms and treatment for mefloquine toxicity and vestibular damage; and personal accounts - was posted on the Internet by individuals who experienced a serious adverse reaction to mefloquine. What follows are some examples of this layexpertise and advocacy on the topic of mefloquine safety. It should be noted that the following were selected because they are examples of lay-expertise and because they provide information that runs counter to that which was summarised above, i.e., that mefloquine is the drug of choice for preventing malaria in all chloroquine-resistant areas of the globe. In other words, these are a biased sample of 'blogs', created by individuals who have experienced a negative reaction and want to share their experience and their knowledge. These 'blogs' are presented to show how counter-knowledge is created and circulates. The following chapter presents a more balanced outlook of weblogs, and indicates the various reasons why people might be compelled to 'blog' on mefloquine.

Martha K. Holder, a primatologist from Indiana University, writes:

I suffered severe and debilitating side-effects after taking Lariam ${ }^{\circledR}$ in 1992 in Uganda. After returning stateside, I posted an e-mail regarding Lariam $\circledast$ to a primatological newsgroup in 1995 ; these comments were subsequently archived and popped up when individuals did Internet searches on "Lariamß", so I inadvertently became an international clearing house for people suffering longterm side-effects seeking information. I post this page as a starting point for research. $^{34}$

\footnotetext{
${ }^{34}$ M.K Holder, Lariam Information http://www.indiana.edu/ primate/lariam.html (last accessed 15 December 2005).
} 
A counter on Holder's webpage indicates that 118,517 people have visited it since June of 1997. "Sheldon", a marketing researcher and back-packer, created his own Lariam ${ }^{\circledR}$ information page, which also allows individuals who visit his site to post weblogs. He writes:

I think I can safely say that my worst experience was the chemically induced torture I endured in West Africa during 1995/6 while taking the anti-malarial drug Lariam ${ }^{\circledR}$. . . Lariam ${ }^{\circledR}$ made me very sick in the middle of West Africa, but I didn't know the cause of the sickness. All the doctors in West Africa misdiagnosed me and I got worse ... In desperation I abandoned my "trip of a lifetime" and flew to London. Finally, the Hospital For Tropical Diseases diagnosed my illness. Mefloquine toxicity ... It took the best part of ONE ENTIRE YEAR to properly dissipate the effects of Lariam ${ }^{\circledR}$ from my body . . .. Although all of the Lariam ${ }^{\circledR}$ support groups do a fantastic job getting media exposure about the mefloquine controversy, knowledge about mefloquine and its side-effects amongst Western medical professionals unfortunately appears to remain poor. Because of this many mefloquine sufferers are forced to go at it alone and research the potential cause of their illness by themselves. I hope that the this site helps them find out more about 'Lariamitis' and helps them realise that they aren't going crackers, and hopefully gets them in contact with a support group in their own country. ${ }^{35}$

\footnotetext{
${ }^{35}$ Sheldon, My Bad Lariam Story, http://www.geocities.com/TheTropics/6913/lariamlinksf.htm (last accessed 26 July 2006).
} 
Anne T. Merriman writes:

I awoke suddenly from a terrible nightmare with sweat beading down my forehead. My sleep was haunted by terrifying visions and my days were plagued by anxiety and restlessness. I thought I was suffering a nervous breakdown in the middle of Tanzania, East Africa. Apparently, I was not alone. My African adventure turned sour as a result of a drug I was taking to ward off malaria ... The drug, Lariam ${ }^{\circledR}$, was recommended to me by the U.S. Centers for Disease Control without mention of the side-effects. I and 15 of my companions suffered: nervousness, anxiety, nightmares, and dizziness -- just to name a few. I stopped taking the Lariam $®$ in favour of a European antimalarial combination-Paludrine plus Chloroquine - upon the advice of a doctor from East Africa. My discomforts immediately ceased. ${ }^{36}$

These are only three examples of the growing number of lay-experts on the subject of mefloquine. A search using the Google ${ }^{\mathrm{TM}}$ search engine (www.google.com) for the word "mefloquine" uncovers approximately 29,900 hits; about half of these include narrative accounts of severe reactions, or 'weblogs' about the drug.

The growth of lay expertise on mefloquine included the formation of advocacy groups such as 'Lariam Action', ${ }^{37}$ whose mandate is to provide information on the risks associated with mefloquine, to allow people who have suffered adverse reactions to share their experiences and to lobby for changes in the regulation of pharmaceutical drugs. In

\footnotetext{
${ }^{36}$ Anne T. Merriman Readers Write The Malaria Debate, http://www.travelassist.com/mag/rw007.html (last accessed 26 July 2006).

${ }^{37}$ See www.Lariaminfo.org
} 
fact, the work of 'Lariam Action' and the U.P.I., led, for example, to changes in the American product insert by Hoffmann-La Roche. In the eyes of drug regulators, these advocates and the people who suffered adverse drug reactions are often dismissed as "interest groups [that] can amplify and mobilize risk perception" (Vertinsky and Wehrung, 1990). However, in the longer term, they can effect changes in the health system. Moreover, these lay-experts clearly have a role to play in the democratisation of knowledge on mefloquine, and in the reflexivity of scientific knowledge on risk: that is, to supplement the official discourse on mefloquine with subjective knowledge; to foster further research on the question of mefloquine safety; and to enable individuals who are suffering from mefloquine toxicity to get the support and treatment needed to cope with their problems. ${ }^{38}$

\subsection{Chapter Summary and Discussion}

Malaria is a serious disease. It leads to one million deaths annually. A spectrum of drugs is needed to prevent the transmission of the parasite. Mefloquine is an effective weapon in the arsenal used to combat malaria. These are the usual messages of public health agencies like the WHO, the CDC, and Health Canada. Granted, mefloquine may be effective in preventing malaria in areas of the world where the parasite is resistant to chloroquine, but at what cost? In assessing the available research on the safety and tolerability of mefloquine, it seems that anywhere between 1 in 13,000 (Canadian

\footnotetext{
${ }^{38}$ I use the term 'lay-experts' to mean individuals who may or may not have any scientific training but who have expertise in an area of scientific knowledge. In this paper I refer to the lay-experts who have gained expertise on the statistics of prevalence rates of adverse reactions and on knowledge regarding anti-malarial drugs.
} 
Pharmacists' Association (CPA), 2002) to 42 per cent (Overbosch et al., 2001;

Schlagenhauf et al., 2003) of people who take it will be afflicted with a serious neuropsychiatric adverse reaction that will prevent them from carrying out their daily activities. At this time, the precise incidence of these events remains unknown. The official statistics are extrapolated from data of spontaneous reports of adverse reactions and estimated sales figures. Randomised, double blind, clinical studies of mefloquine tolerability are lacking. On this point, Dr John Gueriguian, a former FDA scientist, said that the laws governing the FDA stipulate that a drug must be tested on the populations and under the conditions for which it is indicated. To his knowledge, Hoffmann-La Roche never conducted this investigation for mefloquine (Lese, Gregory, and Rose, 2005).

The review of Canadian knowledge on mefloquine also revealed some loopholes and gaps in the work done by Health Canada to ensure the safety of new drugs. Transcripts from public hearings revealed that Health Canada does not oversee clinical trials of new or experimental drugs, nor does it have a systematic, statistical or other way of defining risk benefit analysis when it comes to the safety of pharmaceutical products.

The uninformed traveller who walks into a travel medicine clinic, or military member who gets posted in a malarial country, is usually unaware of the potential sideeffects of mefloquine. Moreover, those afflicted with mefloquine toxicity, or those who suffer severe reactions to the drug, are often in the dark about the cause of their symptoms, and continue taking mefloquine. Once they learn that mefloquine is the cause of their troubles, they remain in the dark as to how long their symptoms will persevere and how to get rid of them. The manufacturer of the drug cannot even answer these 
questions. Meanwhile, the tremendous amount of unofficial knowledge or lay-expertise about mefloquine can offer some comfort to those who suffer from adverse reactions to mefloquine and who cannot find answers or support from the mainstream medical establishment. The question that remains unanswered is whether or not these mainstream health institutions learn and grow from these forms of lay expertise.

The pages above presented an amended rendition of the historical and political interests behind contemporary 'official' knowledge about mefloquine and malaria. They show that the drive to battle malaria during the early days of the development of antimalarial drugs in general, and mefloquine in particular, by Western industrialised countries (most notably Canada and the U.S.A.), came about as a result of colonial and military imperatives. Today, individuals from Western industrialised countries continue to travel to malaria-endemic parts of the world, in the context of military deployments, humanitarian efforts, natural resources exploitation, or for pleasure. Anti-malarial drugs are developed in the West for these pursuits. The existence of mefloquine and other Western-developed anti-malarial drugs does nothing to meet the objective of malaria eradication where it is most dangerous and endemic: in sub-Saharan Africa. The majority of antimalarial drugs developed in Western industrialised countries are, overall, inappropriate and financially out of reach for those who need them most.

While this chapter focussed on secondary data sources to summarise the history of mefloquine use in Canada, the following chapter presents an overview of findings from the primary data sources. Interview, survey and weblog data show the following: how various individuals from different walks of life evaluate the risk of malaria; the availability of health information; and the safety of mefloquine. 


\section{Personal Narrative \#4 - Workplace Safety Insurance Board Documentation}

What follows is an excerpt from a letter written by my supervisor to the Workplace Safety Insurance Board (WSIB) and a memorandum that I wrote about my experience with mefloquine. These two documents were necessary because I had been placed on 'paid leave for medical reasons' and documentation was required by the $W S I B$, in order for my employer to recuperate my wages (see Appendix I for the full text of these documents). This official documentation makes me the first Canadian civilian in the Department of National Defence's history to have been injured while on duty in a military theatre.

"As part of her duties Ms Ford was required to undertake the immunization protocols to permit her to travel to Africa... The anti-malaria drug mefloquine is part of the prescribed suite of immunizations... The site visit was conducted without incident from 15 to 18 March 2001 .... On April $7^{\text {th }}$, Ms. Ford experienced a severe psychological reaction to mefloquine and had to be involuntarily committed to the Psychiatric Unit of the Ottawa Civic Hospital.... Once Ms. Ford's situation was understood, her employer took steps to place her on "Injury on Duty Leave With Pay" in accordance with Article 18.18 of the 'Defence Scientist Employment Agreement'.'”

Re: $\quad$ Mefloquine Madness

I still remember many of the delusions.... At one point, I thought that I was preparing for a DND experiment in which I would be sent to Mars. Later, I imagined that I had to go to the Supreme Court to participate in an experiment to halt the spread of 
HIV. This is when I actually got out of my hospital bed, got dressed and attempted to leave the hospital... A nurse gave me a tranquiliser and I slept.

(...) As a DND Defence Scientist, I feel that it is my duty to warn the military of the unnecessary danger to which it seems to be exposing its troops and surrounding civilians (i.e., can you imagine what might have happened if I were an infantry soldier in possession of a weapon during that episode?). I would also like to request an indefinite period of leave, so that I may fully recover from this traumatic incident.

Over the course of conducting research, I submitted numerous requests to the Access to Information office of the Department of National Defence, for "all documents including personal correspondence and internal memoranda pertaining to mefloquine". I never received any of these documents. Moreover, there are other documents that I was told about 'off the record', which I could not access officially. This can be seen as an institutional means to silence dissenting voices and maintain control over information. So much of what goes on under the guises of 'risk management' seems to proceed this way: things stated off the record, without leaving any paper trail, so that there can be no accountability. Is this 'the' trouble with risk management thinking: the inability to hold anyone accountable? 


\section{Chapter 5 A Cacophony of Voices}

This chapter presents the results of interview, survey, and weblog analysis. It should be noted that this chapter simply lays the groundwork for a more fruitful analysis, which is provided in chapter six. As such, the following pages offer a synthesis of the raw materials collected from the various data sources. More in-depth analysis, which builds upon the theory, is presented in the following chapter.

The findings are organised under key headings, which were derived from a thematic analysis of the data (as described in Chapter Three). The final section of the chapter examines the Health Canada database to determine, when possible, if 'serious' reactions that have been described in weblogs and in interviews are recorded there. ${ }^{39}$

As discussed throughout Chapter Three (the methodology chapter), these findings are meant to represent the many, and, at times, dissenting viewpoints and voices that mingle and communicate on the topic of malaria prevention and the safety of antimalarial drugs. As such, the multi-method approach is not used to validate the data, but rather, to reveal different perspectives, thereby highlighting the contradictions that exist in health care policy and practice. Ultimately, these multiple forms of data expose how subjective knowledge is marginalised from the process of pharmaceutical drug regulation, and the simultaneous need for greater citizen involvement in this process.

\footnotetext{
${ }^{39}$ The definition of a 'serious' reaction is one that causes prolonged hospitalization, severe disability or death. This is the definition used by Health Canada and the WHO. Unexpected reactions (those that are not included in the CPA, (2002) list of common side-effects, were also included.
} 
The following chapter takes these raw findings and illuminates the power dynamics and strategies employed by each of the different 'stakeholders' to actualise their power.

\subsection{Interview Participants. . Who Are They?}

The majority of interview respondents have, in some way, been personally affected by mefloquine. Five out of eight of the subject-matter experts are, or have been, involved in some form of mefloquine-related activism, or public activity. The preceding chapter introduced the notion that personal experience has led to a growing mass of layexpertise about the potential negative effects of mefloquine. The following discussion explores how personal experience led to public action, for some of the interview respondents.

One respondent, a female academic, maintains an educational website on mefloquine - the first of its kind on the Internet. ${ }^{40}$ She describes how, after experiencing serious and debilitating adverse reactions to mefloquine while conducting field research in Africa, she unintentionally became a global expert on mefloquine:

${ }^{40}$ See footnote 34 (above). 
Upon return stateside several months [after my reaction], I posted a warning about [mefloquine] to a professional ... news group. Later, these archival e-mail postings were made public via the then-new HTML web page format, so that when anyone searched for 'Lariam ${ }^{\circledR}$ ', my e-mail popped up as a web page, so people worldwide felt free to contact me. I thus inadvertently became a sort of global clearing-house for people suffering from severe side-effects of the drug. What moved me to post and maintain online information on mefloquine was that I know of several people whose debilitating side-effects (they had to quit professional careers, move in with their parents or have spouses care for them) have not [yet been] resolved, even years later. Even if this only occurs in a fraction of a percent of consumers, there is clearly something going on with mefloquine that researchers need to understand, and consumers need to be informed of risks of this magnitude, however rare. While I am not formally affiliated with any action group, the web page that I maintain [which is linked to the 'Lariam Action' Group's web page] provides lay people and medical professionals alike easy access to the published medical and research articles concerning mefloquine .... The page has been accessed 85,269 times between June 1997 and January 2004, suggesting [that] it has some usefulness. (Interview Respondent 1.3, female, academic)

As noted in the previous chapter, and not surprisingly, it is often the case that those who are most outspoken about the possible adverse effects to mefloquine have themselves experienced one. What is remarkable is that these activists have created the most up-to- 
date, and often the only, available information about potential reactions and mefloquine toxicity.

Another interview respondent took mefloquine in 1994 and again in 1997 for travel to Africa. He suffered very serious adverse effects, in the form of paranoia, lesions on his scalp and head, sleep deprivation, ringing in the ears, hallucinations, anxiety and abnormally high levels of aggression. He was convicted of robbery in 1998, for robbing an automatic teller machine (ATM) and shooting at security guards. Prior to the interview, he had already served six years of jail time for his crime. He offered a detailed account of this crime in the interview, which took place two days before his parole hearing. He ended by discussing how his defence would be precedent setting:

The National Parole Board is a political organization. [I] don't know how this will turn out. They might reject the Lariam ${ }^{\circledR}$ defence altogether. We'll be very vocal. It's the first time ever that they have been presented with Lariam $($ as a defence. So this is unusual, it could be precedent setting. The worst-case scenario is that I will stay on day parole. (Interview Respondent 1.4, male, student)

Two days later, Corrections Canada did, indeed, officially recognise that mefloquine played a role in the crime; it was ruled that it was a contributing factor, and he was granted full parole. ${ }^{41}$ While this interview respondent was not directly involved in any form of activism (although he did mention that he was looking into the possibility of

${ }^{41}$ For more details regarding this case, see Jason van Rassel "Brinks bandit freed on parole -- Patrick Ryan insists he's 'a decent fellow'" Calgary Herald, Thursday, April 22, 2004. 
reviving the then-defunct 'Lariam Action Canada'), he inadvertently became a public example of the serious impact that mefloquine can have on individual psychology and on the judicial system. Reporter Jason Van Rassal (2004: A1) writes, that the verdict of his parole hearing "was a precedent-setting acknowledgment of his claim that the drug, Lariam ${ }^{\circledR}$, caused [...] a 'Jekyll and Hyde' transformation'.

Media stories about adverse effects of mefloquine can lead others to take a personal interest in the medication, and become involved in some form of public action. This was the case for a Canadian Member of Parliament who has been active in debating the safety of mefloquine in the House of Commons, tabling questions for the Minister of National Defence and Health Canada on the risks associated with mefloquine. He and his staff became interested in the drug after reading about the story of a military member who was court-marshalled for the torture and murder of the Somali teenager. This individual subsequently attempted to commit suicide, and his attempted suicide has left him paralysed. He and his family members have always maintained that mefloquine was at the root of the events that took place in Somalia. When asked about the M.P.'s personal interest in mefloquine, a member of his staff explained:

An article in the Saturday Night Magazine about Carl Browning fascinated [the M.P.]. He wanted to see whether this man had been mistreated. He phoned [the Department of National Defence DND]. [Someone at] DND said that mefloquine may have been implicated [in the Somalia events and related events that followed]. M.P.s all have a rescue mentality. (Interview Respondent 5.8, male, representative of Parliament) 
When speaking about their effort, the representative of Parliament stated: "We raised questions in Parliament. They have been answered over time. [Eventually this] led to Health Canada demanding answers from Hoffmann-La Roche. If you look at dates, you can see that our questions had an impact" (Interview Respondent 5.8, male, representative of Parliament). ${ }^{42}$ As noted in Chapter Four, this effort had important consequences for the status of mefloquine and led to changes in the Canadian product insert, for instance.

Two other interview respondents became involved in Lariam ${ }^{\circledR}$ education and advocacy as a direct result of a close friend's serious reaction to the drug. The remaining interview respondents were sought for their expertise in medicine or in regulatory matters. One is a medical doctor with extensive experience in travel medicine, and the other two acted as advisors to Health Canada, on matters related to the regulation of pharmaceutical drugs.

In sum, the interviews showed that those who are involved in health advocacy related to the safety of pharmaceutical drugs have usually, either directly or indirectly, experienced an adverse reaction. The following section presents respondents' views on the safety of mefloquine.

\subsubsection{Interview Participants Address the Safety of Mefloquine}

The interviews with respondents focused on the safety of mefloquine and its potential health concerns. Prior to the agreeing to participate in the interview, two of the respondents (the two Health Canada advisors) had no knowledge at all about mefloquine.

\footnotetext{
42 To see documentation pertaining to the questions raised about mefloquine in the Canadian House of Commons, see http://www.johncummins.ca/jcdocs.htm
} 
One even admitted to doing a quick Google ${ }^{\mathrm{TM}}$ search just prior to their interview! For this reason, their responses are not included in this section. These two respondents were, on the other hand, very informative regarding the process of drug regulation on the whole. The remaining respondents gave very detailed accounts of the health concerns associated with mefloquine. One interview respondent had extensive first hand knowledge of cases of 'mefloquine toxicity' and 'chemical brain damage', for instance. She described these ailments in detail as:

Severe mental health problems, including frank psychosis, suicidal ideation, suicides, homicides. Vestibular damage or brain stem damage: damage to balance system, $8^{\text {th }}$ cranial nerve: dizzy, off balance, unstable gait, sensitivity to visual stimuli, anxiety or panic due to vagal nerve over stimulation, a host of cognitive and psychological side-effects. This damage can be permanent. It may take 7-10 years for people to start to get better. Other brain damage: I call it chemical brain damage: includes memory loss, confusion, and slurred speech, and can last for years. (Interview Respondent 1.2, female, member of an advocacy group)

She added: "The brain does heal, but it takes time...". This same respondent outlined one very serious case of mefloquine toxicity: 
One child (14) lost the ability to read. One day, after taking the drug, the pages in front of him just made no sense-it was like trying to read Arabic. He taught himself to read again, starting with pre-school books. He spent one year doing rehab. at an acquired brain damage institute. He is in college now but still has some difficulty with reading. (Interview Respondent 1.2, female, member of an advocacy group $)^{43}$

Anther interview respondent challenged the manufacturer's safety research, and alluded to their negligence in failing to warn consumers about the potential long-lasting harmful effects of the drug, affirming:

The potential negative side-effects of mefloquine have proven to be both more severe and more frequent than the early clinical trials predicted (as documented in many research findings). Despite clear documentation of this, the manufacturer, Hoffmann-La Roche, has failed to implement timely and consistent changes in its product fact sheet (which varies from country to country). Debilitating sideeffects are disruptive and can have real costs associated with them. But sideeffects that include long-term or permanent change to the neural system or that lead to suicidal states, no matter how rare, should (a) lead to additional medical research, and (b) be included in the product fact sheet and prescribing physician warning to consumers. (Interview Respondent 1.3, female, academic)

Another challenged the commonly-cited incidence rates, claiming:

\footnotetext{
${ }^{43}$ This individual was featured in the documentary film "Taken as Directed" (Lese, Gregory, and Rose, 2005).
} 
Mefloquine has been shown by two double-blind studies (Overbosch 2001, Schlaugenhauf 2003) to cause neuropsychiatric side-effects in 29 to $42 \%$ of those who take the drug. The WHO and [Hoffmann-La] Roche issued a report on such effects in 1991. There are a host of physical effects as well that have never been researched anywhere, because [Hoffmann-La] Roche has whitewashed the drug so completely in the eyes of physicians all over the world. Even though the product label has been updated countless times to even include suicide [for the U.S. label], these warnings go unheeded and the drug is still prescribed it to tourists, the military, etc.. (Interview Respondent 1.1, female, member of an advocacy group)

Another interview respondent provided a detailed first-person account of his adverse effects, insisting:

All I can say is that I feel like I am beginning to wake up from a ten-year coma. I am coming out of this... It's only in 2002 that I began to be cognizant of reality again. At times I want to forget it all. Did my life change because Lariam ${ }^{\circledR}$ or not? Just to give you some background, I graduated from the university of Regina, did some time in the military, had a good job managing a doctor's office. Then I went to Africa. After that point I just couldn't get my life back together again. I couldn't read, I couldn't focus... I had a Jekyll and Hyde syndrome. Looking back now, I just can't believe what's gone on.... (Interview Respondent 1.4 , male, student) 
In comparison to the listed above, a medical doctor gave a more brief description, stating simply: "Like any drug, it has side-effects. It can cause seizures. It should not be taken by people with history of depression or seizures. It has been linked to suicidal ideation. More commonly, it causes sleep disturbances or vivid dreams" (Interview Respondent 3.12, female, medical doctor).

What was most noteworthy in their accounts of the health concerns associated with mefloquine, is the opinion held by some interview respondents, that the drug is a good treatment for malaria, but that it is too toxic to be used as a preventative. In one interview respondent's words: "It should be reserved for treatment only of malaria. In my opinion it should not be used for prophylaxis because of its side-effects" (Interview Respondent 1.1, female, member of an advocacy group). Another expanded upon this idea, adding that mefloquine is not a true preventative, but rather a very early treatment, and noting that the dosage of mefloquine seems to been adjusted in a cavalier manner. She explains: 
It's too toxic to be used for prophylaxis. It may be a good cure. From 1989 to 1991, it was prescribed every 2 weeks instead of once a week. Based on very weak scientific evidence, the CDC requested that the dose be doubled and the FDA agreed. The FDA had efficacy data, but no safety data, yet they went ahead and doubled the dose.... It's not a true preventative. It kills the parasite after it has left the liver, so the parasite does not multiply and make you sick. So really, mefloquine, even when given as a prophylactic, is acting as a treatment for a very early stage of malaria. That's why you have to keep taking it for 4 weeks after you've left the malarial country to make sure you've killed off any malaria parasites you might have picked up, despite taking the drug. (Interview Respondent 1.2, female, member of an advocacy group)

In contrast to the above statements, however, one medical doctor strongly supports the use of mefloquine for prophylactic, stating: "It is a very good drug for those who can tolerate it!" She added that improved screening has reduced adverse reactions, stating:

It is very effective, and not expensive. Interestingly, when studied in controlled settings, placebo groups also complain of side-effects. The early literature said that 1 in every 13000 experience serious psychotropic reactions. However, now, many of these people would not even be given mefloquine, because they have a history of depression, seizures, etc. It is important, also when considering cases of suicide to compare suicide data by mefloquine takers to the general population. (Interview Respondent 3.12, female, medical doctor) 
This same interview respondent noted a shift in Health Canada's position, instead of promoting mefloquine as the drug of choice for use in all chloroquine-resistant endemic regions; they are now formulating new guidelines that speak of three "first line of defence drugs":

Health Canada will post new guidelines for Canadian travellers for the prevention of malaria on their website. These new guidelines will have myths about malaria and also more complete information about the three "first line drugs" mefloquine, malarone and doxycycline. These three drugs are all between 90 and $95 \%$ effective. (Interview Respondent 3.12, female, medical doctor)

Interview respondents were also asked about health concerns with other antimalarials. One respondent commented:

The historical trend is that, as strains of malaria become resistant to existing antimalarials, the newer generations of anti-malarials that are developed tend to have more negative side-effects. There are no easy answers to health concerns because of the complexity of the interactions: (a) all medications have potential sideeffects, (b) strains of malaria are variously resistant to various anti-malarials, (c) life-style practices (such as alcohol consumption) of individuals affect drug efficacy and safety, (d) individuals vary widely in their sensitivity to medication, their existing medical conditions, their current drug consumption, their size (a dosage standardized for a 180-pound male may be inappropriate for a 100-lb. female), etc.. (Interview Respondent 1.3, female, academic) 
The medical doctor clarified with a succinct account of adverse reactions to the two other commonly prescribed anti-malarial drugs:

Doxycycline: sun sensitivity, yeast infections, gastro-intestinal irritation. Can not be taken by pregnant women or by young children. Must be taken every day. Malarone: generally very well tolerated but expensive. (Interview Respondent \#3.12, female, medical doctor)

To sum up, all but two interview respondents gave detailed accounts of the health problems associated with mefloquine. In most cases, their accounts detailed higher incidence rates and more serious problems than those cited in the mainstream literature (as discussed in Chapter Four).

\subsubsection{Interview Participants Describe Drug Regulation}

This section summarises the interview data pertaining to the process of pharmaceutical drug regulation in Canada. As noted above, some of the 'key informants' were selected because of their expertise in this area. They provided detailed accounts of the processes involved in pre- and post-marketing drug regulation in Canada, and outlined the roles of various factors involved in the processes.

Hughesman (2004), identifies the four stages of the drug development process as follows: discovery and early research; pre-clinical testing; clinical trials; and approval and post-marketing testing. Interview respondents were asked to discuss the premarketing and post-marketing regulation of pharmaceutical products in more detail: Are you aware of the process by which a drug goes from testing to approval for sale in 
Canada, and if so, can you describe it? One interview respondent described each of the "three phases of pre-approval and pre-marketing tests for new drugs", as follows:

Phase 1: A scientist discovers a new molecule and speculates that this might have therapeutic properties (this can be done in vitro). Research labs in universities and pharmaceutical companies are involved in this process. The first step is to test for toxicity. This is done using a small sample of subjects [humans].

Phase 2: Once it has been established that the product is not toxic, tests for the effects of the product are conducted. This involves a larger sample.

Phase 3: [This phase] is used to validate the findings regarding the properties and effects [of the chemical]. This is done using a much bigger sample, and involves statistical tests, it can involve a placebo, it usually involves double blind study. It is very important to note that in this pre-marketing evaluation of safety, all parties involved are compelled by law to report toxicity or adverse reactions. (Interview Respondent 5.2, male, Health Canada advisor)

Two other interview respondents described much the same process, overall, in some cases adding an initial phase involving tests on non-humans. Therefore, at least three of the Canadian interview respondents are generally well-informed on the process of drug regulation, and gave detailed accounts of the processes involved. ${ }^{44}$

When asked about post-marketing surveillance of drugs in Canada, in the following question: Are you aware of the process by which the safety of pharmaceutical

\footnotetext{
${ }^{44}$ American interview respondents were knowledgeable regarding the American system, but did not wish to comment on the Canadian system.
} 
drugs is monitored in Canada (once the drug has been approved)? - one interview respondent stated:

[Medical Doctors] are expected to report adverse reactions to Health Canada and there is a mechanism in place, but they are not required to do so [by law]. Therefore chronic under-reporting is a problem. (Interview Respondent 5.3, female, Health Canada advisor)

She added:

[It] occurs on different levels: Patients are expected to report adverse reactions to [doctors]; [doctors] are then expected to report to Health Canada. Pharmaceutical companies take calls from consumers; they are expected to report adverse reactions to Health Canada. Consumers can call Health Canada directly to report adverse reactions. Health Canada has a responsibility to report results-critical numbers of adverse reactions, but the databases are not public. There is no legislation in place (only processes and mechanisms) to ensure that adverse reactions get reported by consumers, M.Ds, [and] industry to Health Canada. (Interview Respondent 5.3, female, Health Canada advisor) ${ }^{45}$

Another interview respondent explained why this stage is so important in ensuring the safety of pharmaceutical products:

${ }^{45}$ In fact, the Canadian Health Act requires pharmaceutical companies to report all adverse reactions to their products, to Health Canada as soon as they become aware of them. 
Post-marketing surveillance is not a controlled study. This is the stage at which adverse reactions are determined. At this stage, it is possible to see how the drug interacts with all of the other drugs that patients might be taking concurrently, and to see real reactions to the drug. 'Purple Sheets' are filled out by medical doctors who have reports of 'rare'[and] 'severe' adverse reactions and spontaneous reactions. They send these sheets to Health Canada... Also, drug companies get direct spontaneous reports of adverse reactions by consumers. (Interview Respondent 3.12, female, medical doctor)

In other words, it is during this stage that spontaneous reactions can be recorded and the drug observed to determine how it reacts outside of the laboratory, with everyday use. The system in place to monitor this procedure is by no means flawless. Apparently, Health Canada acknowledges that, because the system is based on voluntary reporting, it is somewhat problematic, due to under-reporting. This was indicated by one of the Health Canada advisors:

[Medical doctors] are not required by law to report adverse reactions. Even serious adverse reactions can go unreported by physicians. Health Canada wants to improve this system of post-marketing surveillance and recognises that there is a serious problem. (Interview Respondent 5.2, male, Health Canada advisor)

One interview respondent noted that Health Canada's registry of adverse reactions should be public, stating: "Health Canada keeps a registry of side-effects. This should be made public. Some drugs are problem drugs and in some cases the problems are serious" (Interview Respondent 5.8, male, representative of Parliament). Despite the fact that the 
problem of under-reporting is widely discussed, no effort has been made to rectify this. However, as shown later on in this chapter, the database of adverse reactions is now accessible to the public in searchable form.

\subsection{2 a) Non/Government Factors in Drug Regulation}

When asked: Are you aware of any of the government agencies involved in the regulation of pharmaceutical drugs in Canada? If so, can you identify them and describe in your words what each of them does? One interview respondent spoke about the roles of Health Canada, the Department of National Defence (with respect to some drugs, most notably anti-malarials), the Canadian Institutes of Health Research, and the Food and Drug Administration (FDA), explaining:

Health Canada does post marketing surveillance; CIHR provides grants to researchers who are evaluating the drugs. These grants go to pharmaceutical companies or to researchers in universities; DND provides health care to its members, therefore they can follow up on reactions to and effectiveness of certain drugs. (Interview Respondent 3.12, female, medical doctor)

As such, this interview respondent believes that DND plays an important role in drug testing, because it can closely monitor the effects of certain health products that are given to military personnel. However, as discussed in detail in Chapter Four, DND failed to do this with respect to mefloquine, despite being officially involved in the early safety monitoring protocol for the drug. Another respondent discussed the role of Industry Canada, stating: 
[The] Health Products and Food Safety Branch of Health Canada issues drugs and provide approvals [it is also] involved in the process through to post marketing regulation; advertising and communicating information of adverse reactions. Industry Canada issues patents to pharmaceutical companies. (Interview Respondent 5.3, female, Health Canada advisor)

These two responses suggest that the processes involved in ensuring drug safety are politically complex and can involve a variety of different government agencies.

Interview respondents were in general agreement that Health Canada's job is to use objective measures to ensure the safety of health products. One Health Canada advisor noted: "Health organizations (WHO, HC, CDC) have experts who are knowledgeable and can work on these issues regarding safety. This is their job" (Interview Respondent 5.2, male, Health Canada advisor). A medical doctor clarified: “[Health] Canada uses 'evidence based guidelines'... based on scientific study, not just what drugs are available" (Interview Respondent \#3.12, female, medical doctor). However, as discussed in the previous chapter, when questioned during the Mefloquine safety evaluation protocol hearings, representatives from Health Canada stated that it was not their responsibility at all to monitor drug safety studies.

Another interview respondent spoke about the role of representatives in the House of Commons: "to hold government accountable. Health Canada as a statutory decision maker has a job to do...[to] hold the Minister of Health accountable" (Interview Respondent \#5.8, male, representative of Parliament).

The process becomes even more politically complex when one considers all other (non-governmental) factors that influence the processes of drug regulation. Interview 
respondents largely agreed that market forces and consumer demand are the greatest nongovernmental influences on the process, asserting, for example:

I worked with the regulatory department of a major drug company. I saw firsthand that the marketing department wages constant battle with the regulators about making claims of a drug's safety and efficacy. I have seen words being weighed and numbers reinterpreted so that the results might be more favourable. Sales drive the pharmaceutical engine (Interview Respondent 1.1, female, member of an advocacy group).

Others non-governmental factors were mentioned, for example:

[Special interest] groups can impact on the process by trying to get drugs pushed through the system for faster approval. [For] example, activists played a big role in getting approval for HIV drugs. [Medical doctors] do post-marketing surveillance. The media can play a significant role in promoting the views of [special interest] groups (Interview Respondent 3.12, female, medical doctor);

Consumer demand and risk perception; Pharmaceutical companies through lobby groups; Health Canada; U.S. policy; Scientists through medical reports and research; Medical doctors. (Interview Respondent 5.3, female, Health Canada advisor)

One interviewee simplifies the politics of drug regulation in his discussion of the two key players involved, and emphasises the need for transparency in this "imperfect" process. In his words: 
There is no great evil or great conspiracy to uncover. The evil is... laziness. We only learn about the medical researchers when there is some kind of court case. The advocacy groups are a voice in the wilderness. In a perfect world you would not need them. This is the last line of defence. There is often no place for someone to go if they have a negative experience. Health Canada and the drug companies are the only two players... Therefore only transparency yields confidence about the regulatory process. There is too little transparency. (Interview Respondent 5.8, male, representative of Parliament)

\subsection{2 b) Individual Experience and Drug Regulation}

Interview respondents were asked to comment on the impact that individual experience might have on the mechanism of pharmaceutical regulation. Many of them spoke about the need to publicly shame pharmaceutical companies in order for an individual reaction to have an impact on the overall process, and explained how individual experience, when made public, can perform this shaming function. One interview respondent stated, for example:

Individuals and advocacy groups put pressure on Health Canada. Pharmaceutical companies do not want to lose face. Negative reactions and the publicity of negative reactions can have a serious impact. Like with mefloquine, there are big problems for the pharmaceutical corporations. (Interview Respondent 5.2, male, Health Canada advisor)

Similarly, when asked what might lead to a change in the status of a pharmaceutical drug? Many interview respondents noted the role of the media and 
public shaming of corporations with regard to serious adverse reactions. One interview respondent felt that "More media reports like the Fifth Estate show The Nightmare Drug (about mefloquine)" could lead to some changes. He added that there is a need to: "Talk about the veterans and civilians who have had problems" (Interview Respondent 1.4, male, student). Others spoke about the severity of reactions, stating that only severe reactions (usually deaths) lead to any changes. For example, one interview respondent said that "It depends on the seriousness of events, there is no formula. [The] media plays a role in people's perceptions of risk" (Interview Respondent 5.3, female, Health Canada advisor). Another echoed these thoughts, emphasising the importance of reporting adverse reactions:

Severe reactions, death, (for example the Thalidomide babies) [can lead to changes]. Monitoring occurs in hospital. Health Canada is producing new safety data... People must recognise and report an adverse reaction... This does not always occur. Many people take a drug and then start to feel ill and have no idea that their illness is probably related to the drug! (Interview Respondent 3.12, female, medical doctor)

One respondent noted that there comes a time when regulators can no longer ignore serious adverse reactions, and this leads to changes:

Adverse effects that have never been documented or serious adverse reactions are reported repeatedly, at one point the problem becomes too serious too ignore. There is a question of severity and a question of ethics... Once the number of cases reaches a certain point, things become too serious and the status of a product must change. (Interview Respondent 5.2, male, Health Canada advisor) 
On the whole, then, interview respondents thought that individual experience serves as a red flag to alert regulators at Health Canada of problems and to shame manufacturers into coping with potentially hazardous products. One interview respondent mentioned this, and followed up with a comment on adequate benchmarks of safety, asking: is "once a problem becomes too serious to ignore" the best time to deal with potentially life threatening adverse reactions to certain products, in particular those used for the prevention of an illness, as in the case of mefloquine? She further raised the issue of the clinical understanding of a 'serious' reaction (as was also discussed in Chapter Four), arguing:

Serious equals death, hospitalisation, or prolonged disability. This is okay for a treatment for diseases, but it is not appropriate when you are giving a drug for prevention to healthy people. The risk/benefit analysis has got to be changed in this case. That's why I like the MASTA definition (Barrett, Emmins, Clarke, and Bradley, 1996); they defined "serious" as any reaction that inhibits or prevents any normal activity that the traveler wants to do and was the purpose for which he/she made the trip. (Interview Respondent 1.2, female, member of an advocacy group)

It seems that there should be a more 'precautionary' (to use a public policy word) way to delineate drug safety, and a more proactive way to put individual experience to work.

\subsection{2 c) Controversy and Advocacy in the Regulatory Process}

As exemplified by the above discussion on mefloquine, the field of pharmaceutical drug regulation can be very controversial. Interview respondents were asked to comment on the effect, in general, of controversy, on the safety of 
pharmaceutical products? They generally agreed with the idea that "it takes controversy to create public pressure" (Interview Respondent 1.4, male, student). However, one respondent was ambivalent about the role of controversy, saying:

The danger associated with controversy is that it may cause undue public alarm and unjustified banning of certain products. The benefit of controversy is that it can effectively garner quick public attention and reaction to a real danger or injustice. Personally, where public health is concerned, I would rather see errors committed on the side of caution and overly-conservative guidelines, rather than on the side of lax standards (Interview Respondent 1.3, female, academic).

Conversely, another respondent purported that, with respect to mefloquine, the controversy may actually be downplayed:

[With respect to mefloquine], the controversies have been downplayed by the government and the military, partly because the military did the initial research on mefloquine. They are reluctant to take responsibility for the damage the drug they invented can do. (Interview Respondent 1.1, female, member of an advocacy group)

One interview respondent stressed the fact that all knowledge is a form of empowerment, however, she equated the controversy over mefloquine with urban myth, asserting that: 
If you understand fully the possibility of side-effects, knowledge is not a bad thing .... Knowledge can empower the patient, and then they are more likely to follow through with a regimen if they are fully aware and prepared .... Some people should not take mefloquine. That's why a home trial is important. There is a kind of sport that goes on among travellers in malarial areas, and that is try[ing] to get people off their anti-malarials. If we empower people here before they go, then maybe they will not be convinced by the stories. Urban myths have power abroad. (Interview Respondent 3.12, female, medical doctor)

Since many of the interview respondents were either themselves involved in, or had experience with, advocacy groups, they were asked how such groups (advocacy groups or special interest groups) might influence the process of pharmaceutical drug regulation. In general, they believe that these organisations or groups play an important role and that such activism is effective. Not surprisingly, interview respondents involved in advocacy groups, tend to emphasise the importance of the work done by such groups. For example, one member of an advocacy group proclaimed:

In an ideal world advocacy groups would play a key role in post-marketing drug regulation. However, in the real world the FDA (and probably governmental regulation agencies in other countries) regard these groups with scepticism and mistrust .... Advocacy groups are the only way the truth about adverse effects can really get out. (Interview Respondent 1.1, female, member of an advocacy group) 
Two other interview respondents spoke at length of the role of advocacy groups related to the case of mefloquine. The first argued that advocacy groups disclose the true risks associated with mefloquine, and help people deal with 'Lariam toxicity':

As long as Roche (and the FDA) is not disclosing the true risk of Lariam®'s sideeffects, we will continue to provide this critical information. As well as helping people who have been damaged by 'Lariam toxicity'- something that most doctors in the US know nothing about. (Interview Respondent 1.2, female, member of an advocacy group)

The second noted the important watchdog function that advocacy groups play:

In the case of mefloquine, advocacy groups (as well as litigation by individuals) have been effective in encouraging the manufacturer to revise its' product fact sheet to include certain debilitating side-effects documented by the growing research literature on the safety and efficacy of Lariam ${ }^{\circledR}$. At the time, this change was made only in the fact sheets distributed in the country that required the manufacturer to update its' information, not in the fact sheets distributed in others countries. It is important to note that the change was not made in response to wild, undocumented claims, but was based on growing, published medical and scientific evidence. 'Advocacy', in this case, whether via a group or via individual litigation, serves an important public watchdog function. (Interview Respondent 1.3, female, academic)

Meanwhile, one Health Canada advisor argues that advocacy work is biased, and must be supported through further research: 
It can be biased [as noted above], so we must be careful when evaluating their effects. When it comes to advocacy, things are always unidirectional; you are either for or against something. In this case, you are against a drug and you form a group. Its impact can be important, however their claims must be supported through research.... Only those negatively impacted form these groups. However, they have an important message to convey. They can bring out strong messages regarding serious adverse reactions that might otherwise go unmentioned. (Interview Respondent 5.2, male, Health Canada advisor)

On the whole, advocacy groups play an important role in alerting the public of potential dangers and pushing for increased safety of pharmaceutical products. Because of its focus on negative adverse reactions, the work of groups such as 'Lariam Action' is necessarily biased. However, it serves as a counter balance to the biased position of drug makers, which overwhelmingly present the merits of their products and gloss over the negative side-effects. Nevertheless, advocacy and research should go hand in hand in the creation of knowledge on pharmaceutical products.

\subsection{2 d) The Role of the Public in the Regulatory Process}

Not surprisingly, given their own involvement in pharmaceutical drug-related matters, many of the interview respondents have a keen sense of public responsibility with respect to health matters. Many interview respondents described the notion of joint responsibility or shared decision-making vis-à-vis health-related issues. On the individual level, they spoke of health care as a 'shared responsibility', asserting, for instance, that it is the patient's responsibility to make informed decisions and to be actively involved in ensuring one's health. As one respondent stated: 
Ideally, information [about malaria and mefloquine] should come from the prescribing physician's office. However, in reality, today, one must be one's own advocate and consult the Internet, libraries, friends, relatives, and others who have conditions similar to yours. (Interview Respondent 1.1, female, member of an advocacy group)

However, one interview respondent voiced his view that it is a doctor's responsibility to inform patients about potential dangers associated with medications, asserting:

That responsibility [of providing information] should fall on the shoulders of the medical field or the prescribing doctor. You, the patient, shouldn't have to go digging to find out [for example] that a drug can be unsafe. (Interview Respondent 1.4, male, student)

Interview respondents held diverging opinions as to whether or not the public has any role to play in ensuring the safety of pharmaceutical products. When asked: Does the public have any role to play in ensuring the safety of pharmaceutical drugs? One respondent stated: "No... The public is the weakest link and is virtually powerless in ensuring drug safety" (Interview Respondent 1.1, female, member of an advocacy group). Another one took a slightly different stance, arguing that it is not the powerlessness of the public, but rather its ignorance, saying: 
Health Canada wants to increase transparency, and to involve the public, but the public's role can not always be high. We are not the individuals who conduct the studies. The experts are more competent then we (the public) on the safety of pharmaceutical products .... To trust in the population would be an error. The population is mis-informed. So many myths are transmitted throughout the population. The public must instead trust those who are more educated to inform their decision-making. (Interview Respondent 5.2, male, Health Canada advisor)

He went on to add that:

Canadian citizen-Mr. and Mrs. everybody-are usually not knowledgeable or are at times mis-informed. Many health myths circulate. For example, the majority of the population believes that cold weather leads to catching a cold. This is completely false. Health organisations (WHO, HC, CDC) have experts who are knowledgeable and can work on these issues regarding safety. This is their job. (Interview Respondent 5.2, male, Health Canada advisor)

On the other hand, the rest of the interview respondents stated emphatically that the role of the public is important. For example, insisting that:

In a democracy, it is a citizen's duty to be informed of government agencies and policies, and to speak out if $\mathrm{s} / \mathrm{he}$ is dissatisfied. The public that chooses to abdicate all responsibility for drug regulation and oversight to a single agency finds itself in a poor position to correct any problem that emerges. (Interview Respondent 1.3, female, academic) 
Essentially, there was agreement that, at the very minimum, the public's responsibility is to "report the reaction. It is not hard to do. Write a letter (I recommend that people put it in writing). If enough people speak up, something will get done. Many people at Health Canada want to do their job well. The patient can have some impact" (Interview Respondent 5.8, male, representative of Parliament).

One respondent advanced the position that the public's role is to act as guinea pigs for newly-approved drugs. She refers to the case of rezulin (a diabetes drug that caused fatal liver damage to 67 people) to argue her point that post marketing surveillance should not be a replacement for good clinical research: 
Before the drug is marketed, [the public can have] no role. After it is approved and sold, they should have more of a role. The FDA collects data [of adverse reactions] but they don't do anything with it unless there are suddenly many deaths. [In] phase 4 studies ... the 'post-marketing studies', members of the public are really the guinea pigs in testing a new drug. This is where you will see the rare side-effects start to show up-when the drug is given to hundreds of patients. Take the example of Rezulin, a diabetes drug that killed 67 people. Pharmaceutical companies said that they were losing $\$ 1,000,000 /$ day every day that this drug was not approved, so it got approved over the objections of the primary medical officer, who wanted more clinical trials because he was worried about liver failure problems. It was approved by the administrators who were listening to the drug company. Sixty-seven deaths later, the FDA pulled it off the market. If the drug company had done the clinical trials, if the FDA had backed their medical officer instead of caving in, those deaths might have been prevented. The L.A. Times did a great series of investigative reports on this situation. And, of course, now, there is [sic.] lots of litigation. (Interview Respondent 1.2, female, member of an advocacy group)

In the case of mefloquine in Canada, we also know that the drug was released onto the market without the adequate safety data. Could it be that cases of suicide, suicidal tendencies, rage, and other serious side-effects that we are increasingly seeing with respect to mefloquine (and as illustrated in changes to the product monograph in Canada and the U.S.A.) would have been revealed had due diligence been ensured during the Mefloquine Safety Evaluation Protocol? We cannot know for sure. 


\subsection{2 e) What is a 'Safe' Drug?}

Interview respondents were asked for their definition of a 'safe' drug. Most of them indicated that no drug is completely safe, claiming, for instance:

No medication does what it purports to do $100 \%$ of the time, and no medication is free from side-effects in all consumers. 'Safety' is a relative term, defined by the pharmaceutical industry and by regulatory bodies, in terms of study population percentages (of efficacy, of ill-effects), not in terms of the severity of experiences by individuals. Thus, [although] many people could die, solely from taking a given drug ... that drug may still be considered "safe" in statistical terms. (Interview Respondent 1.3, female, academic)

Another differentiated between an 'ideal'; drug and a 'safe' drug: The question is really: What is an ideal drug versus a safe drug. An ideal drug is effective, does exactly what it is supposed to and causes no side-effects or adverse reactions ... that just does not exist. You must take into context the reason for taking a drug some reasons outweigh risks. It's a cost benefit analysis. Even aspirin has risks. (Interview Respondent 3.12, female, medical doctor)

One interview respondent explained that the long-term consequences of a drug may not be known when it is deemed 'safe' and given a stamp of approval: 
All drugs carry a risk. A 'safe drug' does not equal a risk-free drug. Individuals and the public do not comprehend this. A drug is safe when it has been tested in an exhaustive and statistical manner. Post-marketing surveillance is essential to ensure the safety of drugs in the long term. The benefit of a drug might be immediate, but its long-term consequences might not be known. Therefore, a safe drug is one for which the short, medium and long term effects have all been verified and known. (Interview Respondent 5.2, male, Health Canada advisor)

Only one member of an advocacy group did provide her definition of a safe drug: "One that does the job it was designed to do, with a low rate of mild to moderate, tolerable, and reversible adverse reactions" (Interview Respondent 1.2, female, member of an advocacy group).

In sum, interview respondents described the main phases of pre- and postmarketing drug regulation. Two things are noteworthy with respect to the safety of mefloquine. First and foremost, there is a clear disjuncture between what occurred during the Mefloquine Safety Monitoring Study (as discussed in Chapter Four) with its missing data and premature approval of the drug, and the official definition of this stage of pre-approval testing, which, in theory, usually includes a placebo, a double blind study, and wherein all parties involved are compelled by law to compile statistics and report toxicity or adverse reactions. Second, based on interview respondents' discussions of the process of post-marketing approval, one can come to understand the changes to the mefloquine product insert as part of the ongoing process to evaluate the safety of the drug, with individual consumers acting as research subjects, testing the effects of the drug in the real world. 
Interview respondents also explained the respective roles of several government bodies such as Health Canada, Industry Canada, and other influences such as advocacy groups, the media, and the public, which affect the drug regulation process. They were in general agreement that the public has an important role to play, since health care is seen as a shared responsibility. Therefore, it is up to the public to report adverse reactions, so that unexpected and serious reactions can be recorded.

\subsubsection{Interview Participants Discuss Non-Expert Knowledge}

The following sub-section presents interview respondents' thoughts on the subjective interpretation of the risks that are associated with malaria and mefloquine. It begins with a discussion of the availability and the quality of health information that is related to malaria and mefloquine.

\subsection{3 a) The Availability of Health Information}

Interview respondents were asked whether or not they feel that adequate travel health information about the risk of malaria and ways to prevent it is available for individuals who are planning a trip overseas. While one respondent made clear her views that, yes, "There is a lot of information, much is known about malaria. For example, there is a lot of information available on WHO, CDC and Health Canada web pages. Again it is the M.D.'s responsibility to direct the patient to the relevant sources" (Interview Respondent 5.3, female, Health Canada advisor), the majority wavered in their response, stating, for instance: 
Yes and no .... There is good information out there if you know how to find it. However, most doctors and travel clinics simply rely on the CDC's website and are not aware of the recent medical studies about the side-effects of anti-malarial drugs. So the public is also unaware of the true risks. (Interview Respondent 1.2, female, member of an advocacy group)

Yes, but there could be more. Good science considers people's tolerance and includes post-market surveillance. The ISTM (international society for travel medicine) is doing work in this area. (Interview Respondent 3.12, female, medical doctor)

Others were adamant that the overwhelming public health message is that: "Malaria can kill you, so take this drug", and add: "Precautionary information is given, however, the side-effects are glossed over"' (Interview Respondent 1.4, male, student). Another respondent steadfastly responded that health care professionals do not know all that there is to know about mefloquine, purporting that: 
American health care professionals in general know very little about tropical medicine, including the prevention and treatment of malaria. Specifically, most prescribing physicians cannot tell you: 1) the top five prophylactic medications to choose from, 2) which geographic areas have which strains of malaria, and 3) which strains of malaria are resistant to which medications -- all critical information for choosing a prophylactic. Additionally, physicians may not be fully aware of the side-effects, the counter-indications, and fail to ask about lifestyle and health of patient, which also contributes to poor medical decisionmaking. For instance, the three times that a physician has prescribed malaria prophylactics to me, I was never asked: if I was pregnant, or planning a pregnancy; if I regularly consumed alcohol or took recreational drugs; or if I was currently on any counter-indicated medications, or had a medical history of any problems counter-indicated for certain drugs -- all critical to decision-making. Nor was I warned against mixing the prophylactic drug with alcohol or other medications, or of possible side-effects, or what to do in case of a serious (if rare) side-effect. (Interview Respondent 1.3, female, academic)

As discussed below, most travel medicine providers (TMPs) do, in fact, know about the three first points mentioned in the above quote, and are, in effect quite knowledgeable about the risk of malaria and the different methods to prevent it. However, it does seem, from the absence of any discussion or mention of this, that TMPs do not ask a slew of lifestyle questions that could predict a reaction to the drug. On the whole, interview respondents are ambivalent about the availability of health information. 


\subsection{3 b) The Subjective Experience of Risk}

Interview respondents were asked to discuss their perceptions of how individuals assess the possibility of experiencing two risks: the risk of experiencing an adverse reaction to an anti-malarial drug and the risk of contracting malaria. Interestingly enough, interview respondents all answered that they believe that people underestimate the risk of experiencing a side-effect from a drug. Meanwhile, their responses differed with respect to the risk of contracting malaria. The following table illustrates the responses to these two questions.

Table 5.1 Do People 'Overestimate', 'Properly Evaluate', or 'Underestimate' the Risk of Experiencing a Side-effect and the Risk of Getting Malaria? Interview Respondents' Views

\begin{tabular}{|l|c|c|c|c|c|}
\hline & Overestimate & $\begin{array}{l}\text { Properly } \\
\text { Evaluate }\end{array}$ & Underestimate & $\begin{array}{l}\text { Multiple } \\
\text { response(s) }\end{array}$ & Total \\
\hline $\begin{array}{l}\text { Risk of } \\
\text { contracting } \\
\text { malaria }\end{array}$ & 3 & 2 & 2 & 1 & 8 \\
\hline $\begin{array}{l}\text { Risk of } \\
\text { experiencing } \\
\text { a side-effect }\end{array}$ & 0 & 0 & 8 & 0 & 8 \\
\hline
\end{tabular}

All of the interview respondents agreed that individuals underestimate the risk of experiencing a side-effect when taking a pharmaceutical drug, affirming, for example:

"Most people have no clue that drugs can harm as well as help them" (Interview Respondent \#1.1, female, member of an advocacy group). Two interview respondents spoke of "undue trust" that is placed by consumers in the medical establishment: 
People have undue faith in Health Canada. If a product is on the shelf, people think that it is safe, even pharmacologists are surprised by the risks associated with common drugs. So the general public does underestimate their risks. (Interview Respondent \#5.3, female, Health Canada advisor)

People in general place an enormous amount of trust in doctors and in the medical profession. Most people are not concerned with the details of how drugs are developed, approved, or marketed, and may not appreciate the weaknesses in the system. (Interview Respondent \#1.3, female, academic)

One interview respondent argued that citizens have too much faith in 'the system', in general, asserting that:

We are so used to taking pills for everything... aspirin, anti-depressants, etc, and not realising the side-effects. Medical Doctors tell you to do it and you just do it. I took both of my Lariam ${ }^{\circledR}$ cycles in full. It's fear; it's denial. We underestimate the risk and we trust the system, we trust that a drug that is approved by the system won't mess us up. (Interview Respondent \#1.4, male, student)

Meanwhile, when asked to comment on people's assessment of the risk of getting malaria, interview respondents held diverging positions. Some thought that public health discourse leads to an over-estimation of the risk of getting malaria, for example stating that, "travel medicine providers leave individuals with the impression that if they see a mosquito they will get malaria. That's just not true" (Interview Respondent \#1.2, female, member of an advocacy group). Many mentioned that the military seems to overplay the 
risk of malaria and this gets fed back into malaria prevention strategies for the general public:

Look how the military operates, they completely over-state the risk. In Iraq the

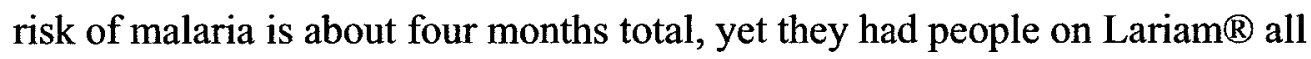
year long. The same in Afghanistan (May thru November). (Interview Respondent \#1.2, female, member of an advocacy group)

Others had mixed reactions to the question, stating:

Travellers to low risk areas can over-estimate their risk. For example travelers to Thailand think that malaria exists throughout the country when, in fact, it is only in border areas where tourists rarely go. On the other hand, in India, for example, the risk of malaria is increasing. So travellers, in particular people returning to India, can under-estimate the risk. Malaria risk is always changing due to resistance, also changes in season, temperature, all impact on the risk. (Interview Respondent \#3.2, female, medical doctor)

Some interview respondents think that individuals underestimate the risk of getting malaria, rationalising to themselves that "It will never happen to me ... this is the attitude that many people take vis-à-vis diseases . . whether it is malaria or AIDS, for example it is the same thing ..." (Interview Respondent \#5.2, male, advisor to Health Canada). Another remarked: 
Young people, and those who have not previously travelled to endemic areas, often underestimate the risk. Or worse, a few armchair adventurers "romanticise" malaria - think it is "exotic/cool/impressive" to say that you have had malaria (without knowing exactly what the symptoms of malaria are, or that it can recur). Many people from the privileged Western world often believe that they are invincible, in the sense that that nothing bad will happen to them, and that packaged tours provide complete safety. Few first-time travellers understand the potential to die from malaria, being unaware of the different types, such as cerebral malaria. (Interview Respondent \#1.3, female, medical doctor)

In sum, interview respondents were of mixed opinion regarding the availability of information about malaria and anti-malarial drugs. Most agreed that good information can be difficult to find. When asked about the subjective assessment of two related risks, they all shared the view that people tend to underestimate the risk of experiencing an adverse reaction to a drug. Meanwhile, interview respondents held differing opinions about people's perceptions of the risk of getting malaria.

\subsubsection{Summary of Interview Findings}

Interview respondents demonstrate the connection between personal experience and health advocacy. Many of them epitomise the phenomenological notion that lived experience shapes one's ways of 'being in the world' (Blackburn, 1994: 239). In this case, their reactions to mefloquine or their loved ones' reactions urged them to become involved in advocacy about the drug. Overall, they provided very detailed accounts of the health concerns associated with mefloquine, and most argue that it is too toxic to be considered an appropriate malaria prophylactic. Interview respondents also outlined the 
various stages involved in ensuring the safety of pharmaceutical products. In their discussions of how various factors influence these processes, it became apparent that the public and advocacy groups play a crucial role in revealing potentially dangerous drugs and in "shaming" pharmaceutical corporations into improving their safety measures. They advance the position that only deaths and/or "bad press" (negative publicity) lead to changes with respect to drug safety. When asked for their perceptions on the subjective evaluation of two related risks, all interview respondents held varying opinions on people's interpretation about the risk of contracting malaria, yet they all maintained that people tend to underestimate the risk of experiencing an adverse reaction to a drug.

\subsection{Survey Respondents (TMPs). . Who Are They?}

The following pages present results from the survey of travel medicine providers (TMPs). The main objectives of this survey were to get a sense of the following: travel medicine experts' views about the safety of mefloquine; their thoughts on the regulation of the pharmaceutical products that they prescribe to their clients; their perception of the risk of malaria; and, the role of their patients' knowledge and experience in the regulatory process. Whenever relevant, some themes that were addressed in the interviews were repeated in the survey of TMPs, in order to get a more well-rounded perspective on those issues.

\subsubsection{TMPs Address the Safety of Mefloquine}

The survey asked TMPs about their views on the safety and efficacy of mefloquine. TMPs confirmed that mefloquine remains the most commonly prescribed anti-malarial drug in Canada today. Only two out of 28 TMPs identified chloroquine as 
the "most commonly prescribed anti-malarial drug"; a further four out of $28 \mathrm{did}$ not answer the question. The remaining TMPs $(22 / 28)$ named mefloquine as the, or one of the, "most commonly prescribed anti-malarial drug(s)" ${ }^{46}$ The following table shows the frequencies and percentages of TMPs who identified each of the anti-malarial drugs and the, or one among the, most commonly prescribed anti-malarial drugs to Canadian travellers.

Table 5.2 The Most-Commonly Prescribed Anti-Malarial Drug(s) According to TMPs

\begin{tabular}{|l|c|}
\hline Drug Name & $\begin{array}{c}\text { Number of TMPs who indicated this } \\
\text { (these) as the 'most commonly prescribed } \\
\text { anti-malarial drug(s)' }\end{array}$ \\
\hline Mefloquine & $17(61 \%)$ \\
\hline Chloroquine & $2(7 \%)$ \\
\hline Mefloquine, Malarone, Doxycyclen & $2(7 \%)$ \\
\hline Chloroquine, Mefloquine & $1(4 \%)$ \\
\hline Mefloquine, Malarone & $2(7 \%)$ \\
\hline No answer & $4(14 \%)$ \\
\hline Total & $28\left(100 \%{ }^{47}\right)$ \\
\hline
\end{tabular}

\footnotetext{
${ }^{46}$ TMPs were asked whether or not statistics have been published on the numbers of prescriptions sold for each of the various anti-malarial drugs available in Canada. None of them knew for sure. Some suggested that Health Canada might have these; others suggested that regional health centres might have them. In the end, it was impossible to identify any sources of publicly available statistics on sales of anti-malarial drugs.

${ }^{47}$ Percentages included in the tables have been rounded to the nearest full percentage.
} 
TMPs were asked: Are you aware of any health concerns with the drug mefloquine (also sold under the name Lariam $(\mathbb{R})$ ? All of them (28/28) stated that 'yes', they are aware. When asked to describe what they know about these concerns, however, there was a lot of variation in their responses. Some of them focussed on media reports of the military incidents surrounding mefloquine, stating, for example: "[I've heard] everything there is to hear-W5, Fifth Estate, anecdotes ..." (TMP 207). The majority of TMPs did provide an account of some of the possible side-effects and contraindications associated with the drug. These accounts focussed on neuro-psychiatric sideeffects and differed with respect to the effects mentioned and the prevalence rates. For example, the incidence rates that were given for 'less serious' side-effects ranged from 15 to $42 \%$. In their words: "one in 10,000 risk of psychosis, depression, severe anxiety, 15 $30 \%$ risk of other adverse effects: dreams, moodiness, insomnia, gastro intestinal upset, headache, rash, etc.” (TMP 202); “30\% of patients have neuro-psychiatric side-effects ranging from bad dreams to frank psychosis and a variety of things in between (personality changes, etc.)" (TMP 94); and "Neuropsychiatric adverse effects in $42 \%$ of 486 patients studied" (TMP 83). In other cases the responses to this question were vague, dismissive, and/or very brief, as was the case in the following responses:

[The] Literature points to clients with underlying psychological conditions i.e., anxiety disorders, depression, etc. having difficulty on this medication. It may exacerbate their symptoms and side-effects. Generally can cause nausea, vomiting, headache, dizziness and increased anxiousness. Some clients report bizarre and nightmarish dreams. (TMP 52) 
Possible psychiatric and delusions side-effects although very rare. Does not go well with alcohol. (TMP 88)

Much concern [has been] raised over sleep disturbances, psychosis with those who are pre-disposed, the extent of the problem is poorly documented, mostly case reports. Thus this needs to be carefully reviewed and education of the public/patients. (TMP 82)

Patients suffer from cardiac conduction disorders; hazardous when driving; interacts with other drugs. (TMP 144)

There are contra indications: epilepsy, allergy to medication, neuropsychiatric events in the past, health disease. Side-effects: minor sleep disturbances; major, psychosis (rare). (TMP 108)

Should not be used in clients with epilepsy, mental illness, liver disease, or dysrethmia. Must be used cautiously (benefits versus risks) in pregnancy and in people using calcium channel and beta-blockers. Some people will have unusual reactions including psychosis. (TMP 29)

Thus, while most TMPs did mention a variety of potential neuro-psychiatric and other physiological side-effects and a range of contra indications, these answers were quite diverse and did not always equate to the list of adverse reactions noted in the Compendium of Pharmaceutical Products (C.P.A. 2002). This indicates that that they do not provide a standard understanding to their clients of all of the potential health concerns associated with the drug. Furthermore, they overwhelmingly endorse the drug. TMPs 
were asked for their overall assessment of mefloquine (Lariam $\circledR$ ) as an anti-malarial drug? A large majority (20/28) steadfastly endorsed the drug, affirming, for instance that it is a "very good drug ... practical and good compliance" (TMP 88). Others agreed, stating: "It is effective; the majority of people can tolerate it. Discontinuity rate is [one per] 200 (similar to chloroquine) ..." (TMP 35); "Effective, convenient, cost-effective, rarely causes side-effects"(TMP 135); "Safe and effective for most travellers to endemic areas" (TMP 24); and "Many clients have no difficulties" (TMP 52). An additional 6/28 gave a more cautious endorsement, saying that the drug is: "not so bad" (TMP 206); and "It is still an excellent drug and vital in areas of chloroquine resistance. There needs to be more careful assessment of the true risk factors" (TMP 82). Another TMP reports being more cautious with mefloquine, stating that:

I use it rarely as a long-term prophylactic where dosage convenience and efficacy and cost dictate it may be the best and easiest to use. I always administer at least three doses prior to departure of the traveller to assess tolerance and I caution the traveller about side-effects. (TMP 94)

Only two TMPs responded that they do not prescribe mefloquine at all. TMPs were also asked whether they are aware of any changes in the status of mefloquine since it was licensed in Canada in 1993? (i.e., have any new warnings been issued by Health Canada?). Less than half of them (11/28) reported being aware of such changes, and once again, when they did provide answers, their responses varied quite considerably, and included some very vague recollections, such as: "I think there was an alert re[garding] neuropsychological side-effects and as well information describing other concerns by patients" (TMP 137); and some unrelated, unfounded notions: 
Related to similar prescriptions and psychiatric illness, depression, the simultaneous use of buproprian (Zyban). Can now be used in pregnancy ... approved for younger/smaller kids. (TMP 31)

A further 11/28 said that they 'don't know', in one case admitting specifically to not keeping abreast of any warnings, confessing: "There is a lot of press but I'm so close to it, I must confess I haven't specifically looked at the warnings certainly as recently as 2000 it was advocated but I don't think official warnings have been issued" (TMP 94). This is quite remarkable, given that, as described in the previous chapter, the most recent change indicated that some people who take mefloquine think about killing themselves and there have been reports of suicides.

In sum, TMPs confirm that mefloquine continues to be the, or at least one of the, most commonly prescribed anti-malarial drug(s) for Canadian travellers. On the whole, they endorse the drug and believe it to be safe and effective for use in chloroquineresistant, malaria-endemic regions of the world. When asked to describe the health problems associated with mefloquine, they provided succinct responses, which in some cases were in line with information described in the literature, but which, in most cases, did not cover the gamut of possible adverse effects. Moreover, in some cases the health concerns which they associated with mefloquine use, are not reactions that are listed in the C.P.A. (2002). When asked about any changes in the safety status of the drug, fewer than half knew about any of these changes, and none of them mentioned recent changes to the product monograph, most notably the potential risk of suicide. In fact, of all the 28 TMPs who responded to the survey, only one of them mentioned the risk of suicide at all. 


\subsubsection{TMPs Describe Drug Regulation}

When asked: Are you aware of the process by which the safety of pharmaceutical drugs is monitored in Canada, once is has been approved for sale? If so, can you describe it? Three out of 28 TMPs did not answer the question, while seven out of 28 said that they are not aware of the process, or are "somewhat aware but not enough to describe it" (TMP 211). The remaining 18/28 did, at least, mention the existence of adverse reaction reports that are sent to Health Canada; however, the majority of these TMPs did not explain how the monitoring takes place. For example, one respondent said: "There is an adverse reaction report but beyond that I am unfamiliar with monitoring" (TMP 29).

Others did describe it in greater detail. For example, one TMP stated that "Post marketing surveillance . . . appears to have a significant element of dependence on luck and intent of people who are busy and unable to devote energy to it" (TMP 137)! Granted, it is true that medical doctors are busy people, but if they do not devote energy to getting to know the system that ensures the safety of pharmaceutical products (products that they themselves prescribe), then who else will?

TMPs were also asked: Is the system in place to monitor the safety of pharmaceutical drugs effective in alerting Health Canada of a potentially dangerous drug? Almost half of them stated 'yes' (13/28), while an additional 10/28 TMPs said that they 'don't know or can't say'. Of the remaining, 2/28 answered 'no'; 1/28 said 'yes and no'; and $2 / 28$ did not answer the question. When asked to comment, many of those who said 'yes' in response to the question, equivocated in their comments, adding: “. . . but the process is too slow (TMP 83); and "in as much that only frequent side-effects can be 
detected" (TMP 201); and "because of Tasmar or other [dangerous] drugs" (TMP 206). ${ }^{48}$ Those who said 'no' explained: "It would appear over the years that it has taken a significant length of time for dangerous drugs to be discovered through current procedures" (TMP 137); and "Because the system is largely voluntary, the amount of information is limited and takes a long time to be generated" (TMP 143). So, on the whole, TMPs do not think that the drug monitoring system is effective.

\subsection{2 a) What is a 'Safe' Drug}

TMPs were asked for their opinions on what constitutes a 'safe' pharmaceutical drug? Some travel medicine providers indicated that there is "no such thing as a safe drug" (3/28), stating, "there is no safe drug. In dreamland a drug which does the job with absolutely no adverse effects and whose efficacy remains constant would be a "safe" drug" (TMP 94). Similarly, another noted that: "No drug is safe $100 \%$ of the time" (TMP 202). However, the majority $(22 / 28)$ did provide their own definition of what constitutes a 'safe' drug: One that has "good therapeutic value; very low to no incidence of dangerous side-effects; reasonable incidence of nuisance side-effects" (TMP 137), for example; or on in which the "benefits outweigh the adverse effects" (TMP 31). Some put forth a more detailed set of criteria for a safe drug, listing for example:

1: has had adequate animal and clinical trials; 2 : history of [the] chemical [has been] known for many years; 3: [has a] record of all adverse/precautions and those who are excluded from use; 4 : [has a] clear record of drug interactionsprecautions. (TMP 82)

\footnotetext{
${ }^{48}$ Tasmar is a drug used to treat Parkinson's disease. It has been shown to cause fatal liver failure.
} 
One TMP provided the very lenient definition that a 'safe' drug is: "a drug that in the majority of cases leads to the wanted effect" (TMP 211). The remaining 3/28 TMPs did not answer the question.

Only two-thirds of TMPs were able or willing to describe the process of postmarketing surveillance. A full third of them made no mention of adverse reactions reports. This is significant because, as prescribing physicians, it is their responsibility to warn patients of potential adverse reactions and to encourage them to report any severe reactions that they may experience. Not surprisingly, a majority of TMPs did not think that the process of post-marketing regulation is effective in alerting Health Canada of potentially harmful drugs.

\subsubsection{TMPs Discuss Non-Expert Knowledge and Experience}

The following section deals with the TMPs' evaluation of their clients' knowledge about malaria and anti-malarial drugs. It also discusses the views held by TMPs about their clients' subjective interpretation of the risk of malaria and the risk of experiencing an adverse reaction to the drug. It begins with an overview of their thoughts on the availability of health information and the level of awareness of their clients.

\subsection{3 a) Information about the Risk of Malaria}

TMPs note that the trouble with much of the publicly accessible information about malaria is that it is only country-specific. They argue that, instead, good information should be differentiated by geographical, climactic and seasonal factors. When asked: In your own words, how would you define the term 'malaria zone'? They provided similar responses, overall, stressing the importance of climactic variables and the presence of vectors, defining it as: 
Any area in the world in which, due to appropriate climate, vector presence and the presence of infected donors, malaria transmission regularly occurs. I would not include areas of sporadic transmission which are only rarely visited with the required temperature, bugs and carriers. (TMP 94)

Another notes that: "A geographical area of endemic malaria-may vary depending on mosquito population and other environmental factors. Areas of endemnicity likely harbouring DDT resistant mosquitoes ..." (TMP 83). One TMP specified that the chemical sensitivity of the parasite had to be known for an area to be qualified as a 'malaria zone', stating: “A malaria zone is an area of a country with similar geographic climate conditions that have clinically/laboratory confirmed cases of malaria with treatment chemical sensitivity known" (TMP 82). Another, meanwhile, asserted that a 'malaria zone' is “A geographical area defined by known or suspected seasonal or yearround transmission of malaria" (TMP 202). Some TMPs also provided responses that spoke of large scale (e.g. country level or even continent level) transmission; stating, for example, that a malaria zone is an "area at risk", adding: "some are more at risk than others. Ex: Africa, Asia, South America, Central America" (TMP 108); or, "South America, Central and East Africa, and [the] far East including Asia. Malaria zones usually [are] in the above mentioned countries [sic.] in areas of altitude of $<2000$ meters" (TMP 200).

In sum, when asked to define what constitutes a 'malaria zone', most TMPs emphasised the importance of seasonal, geographical and climactic factors. 


\subsection{3 b) The Availability of Adequate Health Information}

The majority of TMPs believe that adequate travel health information is available for individuals planning a trip to a malaria-endemic country. When asked, Do you feel that adequate travel health information about the risk of malaria and ways to prevent it, is available for individuals who are planning a trip to a malaria endemic country? More than three quarters of them responded 'yes' $(22 / 28)$. When asked to comment on their answers, some of those who responded in the affirmative, made strong claims, such as:

"There is no shortage of reliable well written information" (TMP 207); and "Websites and publications are readily available and are concise and easy to read" (TMP 137). While others were more hesitant regarding the quality of information, commenting that [good information] "is available at specialised travel clinics. General info is also available from other sources, but the quality may be so-so" (TMP 201). They also questioned the discernment of travellers about this knowledge, stating, for example that:

Canada is currently replete with travel health clinics (available by phone/fax/net if not geographically convenient) also many books on travel health, government publications, Internet sites, etc. [Is it] appropriate? Only if they understand it. (TMP 94)

Of course appropriate info is out there-finding it and knowing who/what is reliable is the issue. What is more of a problem is the level of awareness that malaria (and other health issues) may be a concern - if they don't know, they won't seek info to begin with. (TMP 202) 
At the heart of this issue is the belief by some TMPs that travellers are not concerned enough about the risk of malaria to begin with. ${ }^{49}$ As two TMPs succinctly put it, "The information is available through travel medicine clinics, however, often it seems they are not aware of such clinics or a risk in general" (TMP 52) and [the information is] “available’ but not known” (TMP 24).

Some of the TMPs who do not think that adequate information is available, and responded 'no' to the aforementioned question, thought that accessibility was a problem, affirming: "accessibility is an issue, i.e., cost Internet access, geographic location of travel clinics" (TMP 135); "There are few publicly available sites. Generally, this requires contracting a service for a fee" (TMP 143).

While there are some qualified travel clinics who obtain up to date global travel material risk information, the de-listing of travel medicine [from Medicare] and limited qualified physicians leaves many people without access to a quality clinic/physician. (TMP 82)

Others spoke about some myths, or misinformation that circulates, for example: "Many people believe that malaria is only present in rural areas and not in urban or resorts and no need for prevention" (TMP 88). Similarly, another TMP stated that: “Although travellers are aware of the risk, the major group at risk are recent immigrants who grew up in a malaria-endemic country and think that they are immune to malaria and therefore

\footnotetext{
${ }^{49}$ This relates to the fact that TMPs state that their greatest challenge is to convince people of the risk of malaria and to take anti-malarial drugs.
} 
do not take any precautions" (TMP 200). ${ }^{50}$ One TMP noted, as discussed above, that: "The dilemma is always that the information is general for the country and not specific for the individual and their [sic.] trip" (TMP 35).

Not surprisingly, TMPs showed a bias for information that comes out of a travel medicine clinic and consider themselves best source of information on travel medicine. When they were asked, for example: In general, where, or from what sources, should individuals who are planning a trip to a malaria-endemic region, get information about health and safety? Please list all that apply. All of them listed 'an experienced travel medicine practitioner', 'a travel medicine clinic', or a synonym of these terms, and for over one-third (19/28) of them it was their first response. Other first responses offered were: government publications (1/28); family physician (2/28); travel agents $(2 / 28)$; local public health unit (1/28); CDC (1/28); and Internet/books (2/28).

In the same vein, when TMPs were presented with a list of sources of information, and asked how relevant (very relevant, somewhat relevant, not particularly relevant, not at all relevant or don't know) each one is, for individuals who are preparing to travel to a country where malaria is present, a full $27 / 28$ indicated that 'Travel Medicine Providers' are "Very relevant". Official publications, i.e., from Health Canada or the WHO, were also deemed 'very relevant' by the vast majority of TMPs. Meanwhile, only $3 / 28$ stated the same about the family physician. Half of the TMPs overtly discredit the role of the family physician, noting that they do not have expertise in the field of travel medicine. They asserted, for example that:

\footnotetext{
${ }^{50}$ It should be noted that the complacency of immigrants from malaria-endemic regions regarding anti-malarial drugs was commonly mentioned throughout the surveys by a number of TMPs.
} 
The majority of documents, in their attempt to simplify the issues, can be confusing to the average traveller. I feel that direct contact with expert counsel is far more effective. Past personal experience and family are only as valuable as the experience behind them. Family physicians are becoming more knowledgeable, but often mislead or mis-prescribe. (TMP 94)

On the whole, TMPs generally underscored the expertise of TMPs over general practitioners:

Travel medicine professionals deal with this info every day. They are the best source of information. They know where to find the relevant information for the traveller. The family physician may or may not be knowledgeable about malaria. Knowledge from other travellers and family can be very helpful or very misleading. (TMP 137)

Some TMPs spoke about the resources that they have at their disposal to ensure their expertise. For instance, they note that Canadian recommendations are usually outdated (in particular those put out by the Committee to Advise on Tropical Medicine and Travel or CATMAT), and assert that they must rely on CDC reports and Travax software, which provides them with up-to-date statistics on prevalence rates and drug resistance. As one TMP put it: 
The "Canadian recommendations for the treatment and prevention of malaria among international travellers" is usually our \#1 resource, but it has not been updated since 2000. We [therefore] advise our clients according to CDC and Travax recommendations. Our Travax ${ }^{\mathrm{TM}}$ software is updated on a weekly basis.

Family physicians in our area are not all up to date as far as malaria recommendations and often will refer their clients who are travelling to us for travel counselling. Other travellers may be misinformed. (TMP 60)

Most TMPs discredited family or friends' personal experience, explaining, as one did, that "In too many instances, family members and/or other travellers have underestimated the risk of malaria and the consequences" (TMP 211). The following table shows how relevant TMPs consider each source of information to be, when individuals are preparing to travel to a malaria-endemic country.

Table 5.3 TMPs Rate the Relevance of Various Sources of Information for Individuals who are Planning Travel to a Malaria- Endemic Country

\begin{tabular}{|l|l|l|l|l|l|l|}
\hline & $\begin{array}{l}\text { Very } \\
\text { Relevant }\end{array}$ & $\begin{array}{l}\text { Somewhat } \\
\text { Relevant }\end{array}$ & $\begin{array}{l}\text { Not } \\
\text { Particularly } \\
\text { Relevant }\end{array}$ & $\begin{array}{l}\text { Not at all } \\
\text { Relevant }\end{array}$ & $\begin{array}{l}\text { Don't } \\
\text { Know }\end{array}$ & Total \\
\hline $\begin{array}{l}\text { Health Canada } \\
\text { Publications }\end{array}$ & 18 & 8 & 2 & 0 & 0 & 28 \\
\hline $\begin{array}{l}\text { WHO } \\
\text { Publications }\end{array}$ & 17 & 6 & 3 & 0 & 2 & 28 \\
\hline Family Physician & 3 & 10 & 8 & 5 & 2 & 28 \\
\hline $\begin{array}{l}\text { Travel Medicine } \\
\text { Provider }\end{array}$ & 27 & 1 & 0 & 0 & 0 & 28 \\
\hline Other travellers & 2 & 10 & 12 & 2 & 2 & 28 \\
\hline Past experience & 3 & 14 & 4 & 2 & 5 & 28 \\
\hline Family members & 0 & 3 & 11 & 6 & 8 & 28 \\
\hline
\end{tabular}


Most noteworthy in this table is the fact that half of the TMPs deny that family physicians have any role to play in assisting travellers who are planning a trip abroad, stating that their role in "not particularly relevant" or "not at all relevant", when, in fact, is it most likely that family physicians, who would then direct their clients to TMPs, would be the first point of contact for those who need travel health information. Also noteworthy is that almost all TMPs (26/28) asserted that Health Canada publications are relevant, however, many of them remarked, at one point or another in their responses, that Health Canada publications are often out of date and not geographically specific enough.

\section{2 .3 c) Clients' / Patients' Knowledge}

TMPs were asked: Have the malaria prevention strategies used by Western travellers to malaria-endemic countries changed over the past decade? Over half of them said 'yes' (16/28), while an additional one third (9/28) did not respond (usually because they have not been TMPs for that long). They were also asked for their comments, and one spoke of a "Greater use of bed nets (treated), insect repellent, [and that] alternative medications [are] frequently sought" (TMP 143); and another stated that patients are asking for "more drug options" (TMP 202). Furthermore, many TMPs spoke specifically of the decrease in use of chloroquine (due to increased resistance), and about the influx of new drugs on the market leading patients to be more vocal about getting an alternative to mefloquine-either in the form of doxycyclen or malarone. One TMP stated that these "yuppie anti-malarials" are becoming more popular (TMP 35). Some TMPs acknowledge an increase in their patients' information and knowledge levels, stating for instance that "travellers are more aware of malaria in endemic countries" 
(TMP 83), and emphasising that, while clients are still savvy, they are willing to take TMPs' advice:

My clients are savvier having accessed info on the web before seeing me. Some have heard stories in the media about deet or mefloquine. For the majority of clients, they are aware of the risks and are willing to take my advice. (TMP 29)

Only three out of 28 stated that malaria prevention strategies used by Western travellers have not changed. One TMP explained: "Strategies have not really changed . . . the evolution of travel health as a discipline has afforded greater accessibility. It is also training more physicians/nurses etc. about what to say and when to intervene (pretravel)" (TMP 94).

TMPs were also asked: In general, are your patients who are planning a trip to a malaria-endemic region, well informed about the various ways to prevent malaria infection, yes or no? Twenty-two of the 28 TMPs responded that 'yes', their patients are well informed; while only $6 / 28$ stated that they are not. However, the interpretation of this question by TMPs, and their subsequent commentary was quite interesting: No matter how they read the question, and whether they responded 'yes' or 'no' to it, their comments indicate that they believe that they must do all of the informing on the topic; stating that their patients, for example, are informed, "but only after they have had a visit with me" (TMP 203). Likewise, other TMPs who said that their patients are wellinformed, also stated: "I make very sure they are and reinforce essentials even while continuing to touch on other subjects" (TMP 94); or "we do the informing! When they come in most do not have a lot of information, some have more than they need" (TMP 52). Another noted that: 
Our clients are given detailed information (oral and printed) on the appropriate anti-malarials for the specific area they are travelling to. We give them detailed information on personal precautions (deet and permethrin) and protective measures (clothing, nets). (TMP 29)

Similarly, those who responded that 'no', their patients are not informed, added, for example, that: "The goal is for them to leave the consultation well informed" (TMP 35). Only one TMP acknowledged the value of the outside information that his/her clients bring with them prior to consultation, declaring: "Yes. Some access information on the Internet prior to their appointment here" (TMP 60). In general, however, the few who spoke about their clients level of information prior to their appointments, usually did so disparagingly, for example saying:

A lot of people who get advice don't keep it straight or are just interested in taking a pill and forgetting about it or just avoiding thinking about it. Most people I see are 1-2 weeks away from leaving for endemic zones when they see me. (TMP 137)

TMPs think that good information is available, however they are biased in favour of information that comes from a travel clinic. Moreover, they see it as solely their responsibility to inform clients, and to dispel the 'health myths' that arise when client have sought information from other sources prior to seeing them.

\subsection{3 d) The Subjective Experience of Risk}

TMPs were asked: In your opinion, do individuals, who are travelling to an area where malaria is present, overestimate, properly evaluate, or underestimate their risk 
of contracting malaria? They were also asked: In your opinion, individuals, who are travelling to an area where malaria is present, overestimate, properly evaluate, or underestimate their risk of experiencing a side-effect when taking a pharmaceutical drug? Interestingly enough, the majority of TMPs believe that travellers underestimate the risk of malaria, however, their views are split with regard to the risk of experiencing a side-effect. Table 5.4 below presents these results.

Table 5.4 Do People 'Overestimate', 'Properly Evaluate', or 'Underestimate' the Risk of Experiencing a Side-effect and the Risk of Getting Malaria? TMPs' Views

\begin{tabular}{|l|c|c|c|c|c|}
\hline & Overestimate & $\begin{array}{c}\text { Properly } \\
\text { Evaluate }\end{array}$ & Underestimate & $\begin{array}{c}\text { Multiple or } \\
\text { no } \\
\text { response(s) }\end{array}$ & Total \\
\hline $\begin{array}{l}\text { Risk of } \\
\text { contracting } \\
\text { malaria }\end{array}$ & 1 & 2 & 20 & 5 & 28 \\
\hline $\begin{array}{l}\text { Risk of } \\
\text { experiencing } \\
\text { a side-effect }\end{array}$ & 7 & 3 & 11 & 7 & 28 \\
\hline
\end{tabular}

When asked to comment on their answers, a large majority of TMPs state that individuals underestimate the risk of contracting malaria. Some spoke about the immigrant population as a population that tends to underestimate the risk of contracting malaria, stating, for instance: "In my clientele many people are expatriates and feel they have immunity. They usually will protect their children but even there compliance is poor" (TMP 88).

The major group who underestimate their risk is those who grew up in the country. They are visiting and think that because they didn't get malaria as a child they will not get it now. (TMP 35) 
While others spoke more generally of the tendency to underestimate the risk of getting malaria:

Many believe there is little risk where they are travelling because travel agents tend to downplay the risk. A lot of our travellers have done their homework and know the risks. (TMP 52)

Many TMPs also spoke of the 'myths' that people buy into, notably myths that downplay the risk of malaria, affirming, for example:

Many travellers buy into the myths such as 'malaria isn't such a big deal' 'most people taking mefloquine will have side-effects' 'it's better to treat malaria if you get it than take the med[ication] to prevent it'. It is a travel health professional's responsibility to emphasise the serious[ness] of the illness and importance of the prophylaxis. (TMP 29)

Many myths still exists regarding the antimalarial medication. Many feel that they could treat malaria if they should get it, rather than prevent it by taking antimalarials. (TMP 60)

Others added that travellers underestimate the devastation caused by malaria:

Many people have no idea of the devastating effect malaria has in endemic countries [and] often they'll ask why do I have to take something? What do the local people do? (TMP 137) 
Meanwhile, their comments on the subjective evaluation of the risk of experiencing a side-effect when taking a drug were quite varied. Many gave more ambivalent responses:

Some are afraid of everything and are sure each is causing adverse effects . ... A few accept anything a physician or pharmacist offers without question .... Many accept with some appropriate questions. (TMP 94)

S]ome people just don't like taking medication and others like taking something to be safe and others leave it up to the doctor. In general, people are cautious and what they do is reasonable based on the level of information they have. (TMP 137)

Those who think that people underestimate the risk experiencing a side-effect when taking a drug noted that:

Society expects a quick fix to problems. Does not want to hear bad news. Docs do not have much time [for] explaining potential side-effects or interactions with other drugs. (TMP 83)

Most consumers have developed a trust in medications and thus assume that medications are always safe. (TMP 82)

Patients are not always told about their medication and many don't know the names, let alone the side-effects. (TMP 144)

TMPs who thought that people overestimate the risk of experiencing a side-effect when taking a drug, commented on the example of mefloquine, with one stating: 
“especially with mefloquine due to media hype" (TMP 31). Another indicated that:

"Mefloquine is the classic example-most have heard that it can "make you crazy", yet the risk is [one in] 10,000 for psychotic episodes" (TMP 35).

A large proportion of TMPs (12/28) either did not answer the question, or provided multiple responses to the question. In both of these situations, they overwhelmingly commented that the reality is too varied to select one response category, so, they either did not answer, or else they chose multiple responses. Their comments, in this circumstance, included the following: With regard to the risk of getting malaria, one TMP provided multiple responses and stated: “. . . detailed travel history and exposure misinformation often leaves most people either getting over-treated or under-treated, [this $\therefore$

is] especially true in chloroquine or multi-drug resistant areas (TMP \#82). Another TMP, speaking about the risk of experiencing a side-effect, chose multiple response categories and commented:

A patient can do all three depending on the information they're receiving -e.g., from friends and commercials. Some people just don't like taking medication and others like taking something to be safe and others leave it up to the doctor. ... (TMP \#137)

A third TMP did not answer the questions, and commented: "There is a whole range of perceptions. .." and "impossible to answer, depends on the drug" (TMP \#204).

All of the TMPs acknowledge the importance of their clients' direct experience with anti-malarial drugs or with respect to travel to a malarial country. For example, they acknowledge that visiting a malaria zone, all the while not taking any anti-malarial drugs, and not getting malaria, may lead people to feel invincible. They also agree that having 
experienced a side-effect in the past is important when deciding upon a new prophylactic. As one TMP summed it up: “Once bitten twice shy” (TMP 83)! However, subjective knowledge - knowledge gained by listening to friends and family, or hunches that are based on knowledge of one's own body, common sense, the 'traveller's grapevine' -in all its' forms is disavowed. For example, when asked: What role does a patient's personal experience and/or past history play in selecting appropriate anti-malarial precautions?, one TMP replied:

A large one if he/she has been exposed one way or another. Unfortunately the untutored but "experienced" traveller or one who has researched on his/her own often draws conclusions that are inaccurate and can lead to improper action in the field. It took me years to devise appropriate recommendations for each geographic area. Somehow the .. 'I was there 10 years ago' traveller feels that they [sic.] have all the answers. (TMP 94)

TMPs were also asked for their thoughts on the role of the public in ensuring the safety of pharmaceutical products. When asked: Does the public have any role to play in ensuring the safety of pharmaceutical drugs? Almost all responded 'yes' (22/28), while only two out of 28 said 'no' and the remaining four out of 28 'did not know' or 'can't say'. They were asked to comment on their responses. All those who said 'yes', also said that the patient must report adverse reactions/side-effects to doctors, or Health Canada or pharmacists, stating, for example that, "they need to report adverse reactions as soon as possible to doctors or health care providers. They need to ask questions regarding safety" (TMP 52). Some added that patients give a personal perspective on the various drugs available. For example, one TMP stated that patients should: 
Report what they experience while using a drug both [in terms of] efficacy and adverse effects. Eventually physicians get the message. By listening to patients when I first started tentatively using mefloquine (before its regular release) I learned that $30 \%$ of people didn't like it. (TMP 94)

This quote shows that in some cases TMPs are willing to entertain their clients' preferences. Many spoke of the fact that health care is a 'joint responsibility' between the health care provider and patient:

There has to be a way for the public to voice concerns. Given that the subject is confusing enough to the educated caregiver, it is difficult for the public to fathom the whole thing. However, on the other side, it is the patient's problem and the patient's body and there has to be a source of information that allows the patient to make choices intelligently for them [sic.]. (TMP 137)

Others, still, spoke of an even broader role for the patient in the regulation of pharmaceuticals: "Lobbying to ensure that we have a quality service that is accountable to the public" (TMP 205). Of the two TMPs who did not think that the patients have any role, one expressed the idea that: "We have regulators because consumers are not in a position to judge" (TMP 204).

TMPs were asked: What are the major challenges that you face, as a travel medicine provider, with respect to the prevention of malaria among Canadian travellers? Interestingly, most of them spoke about the need to convince the population of travellers, in particular immigrant travellers from endemic areas of the world, of the need to take anti-malarial drugs; and to dispel 'myths' regarding malaria and mefloquine. In other 
words, to convince high-risk travellers (i.e., to Africa) that it is best for them to take preventative medication: "immigrants from malaria zones ... who have been here for a long time are hard to convince that they need prophylaxis" (TMP 209). TMPs spoke of two other important challenges: the "Low percentage of travellers seen at travel clinics [and] people refusing anti-malarials" (TMP 135). In their words, their duty is "Getting [travellers] educated and getting them to take [the risk of malaria] seriously and getting them to take prophylactic medicine" (TMP 137); and "getting people to appreciate they are at risk and that drug side-effects are usually mild" (TMP 209). One TMP summed up the difficulty of dispelling "myths" as follows:

"I am not at risk" "I hate DEET" "Deet is harmful" "insecticides are harmful" "These drugs are worse than the disease"; "my friend travels there every year and never gets sick". We have to dispel the myths and provide accurate, country specific appropriate information. (TMP 29)

Other concerns were related to the difficulty of carving out a sense of expertise for the profession of travel medicine and delineating the expertise of TMPs. They spoke of this difficulty, stating that "Education of other health care providers [is necessary] to help them understand when they do not have enough knowledge to carry out this activity" (TMP 209) and argued the need for greater "awareness of risk; appreciation of travel medicine as an area of special expertise ..." (TMP 202). Other challenges included keeping up-to-date on the issues, the lack of accessibility of travel medicine providers for some Canadians, and ensuring drug compliance by their patients.

The role of TMPs, as agents of public health, is a social one: to educate the population of travellers who may or may not be putting the rest of 'us' at risk through 
their travel to malaria-endemic regions of the world, by becoming a drain on 'our' health care system and by increasing rates of mortality and morbidity in Canada. TMPs must thus ensure that travellers "take seriously" the risk of contracting malaria, and must convince them to take one of four anti-malarial drugs that are available in Canada. Moreover, this role is exacerbated when dealing with immigrant populations from malaria-endemic regions of the world, who may have their own cultural assumptions and local knowledge about malaria and its prevention and may be even less willing to follow the TMPs' advice.

\subsubsection{Summary of Survey Findings}

TMPs confirm that mefloquine is the, or at least one of the, most commonly prescribed anti-malarial drugs for Canadians who are travelling to a malaria-endemic country. On the whole, they affirmed that they are aware of the health concerns associated with mefloquine, however, when asked to describe these concerns, they provided very diverse responses. It was most notable that none of the TMPs mentioned the recent changes to the mefloquine product monograph, which highlight the potential risk of suicidal ideation. In fact, only one TMP mentioned the risk of suicide at all, stating that mefloquine can cause "psychological problems that can lead to suicide" (TMP 205).

When asked to discuss the regulation of pharmaceutical drug safety, under twothirds of the TMPs surveyed described the process of post-marketing drug surveillance. In other words, over one third of them did not mention the adverse reactions reports that they must fill out and send to Health Canada when their patients experience an adverse reaction. The most likely explanation for this, is that patients are more likely to see their 
family doctor if they experience a serious reaction, as opposed to returning to see a TMP, especially since travel medicine is no longer covered by the Canadian Medicare system, and currently patients have to pay to see a TMP. Nonetheless, it is surprising that they are not able/willing to discuss the process.

While TMPs affirmed that adequate, or even good, information about the risk of malaria and ways to prevent it is available for individuals who are planning a trip to a malaria-endemic country, they still asserted that they must do all of the informing on the topic. Their greatest challenge, they stated, is to convince individuals to take seriously the risk of malaria and to take an anti-malarial drug, most often prescribing mefloquine. They related non-adherence to conventional medicine to misinformation or myth. Over two thirds of TMPs survey respondents believed that travellers underestimate the risk of getting malaria.

\section{3 'Bloggers'. . . Who Are They?}

The following is a synopsis of weblog data. As specified in chapter two, the 50 weblogs that were posted on the Internet by Canadian citizens were extracted from a larger sample of weblog data. It was important to do so, and to get a Canadian sample, in order to ensure that comments about mefloquine were applicable to the Canadian regulatory system. Also, it was critical to have a sample of data from Canadians only, in order to examine whether some of the serious reactions experienced by Canadians who 
took mefloquine and reported this online, are reflected in the Health Canada database of adverse reactions..$^{51}$

Upon analysing the weblogs, it was determined that 14 of the 50 Canadians who posted weblogs (hereafter 'bloggers'), did not experience any adverse reactions. In most of these cases, individuals were planning to travel to a malaria-endemic country and were writing to get information about the drug. In three cases, individuals simply wrote about positive experiences with mefloquine, remarking, for example: "I have taken Lariam® on and off since it was approved in the eighties. I have travelled in the most malarial areas (East and West African coasts, Solomon islands, etc.) and have never had malaria and never experienced the slightest side-effect" (blogger \#1). In two cases, health care professional were writing to get information from non-mainstream sources. One medical doctor, for example, wrote:

I am a physician's assistant and will be going to the Central African Republic for approximately three months. I will be providing first line medical care for a

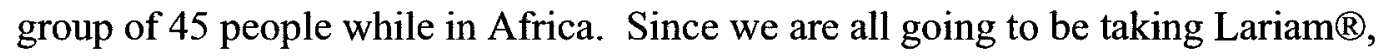
I thought that it would be interesting to seek information from sources other than the usual medical \& pharmaceutical resources. From what I have seen so far, your site is an excellent source of information. (blogger \#17)

Five bloggers described an adverse reaction experienced by someone close to them. For example, one mother wrote:

\footnotetext{
${ }^{51}$ This procedure is meant to be exploratory and cannot be seen to represent an adequate measure of the databases' effectiveness, since, in some cases, it is impossible to know whether the reactions were reported to the proper Canadian health authorities.
} 
My daughter took Lariam ${ }^{\circledR}$ several years ago. Thanks to this site and Sheldon, we found out how to control her symptoms (typical — heart palpitations, cold sweats, panic attacks, claustrophobia, etc.). No alcohol, very little caffeine and little stress made a big difference for her. (blogger \#9)

Another wrote: "I have a friend who took Lariam® starting in January 1998. He was diagnosed with Guillain-Barre syndrome (a type of unexplained neuropathy) in midMarch 1998 and died from complications last week" (blogger \#27).

The remaining 36 out of 50 'bloggers' personally experienced an adverse reaction to mefloquine. In 11 of these cases, the reaction was not 'serious' and consisted mainly of nausea, vomiting, headaches and nightmares. In a further 12 cases, the reactions were severe enough to disrupt their daily activities, but would not necessarily be considered 'serious' by health authorities, and consisted of: hallucinations, sleep disorders, panic attacks, vertigo, and irrational behaviour, among others. One woman stated, for instance, that:

I realised after swimming in the Andaman Sea during a monsoon that certainly my behaviour was irrational. I'd also experienced on a daily basis a low-grade sense of paranoia which I thought I could control with massage and exercise. These provided temporary relief but after discussing my symptoms with fellow seasoned travellers, each of whom strongly advised me to stop taking the drug, I decided to see a physician here in Singapore for alternative drugs. Lariam ${ }^{\circledR}$ is a terrible thing and I regret the happy travel time lost because of it. (blogger \#36)

Another wrote: 
I thought I was crazy. I had connected my symptoms to Lariam ${ }^{\circledR}$ but I wasn't totally sure that they were side affects from it. I stopped taking the drug in Africa [be]cause I couldn't go on, even though numerous doctors had warned me not to. . .. I still to this day (three years later!) get headaches and have what I've always referred to as 'Lariam ${ }^{\circledR}$ flashbacks'. Not a fond souvenir of my adventurous trip. That's for sure! (blogger \#14)

In one case, a man claims that his side-effects to mefloquine contributed to the breakdown of his marriage, confessing:

I have experienced the same side affects [sic.] as you have described, especially depression, anxiety attacks and aggression. My wife could not live with the changes in me and now we are in the process of divorcing. Now, I am starting to figure out the problem. (blogger \#32)

The most 'serious' reactions, which occurred among 13 of the 36 bloggers who experienced a reaction, were either life threatening or involved prolonged disability. One former student wrote about how mefloquine put an end to his academic career, avowing:

I took mefloquine three years ago and started having severe headaches. I have never recovered and I now have, according to recent neuro psyche tests at Mayo Clinic in Minnesota, severe cognitive impairment. I am unable to work or read. I was a Ph.D. candidate at the cutting edge of my field. (blogger \#8)

Most bloggers attested to prolonged reactions, which persist long after the drug has been stopped. For example, a 63 year-old man described major skin complications that he has suffered for years, stating: 
I received a large dose of Lariam $®$ in Saudi Arabia, after receiving over 300 mosquito bites in one night. The dose was 6 by $500 \mathrm{mg}$ in 16 hours, administered by Doctors who suspected that I had Malaria, which turned out to be the wrong diagnosis. I now suffer from a rash and many skin problems that have been with me [for over one year]. The rash will not leave. Prickly heat was a severe problem last summer. I lost the skin off my hands 14 times, and off my feet four times. I anticipate this summer with a great deal of anxiety. There seems to be no end to my situation. I am male and 63 years old. Help! (blogger \#26)

Another expressed the same kind of despair and frustration at her prolonged reaction, asserting:

After only three weeks worth of pills I have experienced nervous tremors, epileptic-like seizures (my first sent me to a clinic in Ho Chi Minh City), constant ringing in the ears, aching joints, dizziness and depression. I stopped taking the medication immediately although I was advised not to. My symptoms are improving but very slowly. The ringing in the ears has not improved, and I am trying to accept that I may have this forever. (blogger \#37)

These same people often describe alternative treatments that alleviate their symptoms and discomfort, for instance, the above blogger notes: 
Things that seem to ease the discomfort: Rest, avoiding stress, alcohol and caffeine, doing yoga and psychotherapy. Things that didn't work for me: Acupuncture, detoxing juice cleanse (3 days), Kava, detoxing tinctures, cranialsacral therapy (though I read that for one person it really helped), naturopathy. I would be interested in knowing what has helped others. (blogger \#37)

To which another blogger who had experienced a serious reaction rejoined: "I took different drugs and products, but the ones that helped and still help are: multivitamins, vitamin E, Detoxosode, Activated Charcoal. Yoga is also really useful"' (blogger \#38). In many of the cases, individuals were not warned of any potential adverse reactions to mefloquine. As such, a number of bloggers affirmed that they did not know that their symptoms could be related to mefloquine when they first experienced them. For instance, one blogger exclaimed: “This site helped me realize that I wasn't going crazy" (blogger \#22). Other bloggers echoed these sentiments, saying: "When we met an Australian doctor, he told me that there was a lot of controversy about Lariam ${ }^{\circledR}$. This was the first I heard about anyone having a problem with it." (blogger \#39) Another concurred, stating that: 
I wish I had found this out before I took this medication. Fortunately, I did not suffer many side-effects, apart for a few very bad nightmares the 2 first weeks of treatment. But I had no idea until I started taking it, that the effects could have been devastating. The clinic that I visited before my trip did not inform me of the side-effects .... I consider myself lucky in a way, even though I still ended up getting Malaria (Falciparum and Vivax) three months after coming home from the Ecuadorian jungle. I've learned that it is important to ask questions and be informed of all the risk of taking medication AND going to a malaria infected area. (blogger \#3)

Faced with a lack of information or a lack of support or care from the mainstream medical community, individuals look to Internet sites like these for ways to control their symptoms and for sources of support as evidenced, for example, in the following blog:

Many thanks Sheldon for putting this site together. You have helped me a lot in going through the worst of this horrible experience. It has now been 12 months since I 'went down' with Lariam ${ }^{\circledR}$. I am still under treatment but feeling much better. I am now trying to get a job and try to get back to a normal life. I am in the process of writing down my story. I find it very painful to do. I do not like to force myself to remember all the details. I'd rather forget all this . ... I admire your strength and courage. I do not feel I have as much. Thanks again for your help. (blogger \#6) 


\subsubsection{Bloggers' Experiences and the Adverse Reactions Database}

The adverse reactions database is Health Canada's way of monitoring adverse reactions to pharmaceutical products. Each record includes the following information: a record identification number, patient details such as the gender, age and weight of the patient, the source of the adverse reaction report (i.e., who reported the reaction-patient, doctor, or other), the level of seriousness, the name of the health product that is the suspected cause of the reaction as well as other drugs that were taken concurrently. It also includes the adverse reaction terms, or symptoms experienced and the outcome of the reaction (i.e., recovery status). Figure 5.1 (below) is one example of an adverse reaction report as seen in the database. 
Figure 5.1 Sample Health Canada Adverse Reaction Report

$\begin{array}{ll}\text { Report ID: } 182566 & \text { Gender: Male } \\ \text { Manufacturer ID: CA200501152 } & \text { Age: } 39 \text { Year(s) } \\ \text { Date Received at MHPD: } 2005-04-27 & \text { Weight: - kg } \\ \text { Date of last Follow-up: } 2005-09-28 & \text { Height: }-\mathrm{cm} \\ \text { Serious: Yes } & \text { Outcome: Died drug may be contributory } \\ \text { Feature of Report: Adverse reaction } & \text { Notifier Type: Coroner } \\ \text { Report Type: Spontaneous } & \text { Notifier Location: Manufacturer }\end{array}$

\begin{tabular}{|c|c|c|c|c|c|c|}
\hline $\begin{array}{l}\text { Health Product } \\
\text { Name(s) }\end{array}$ & $\begin{array}{l}\text { Dosage } \\
\text { Form }\end{array}$ & $\begin{array}{l}\text { Health Product } \\
\text { Involvement }\end{array}$ & $\begin{array}{l}\text { Route of } \\
\text { Admin. }\end{array}$ & Amt & Freq. & Durat \\
\hline CIPRO & - & Concomitant & $\begin{array}{l}\text { Not } \\
\text { specified }\end{array}$ & -- & -- & -- \\
\hline $\begin{array}{l}\text { ANTIDIARRHEAL } \\
\text { MEDICATION }\end{array}$ & - & Concomitant & $\begin{array}{l}\text { Not } \\
\text { specified }\end{array}$ & -- & -- & -- \\
\hline $\begin{array}{l}\text { MEFLOQUINE } \\
\text { HYDROCHLORIDE }\end{array}$ & - & OTHER & $\begin{array}{l}\text { Not } \\
\text { specified }\end{array}$ & -- & - & - \\
\hline MALARONE & $\mathrm{TAB}$ & Suspected & $\begin{array}{l}\text { Not } \\
\text { specified }\end{array}$ & $250 \mathrm{Mg}$ & - Daily & 15 Days \\
\hline Adverse Reaction(s) & & & \multicolumn{2}{|c|}{ Date of Onset } & \multicolumn{2}{|c|}{ Date of Resolution } \\
\hline SUICIDE & & & - & & \multicolumn{2}{|c|}{-} \\
\hline DEPRESSION & & & - & & \multicolumn{2}{|c|}{-} \\
\hline MENTAL STATE AE & 3NORMA & $\mathrm{AL}$ & - & & \multicolumn{2}{|c|}{-} \\
\hline CONFUSION & & & - & & \multicolumn{2}{|c|}{-} \\
\hline DEPRESSION PSYC & HOTIC & & - & & \multicolumn{2}{|c|}{-} \\
\hline HALLUCINATION & & & - & & \multicolumn{2}{|l|}{ - } \\
\hline
\end{tabular}

Adapted from: (Health Canada, 2006) 
Upon searching the Health Canada database (Health Canada, 2006), using the search terms 'mefloquine' and 'Lariam ${ }^{\circledR}$ ', it was determined that it contains 76 records of adverse reactions to Lariam ${ }^{\circledR}$, and 12 more to mefloquine, occurring between 1990 and 2006. Based upon the gender, the date of the reaction, and a description of symptoms, as posted in each of the weblogs, an attempt was made to ascertain whether or not each case was included in the database (see Appendix L for the characteristics of Mefloquine Bloggers). It should be noted that in two cases, bloggers were writing about someone else's adverse reaction. In these cases the relationship of the 'victim' to the blogger is included in parentheses. The symptoms listed in this table were taken from the individual blogs, and were edited for conciseness.

In most cases, bloggers mention having reported their symptoms to one or several medical doctor. It should be noted, however, that in four out of the 11 cases, it is impossible to know for sure whether or not the bloggers reported their reactions to a medical doctor, or any other health official, because they did not state this specifically. However, due to the seriousness of the reactions described, we can assume that they did report their reactions to a doctor. For example, one blogger wrote: "On my return [to Canada] I found that my blood pressure was raised" (blogger \#7); it is safe to assume that he found this out by seeing a medical doctor. Similarly, we can assume that the 63 -yearold man who reported having lost all of the skin from his hands and feet, several times, saw a Canadian medical doctor about his condition. In the remaining seven cases, the bloggers specifically mention that they reported their symptoms to a doctor (this is indicated in the following table in italics). In one case, for instance, an individual who had suffered from anxiety, panic, dizziness, palpitations, diarrhoea, and depression, and 
who thought that he was going to die, said "My family doctor ... laughed when I said that I might be suffering from Lariam side-effects" (blogger \#11).

Of the 11 serious reactions experienced by bloggers, there were two possible matches in the database. ${ }^{52}$ In two additional cases it was impossible to determine whether or not the case was included in the database, because the symptoms described were too vague, and it is impossible to determine the gender of the blogger. The remaining seven cases were definitely not included in the database. This was determined with certainty, because of the absence of any cases in the database with matching symptoms, genders and dates as those reported in weblogs. For example, Blogger \#7 experienced three months of ringing in the ears, high blood pressure, low concentration and sleep disturbances. He experienced these symptoms around June $30^{\text {th }} 1999$. However, there is no report of a male with those symptoms at any time in 1999. Therefore, we can conclude that this blogger's reaction is not included in the database.

The following table shows the characteristics of Canadian bloggers who suffered from 'serious' reactions to mefloquine, and indicates whether or not there are any possible matches of records in the database, for each of the reactions described in the blogs (See Appendix L for the characteristics of all Canadian mefloquine bloggers).

\footnotetext{
${ }^{52}$ Again it should be emphasised that this is not a definitive match but only speculation.
} 


\section{Table 5.5 Characteristics of Canadian Bloggers who Experienced a 'Serious'} Reaction to Mefloquine

\begin{tabular}{|c|c|c|c|c|}
\hline $\begin{array}{l}\text { Blog } \\
\#\end{array}$ & $\begin{array}{l}\text { Gender } \\
\text { \& Age* }\end{array}$ & Symptoms and Duration & $\begin{array}{l}\text { Date Posted** } \\
\text { (when the reaction } \\
\text { occurred) }\end{array}$ & $\begin{array}{l}\text { Any Possible } \\
\text { Match in the } \\
\text { Database? }\end{array}$ \\
\hline 6 & Male & $\begin{array}{l}12 \text { Months } \\
\text { "Under treatment" }\end{array}$ & $\begin{array}{l}10-07-99 \\
\text { (12 months ago) }\end{array}$ & $\begin{array}{l}\text { Not knowable } \\
\text { (symptoms } \\
\text { too vague) } \\
\end{array}$ \\
\hline 7 & Male & $\begin{array}{l}3 \text { Months } \\
\text { ringing in ears, high blood } \\
\text { pressure, low concentration, } \\
\text { sleep disturbances }\end{array}$ & $\begin{array}{l}09-30-99 \\
\text { (3 months ago) }\end{array}$ & 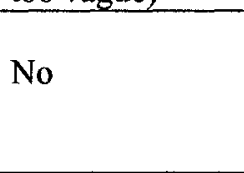 \\
\hline 8 & Male & $\begin{array}{l}\text { Serious cognitive impairment } \\
\text { Headaches. } \\
\text { Treated at Mayo Clinic }\end{array}$ & $\begin{array}{l}09-24-99 \text { ( } 3 \text { years } \\
\text { ago, never } \\
\text { recovered) }\end{array}$ & $\begin{array}{l}\text { Yes } \\
\text { Report } \\
\text { ID\#122195 }\end{array}$ \\
\hline 9 & Female & $\begin{array}{l}\text { (Daughter) } \\
4 \text { Months } \\
\text { Mefloquine toxicity, heart } \\
\text { palpitations, cold sweat, panic }\end{array}$ & $\begin{array}{l}\text { 09-13-99 (four } \\
\text { months ago) }\end{array}$ & No \\
\hline 10 & Male & $\begin{array}{l}\text { Severe and persistent muscular } \\
\text { pain in low back and abdomen } \\
\text { Extensive diagnostic testing }\end{array}$ & $06-02-99$ & No \\
\hline 11 & $?$ & $\begin{array}{l}\text { Anxiety, panic, dizziness, } \\
\text { palpitations, diarrhoea, } \\
\text { depression, "thought that I was } \\
\text { going to die" }\end{array}$ & & $\begin{array}{l}\text { Not knowable } \\
\text { (no gender, date } \\
\text { and symptoms } \\
\text { too vague) }\end{array}$ \\
\hline 26 & $\begin{array}{l}\text { Male } \\
63 \mathrm{yrs}\end{array}$ & $\begin{array}{l}\text { Loss of skin on hands (14 times) } \\
\text { and feet ( } 4 \text { times) }\end{array}$ & $04-05-98$ & No \\
\hline 27 & Male & $\begin{array}{l}\text { (Friend) } \\
\text { Guillain-Barre syndrome } \\
\text { (unexplained neuropathy) } \\
\text { diagnosed in March 1998 died } \\
\end{array}$ & $\begin{array}{l}03-30-98 \\
\text { (one week ago) }\end{array}$ & No \\
\hline 34 & Male & $\begin{array}{l}\text { Anxiety, panic, heart } \\
\text { palpitations, weight loss }\end{array}$ & $12-08-00$ & $\begin{array}{l}\text { Report } \\
\text { ID\#125424 }\end{array}$ \\
\hline 37 & Female & $\begin{array}{l}\text { Epileptic-like seizures, ringing } \\
\text { in the ears, aching joints, } \\
\text { dizziness, depression } \\
\text { Reported to a medical doctor }\end{array}$ & $10-04-00$ & No \\
\hline 38 & Female & $\begin{array}{l}\text { Anxiety, skin problems, fatigue, } \\
\text { urticaria } \\
\text { Saw } 10 \text { M.D.s }\end{array}$ & $08-30-00$ & No \\
\hline
\end{tabular}

*This information was not always included in the blog.

** For example, a blogger might have posted a message on July $15^{\text {th }}, 2000$ and indicated that the reaction occurred two months earlier. In this case the database would be searched from May 01, 2000. 
The fact that only two out of 11 serious reactions are included in the database is not really that surprising, given that Health Canada acknowledges that under-reporting of adverse reactions is a serious problem, and that it is estimated by the $\mathrm{CBC}$ that the database only includes about $10 \%$ of all adverse reactions (Canadian Broadcasting Corporation (CBC), 2004c).

It was also possible to determine that the case of the Canadian student who participated in an interview was not included in the database. When asked whether or not he reported his reaction to a medical doctor, he replied:

Oh yes, in Calgary, in 1994, I think his name was Dr. Lynch. I was of course being a typical man, I was reluctant to admit that I had had problems. But I told him that I felt like I was going crazy, had signs of depressions, paranoia. I told [him] that I was on this drug. When I visited the Regina travel medicine clinic, I was told that the drug was safe. All that I was told to expect was some upset stomach and maybe strange dreams. The Dr in Calgary suggested that I see a psychiatrist .... (Interview Respondent 1.4; male; student)

However, there are no cases of adverse reactions by a male with his symptoms in 1994 (or 1993 or 1995, for that matter). Moreover, the author's own adverse reaction, which was diagnosed by three medical doctors and recorded by the Canadian Workplace Safety Insurance Board, is not included in the database.

What is more noteworthy than the small proportion of adverse reactions that were experienced by bloggers and interview subjects that are included in the database, is the near absence of any deaths attributed to mefloquine in the database. Mefloquine is 'officially' associated with only one death in the database. Whereas, in the U.S.A., 
Benjamin and Olmstead (2002b: 1) found that "The U.S. Food and Drug Administration's files contain reports over the past four years alone of 11 suicides, 12 suicide attempts, 41 cases of thinking about suicide and 144 cases of depression among Lariam ${ }^{\circledR}$ users". Despite this near absence of suicide cases in the database, the most recent changes to the Canadian mefloquine product insert mention the risk of suicide. One interview respondent clearly outlined how his suicidal thoughts were related to his adverse reaction to mefloquine, explaining

It is not a traditional desire to commit suicide because of sadness or thinking that life is so bad. You have suicidal thoughts because you want to get out of your skin. You feel like you have been taken over by a foreign entity and you need to escape it. You could become convinced that the only way to do this is to kill yourself. . . It's not that life is so bad, it's just that you have to get out of your own skin. (Interview Respondent \#1.4, male, student)

His own reaction and suicidal thoughts along with those of this author's were not included in the Health Canada database.

The one instance of a Canadian individual who was using mefloquine and committed suicide, that was found in the database, was officially attributed to another drug: Malarone. This case, which is shown in the sample database record (Figure 5.1, above) reports the experience of a 39 year-old male, who experienced depression, hallucination, confusion, and an abnormal mental state, and committed suicide in 2005. Since the case is attributed to Malarone, it can only be found when searching the database for reactions to this drug (the database is searchable by drug name only, not by adverse reaction symptoms). However, it is noted in the detailed record that the patient was also 
taking mefloquine. Therefore, this case would not show up in statistic of adverse reactions to mefloquine, because mefloquine is simply included as an 'other' drug being taken, but not as a 'suspected' source of the reaction. Unfortunately, it is impossible to examine whether there are other instances such as this one, in which a patient died while taking mefloquine, but which is officially attributed to another drug, because one can only search the database for product names, and not symptoms.

\subsubsection{Summary of Weblog Analysis}

In sum, this health-related weblog can be seen as a site of resistance to mainstream medical discourse about the safety of mefloquine in particular, and about travel health in general. It is also a source of non-traditional medical information for mainstream medical practitioners. One traveller encapsulated the main themes evoked throughout this section of the chapter, in her blog, in which she writes: 
The travel clinic doctors were adamant that we needed mefloquine as we were travelling in areas that were identified as chloroquine-resistant. After one pill (and a night of nightmares), my sister threw hers out. Like many other travellers, I discontinued the mefloquine while in Thailand. ... I couldn't stand the hallucinations (visual and aural) any longer (frequency and length of hallucinations appeared to increase with each pill). I would estimate that it took from 6 to 12 months for the drug to leave my system completely. ... David Suzuki hosted a TV show months after I returned exploring the issue of resistant strains of malaria, the effect of global travel, etc. According to his medical experts, I didn't need mefloquine for the areas in which I was travelling. Doctors are over-reacting, while dismissing the effects of this drug as not comparable to those of malaria. Yes, malaria can affect your health for the rest of your life. I only wish that the real effects of the drug had been presented to me for a more informed choice as to what trade-offs I was willing to make. (blogger \#30)

Nearly three-quarters of bloggers experienced an adverse reaction to mefloquine and wrote about their experience taking the drug. The remaining bloggers were writing for the following reasons: to get information about the drug; to comment on their positive experience (or absence of a reaction to) the drug; to report someone else's adverse reaction; or, they were medical professionals writing to gain non-mainstream sources of information about mefloquine (in that order of frequency). On the whole, bloggers expressed thanks to the web designer for providing useful information that is difficult, if not impossible, to find elsewhere. 
One way of examining the degree to which subjective experience is factored into the regulation of pharmaceutical drugs in Canada, is to explore post-marketing surveillance of adverse reactions. Since the Health Canada adverse reactions database is the primary means by which Health Canada tracks and monitors the safety of health products, it is useful to know whether serious and unexpected reactions are well documented in the database. Based on exploratory analysis, it was determined that data from just over $15 \%$ of serious reactions reported by bloggers, one interview respondent and the author are included in the database. This is slightly better than the assertion made in a report entitled Faint Warning: From Coloured Tabs to Computerized Signals: How Canada Tracks Dangerous Drugs (Canadian Broadcasting Corporation (CBC), 2004a) that only one in 10 serious adverse reactions are reported in the database. However, what is most striking is the near absence of any deaths attributed to mefloquine in the database.

\subsection{Chapter Summary and Discussion}

This chapter has presented the results from analyses of interview (8 participants), survey (28 TMPs) and weblog (50 bloggers) data. Throughout this "cacophony of voices" (Fine et. al, 2000), there was little agreement among all research participants on the central themes. Interview respondents and TMPs did share the view that health care is a shared responsibility between the health care professional and the patient. They also agreed that the role of the public with respect to the safety of pharmaceutical products is important: to report adverse reactions to Health Canada.

There were numerous instances of disagreement or contestation between respondent groups. First and foremost, while interview respondents and bloggers 
demonstrate the connection between personal experience and health advocacy, TMPs, tend to denigrate the role of personal experience in the health care process.

Patterns of disagreement between TMPs and interview respondents also emerged. For example, interview respondents all believed that individuals generally underestimate the risk of experiencing an adverse reaction to a pharmaceutical drug, and, they held ambivalent viewpoints about the interpretation of the risk of malaria. Conversely, while TMPs share the view that people tend to underestimate the risk of getting malaria, they held diverging views about the risk of experiencing an adverse reaction to a drug. TMPs were also far more likely to provide a definition of what constitutes a 'safe' drug, whereas interview respondents agreed that there is no such thing as a safe drug, and that patients must do a cost benefit analysis before they choose to take any drug.

All research participants can list several health concerns associated with mefloquine, however, TMPs do not always list adverse reactions to mefloquine that are included in the Compendium of Pharmaceutical Products, and interview respondents list more severe and persistent health problems. TMPs on the whole view mefloquine as a safe and effective prophylactic drug, while, overall, interview respondents deem that it is too toxic to be used as a prophylactic, and bloggers generally express opposition to the drug.

With respect to knowledge levels, some interview respondents say that prescribing physicians (TMPs) are not knowledgeable regarding anti-malarial drugs; whereas TMPs say that they are the best sources of travel-health information. Meanwhile, some prescribing physicians go to bloggers' web pages to gain unconventional medical knowledge. This triad shows that 'expert' and 'non-expert' are 
not discrete categories, but rather extremes on a continuum of medical expertise.

Traditionally, and perhaps still overwhelmingly today, non-expert knowledge with regard to health is not validated in the medical community. Brashers et al. (2000: 387) note that: "Physicians are trained to conduct a medical consultation in a way that minimizes input from patients" but that "Activism encourages a more assertive style of encounter with physicians (in private) and in the public sphere." Perhaps this form of activism and the

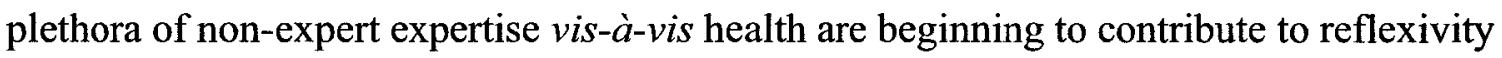
within the creation of medical knowledge. 


\section{Personal Narrative \#5 - Medical Doctors Confirm the Diagnosis}

Two Medical Doctors confirmed that I went crazy because of mefloquine (see Appendix K for letters of diagnosis)! They wrote, for example:

"Please be advised that the above named was admitted to hospital under my care from 01-04-08 to 01-04-11. I believe that the admission was precipitated by side-effects of her anti-malarial medication", and "Diagnosis: Acute Psychotic Episode secondary to Mefloquine."

Ifelt relieved to get this official recognition that my psychosis was, in fact, mefloquine induced. I was dismayed when I later found out that my case remains excluded from Health Canada's database of adverse drug reactions. I did not report my reaction to mefloquine to the makers of the drug or to Health Canada. Before beginning this research project I had never thought about reporting adverse reactions. I had never questioned how side-effects are recorded, nor was I even aware of the idea that citizens could somehow be involved in the process. Now that I am engaged in this research project, I have noticed that there is no contact information, or any indication that unwanted side-effects should be reported to the manufacturer, on the mefloquine product insert, for example. On closer examination of the printout from my pharmacist, I see that it is stated that rashes and difficulty breathing should be reported, but it does not say where or how, and my pharmacist did not mention this. From my own experience and this research, it is evident that the system in place to monitor adverse reactions is not very user friendly, nor does it actively seek out citizen participation. 


\section{Chapter 6 Power/Knowledge in the Prevention of Malaria and the Regulation of Anti-Malarial Drugs}

This chapter draws from the findings presented in Chapters Four and Five to elucidate the power dynamics at play in the regulation of pharmaceutical drugs in Canada and in the creation and perpetuation of travel medicine health campaigns. The first section of this chapter outlines Foucault's (1980) discussion of power in contemporary society. The second section clarifies how medicine operates as a technology of power in the present case study. In order to comprehend the place of subjective knowledge within the intertwined problematics of ensuring the safety of pharmaceutical products and devising public health campaigns, it is necessary to expose the 'dividing practices', 'assemblages', 'technologies of governance', and 'strategies' (Foucault, 1980; Foucault, 1991; Rose, 1994; Rose and Miller, 1992) at play in the governance of this area of health. The third and final section of this chapter presents a post-structuralist stakeholder analysis.

This chapter grapples with the nature of power in contemporary society. It contends that power is an interplay of forces and that it is deployed through a variety of strategies and technologies. It will also make the case that power does not serve a single master, but that it is often enlisted in the service of economic interests and maintains the epistemological tension between the individual and the population (as discussed in Foucault, 1980: 254). This conception of power leads to an understanding of the role of subjective knowledge in modern forms of governance, which includes the regulation, creation, and/or promotion of public health campaigns. 


\subsection{What is 'Power'?}

In any post-structuralist examination of resistance or social struggle, it is no longer sufficient to ask simply: who has power and who does not? Post-structuralist writers-in particular political theorist Michel Foucault $(1980 ; 1991)$ and philosopher Gilles Deleuze (1994) - have shown that power no longer simply means that 'dominators' exert their will over the 'dominated'. Instead, power is seen as the exercise of multiple wills on a micro level, always present and always in flux. Furthermore, Foucault asserts that, at the macro level, power operates in service of the production of 'truths' and knowledge. The role for theorists today, then, is no longer to formulate or to uncover global systems of domination, but rather to expound "the logic of the specificities of power relations and the struggles around them" (Foucault, 1980: 145). Before delving into the analysis of the micro-level struggles involved in the politics of health, the following paragraphs further develop this conceptualisation of power.

To begin with, it is important to note that while Foucault (1980: 142) dismisses the idea of power as being in the service of 'a master' or of 'the state', and opposes the notion of one overarching 'class struggle' as the main organising feature of society, he acknowledges that power often serves economic interests. However, the primary pursuit of power, or the means through which power is primarily deployed in contemporary society, according to Foucault's theory of power, is the creation and production of 'truths' and knowledge. In his words: 
Power never ceases its interrogation, its inquisition, its registration of truth: it institutionalizes, professionalizes and rewards its pursuit. In the last analysis we must produce truth as we must produce wealth, indeed we must produce truth in order to produce wealth in the first place. (Foucault, 1980: 94)

If we accept Foucault's assertion that power is ". . . the way in which relations of forces are deployed and given concrete expression ..." (Foucault, 1980: 90), then we must also accept that the best way to analyse power is not in terms of repression, but rather as an ongoing struggle. This study adopts this view of power as the expression of different relations of forces, and the following pages examine this notion of power in the context of the struggle over the regulation of pharmaceutical drugs.

Foucault (1980: 142) proposes six provisional hypotheses on power: that power is co-extensive with the social body; that relations of power are interwoven with relations of production, kin, family, sexuality and other types of relations; that these relations of power take on multiple forms, not only the form of prohibition; that their interconnections delineate general conditions of domination; that power relations do indeed 'serve' economic interests because they are capable of being utilised in economic strategies; and that there are no relations of power without resistances, which are multiple, local, and can be integrated into global strategies of power. Foucault designates these hypotheses as temporary, and requiring investigation of the specificities of power at the micro level. As such, they will be examined again in light of the following analysis. 


\subsection{Technologies of Government ${ }^{33}$}

The preceding two chapters revealed that subjective experience, on the whole, is marginalised from knowledge-building on anti-malarial drugs and the regulation of pharmaceutical products. While it is used as a 'red flag' or warning system in the process of drug regulation, to alert regulators of serious consequences of a health product (this usually involves death or disability), we cannot say that public criticism of the sciences guides future scientific knowledge. Instead, criticism is silenced and the subjective voice is marginalised. This is accomplished in two important ways: First, instrumentally-a number of individual cases were excluded from the Mefloquine Safety Monitoring Study, for example. The system in place to monitor individual experiences with particular drugs captures only one in 10 adverse reactions $(10 \%)$. Second, interactively—individuals' beliefs about the risks associated with mefloquine are disparaged. Conversely, we also know that subjective experience and subjective knowledge has led to a massive creation of non-expert expertise about mefloquine and mefloquine toxicity and ways to cope with this. However, there is a major lag or disconnect between the subjective experience of travellers who have taken the drug and the official travel health knowledge and prevention strategies that are advocated by Canadian TMPs and by Health Canada. The following pages reiterate the theory of governmentality, and elucidate the role of subjective knowledge in drug regulation from this perspective.

\footnotetext{
${ }^{53}$ It should be noted that a portion of section 6.2 will be published in the following: Kimberly-Anne Ford "Citizenship and Health: The Governance of 'Imported Malaria' and the Safety of Anti-Malarial Drugs." Sociology in Canada: A Canadian Sociology and Anthropology Association Reader. (Toronto: Oxford University Press, forthcoming)
} 
To restate the central argument of the 'governmentality' thesis that was discussed in depth in Chapter Two: the governance of citizens in contemporary society depends them internalising norms and discourses and behaving accordingly, of their own 'free' will. Rose and Miller (1992: 183) write:

Governing is a sphere of strategies, techniques, and procedures through which different forces seek to render programmes operable, and by means of which a multitude of connections are established between the aspirations of authorities and the activities of individuals and groups. These heterogeneous mechanisms we term technologies of government.

They also assert that knowledge is central to government. They specify: "Knowledge here does not simply mean 'ideas', but refers to the vast assemblage of persons, theories, projects, experiments and techniques that has become such a central component of government"; it is this 'know how' that makes government possible (Rose and Miller, 1992: 177). Through the data, it has become clear that what are operating are the 'technologies of government' as discussed in the writings on governmentality (in particular Rose, 1993; Rose, 1994; Rose and Miller, 1992). Therefore, in order to excavate the ways in which governance takes place in the arena of malaria prevention, it is necessary to examine the 'dividing practices', 'assemblages', 'expertise' and 'strategies' (as defined in Rose, 1994: 51-53) involved in the creation and actualisation of public health campaigns. This is done in reference to findings presented in the preceding two chapters. 


\subsubsection{Dividing Practices}

Strategies of governance are based on 'dividing practices', in other words, being able to distinguish sickness from health, and disease from fate, for example, and to have the knowledge basis that allows these distinct entities to be labelled as such. One obvious dividing practice at play in the case study is the differentiation between the harm associated with malaria (a disease that kills) from an adverse reaction to an anti-malarial drug (which is said to be uncommon, temporary, and mild). Malaria must therefore be seen as the disease and the true threat, while a serious adverse reaction to a drug is plain old bad luck. Convincing individual travellers of this, by providing a surfeit of information on malaria transmission rates and a comparative dearth of information about mefloquine toxicity, for example, is one of the central strategies used to guide the conduct of citizens. Another is the creation of blatant public health campaigns that assert that mefloquine reactions are rare and reversible, while death from malaria is not (e.g., Health Canada, 2000: 1). Implicit in these statements, is the false notion that mefloquine never causes death and that malaria always does. This dividing practice (of marking a clear-though erroneous - distinction between the real risk of malaria versus the perceived risk of experiencing a side-effect) trickles down to the level of doctor-patient interaction. One blogger, for example, noticed it when she tried discussing her apprehensions about mefloquine side-effects with her physician. She remarked:

When I discussed the [potential] effects [of mefloquine] with my general practitioner, I was told that it was better than getting malaria. Really? Try travelling in a foreign country, while experiencing frightening hallucinations as you walk down the street. (blogger \#30) 
This blogger follows up by clarifying that she acknowledges that malaria is a serious threat. She would, nonetheless, have liked to receive all of the relevant information about the prophylactic. As such, it is important to note here that the danger of malaria is not disputed, what is called into question is the need to juxtapose affirmations of the danger of malaria with the dismissal of any possible risks associated with mefloquine. This, clearly, is used as a means to control individuals' health choices by manipulating information.

Many of the dividing practices at play in the case study are based upon a 'pointillist' epistemology (as explained in Chapter two), for instance, the distinction between 'serious' versus 'benign' and/or 'sane' and 'insane' reactions to mefloquine. A similarly pointillist dividing practice is at play in the carving up of "malarial" and "nonmalarial" zones.

By contrast, the reality of malaria and of mefloquine alike, is, conversely, fluid, as discussed in Chapter Three. However, it is difficult to govern the grey areas, so a clear line must be drawn between safe practices and risky behaviours, for example. Risk thinking is probabilistic thinking, and populations can be governed according to statistics. At the individual level, however, personal safety seems to be ensured using both an intuitive (or subjective) and intellectual approach. For example, numerous bloggers disagreed with the statement that malaria is worse than experiencing a side-effect from mefloquine. Similarly, many participants in the study mentioned the idea that the operational definition of a serious reaction that is used by Health Canada is too restrictive when dealing with a preventative drug. Many travellers are, unfortunately, simply opting to take their chances with malaria, rather than run the risk of experiencing a serious 
reaction to mefloquine. More, still, are turning to alternative ways of protecting themselves, such as asking for alternative drugs, or using barrier methods to reduce the likelihood of being stung by mosquitoes-wearing light coloured clothing, staying indoors around dusk and dawn, and sleeping under mosquito nets.

\subsubsection{Assemblages}

According to Gilles Deleuze and Felix Guattari (1987), assemblages are connections between 'machines', and the meaning of any single element of a 'machinic assemblage' cannot be deciphered outside of its relation to other elements. With respect to the governance of health, Rose's (1994: 51) notion of 'assemblages' refers to the medical-administrative apparatuses that regulates social space and transforms fate into risk to enable individuals and societies to secure themselves against disease. In this case, 'assemblages' are made up of complex linkages between institutions, spaces, persons and techniques, in which the notions of international travel and drug regulation are problematised as domains of government, which are then translated into systems and strategies of health regulation.

An examination of the 'assemblages' that are implicated in the case study reveal that the governance of health is based on a complex network with many interconnected players. For instance, Health Canada's Population and Public Health Branch draws upon data from the Centre for Disease Control (CDC); the Canadian Institutes for Health Research; and regional health institutes, in order to devise its travel health campaigns. TMPs use this knowledge and affirm that it is access to this most up-to-date information that allows them to claim expertise in the area of malaria prevention. They further add that the most up-to-date information is largely provided through the software program 
Travax, which is manufactured in the U.S.A., thus connecting Canadian and American public health strategies. The Committee to Advise on Tropical Medicine and Travel (CATMAT 2006) "provides the Public Health Agency of Canada (PHAC) with ongoing and timely medical, scientific, and public health advice relating to tropical infectious disease and health risks associated with international travel" ${ }^{54}$ This group must align travel medicine strategies from the aforementioned sources, with the available pharmaceutical products. Decisions are then made about which drugs will be recommended to the public, and/or used to protect the Canadian military, for example. By sending large numbers of individuals to malaria-endemic regions of the world and recording reactions to various drugs, the military serves as a site for the production of further knowledge and testing of health products. Health regulators, such as representatives of Health Canada and Members of Parliament, can demand information about health products from their manufacturers. At the same time, these regulators can withhold such information from the Canadian public, when deemed appropriate under trade law. For example, numerous pages of documentation received from Health Canada for this study had sections that were blocked out, because they supposedly contained trade secrets from Hoffmann-La Roche. This web of social actors and technological elements that are involved in the regulation of pharmaceutical drugs extends to advocacy groups who use information from the aforementioned sources, along with myriad alternative sources, to create new knowledge about mefloquine. These groups influence

\footnotetext{
${ }^{54}$ The Committee to Advise on Tropical Medicine and Travel (CATMAT) also produces the Canada Communicable Diseases Report for Health Canada. See http:/www.phacaspc.gc.ca/publicat/ccdr-rmtc/06vol32/acs-03/index.html (last accessed 24 July 2006).
} 
the process of drug regulation, for instance, when they utilise the media, or their M.P.s, to push for desired changes in the regulation of pharmaceutical products.

In terms of the technologies of health, we can see in the case study how different agents are deployed differently, in the production of 'truths' regarding mefloquine and malaria. Health Canada, the Canadian military, and Hoffmann-La Roche all played a key role in testing mefloquine and producing the knowledge behind the assertion that it is 'safe'. The military's persistent use of the drug, along with (largely American-supplied) international health information, continues to uphold the perception of mefloquine as the best 'first line' of defence drugs for travel to chloroquine resistant malaria-endemic countries. Individual travellers who refuse to take mefloquine, along with members of advocacy groups and bloggers, contest mainstream information about mefloquine. They refer to subjective experience and point to international publications and health policies to support their claims. They also enlist the help of the legal system to charge the manufacturer with producing and marketing an unsafe drug, and failing to warn the public of the health concerns associated with mefloquine.

A network of institutional and individual agents of public health, including Health Canada, international health agencies (WHO, CDC and others), Western military organisations, medical doctors and nurses, pharmaceutical corporations, TMPs, and individual travellers are all enmeshed in the governance of malaria, and the creation of public health campaigns. These agents are also, to varying degrees, responsible for approving or authorising the particular anti-malarial drugs prescribed to travellers. Travellers are implicated in the feedback process, to some degree. However, as discussed 
in depth in the following chapter, their influence over the production of knowledge on, and the regulation of, pharmaceutical drugs, should be increased. .

The travel clinic occupies a central place in this assemblage, because it is here that knowledge is synthesised and communicated to individual citizens who must then be persuaded to fulfill governmental objectives (take drugs and ostensibly remain malaria free). TMPs, in this case, have a critical role to play as 'agents of liaison' (Foucault, 1980: 62): in their efforts to convince citizens to make health decisions that are in line with governmental health strategies.

\subsubsection{Expertise}

The notion of 'expertise' plays a crucial role in governmental politics. Asserting expertise in the field of travel medicine is considered by TMPs to be an important part of their job (if not the most important part). For example, in response to the survey, all TMPs were quick to state that their knowledge far surpasses that of the general or family practitioner, when it comes to travel health. One TMP clearly stated that conveying an "appreciation of travel medicine as an area of special expertise" is a central part of a TMPs job, and one of the greatest challenges faced (TMP \#202). Many other TMPs echoed this sentiment.

The notion of 'expertise' and the 'assemblages' that are discussed above are interlaced. A network, or fragment of a network, is much stronger when there is an avowal of expertise within. For example, Hoffmann-La Roche is more successful at convincing the media and regulators of the safety of its products when an impartial expert (i.e., a scientist) can be hired to support their claims. Likewise, advocates such as the group 'Lariam Action' are more successful at persuading health regulators that their 
members' health needs are relevant when an expert has verified the claims made by members of such advocacy groups regarding the potential risks associated with mefloquine use. We can begin to see how different networks of consumers and advocacy groups, for example, become aligned. Once these networks gain expertise, either by accessing a body of literature to support their assertions, by filling lawsuits, or by finding an "expert" to support their position, they become more powerful. This suggests that in order for individuals to gain power and have their claims about mefloquine heard, they must align themselves with experts. Another way that groups like Lariam Action and its members become powerful is by creating new knowledge about mefloquine that is useful for the broader community of travellers. This is the case, for example, with respect to the knowledge created by Lariam Action about mefloquine toxicity, as discussed in Chapter Five.

\subsubsection{Strategies}

Foucault (1980: 252-254) explains that "what is meant by strategy of power is the interplay between one or more programmes/technologies and an operational evaluation in terms of strategy: a logically hybrid (and sometimes elusive) function which integrates the production of effects with the utilisation of those effects." This is where subjective knowledge is most important, since it is usurped by 'the system' to validate 'the system'. For example, with reference to the case study, it is the lived experience of the first travellers to take mefloquine that (in part) furnished the materials to produce the safety data that we now have today. As seen in the discussion of the different stages involved in the regulation of pharmaceutical products, what goes on in the laboratory is not the most important component of ensuring that a drug is useful and safe. In fact, most unexpected 
reactions come to light once ordinary people start taking the products in their everyday lives.

In order for governing campaigns to be successful, there must be a mechanism by which subjective knowledge (or the lived experience) of citizens must be 'recuperated', or, as Foucault clarifies, for there to be a "usual strategic development of a struggle" (Foucault, 1980: 56). In order for public health campaigns to develop, individual travellers must share their subjective experience with the medical establishment and health institutions. This subjective knowledge is coded and recorded then it is transformed into statistics on disease prevalence and drug side-effects. This 'clinical knowledge' (Foucault 1973) becomes that which can uphold or transform medical knowledge and/or health discourse.

On the surface, findings from the case study suggest that TMPs act as 'agents of liaison' who must encourage citizens to behave in ways that are in line with national public health campaigns. Present-day guidelines from Health Canada identify mefloquine as the 'first line of defence' drug for Canadian travellers who are heading to regions of the world with chloroquine-resistant strains of malaria. ${ }^{55}$ All of the TMPs who responded to the survey acknowledge the importance of their clients' direct experience with anti-malarial drugs, or travel to a malarial country. For example, TMPs recognised that for travellers', having experienced a side-effect directly affects their choice of a new prophylactic. However, intuition, 'interactive knowledge'-i.e., knowledge that is gained by sharing a lifeworld with others, listening to friends and family, or indirect experience

\footnotetext{
${ }^{55}$ According to one interview respondent, as of 2005, Health Canada was in the process of changing its travel health guidelines and endorsing three "first line of defence" drugs: mefloquine, malarone and doxycycline.
} 
(Park 1993) - and common sense or the travellers' grapevine, are all disavowed by TMPs, who assert that it is their role to dispel "myths" about mefloquine and convince their clients to take a prophylaxis-usually mefloquine. In other words, the data supports Beck's claim (1992: 57; as noted above): TMPs act in accordance with, and want to uphold, the dichotomous view that "science 'determines risk' and the population 'perceives risk". This division between experts and non-experts, in Beck's view, shapes an image of the public as ignorant, but well intentioned. It encourages the belief that "protests, fears, criticism or resistance in the public sphere are pure problems of information. If the public knew what the technical people know, they would be at easeotherwise they are just hopelessly irrational" (Beck, 1992: 58). Although TMPs affirm that information about malaria and the various ways to prevent it is available, they consider their patients to be misinformed or ignorant. Therefore, they see it as their greatest challenge to get their patients to take the risk of malaria seriously and to take mefloquine to protect themselves. TMP survey respondents acknowledge that the individual has control over his or her own body, and thus is free to choose which antimalarial drug to use. However, they do not concede that citizens can have any role in the broader realm of public health, and they dismiss the experiential knowledge possessed by individual travellers as being mythical or non-factual.

Governance requires control over knowledge production and reproduction. Certain modes of knowledge (intuitive and subjective) are necessarily outwardly marginalised and discredited in order to encourage compliance with mainstream public health campaigns. However, it is important to note that these subjugated knowledges are 
not excluded from the governing process; rather, they are fundamental to the development of knowledge and discourse. Foucault explains:

In fact, those unitary discourses, which first disqualified and then ignored [subjugated knowledges] when they made their appearance, are, it seems, quite ready now to annex them, to take them back within the fold of their own discourse and to invest them with everything this implies in terms of their effects of knowledge and power (Foucault, 1980: 86).

This knowledge is thus enmeshed in the re-creation of discourses of power and may lead public health institutes to re-evaluate their strategies. Slowly, but surely, this is taking place in North America. Public pressure has led to a number of Food and Drug Administration (FDA) warnings about mefloquine, and there have been a number of changes in the product insert, including information about the potential risk of suicidal ideation. Moreover, the FDA has recently allowed the Glaxo-Wellcome pharmaceutical corporation to market the drug Malarone $(\mathbb{B}$ as the 'safer anti-malarial drug' in the U.S.A., and to state that it has a better safety profile than mefloquine (GlaxoSmithKline, 2002). In Canada, one public health official noted: 
Health Canada will post new guidelines for Canadian travellers for the prevention of malaria on their website. These new guidelines will have myths about malaria and also more complete information about the three "first line drugs" mefloquine, malarone and doxycycline. These three drugs are all between 90 and $95 \%$ effective (Interview Respondent \#3.1, female, medical doctor) ${ }^{56}$

In sum, although it is outwardly dismissed by TMPs as irrational and counterfactual, citizen concern over the safety of mefloquine is actually contributing to a shift in Canadian malaria prevention strategies. This is taking place with respect to other pharmaceutical drugs and health issues as well (for example, see Canadian Broadcasting Corporation (CBC), 2004).

Non-expert knowledge is outwardly disparaged, but, internally, it is used strategically to inform health policy and regulation mechanisms. Perhaps this is a key part of the strategy to make people listen to the "experts" and govern themselves accordingly. Meanwhile, power 'recuperates' non-expert, subjugated knowledge, recoding and reinterpreting it, and finally giving it a stamp of approval, before enfolding it into the strategies and mechanisms of governance.

\subsection{Stakeholder Analysis: A Lens to Expose Power Dynamics}

The following stakeholder analysis adopts the post-structuralist approach to power as a fluid expression of multiple forces. It delineates the specificities of power

\footnotetext{
${ }^{56}$ Interestingly, like the first set of guidelines that contained "myths about mefloquine", this second set of guidelines also contains a discussion of "myths"; this time "myths about malaria". Herein lies one example of Health Canada's outward criticism of public risk perception.
} 
dynamics at the micro level in order to shed insight on the operation of power at the macro level. Stakeholder analysis allows a researcher to think through the power differentials of individuals and groups who are in some way affected by, or involved in, a social and political problematic that is under investigation. The tools and principles of stakeholder analysis were used to guide the data collection process. In this chapter, they are employed as lenses with which to render visible the flows of power and communication at play in the regulation of pharmaceutical drugs and the creation of travel health campaigns, and are adapted in order to create a post-structural stakeholder analysis.

The first step in conducting a stakeholder analysis is to brainstorm on a list of potential stakeholders. The following list of primary stakeholders was generated during data collection:

Drug makers: chief executives, employees and shareholders of Hofmann-La Roche pharmaceuticals;

Drug takers (or 'forsakers'): travellers to malaria-endemic regions of the world who either adhere to anti-malarial regiments or forsake anti-malarial drugs altogether; Drug Providers: anyone involved in prescribing or dispensing mefloquine, such as TMPs, other medical Doctors, military medical personnel, pharmacists; and Drug Regulators: representatives of from Health Canada, representatives of Parliament, the WHO, CDC, etc.

This list could be expanded to include all of the various governmental agencies, non-governmental organisations individuals and groups who were identified in the previous chapter as being involved in the process of pharmaceutical drug regulation in 
Canada. For the purpose of this analysis, the list of stakeholders is limited to those who have been involved in the research project either directly (as participants) or indirectly (as authors of documents that were used in the study). The result is the following list of stakeholders:

Drug makers: These stakeholders' voices are present in the research project through published works only, since drug makers repeatedly refused to take part in interviews. Drug takers (or 'forsakers'): Include travellers to malaria-endemic regions of the world who either adhere to anti-malarial regiments or forsake anti-malarial drugs altogether; along with bloggers and members of advocacy groups; and members of the military who have been forced to take mefloquine for military deployments

Drug Providers: Include TMPs, other Medical Doctors, and military medical personnel and military officers who order their subordinates to take mefloquine.

Drug Regulators: Include representatives from Health Canada, and representatives of Parliament. The military also plays a part in this group, because of its; role in testing mefloquine (under the auspices of the Mefloquine Safety Evaluation Study).

Based on the above, we know that these stakeholders are all inter-connected in the web of technology/society.

Chevalier (2001) shows how further classification and categorisation of stakeholders can lead to a better understanding of the power dynamics among them. For instance, in a given scenario with one potential objective, stakeholders should be categorised as 'positively' or 'negatively' affected and 'directly' or 'indirectly' affected. Taking the objective of improving drug safety by incorporating subjective experience 
into the regulatory process, for instance, one can map out the various stakeholders' positions as follows: drug takers and forsakers could potentially have access to safer anti-malarial drugs, they are, therefore, positively and directly affected. Drug makers could potentially suffer from a decrease in the sales of mefloquine and decrease in credibility vis-à-vis other stakeholders, they are, therefore, directly and negatively affected. Drug providers could potentially have a better understanding of drug safety and are, therefore, indirectly and positively affected. Finally, drug regulators might have to work with more complex regulatory processes, might have more work, and would need more resources to be devoted to drug regulation. They are, thus, potentially affected indirectly and negatively by the project objective. The following table maps out these objectives 
Table 6.1 Stakeholder Position Vis-à-vis the Objective of Improving Drug Safety by Incorporating Subjective Experience into the Regulatory Process.

\begin{tabular}{|c|c|c|}
\hline $\begin{array}{l}\text { GOAL: Improving drug } \\
\text { safety by incorporating } \\
\text { citizens' 'subjective } \\
\text { experience' into the } \\
\text { regulatory process. }\end{array}$ & $\begin{array}{l}\text { Positively-Affected } \\
\text { Stakeholders }\end{array}$ & $\begin{array}{l}\text { Negatively-Affected } \\
\text { Stakeholders? }\end{array}$ \\
\hline $\begin{array}{l}\text { Directly-Affected } \\
\text { Stakeholders? }\end{array}$ & $\begin{array}{l}\text { Drug Takers or } \\
\text { Forsakers } \\
\text {...would have greater } \\
\text { awareness of potential } \\
\text { side-effects and } \\
\text { contraindications, and } \\
\text { would, ultimately, } \\
\text { have access to safer } \\
\text { anti-malarial drugs. }\end{array}$ & $\begin{array}{l}\text { Drug Makers } \\
\text {...would suffer from a } \\
\text { decrease in sales of } \\
\text { mefloquine; a decrease in } \\
\text { credibility vis-à-vis other } \\
\text { stakeholders. }\end{array}$ \\
\hline $\begin{array}{l}\text { Indirectly-Affected } \\
\text { Stakeholders? }\end{array}$ & $\begin{array}{l}\text { Drug Providers } \\
\text {... would have a better } \\
\text { understanding of drug } \\
\text { safety. }\end{array}$ & $\begin{array}{l}\text { Drug Regulators } \\
\text {... would have to work } \\
\text { with more complex } \\
\text { regulatory processes, } \\
\text { might have more work, } \\
\text { would require more } \\
\text { resources for drug } \\
\text { regulation. }\end{array}$ \\
\hline
\end{tabular}

(adapted from Chevalier, 2001)

A more post-structural approach to the above analysis would require an identification of the many different ways in which stakeholder groups can be classified into each of the distinct cells, given a variety of different contexts. However, this somewhat rough schema is useful in that it illustrates that the marginalisation of subjective knowledge in this political problematic, might indeed serve of economic interests, as Foucault (1980) suggests. It is likely, for instance, that drug makers find ways to delimit the inclusion of subjective knowledge when it can negatively impact sales of their products. The marginalisation of subjective knowledge might also be in 
service of an abstract conception of regulatory efficiency, for, as Gordon (1991: 24) explains, contemporary governmental rationality dictates that governments create technologies that are aimed at accomplishing more through a lesser exertion of force. Accordingly, regulators might reject subjective knowledge that does not fit into an efficient and straightforward means of calculating risk, and one that maximises social control.

Taking the stakeholder analysis to the next level, according to Chevalier (2001), contemporary understandings of stakeholder saliency encompass three elements: power, interest, and legitimacy. Citing the work of Mitchell et al., (1997) Chevalier explains that salience is the degree to which a stakeholder or stakeholder group can succeed in inserting its interests high on other stakeholders' agendas (Chevalier, 2001: 9). Taking a post-structural approach to the analysis, it is not sufficient to ask: which groups have power, interests or legitimacy, or a combination of all three, and which do not. We know from Foucault's (1980) work that, instead, power is always everywhere and is fluid and that every stakeholder group in endowed with interests and some form of legitimacy. Instead, we must develop or expand upon these terms further to get a better sense of stakeholder salience. One can therefore ask the following three sets of questions about each of the primary stakeholder groups in order to get a better understanding of the power dynamics between them:

1. What are their objectives vis-à-vis travel medicine and the regulation of pharmaceutical products, or whose interests are being served? 
2. How do they exert their will, in order to meet their objectives (financial, coercive, discursive, etc.)? In other words, when, where and it what ways are the strategies used to actualise their power?

3. What sources of legitimacy do they possess? Or, in what ways are their actions and objectives supported?

Because this study deals specifically with the creation of knowledge, a further question is asked: What sorts of knowledge do each of the stakeholder groups use, to pursue their interests? Asked another way: How do they support their claims? The following table illustrates stakeholders' interests, power, and sources of legitimacy and forms of knowledge used by each group.

Table 6.2 Stakeholders' Interests, Power, Legitimacy and Types of Knowledge Used

\begin{tabular}{|l|l|l|l|l|}
\hline Stakeholder & Interests & Types of Powers & Legitimacy & Knowledge \\
\hline $\begin{array}{l}\text { Takers and } \\
\text { Forsakers }\end{array}$ & $\begin{array}{l}\text { Individual } \\
\text { Social }\end{array}$ & $\begin{array}{l}\text { Financial } \\
\text { Discursive } \\
\text { Political } \\
\text { Legal } \\
\text { Interactive } \\
\text { Instrumental }\end{array}$ & $\begin{array}{l}\text { Personal } \\
\text { Legal }\end{array}$ & $\begin{array}{l}\text { Instrumental } \\
\text { Interactive } \\
\text { Critical }\end{array}$ \\
\hline Makers & Economic & $\begin{array}{l}\text { Financial } \\
\text { Instrumental } \\
\text { Discursive }\end{array}$ & Legal & Instrumental \\
\hline Regulators & Social & $\begin{array}{l}\text { Discursive } \\
\text { Instrumental } \\
\text { Political }\end{array}$ & Legal & $\begin{array}{l}\text { Instrumental } \\
\text { Interactive } \\
\text { Critical }\end{array}$ \\
\hline Providers & Social & $\begin{array}{l}\text { Discursive } \\
\text { Interactive }\end{array}$ & $\begin{array}{l}\text { Instrumental } \\
\text { Interactive } \\
\text { Critical }\end{array}$ \\
\hline
\end{tabular}


At the basic level, individuals in the 'Drug Takers and Forsakers' stakeholder group, serve their own interests: the desire for travel and need for safe and effective drugs. The group can also be seen to serve social interests, when efforts are made to improve the overall health of travellers (for example, informing others on the potential effects of mefloquine toxicity, or letting others know about the particular places where there have been malaria outbreaks), or when efforts are made to improve the safety of the drugs. The strategies they use to actualise their power are: financial - spending money on drugs; discursive - such as promoting the use of alternative drugs or promoting alternative health knowledge on the Internet; political - by lobbying for changes to the product label; instrumental - by reporting adverse reactions to drugs; and interactive - by using word of mouth to convince other travellers to avoid certain malarial regions or to use alternative drugs. The sources of legitimacy behind this stakeholder group's pursuit of its objectives and interests are personal (i.e., doing what's best for them); legal (since citizens of Canada have the right under our Health Care Act to have access to safe drugs); and social (since travellers might come to count on the work done by activists to get them safer drugs, or individuals look to bloggers to get alternative information about mefloquine).

Drug Makers' interests are economic. This stakeholder group aims for a return on investment and a profit for shareholders. One could argue that drug makers also have societal interests at heart: i.e., producing products that improve the overall health of society. However, nothing in this study has demonstrated that this is the case. Requests for interviews with the manufacturer of the drug were repeatedly denied. Moreover, in 1999, Hoffmann-La Roche was voted the worst corporate criminal of the decade (of the 
1990s) by Corporate Crime Reporter, for fixing prices and market manipulation (Mokhiber, 2000). Based on a cursory Internet search, it was determined that, since then, Hoffmann-La Roche was charged in thousands of lawsuits, for failing to inform consumers of the adverse effects of Lariam ${ }^{\mathrm{TM}}$, Accutane ${ }^{\mathrm{TM}}$, and Versed ${ }^{\mathrm{TM}}$ (all of which have allegedly been implicated in thousands of deaths and countless instances of disability); with price fixing; and deception, for example, in not informing the public of a dye it created to colour farmed salmon its vibrant pink/red colour, without which it would be dull and grey. So, while the interests of Hoffmann-La Roche could be disputed, it seems that although this company is in the business of health, they are likely to turn a blind eye on death and disability in order to make a profit. Their power is largely financial (drug makers have a large budget set aside for legal disputes, for example). It is also instrumental, in that they produce the scientific research involved in developing and testing drugs. They also exert discursive power in their ability to market their drugs and promote certain health campaigns. The legitimacy of the Drug Maker's position is legally predicated. The rights and privileges of the corporation are enshrined in Canadian law, as is the manufacturer's role in producing, testing and marketing health products for Canadians.

Drug Providers' interests are social, improving the overall health of the population. They use discursive means to exert their power (i.e., creating health campaigns); interactive means, for example through doctor-patient interactions citizens are prescribed certain health regimens; and coercive means (for example military commanders can court marshal their subordinates for not taking a drug and medical doctors can hold patients against their will if they experience an adverse reaction that 
renders them incapable of caring for themselves). Drug Providers' legitimacy is institutionally affirmed, since medicine plays a central role in the functioning of society; it is also legal, since it is enshrined in the Canadian Health Act (1984) and in codes of conduct. This is an interesting case, because the interests of 'Drug Providers' are social, but their strategies are in serve economic interests (i.e., the travel industry and the pharmaceutical industry). This will be discussed further below.

Drug Regulators' interests are societal, to ensure that health products are safe and effective, and that the overall health of Canadians is not threatened by epidemics, among others. Their power is discursive, for instance through the creation of public health campaigns, and instrumental, by overseeing the database of adverse reactions. The legitimacy of Drug Regulators is legal, as it is enshrined in Canadian Constitutional Law and the Canada Health Act (1984).

Stakeholder analysis suggests that stakeholders can be categorised into the following groups: 'dormant' stakeholders, who only have power; 'discretionary' stakeholders, who only have legitimacy; 'demanding' stakeholders who only have a strong interest and/or urgent claims; 'dependent' stakeholders, who have both legitimacy and interest; 'dominant' stakeholders, who have power and legitimacy; 'dangerous' stakeholders, who have interest and power; and 'definitive' stakeholders, who have legitimacy, power and strong interests or urgency. According to the stakeholder analysis perspective, power can not be evaluated in the absence of legitimacy and urgency, because ". . power gains authority through legitimacy and it gains exercise through urgency" (Mitchell et al., 1997: 869 as cited in Chevalier, 2001: 9). 
While the four stakeholder groups discussed above each have sources of legitimacy as well as interests and claims, we can see that individual citizens, the 'Drug Takers and Forsakers' group, represent the definitive stakeholder group, because they possess the most varied sources of legitimacy, as well as serve various interests through different types of power strategies. The important question, explored in the following sub-section is the following: given that Drug Takers and Forsakers have the most diverse sources of legitimacy and utilise the most diverse forms of power, why is it that their interests are least likely to be met —or, more specifically, why is their subjective knowledge marginalised?

Before moving onto the next section, because the study deals with the creation of medical knowledge, and its function in society as a discourse of power, the stakeholder analysis is taken one step further in order to elucidate the type(s) of knowledge utilised by each of the stakeholder groups to advance their position. Park (1993) identifies three main types of knowledge: 'instrumental knowledge', which is epitomised in the classic experimental design and embodied in researcher-subject dualism, and which usually employs positivist methods; 'interactive knowledge', which comes from sharing a lifeworld with others and includes lived experience and shared values; and 'critical knowledge', which is gained through the synthesis of reflection and action (or praxis), and often centers on the rational and moral grounds for action (Park, 1993: 6-7). Park argues that science has been colonised by instrumental knowledge, but that it should be composed of all three types of knowledge.

What sorts of knowledge do each of the stakeholder groups use, to pursue their interests? Takers and forsakers use instrumental knowledge when they base their health 
decisions on scientific research and risk/benefit calculations; they use interactive knowledge when basing their health decisions on their values or by listening to the experience of others; they use critical knowledge when involved in advocacy work or the sharing of health information with others (through the creation of blogs, for instance).

Drug Makers use instrumental knowledge, the business of pharmaceutics is largely based on cost/benefit analysis. Drug Providers largely refer to instrumental knowledge; and most allopathic Western doctors follow scientific research—in some cases another form of instrumental knowledge-and ignore all other forms of reasoning. As shown in responses to the TMP survey, the majority of TMPs disparage interactive knowledge and dismiss their patients' subjective knowledge as myth and misinformation. However, some doctors also employ interactive knowledge. In this study, the medical doctors who turned to the Internet to find out more information about mefloquine are a good example of 'drug providers' who use interactive knowledge. Some 'providers' also employ critical knowledge, this is evidenced most clearly in the organisation Medecins Sans Frontieres' objectives: "providing medical aid wherever needed, regardless of race, religion, politics, or sex and raising awareness of the plight of the people we help". Regulators also use all three forms of knowledge. They base their decisions largely on instrumental logic. However, they also employ critical and interactive knowledge. This is shown, for instance, in the case of the M.P. who challenged the use of mefloquine by the military. He was swayed by a personal account of a mefloquine reaction and through interactions with the victim's family. As noted in Chapter Three, this M.P.'s involvement led to questions and debates in the House of Commons. 
In sum, the 'takers and forsakers' group is listed first in the table. This group has two distinct interests, utilises the most diverse kinds of power, and has two sources of legitimacy. Drug 'providers', meanwhile, are at the bottom of the list. They only utilise two types of means to express their power, have one interest and one source of legitimacy.

\subsection{Chapter Summary and Discussion}

The science of risk, which encompasses public health, is inherently political. This is particularly clear in the case of mefloquine and malaria prevention. To make their recommendations, Canadian TMPs are plugged into a network, which is comprised of technological and societal assemblages that are all intertwined in the creation of knowledge about malaria and the best ways to prevent it. Numerous American components factor into this assemblage, for example the $\operatorname{Travax}^{\mathrm{TM}}$ software, which uses data supplied by the American government (through the CDC). Some TMPs have questioned this reliance on American data, while others pride themselves that it is possession of these data that sets them apart from other M.D.s, and secures their expertise in the field of travel medicine.

The stakeholder analysis, above, situates the 'Drug Taker and Forsaker' group of stakeholders in a central position of importance in this project: that of the definitive stakeholder group. Their interests are individual and societal, they utilise a variety of approaches to actualise their power, their interests are underpinned by both legal and personal sources of legitimacy. Moreover, they use various forms of knowledge in order to meet their needs and serve their interests. However, when taking a step back and 
looking at the political processes involved in the creation of travel health knowledge and the regulation of pharmaceutical products, the needs of the consumer seem to be sacrificed in favour of other interests (largely economic interests). This quandary can be attacked by examining the knowledge-position of citizens in the governance of health in our society. Agreeing with Rose and Miller, one can argue that it is through subjectivity that government is shaped and exercised:

Government is the historically constituted matrix within which are articulated all those dreams, schemes, strategies and manoeuvres of authorities that seek to shape the beliefs and conduct of others in desired directions by acting upon their will, their circumstance or their environment. It is in relation to this grid of government that specifically political forms of rule in the modern West define, delimit and regulate themselves. (Rose and Miller, 1992: 175)

In this light, we come to understand that governments do not 'govern' health, rather, it is through the problematisation of health and health issues (among other 'problems of populations'), that governmental bodies define themselves, and through which power is enacted. Subjective knowledge delineates how this will take place. However, this subjective knowledge no longer expresses the individual's values, experience or viewpoints, rather it is a new kind of subjective position, one that has been translated to reflect the needs of the many, or the abstract conception of the average citizen.

While Foucault (1980) does not want to reproduce 'grand' narratives of power, or to locate the source of political power in the figure of a master or the state, he does affirm that there exists 'a structural bipolarity' which characterises all modern projects of human 
governance: the tension between the individual and the population. He argues that governments must struggle to create the perception that every practice of governance has been elaborated to be evaluated at both levels (Foucault, 1980). He explains:

Modern forms of governance are thus conceptualized in terms of a double surface of effects, or by means of a double-entry system of calculation. And the ratio of this bipolarity is the basic premise of modern forms of governmental practices which requires that a good and legitimate government or governance of men [sic.] must be one which is omnium et singulorm, of all and of each. What underpins the evergreen moral and ontological arguments in social and political theory about the 'individual and society', including their current forms as theories of 'the subject' and of 'socialisation' is the strategic rule by which organised relations of power are called upon to integrate these dual imperatives of good government. (Foucault, 1980: 254)

In sum, all forms of governmental action are conceived of in terms of their effects on the individual and the collective. Given the premise advanced by Ian Hacking (1990: 109) in "The Taming of Chance", that the 'average citizen' does not exist (Hacking, citing the early work of Quetelet, refers to "average man"), it is not surprising that strategies in the governance of health might fall short of their desired outcomes at the individual level. One case in point from the data is the idea that prescribed dosages of mefloquine were based on shoddy data, and an approximation of what the 'average male' could safely take. Consequently, for individuals of the other gender, of different sizes, and/or with different lifestyle, the prescribed public health regimen might not be suitable. This has repercussions at the societal level as well. If all of those people who do not 
embody the characteristics of the 'average male' fail to comply with a prophylactic regimen, for example, there will be increases at the societal level of rates of 'imported' malaria. So, while modern projects of governance in the area of health are meant to be omnium et singulorm (of one and of all), they might actually simply be of nemo (nobody) in reality. What interests, then, if not (only) the needs of individuals and society, do public health campaigns serve? This question will be explored, with respect to the case study, in the concluding.

Based on the above analysis, it is possible to review Foucault's six provisional hypotheses on power and apply them to the case of travel medicine and the regulation of pharmaceutical drugs, as a strategy of government: First, power is not only "co-extensive with the social body", but relations of power constitute the social body. The case study shows that government, non-governmental organisations, industry, international health agencies, and the general public, adopt various techniques to exert their will and advance their interests. These relations are ingrained in the general operations of government. Second, relations of power are interwoven with relations of production and in the interactions between physicians and their clients. They also permeate the relations between travellers (in their multiple forms- on the Internet, overseas), and the relations between the military and Health Canada. Third, these relations of power take on multiple forms, not only the form of prohibition (as in coercive or physical forms of power), but also discursive, interactive, financial, legal, instrumental means to exert one's will. Fourth, power relations seem to favour the pursuit of economic interests, in particular, those of the pharmaceutical and the travel industry. Fifth, these overarching relations of power are permeated by local and multiple instances of resistance (such as the refusal of 
clients to take mefloquine, the creation of blogs on mefloquine, media reports on the risks associated with mefloquine, questions raised in the House of Commons of the regulatory process, etc., which are integrated into global strategies of power. Sixth, the interconnections of relations of power do delineate general conditions of domination. (Foucault, 1980: 142).

Although citizens might have diverse strategies to actualise the power at their disposal, along with many different sources of legitimacy and interests, they have difficulty meeting their needs and getting their voices heard. This study indicates that this is for two reasons: first because the social is so closely tied with economic interests; and second, because they are not networked into the massive assemblages involved in the creation of knowledge about health. Furthermore, subjective knowledge is marginalised by the tension between individual and societal interests, wherein individual interests are often compromised in favour of some fictitious ideals or norms or ideas about 'the good' or 'the average man'. 


\section{Personal Narrative \#6-Get Well Soon}

As I set out to write this final entry, I continue to have a nagging feeling about the entire personal narrative and its place in this thesis: I fear that it is too 'soft'; or irrelevant; a distraction from the 'real' product; or worse, a blatant attempt to get sympathy points and an unproblematic defence! Perhaps the social forces at play in my self-doubt are the same forces that denigrate the subjective voice, and marginalise it from scientific knowledge-building endeavours altogether. This last thought, surprisingly, gives me great comfort. I came across some get-well cards in my 'crazy time file'. They are inscribed with messages, such as:

"Here's hoping the days will pass quickly until you feel well once again. Remember that warm thoughts and wishes are with you each day until then." and “We're cheering you on to good health-hoping you'll be feeling better soon."

It was five years ago that I was hospitalised for my adverse reaction to mefloquine. As I sit at my desk, putting the finishing touches on this thesis, I can say finally say that I feel much better now! 


\section{Chapter 7 Conclusion: From Mefloquine Madness to Mefloquine Dreams}

\section{Figure 7.1 Malaria Sucks!}

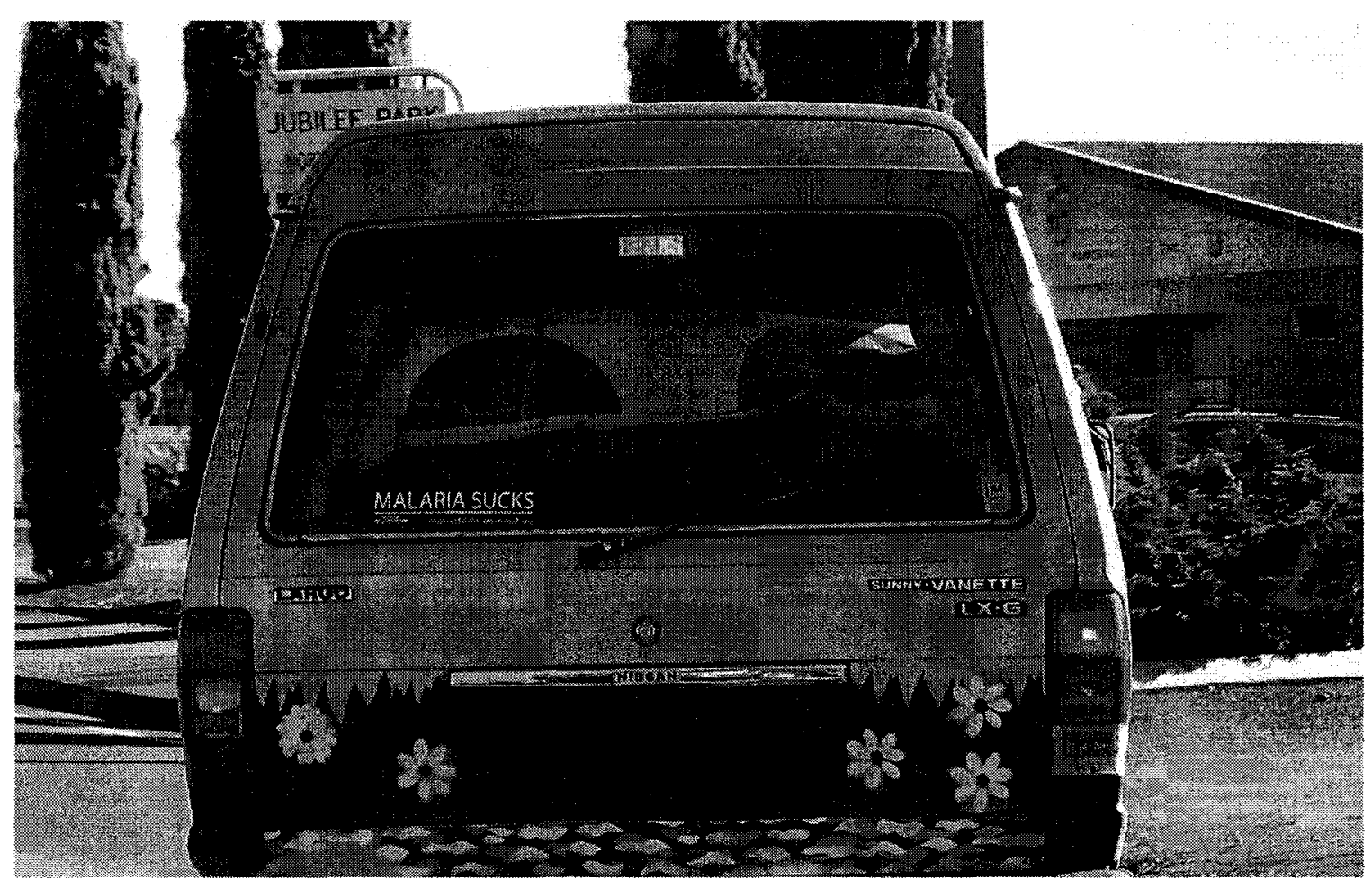

The bumper sticker in the photograph above reads "Malaria Sucks"! It is one of many products on sale through the organisation 'SurfAid', which is comprised of individuals who are connected through their love of surfing, and who are committed to improving the health of people living in isolated regions of the world where they surf. ${ }^{57}$ The group is involved in a number of public health projects in the Mentawai Islands in Indonesia. These projects have had tangible results, for instance one malaria control

\footnotetext{
${ }^{57}$ www.surfaidinternational.org (last accessed 01 May 2006).
} 
project that has resulted in a $75 \%$ reduction in deaths in two Mentawai villages (SurfAid, 2005). SurfAid is also involved in the creation and distribution of 'rapid diagnostic kits' for diagnosing malaria, and in training local health practitioners in their use.

This obscure case is raised because it exemplifies the interpenetration of society and technology. It demonstrates that shared interests, paired with the appropriate local knowledge, can bring about technological change and an overall improvement in health. Surfaid is also a case of reflexivity in action, as discussed by Beck (1992) and expounded below. Based on local knowledge, the group determined that the technology in place for diagnosing malaria (the clinical picture) was "... only right $50 \%$ of the time or less", and that this resulted in "... poor treatments, wasted medicines and the creation of the drug-resistant Malaria currently causing problems in the Mentawai" (SurfAid, 2005: 2). Based on public criticism and a democratisation of science, new techniques were put in place, which allow cases of malaria to be diagnosed and treated within 24 hours.

We are now in the later half of the decade to "Roll Back Malaria", according to the WHO, yet despite global efforts, this preventable disease continues to claim over one million lives worldwide, annually, most of these in Sub-Saharan Africa (WHO, 2004). Closer to home, researchers from the CDC have reported a $3.6 \%$ increase in cases of malaria acquired by Americans outside of the U.S.A., from 1,278 cases in 2003 to 1,324 cases in 2004. Four of these recent cases were fatal. Most importantly, with respect to the case study, they note:

Of 775 U.S. civilians who acquired malaria abroad, only 160 (20.6\%) reported that they had followed a chemoprophylactic drug regimen recommended by CDC for the area to which they had traveled. (Skarbinski et al., 2004) 
A large proportion of travellers forego anti-malarial drugs altogether; this corresponds to an increase in cases of malaria acquired abroad by North American travellers. This trend is reflected in the findings of this study. For example, it is in line with the perspective of many bloggers who affirmed that they would rather take their chances with malaria as opposed to taking mefloquine and running the risk of experiencing a serious adverse reaction. This study highlights the need for greater reflexivity in the realm of public health.

This concluding chapter reiterates the central and peripheral research questions and presents some of the key points that were raised in the findings of this study. This is followed by more in-depth discussions on: reflexivity and reflexive modernisation; the role of subjectivity in the present case study and in the governing process on the whole, along with the ways that subjective knowledge could be maximised and used in a more proactive way; and the epistemic reflexivity involved in incorporating the author's subjective voice in the research process. The thesis concludes with a discussion of its limitations as well as avenues for future research.

\subsection{Re-Visiting the Research Questions}

The research project aimed to provide answers to the following over-arching research question:

With specific reference to the prevention and treatment of malaria, what role do/could alternative epistemologies-based upon subjective experience-play in the construction of medical knowledge and understandings of risk and safety? 
This over-arching research question is addressed in two following sub-sections of this chapter. The role that alternative epistemologies actually play in the construction of medical knowledge and in understandings of risk and safety is quite different from the best-case scenario, which it could play. The role that alternative epistemologies do play is addressed in the section on the question of subjectivity. The role that alternative epistemologies could play, meanwhile, is discussed in the section on reflexivity.

The over-arching question was then broken down into two sub-questions. First, what is the present state of knowledge on malaria and mefloquine? Specifically, what types of knowledge claims do various stakeholder groups put forth regarding mefloquine, and how do these claims come together in discourses of safety and danger regarding malaria and mefloquine? The present state of 'official' knowledge on mefloquine for Canadian travellers is that it is the "drug of choice" for travel to chloroquine-resistant, malaria-endemic, parts of the world. The Department of National Defence is quick to affirm this, for instance, when discussing malaria prophylactics. Moreover, this 'official' position is also behind the propensity among TMPs to identify mefloquine as the most commonly prescribed anti-malarial drug in Canada. Health Canada, another 'official' source of knowledge on public health and anti-malarial drugs, has recently tempered its endorsement of mefloquine. It now identifies it as one among three of the "first line of defence drugs", along with chloroquine and malarone. Not surprisingly, the drug makers stand behind their products. Hoffman-La Roche still claims that mefloquine is the best choice for fighting malaria, while Glaxo Smith Kline argues that Malarone is the safer anti-malarial drug, and has been allowed by the FDA to make this statement. 
Conversely, there is a growing mass of resistance to the 'official' line about mefloquine. Since 1993, members of the House of Commons have raised questions and debated its safety. The advocacy group 'Lariam Action' has amassed a growing body of knowledge on 'Lariam toxicity' and other serious adverse effects of mefloquine.

Moreover, individuals are creating networks on the Internet to discuss the pros and cons of mefloquine, and many of them are coming to the conclusion that mefloquine is too dangerous for prophylactic use.

So, what types of knowledge does each stakeholder group put forth with respect to mefloquine and malaria and how does this knowledge come together in discourses of safety and danger? This question can be answered with reference to the post-structuralist stakeholder analysis and the examination of different types of knowledge claims put forth by each of the stakeholder groups (as presented in Table 6.2 supra). From this analysis, we ascertain that individual travellers refer to instrumental knowledge when they base their health decisions on scientific research and risk/benefit calculations. They also make use of interactive knowledge, when they base their health decisions on their values and/or the experiences of others. They further engage in interactive knowledge-building when they become involved in advocacy work or share health information with others (through the creation of blogs, for instance). Drug makers put forth instrumental and technical claims about the efficacy and safety of their products. Drug providers most often repeat the instrumental technical knowledge put forth by pharmaceutical corporations and health institutions. Drug regulators largely employ instrumental rationale in their decisionmaking, however, at times, they can be swayed by interactive or critical knowledge. 
At the risk of oversimplification, it could be argued that the overwhelming 'official' public health discourse emphasises that malaria is deadly, and that mefloquine is not only safe but also the best method available to protect travellers from the disease. By contrast, the 'alternative' position is that mefloquine is too risky to be used as a prophylactic. That said, the 'official' and the 'alternative' voices are in fact co-extensive and are not truly discrete entities: some military officers contest the use of mefloquine, for example; equally, some bloggers endorse it.

It was also asked: How could or how does subjective experience have an impact on the regulation of drug safety and the creation of public health campaigns (in particular, anti-malarial campaigns)? Put simply, subjective experience-in the form of medical symptoms, reports of illnesses and/or psychotic episodes, and recovery informationprovides material needed for the system to function. It is the 'materiality of power' (Foucault, 1980: 55; see below) that confirms the effectiveness of mefloquine outside of the laboratory, for example, and allows it to become the recommended prophylactic drug. Subjective experience also serves a 'watchdog' function in the system that monitors the safety of pharmaceutical drugs; it can act as a 'red flag' to indicate unexpected, serious health problems that require further investigation. A more proactive role for subjective knowledge is discussed further below.

\subsubsection{The Universal and the Particular - or The "Lies of the State"}

This thesis illustrates that the governance of a population's health involves a politically complex network of actors and institutions. Optimistically speaking, various elements of the network are cooperating to produce the ultimate best health for members of the population. However, as will be addressed in the following section, there are a 
number of other (non health-related) social and political interests that are being served through the governance of health in society. All of the materials of government-the heterogeneous mechanisms, strategies and techniques used to govern citizens-create and uphold a structural bipolarity: that of the tension between the one and the all, or the individual and the social. Some philosophers, most notably Friedrich Nietzsche, have argued that the idea that the state operates to serve the needs of its people in a democratic way is purely fictional. Nietzsche asserts: "State is the name of the coldest of all cold monsters. Coldly it tells lies too; and this lie crawls out of its mouth: "I, the state, am the people" ..." (Nietzsche, 1954: 160-161). Foucault shares this view, and affirms that:

I believe the great fantasy is the idea of a social body constituted by the universality of wills. Now the phenomenon of the social body is the effect not of a consensus but of the materiality of power operating on the very bodies of individuals. (Foucault, 1980: 55)

If the state cannot be seen as representing either its people or the universality of their will, what interests, then, might it serve? Some of the various political and social interests served by the technologies of government are addressed in the following section of this conclusion.

\subsection{Social and Political Interests and the Citizen's Voice}

We know from the data that there is no such thing as a 'safe' drug and that all drugs (even Aspirin ${ }^{\circledR}$, as so often pointed out) carry risks. However, a drug is considered to be 'safe enough', until it is undeniably revealed to be unsafe through subjective experience - that is, until the daily reactions of ordinary people taking the product in their 
everyday lives, shows that it causes high levels of mortality and/or morbidity. At this point, depending on the severity of unexpected reactions, a combination of responses are possible: warnings can be issued, letters can be sent to physicians, and changes can be made to the product insert, or the product can be withdrawn from the market. The system, as such, depends on subjective experience. Why, then, does the system also shun the very same subjective knowledge on which it depends? One point made by a military health officer (as discussed above) is particularly relevant in order to address this question. He remarked that there are inherent risks involved in documenting adverse reactions, referring specifically to the costs associated with having to treat military members who come forth and report a reaction. (Reference omitted for confidentiality of the author - endnote record \# 626). We can apply his comment to the larger picture. More broadly speaking, the inherent risks to the system of documenting adverse reactions include a decrease in confidence and in sales of the health product in question. There is also a more general decrease in confidence in 'the system' itself: as serious adverse reactions to one drug become known, individuals may lose confidence in the system, as a whole, and its ability to ensure the safety of other drugs.

There are other societal risks that could arise from challenges to the safety of mefloquine. Most notably, if mefloquine were definitively shown to be unsafe for prophylactic use, the Canadian military would have to stop using it in its deployments. Consequently, they would either have to opt for a more expensive alternative drug (albeit one deemed 'safer' by the FDA - i.e., Malarone), or else choose to stop sending troops to malaria-endemic parts of the world for long deployments (e.g., Afghanistan, in which the 
Canadian Forces have just committed to serving another two years - with troops on mefloquine).$^{58}$

When it comes to mefloquine, it really does seem that Joel Lexchin is right and that there are systemic loopholes that could jeopardise the health and safety of patients (Lexchin, 1998: 495). In its early days of testing in Canada, for example, the Somalia Commission of Inquiry, the Auditor General Inquiry and the Standing Committee on Public Accounts Hearing all concluded that the Department of National Defence did not meet the requirements of the Mefloquine Safety Evaluation Protocol (MSEP). DND got away with this, because it needed a prophylactic for use by its members in Somalia. Perhaps if it had rigorously followed the guidelines associated with the MSEP, one suicide, one attempted suicide, and a murder, might have all been prevented. We cannot say for certain whether this is the case, because the issue was not conclusively investigated. This is one of the many uncertainties that are left unspoken when it comes to mefloquine. This also indicates that Canada's military imperatives override the need for definitive answers regarding what is 'safe' and what is 'dangerous' for Canadians.

It is important to point out, in this discussion on individual and societal interests, that malaria is a relatively low-level threat for Canadians. When one considers that malaria is the cause of only a handful of deaths in Canada and the U.S.A., annually (Health Canada, 2000; Skarbinski et al., 2004), it can hardly be considered a serious threat. Nonetheless, it is an interesting case study of the ways in which power serves particular societal and political interests, because it illustrates the interests behind

\footnotetext{
${ }^{58}$ In May 2006, Canadian Members of Parliament voted to keep Canadian soldiers in Afghanistan for two years longer than previously planned, amid rumours that Canada could take over leadership of the NATO mission there in 2008 (Puddicombe, 2006).
} 
decisions regarding the channelling of resources with respect to drug safety, and the ways in which individual citizens' health needs are either met or compromised as a result.

The interests of individual travellers are being met when they are presented with the full range of options at their disposal to prevent malaria, and when all of the potential risks (of malaria and of experiencing an adverse drug reaction) are discussed openly and honestly with them, and with reference to their specific itineraries and personal characteristics. Unfortunately, individual travellers often feel that they are not given all of the necessary information to make an informed choice. For instance, one Interview Respondent remarks:

How can a person make an informed choice? Without the information, you cannot make an informed choice. The traveller can ask: Do I really want to go to these places if I am required to take this potentially dangerous drug? Some travellers decide to re-arrange their itinerary, or they decide that their children do not have to see rural Vietnam. But people are not generally encouraged to ask those questions. (Interview Respondent 1.2, female, member of an advocacy group)

Instead, she argues that travellers are over-medicated in order to deal with potential risks. This claim - that travellers are not given all of the necessary information to make an informed decision about malaria prevention-is supported by the data. For example, many of the bloggers who took mefloquine mentioned that they were not warned of any potential adverse reactions. As such, a number of those who did experience a serious adverse reaction affirmed that they did not know that their symptoms could be related to mefloquine when they first experienced them. 
It is impossible to ascertain whether this is intentional or not, but the idea that "people are not generally encouraged to ask those questions" (about not going to certain destinations to protect themselves or their children) does favour corporations and industry -in this case, the travel industry and the pharmaceutical industry. Affirmations that a drug such as mefloquine will protect travellers in all malarial areas of the world are good for business. So, as Foucault suggested (1980:94), and as noted above, although we cannot say that power is directly in the service of the economy, we can say that the power is in service of the production of 'truth', which in turn serves economic interests.

One interviewee (Interview Respondent 5.8, male, representative of Parliament) declared that there is no "great conspiracy" to uncover with respect to mefloquine. He added that the only conspiracy is laziness. However, it is difficult to believe that when an Access to Information request fails to return certain documents, or when documentation on hundreds of pills goes missing during a clinical study, that this can be attributed simply to laziness and/or bureaucratic error. A more lucid hypothesis is that there are tangible interests (notably, military and economic) that align themselves in tackling the problem of travel health, in order to produce desired results: that Canadians keep travelling; that Canadians believe in and purchase pharmaceutical products to protect themselves while travelling; and, that the public has no objection to the military using mefloquine in its deployments. This hypothesis is consistent with theories of governmentality, which argue that the state employs a variety of tactics and aligns itself with experts to convince citizens to act in ways that fulfill the state's objectives.

The genealogical method adopted has shown that North American knowledge about malaria has been produced in order to enable Westerners to travel safely to lands 
where malaria is endemic and deadly, often in order to fight wars, to 'develop' or to exploit these areas, or for their own enjoyment. Early efforts to combat malaria and develop antimalarial drugs in general, and mefloquine in particular, came about as a result of such Western colonial and military objectives. The existence of mefloquine today does nothing to meet the objective of malaria eradication where the disease is most dangerous and endemic: in sub-Saharan Africa. In fact, most of the drugs created in Western industrialised countries are inappropriate and too expensive for impoverished citizens of developing countries who need them most.

\subsection{Reflexive Modernisation -- Are We There Yet?}

So how might 'reflexivity' underwrite (as opposed to undermine) the process of scientific knowledge-building, as Bourdieu (2004: 3) recommended? This thesis supports Bruno Latour's (1994) assertion that "We have Never Been Modern", and shows that, following some of his earlier writings (for instance Latour, 1987), we are not yet 'reflexive'. Put more simply, this study picks up where Giddens (1999), Beck (1992; 1999) and Latour (2004) leave us: with the understanding that the project of modernity, with all of its technological advances, is caught on the treadmill of so-called 'progress' wherein its relics are the cause of serious risks, and is divorced from its early ideals of emancipation and equality. The voice of the people is needed to bring this so-called 'progress' into check, and to align "... scientific and technical developments with general social needs" (Cramer, et al. 1987: 89).

According to the study's three-pronged theoretical framework (medicalisation, governmentality and risk) we might expect society to have moved into a 'reflexive' state 
of production of knowledge on risk. We may, indeed, slowly be getting there. For example, in an article on AIDS activism and non-expert expertise, Brashers et al. (2000), argue that we are moving in that direction. The authors point to "mindful nonadherence" as a potential precursor to collective action in the field of HIV drug regulation and development. However, while the impetus may be in place, it seems, from this study, that we still exist in an overwhelmingly governmentalized state, and that the ideals of reflexive modernisation may be a long way off.

According to Beck, citizens no longer believe blindly in science, and wish to be involved in a more reflexive phase of knowledge production. In "complete reflexive scientization" (Beck, 1992: 155), science is said to grow from criticism, and to become demystified and democratised. He explains that in complete scientization, scientific scepticism is extended to the foundations and external consequences of science itself. In the reflexive stage, therefore, the expansion of science includes a critique of itself. This has an important consequence: “ . . . a momentous de-monopolization of scientific knowledge claims comes about: science becomes more and more necessary, but at the same time, less and less sufficient for the socially binding definitions of truth" (Beck, 1992: 156; emphasis in original).

Giddens (1999:1) notes that a shift away from a world dominated by external dangers (in which scientists provided solutions to lay people), to one dominated by manufactured risks, redefines the relationship between lay people and the scientific community “. . . in an interesting, very deep rooted and complicated way". He cites the philosopher of science, Karl Popper, to explain that: 
As lay people we're all learning what philosophers of science ... [have] treated as an abstract philosophical principle. This is that science does not prove anything. Science does not depend on the accumulation of certainty. Science is built on shifting sand .... Science is a bubble, a form of critical reason. A scientific attitude, in contrast to a religious one ... involves us in being prepared to question even our most cherished suppositions about the world. Science depends on disproving things, it depends upon a critical attitude to our beliefs (Giddens, 1999: 3).

Western discourse on anti-malarial drugs might very well still be situated in what Beck calls the "developmental logic of the first phase" - in which scientific claims are spared from self-criticism and internal scepticism. External forces, such as advocacy groups, can and do challenge statistics on the prevalence of adverse reactions, and layexperts who have first hand experience on the drug can and do publicise their reactions to it, however, the dominant message remains the same: mefloquine is a safe drug. Moreover, the sciences themselves are not reflexive. Pharmaceutical manufacturers are neither sceptical nor self-critical. Instead, they stand firm behind their claims that their products are safe, until they are publicly shamed through 'bad press'. Meanwhile, regulators are not critical of the sciences, perhaps because they do not have the resources to be so. A more cynical view would argue that they, too, share some vested interests in maintaining the status quo, such as needing to continue using mefloquine in the military, for example.

To quell the postmodern anxiety regarding manufactured risks, Giddens calls for a 'public democracy' in which everyday experience can inform public policy and 
democratic regulation; in which a dialogue between the public and regulators is based on principles of openness, engagement, and transparency; or, in Giddens' words, in which “everyday culture ... will be complementary to and add to democracy in the public sphere... based on active trust, based on the capability of respecting other person's opinions" (Giddens, 1999: 4).

A public democracy, with respect to the science of risk, necessitates the institutionalisation of public involvement. One way of accomplishing this, is by transforming interest groups (advocacy groups) into advisory groups, thereby increasing the social relevance of scientific knowledge production, increasing communication between lay people, the scientific community and decision-makers, and increasing accountability in regard to technical decision making (following Ali, 1999: 16). Although the theoretical groundwork for this might already be in place, and although there have been some attempts to put it into practice, for now, it seems, Lexchin (1998: 245 ) is correct: democratisation in the field of drug policy is a long way off.

This study examines how the democratisation of drug policy might take place in Canada. It seems that in principle, at least, Health Canada is moving towards the institutionalisation of public involvement, for instance, by striking up a public advisory committee to provide advice to Health Canada's Health Products and Food Branch, on branch issues and initiatives from the perspective of consumers and the public. Health Canada (2002b: 1) states that, "the committee is a key component of the Health Products and Food Branch strategy to increase public involvement in policy development through consultation processes". The value of this involvement is outwardly acknowledged: 
We realise that health issues are often complex, involving not only life science but social science - like the views of people and communities.... When it comes to health matters, Canadians don't want to be passive observers - active participation is important. Sharing of views, concerns and the results of scientific research is essential to reach a common understanding and produce sound decisions that are acceptable to all. (Health Canada, 2002b: 1)

This effort and findings from the case study show the recent emergence of a process that includes the pluralisation of expertise and criticism of science. However, the study also demonstrates that our political institutions continue to fail to accommodate the subpolitics of knowledge on malaria.

Over the past decade, there emerged a proliferation of lay expertise, first person accounts and media reports on the potential toxicity of mefloquine. The CBC's in-depth coverage on adverse reactions, along with the knowledge generated by advocacy groups such as 'Lariam Action', are examples of the sub-politics of knowledge and resistance to the discourse of risk. However, sub-politics and a strong independent media are not, in themselves, sufficient to exert a significant influence over scientific discourse: “ . . a supplementary step is required. The possibilities of self-control that are held up by all possessors of monopolies must be supplemented by opportunities for self-criticism" (Beck, 1992: 234; emphasis in original). Citizen engagement figures theoretically in public health policy development. This is illustrated in the statement above, for example, and in the 2001 publication Your Health and Safety: Our Priority, which states: “. . we recognise that the values of Canadians are relevant and their willingness to accept or tolerate risk is a legitimate consideration ..." (Health Canada, 2001: 1). However, this 
process is blocked in practice, by a system that marginalises the subjective voice, by health care providers who denigrate subjective experience and by the exclusionary attitude that is held by some Health Canada representatives.

Reflexivity increasingly becomes necessary, as the gap between those who make decisions about risks and those affected by them is narrowing. As Ali (1999) explains:

The defining character of modern risks is that they are attributable to a decisionmaker. It is with [this] realization... that those potentially affected by these decisions now seek to have some input into the decision making process. In other words, the gap between those who make decisions about risk and those affected by risks is narrowing as the latter increasingly attempt to become involved in the formal risk-management process. To respond to such demand for lay involvement requires the formation of new channels for public access. (Ali, 1999: 4)

With respect to the safety of anti-malarial drugs, reflexive modernisation needs to take place in two spheres. Within the Western world, public debate on the safety of pharmaceutical drugs needs to be initiated and supported by our public institutions; and individuals need to have access to, and be able to challenge, information about the safety of pharmaceutical products in an open and transparent manner. In sum, the Health Products and Food Safety Branch of Health Canada must put to use the methods described above to engage openly and actively with Canadian citizens who are interested in participating in this debate about risk. With respect to the risk posed by malaria on an international scale, reflexive modernisation will become actualised when, for example, the inhabitants of malaria-endemic regions of the world are involved in the creation of 
anti-malarial strategies, as was the case in the Surfaid-Mentawai example discussed above. It is only through the inclusion of the sub-politics of knowledge on malaria and malaria prevention that our society can enter into the phase of reflexive knowledge, and thereby adequately cope with the cascading risks associated with malaria and its prevention.

The following section looks at the role and function of subjective knowledge. It highlights the ways in which the subjective voice is currently marginalised, and delineates a way in which subjective knowledge could be used more proactively to mitigate health risks. This is a necessary step in order for citizens truly to have an input in technological and scientific "progress", and for science to become demystified and democratised.

\subsection{The Question of Subjectivity}

What role does subjective experience play in the modern-day conception of risk? Does the individual necessarily inflate risk on the basis of irrational fear and angst, or are the technologies and mechanisms in place to manage risk simply ill-equipped to deal with the individual's needs? This thesis has focused on the role of subjective knowledge in the construction of medical knowledge and knowledge about risk. It has situated subjectivity in each of the phases of medicine: During the course of medicalisation, the role of subjective knowledge in medicine was eroded, in favour of a clinical, positivist rationality. In the era of governmentality, power is wielded through individual free choices. Therefore subjective knowledge is part of the governing process. However, it is also recoded and recuperated, for example in databases that are then used to produce 
reports and to manage risk. In the reflexive stage, subjective knowledge has the potential to have the greatest effect on medical knowledge, because in this stage criticism is embraced internally and fuels new knowledge. That stage, however, has thus far not been reached.

Yet, there may actually be no great conspiracy to uncover. It may not be a simple case of the pharmaceutical industry silencing the subjective voice, or of Health Canada withholding power from the people. In some cases (the author's included) individuals do not know about, or recognise, their own role in ensuring the safety of health products. When one blogger was asked whether she reported her adverse reaction to the health authorities, for example, she stated:

No. I was angry at the medical system. The Tropical Diseases Centre in Vancouver guilt tripped me into taking [mefloquine] by saying my decision to not take anti-malarials was irrational and could spoil my husband's trip if he had to look after me. He had little experience with the tropics and went along with them. It was only after I got back and started researching that I realized there was something seriously wrong with this drug. By then, it was too late to see a doctor. (personal communication with blogger \# 39)

As Foucault argued, this is not a case of one group dominating over another, but rather " . . the usual strategic development of a struggle" (Foucault, 1980: 56). This case study shows that subjective knowledge is performing its critical functions: validating public health campaigns and revealing problems with particular drugs. At the same time, the subjective voice is also being silenced in many ways: in interactions with doctors, when subjective knowledge is equated with myth or faulty logic; instrumentally, in 
databases that only capture one in 10 serious adverse reactions lived out by individuals; physically, when individuals who are suffering from reactions to mefloquine are committed and sedated, supposedly for their own good. The subjective voice is marginalised in the statistic that 'one in 13,000 will experience a serious neuropsychological reaction to mefloquine', because there is no allowance of variations for social settings, lifestyle, behaviour, or individual characteristics, within this generalisation. There is, instead, the objective probability based on the mythical 'average man'. In actuality, one's chances of experiencing a serious neuro-psychological sideeffect might be two or 10 or 100 times higher than 'one in 13,000 ', if the person happens to be, for example, a highly stressed female of petite build who indulges in three or more alcoholic beverages per day. We do not, however, have those figures, because the lived experience behind them is erased in the codification of knowledge and the production of statistics. Subjective knowledge, then, is usurped by 'the system'; it does not change or improve it, but simply validates it. In the case study, for example, the lived experiences of individuals who took mefloquine continue to support the overall claim that it is a safe and effective drug, and that the system in place to monitor the safety of pharmaceutical products works, in spite of the negative consequences of the drug for many of those same individuals.

The case study also demonstrates that subjective knowledge acts as a 'red flag', or a warning signal, to alert regulators about a major problem with a particular pharmaceutical health product. However, this usually transpires only after a significant number of deaths or illnesses is reported. 
Can subjective experience be put to use in a more proactive way? One interview respondent asserted that, in an ideal world, advocacy groups would play a central role in post-marketing drug regulation, liaising between individuals and regulatory bodies. Arguably, this could lead to greater communication between these two entities. The interview respondent believes that "advocacy groups are the only way the truth about adverse effects can really get out." However, she states that, in the real world, "the FDA and probably governmental regulation agencies in other countries regard these groups with scepticism and mistrust (Interview Respondent 1.1, female, member of an advocacy group).

In order to move into a more reflexive phase, individuals must recognise the power of their subjective voices. Health agencies must establish formalised systems to ensure that the intuitive work can happen and that the subjective is acknowledged. This is, as Maria (1999: 28) has noted, simply “ . . . a question of resources and a question of priorities..." (Maria, 1999: 28). There are some cost-efficient ways of giving citizens a greater say when it comes to drug safety. Health Canada could, for instance, ask the drug makers to include a note with every drug purchased, asking clients, should they experience a negative side-effect, to visit a given web site and fill out an adverse drug reaction form. This would increase awareness of the process of pharmaceutical drug regulation and the public's role in it. The number of spontaneous reports received would increase, since it would encourage those that experience them to report them. If this option is too resource intensive (requiring the printed notes and the web site), then, at the very least, all pharmacists could be encouraged to remind clients of their ability to telephone the manufacturer of the drug, or Health Canada directly, should they 
experience any negative side-effects. However, reminding consumers that health products could potentially be unsafe might lead to a decrease in sales of those products. Another possible way of making subjective knowledge count in the regulatory process, in a more proactive manner, might be to invite members of advocacy groups to take part in citizen advisory panels.

The subjective and the intuitive can bring new ideas to knowledge-building processes. As such, it should be encouraged rather than being marginalised. The following section puts forward the various ways in which the subjective voice in this study served to reveal elements of the research area that might not have come to light had the subjective been excluded from the research process.

\subsection{Auto-Ethnography: the Personal Narrative and the Research Process}

The auto-ethnographic approach challenges the subjective/objective divide that characterises much of what constitutes empirical research. Using this approach did reveal certain elements of risk management, that might not have come to light had I not probed and re-visited my own adverse reaction to mefloquine and its aftermath. First and foremost the auto-ethnographic element of this thesis was informative on the denigration of subjectivity from the creation of knowledge. My own hesitation about the idea of including my personal narratives in this thesis is part of the same process that marginalises subjective knowledge from positivist knowledge-building endeavours. My doubting the validity and importance of my own knowledge is part of the same 
phenomenon that makes Health Canada denigrate subjective experience, and makes TMPs equate personal apprehensions about mefloquine with myth or misinformation.

My subjective experience also allowed me to experience firsthand the notion that there is an element of physical coercion involved in the regulation of health. This is exemplified in the state's power to hold people against their will, supposedly for their own good (as exemplified, for instance in the 'Form 42', Appendix A). It is also exemplified in the prosecution in court martial of military personnel who refuse certain medications. $^{59}$

I am not certain that I would have really understood the stigma associated with neuro-psychological reactions, had I not experienced one myself. One interview respondent shared his perceptions on this stigma, purporting:

The stories must get out and be portrayed to the media. This would wake a lot of people up.... [Unfortunately] most people do not understand that a little pill can convert you from a Dr. Jekyl to a Mr. Hyde. ... Stigma prevents honesty. People will think that people blame the drug for their personal problems. (Interview Respondent \#1.4, male, student)

I am similarly not sure that I would have grasped the reality of this, had I not felt the selfdoubt associated with my own reaction, and the shame that I associated with spending time in a psychiatric ward.

${ }^{59}$ As was the case, for example, when Sergeant Mike Kipling of Winnipeg refused to take the experimental vaccine against Anthrax. He was sent home, cited for breach of the National Defence Act, and court marshalled. It was later stated in the House of Commons that "Sergeant Kipling had every right to refuse the Anthrax vaccination and that his case has revealed serious negligence by the Canadian government in the administration of the vaccine generally" (Wasylycia-Leis, 1999). 
I would not have come to know, firsthand, all the different methods through which an institution manages risk and protects its image. In the week following my release from the hospital in 2001, I received a personal and unprecedented visit to my home in the countryside, from a management level defence scientist, a navy commander and an army colonel (who was also a Director General). They came with warm wishes for a speedy recovery, and with a pile of papers for me to sign about the implications of this work-related incident. I later learned that there was a heated debate as to whether or not this should, in fact, be labelled a 'work-related incident' at all in the official record of the event. Over the months that followed I witnessed and was involved in some of the repercussions of this incident for the Department of National Defence. Among other things, I am quite certain that my experience played a minor role in fast-tracking DND efforts to formulate official policies on the deployment of civilians into military theatres (e.g., Dunn and Ford, 2004). Finally, I would not have definitive proof that documents in the bureaucracy are withheld (or lost, or destroyed) if they might tarnish the institutional image, had I not personally authored some of the correspondence which I later requested, and of which I was told did not exist.

\subsection{Limitations of the Study}

There are two main particularities of this study, which can be seen as limitations, or as opportunities for more in-depth commentary on the subject matter at hand. First and foremost, it is empirically limited by the constraints of non-participation of two major stakeholders. Due to time and financial constraints, as well as the institutional barriers that prevented individuals from certain institutions from participating in the study 
or going 'on the record' about what they know regarding mefloquine, the sample of interview respondents was much smaller than hoped for originally. To compensate for this, the survey of TMPs was sent out, weblogs were investigated and official documents were requested from the Department of National Defence, Health Canada and HoffmannLa Roche (although none were received from Hoffmann-La Roche). The study would certainly have been more well-rounded, had it included the perspectives of Health Canada researchers and representatives from Hoffmann-La Roche. Nonetheless, their decision not to participate is itself indicative of how the system of drug regulation operates in Canada.

Second, because the study is partly auto-ethnographic and 'participatory' in its approach, it is necessarily biased, or enhanced by personal experience. Cooke and Kothari (2001) remark on the importance of unmasking biases when engaged in research with communities, rather than attempting to quell them. Biases, values and opinions must be openly discussed. One of the reasons for including the personal narrative was to expose this researcher's positionality with respect to the case study at hand.

\subsection{Future Directions... More Mefloquine Dreams}

This thesis sparks many possible offshoots and follow-up research endeavours. Before discussing these further, a couple of points need to be made on the aftermath of this project. As discussed in the methodology chapter, an effort will be made to inform all participants - who expressed an interest in being notified - of the completion of this study. Furthermore, in preparation for the thesis defence, a power point presentation summarising the thesis has been created. This presentation will be uploaded onto the 
Internet and all interested participants will be directed to it. This might, itself, propel future collaborations or research projects.

The nexus between the incorporation of subjective knowledge into risk management and the inclusion of traditional knowledge in resource management is certainly an area worthy of further exploration. Berkes et al. (2000) note that traditional knowledge plays an important role in monitoring, responding to, and managing ecosystem processes and functions, with special attention to ecological resilience. Similarly, subjective knowledge plays a central role in monitoring, responding to and managing risks, in particular, health risks. The important distinction between the two is that traditional knowledge seems to have gained respect in resource management, while subjective knowledge concerning health remains marginalised from the risk management process. Therefore, the history of the struggle to gain legitimacy for traditional knowledge would be a crucial step in furthering this study, and fulfilling the objectives associated with reflexive modernisation. This would be a timely endeavour since we find ourselves in an era when the biomedical model has revealed its inherent limitations, but the bio-cultural model has not yet proven its power to constitute a replacement. He argues that a bio-cultural model of medicine would be attuned to the influence of the mind, emotion and culture and would subsume medical knowledge within a more comprehensive vision of health and illness. Findings from this study suggest that the actualisation of this bio-cultural model requires that subjective knowledge be recognised and respected as a valuable source of medical knowledge.

Another area that merits further consideration is the network of social actors and technological elements that are involved in health regulation. Applying Foucault 
(1980)'s notion of power, the theory of governmentality, and stakeholder analysis, to the findings from the case study, has revealed the power dynamics at play in the regulation of pharmaceutical drugs in Canada. However, the standard tools of stakeholder analysis were somewhat incongruous with the theoretical concepts discussed. A more in-depth examination of this network would map the relationships, interconnections, and disconnects between various elements-political institutions, social agents, and technologies - in the network. This project would build upon the analysis already undertaken and Manuel Castells' (2000) understandings of the "Network Society", in order to ask: what are the conditions under which various elements collaborate with respect to health regulation, and under what conditions is there conflict between these elements? This analysis would provide a more fluid depiction of the power dynamics at play in the regulation of pharmaceutical products.

\subsection{Concluding Thoughts}

The major problem, with respect to mefloquine, is not whether or not it is safe enough for use as a prophylactic. As carefully explained in the introduction to this thesis, that question lies beyond the scope of a medical sociology study. The critical problem is that numerous uncertainties with respect to the drug have been silenced, for example: the Mefloquine Safety Evaluation Protocol data was never supplied to the manufacturer and never factored into the analysis of whether or not mefloquine is 'safe enough' for use as a prophylactic; the further studies among Canadian Forces members, which were sanctioned and for which funds were earmarked, were never carried out; there is at least one case of suicide that figures in the Health Canada adverse reactions database that was 
(mis)labelled as being caused by another drug (Malarone-a drug deemed "the safer drug" according to the FDA); and there are myriad experiences of serious and debilitating reactions to mefloquine that are not factored into the regulatory mechanism.

When someone decides to take a pharmaceutical drug, they go through their own personal risk/benefit analysis and decide that the discomfort or risks associated with illness outweigh the potential risk of experiencing an adverse reaction. For this, individuals must have all the relevant information needed in order to make a wellinformed decision. With respect to mefloquine, however, time and time again, bloggers mention that when they experienced a neuro-psychological side-effect to the drug, they had no idea what was happening to them. Many reported that they simply thought that they were going crazy. They were not informed of the potential risks associated with the drug. This is not exactly an example of open and transparent risk management. Furthermore, if the early clinical studies in Canada were carefully monitored and standards enforced, and the information about mefloquine's potential side-effects were well documented and publicised, it is quite possible that there would be fewer such experiences occurring today, because medical experts would have more information on the specific circumstances under which serious reactions are likely to occur.

A reduction in the morbidity and mortalities associated with pharmaceutical products could be achieved through the institutionalisation of public involvement in the regulatory process, for instance through the networking of advocacy groups and the Health Products and Food Branch at Health Canada. Despite the inherent compromises to political, military, economic and industrial interests, it is only when such public 
criticism is embraced within the regulatory institutions that the ideals of reflexive modernisation will have become actualised. 


\section{Appendix A Ministry of Health 'Form 42'}

$\begin{array}{lll}\text { Ministry } & \text { Form A2 } & \text { Notice to Porson under Subsection } 38.1 \text { of } \\ \text { of } & \text { Mental Heallh Act } & \text { the Act of Application for Psychlatric } \\ \text { Health } & & \text { Assessment under Section 15 or an Order } \\ \text { under Section } 32 \text { of the Act }\end{array}$

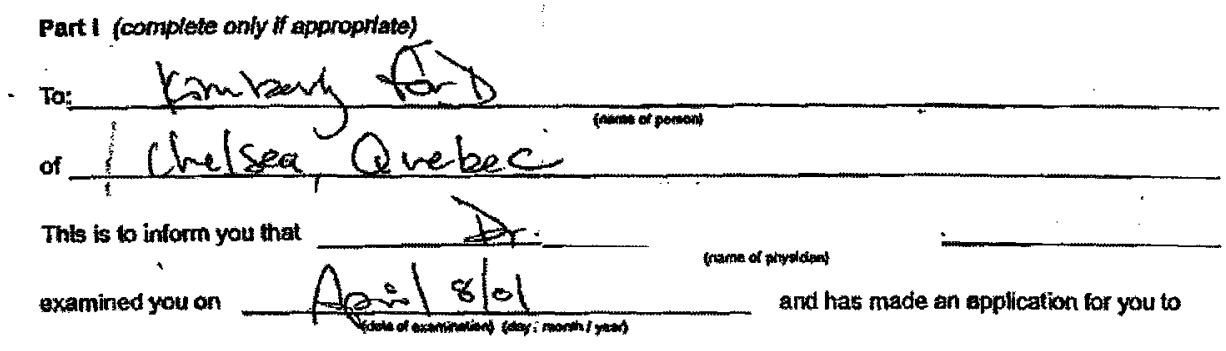

have a psychlatric assessment.

Part $A$ andfor Part $B$ must be completed

Part A

That physictan has contified that he/she has nezsonable cause to belleve that you have:

Check $\square$ threalenod $\alpha$ attempted or are threatering or attempting to causa bodity harm to yourself,

Box(es)

$\square$ behemed or are behaving violently towards mother person or have caused or are causing anothet person to fear bodily harm from you; or

12. shown or are showing a lack of compelence to care tor yourseir.

and that you are suffering from a menkal disorder of nature or quality that ikely witl result in:

Check

Box(es)

25 serious bodity harm to yoursett.

$\square$ serious bodily harm to another personi or

D2serious physical inpairment of you.

Part B

That physictan has certitied that he/sthe has reasonable cause to bellieve thet you:

a) have previously recetved treatment for mental disorder of an ongoing or necurring nature that, when not Irealed, ts of a nhature or quality that thely will resutt in

Q

$\square$ cerious bodily tham to another person,

Пusbstanlial mental of physical deferionation of you, of

$\square$ serious physical impaiment of you;

b) have shown clinical improvement as a msut of the triatment;

c) ane suffeting from the same mental disonder as the one for which you previously necelved

. tredunent or from a mental disorder that is sinllar fo the previous ono:

(Disponible en wersion trancaise) 
Part B (comtinued)

d) given your histony of menlal disonder and current mental or physical condition, you are likely to

$\square$ cause serious bodily harm to yoursel.,

$\square$ cause serbous bodily harm to another person.

$\square$ suffer subsiantial mental or physicat dotertoration, or

Пuffer serious physical impalment;

0) have been found incapable, within the meaning of the Heath Care Consenl Ad, 1996 of consenting to your treatment in a psychiatric facility and the consent of your subsitute decision-maker has been obtainod; and

1) you are not sultable for admission or continuation as an informal or voluntary patient.

The application is sufficient authority to hold you in custody in this hospital tor up to 72 hours.

You have the fight to retain and instruct a tawyer whout dekay.

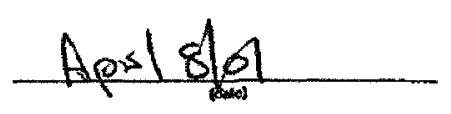

A.
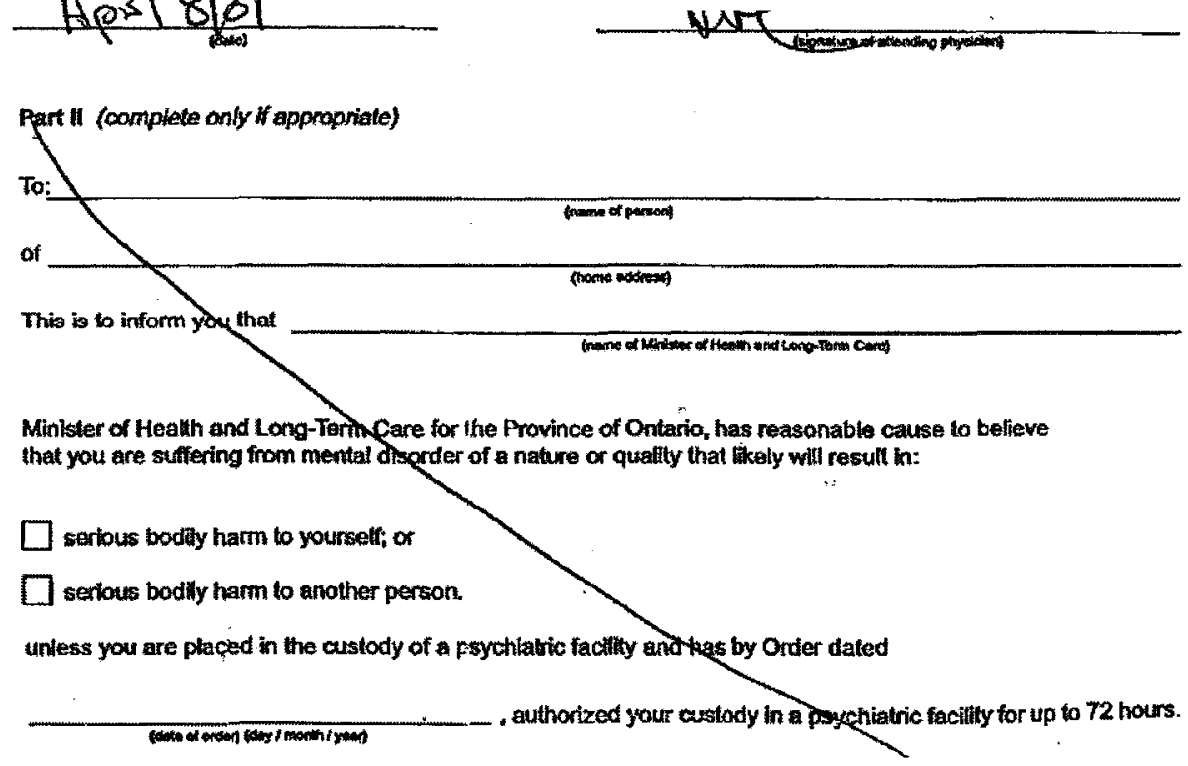

You thave the right to retaln and hstruct a lawyer whout delay.

Apirel 8tol

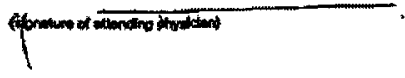




\section{Appendix B Ottawa Hospital Dept. of Psychiatry Orientation Pamphlet}
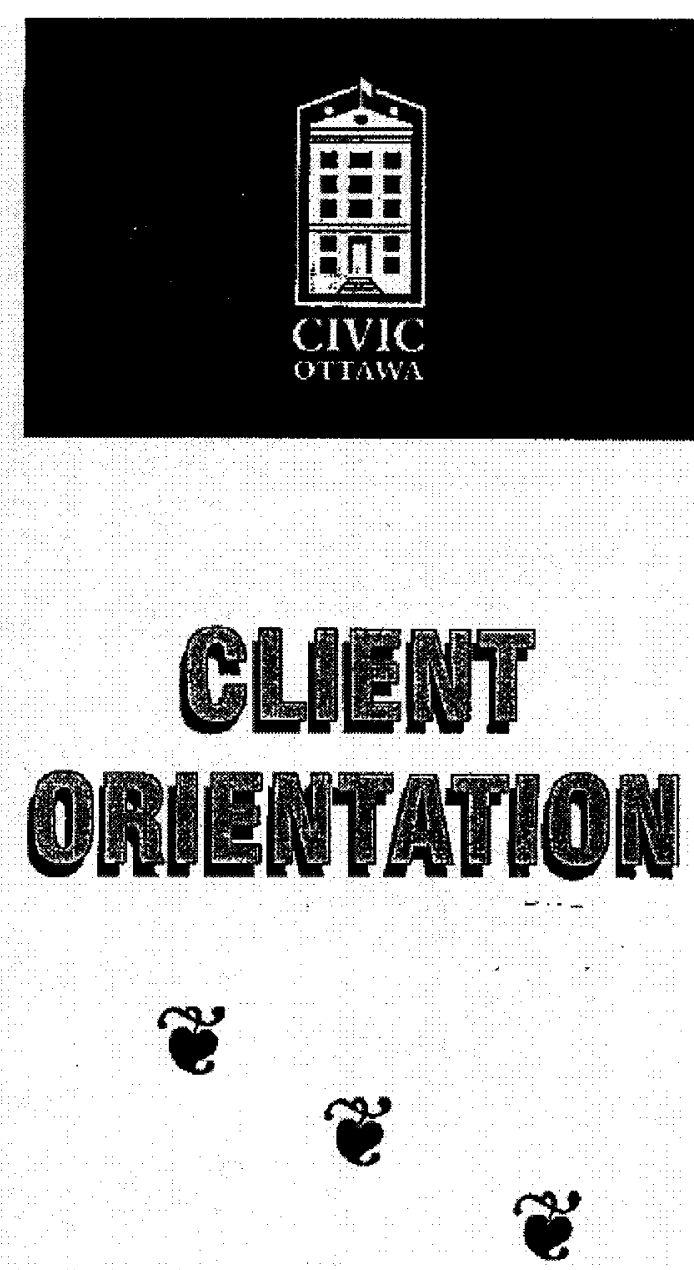

Ottawa Civic Hospital

Department of

Psychiatry

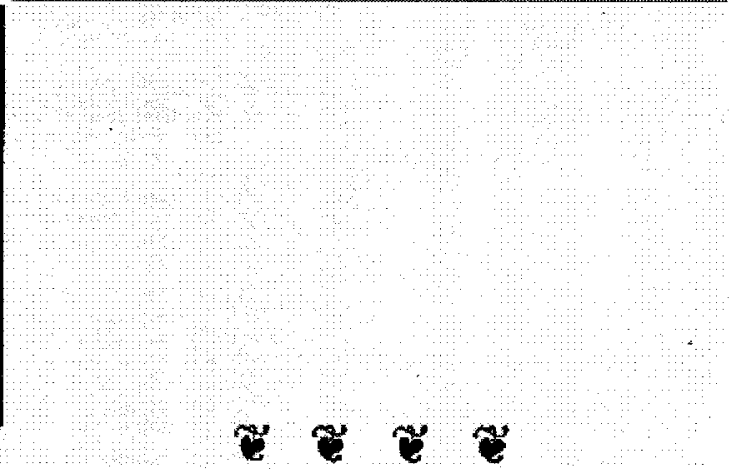

\section{PRIVILEGE LIST}

\section{1 TO 1}

In eJ's. Remain in room at all times other than walks on Unit q 1 hour if condition allows.

\section{CLOSE OBSERVATION}

Patient must semain in pajamas (no logging suits) and remain on the ward. You will be checked even 15 minutes.

\section{WARD PRIYILEGES}

Not allowed to leave the ward unless accompanied by a stafi member. You may wear your own clothes.

\section{OFF WARD PRIVILEGES}

Patient allowed to leave ward during specified off ward times but, to remain on hospital grounds. Orderlies will make the team aware of patients who abuse off ward privileges.

5. Day passes or hours out for constructive purposes

Written specifically. Please Sign book.

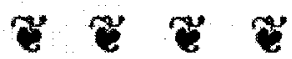




\section{Appendix C Interview Guide}

Ph.D. Dissertation: "Exploring the Subjective Experience of Risk and Safety and its Role in the Regulation of Pharmaceutical Drugs in Canada"

*Please note that while questions remain unchanged, formatting in the original instrument was different.

Introduction

Some of the questions that I am about to ask you pertain to your own experience traveling to a country where malaria is present, and the methods that you used to ward off malaria infection. A larger proportion of the questionnaire will ask for your professional opinion, based on your experience as a malaria researcher, member of the pharmaceutical industry, representative of Health Canada or other health agencies, member of an advocacy group, or as a Doctor of tropical medicine. If at any time, any of the questions are irrelevant to you, we can simply pass to the next question. Also, it is your right to withdraw from this project and ask that we stop the interview at any time. Before we begin I want to thank you for agreeing to take part in this interview, and to let you know that your contribution to this thesis is very important to me, and I hope that the results of the dissertation will be of value to you as well.

\section{Respondent information}

0.1 Respondent number:

0.2 Is the respondent male $\square \quad$ or female $\square$ ?

0.3 Description of occupation, affiliation, or connection to the project: 
1. Demographical Information

1.1 I have received your consent form and wish to ask you again: Do you wish to remain anonymous Yes $\square$ No $\square$

$1.1 \mathrm{~b}$ If you have answered no to question 1.1 , did you fill out a waiver of anonymity form? Yes $\square$ No $\square$

1.2 What is your occupation?

1.3 Have you ever been an employee of Health Canada? $\quad$ Yes $\square \quad$ No $\square$ $1.3 \mathrm{~b}$ What branches of HC have you worked in?

1.4 Have you worked in other health agencies? $\quad$ Yes $\square \quad$ No $\square$ $1.4 \mathrm{~b}$ Which ones?

1.5 Have you ever been employed in the pharmaceutical industry in any capacity (even as a consultant)? Yes $\square \quad$ No $\square$

1.5b If you responded yes to the previous, what company did you work for and in what capacity?

1.6 Are you a member of an advocacy group? Yes $\square$ No $\square$

1.6b If yes, which one?

1.6c Please describe the circumstances that led you to join this group.

1.7 What is your nationality? 
1.8 Have you ever travelled to a country where malaria is present? Yes

$1.8 \mathrm{~b}$ [If yes to 1.6] where did you go?

1.8c [If yes to 1.6] Would you briefly describe the methods you employed to prevent malaria infection?

1.8d [If yes to 1.6] Did you get malaria? Yes $\square$ No $\square$ ?

Section 1 Extra Notes [follow up on possible malaria treatment, report to home doctor, etc]

2. Your views on malaria prevention information

2.1 In general, where, or from what sources, do you think that individuals should get health information when planning a trip abroad? Please list all that apply:

2.2 Do you feel that adequate travel health information about the risk of malaria and ways to prevent it, is available for individuals who are planning a trip overseas? Yes

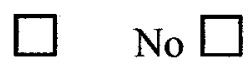

2.2b Please comment.

2.3 In your opinion, do people, who are travelling to an area where malaria is present, overestimate, properly evaluate, or underestimate their risk of contracting malaria?

Overestimate the risk $\square \quad$ Properly Evaluate it $\square \quad$ Underestimate the risk

2.3b Please comment. 
2.4 The following is a list of different sources of information. I will ask you to indicate how relevant (very relevant, somewhat relevant, not particularly relevant, not at all relevant) each of these sources would be to you, if you had to make a decision about malaria prevention, when preparing to travel to a foreign country where malaria is present.

$\begin{array}{llll}\text { Very } & \text { Somewhat } & \text { Not Particularly } & \text { Not at all } \\ \text { Relevant } & \text { Relevant } & \text { Relevant } & \text { Relevant }\end{array}$

Health Canada

Publications

WHO

Publications

DFAIT

Travel Advisor

Family

Physician

Tropical Medicine

Doctor

Other individuals who

have travelled to

the country

Past personal

Experience

Family members

Are there any others?

2.4b Please comment on your choices

2.4 In your own words, how would you define the term 'malaria zone'? 
3. Pharmaceutical Drug Regulation and the Safety of Pharmaceutical Products

3.1 In your opinion, who or what factors exert influence over the process of pharmaceutical drug regulation in Canada? [probe: are there any other factors...]

3.2 Are you aware of any of the government agencies involved in the regulation of pharmaceutical drugs in Canada? If so, can you identify them and describe in your words what each of them does?

3.3 Are you aware of the process by which a drug goes from testing to approval for sale in Canada? If so, can you describe it?

3.4 Are you aware of the process by which the safety of pharmaceutical drugs is monitored in Canada? If so, can you describe it? [probe: are these databases public?]

3.5 Are you familiar with the process by which an individual's experience of negative side-effects or adverse reactions gets accounted for, or factors into, the mechanism of pharmaceutical drug regulation? If yes, please describe the process.

3.6 Are you aware of any way in which patients' or consumers' experiences impact on the process of pharmaceutical drug regulation in Canada? If so, can you please describe it?

3.7 In your view, what might lead to a change in the status of a pharmaceutical drug?

3.8 To your knowledge, has any attempt been made to make records of the incidents of adverse reactions to various pharmaceutical drugs public in Canada?

Yes

No

3.8b Please comment 
3.9 In your opinion, what constitutes a 'safe' pharmaceutical drug?

3.10 I am going to read a list of factors, individuals, social groups, agencies, etc. that may or may not exert an influence on the process of pharmaceutical drug regulation in Canada. For each of these factors, I will ask you to tell me whether, in your opinion, their influence is negligible, weak, moderate or strong.

\begin{tabular}{ccc}
\multicolumn{2}{c}{$\mathbf{1}^{\text {st }}$} & \multicolumn{2}{c}{$\mathbf{2}^{\text {nd }}$} \\
Influence is & \multicolumn{2}{c}{ Influence should be } \\
Neg. Weak Moderate Strong & Neg. $\quad$ Weak Moderate
\end{tabular}

\begin{tabular}{|c|c|c|c|c|c|c|c|c|}
\hline \multicolumn{8}{|l|}{ Medical } & 口 \\
\hline \multicolumn{9}{|l|}{ Pharmaceutical } \\
\hline Companies & $\square$ & $\square$ & $\square$ & $\square$ & $\square$ & $\square$ & $\square$ & $\square$ \\
\hline \multicolumn{9}{|l|}{ Medical } \\
\hline Doctors & $\square$ & $\square$ & $\square$ & $\square$ & $\square$ & $\square$ & $\square$ & $\square$ \\
\hline Patients & $\square$ & $\square$ & $\square$ & $\square$ & $\square$. & 口 & 口 & $\square$ \\
\hline \multicolumn{9}{|l|}{ Canadian } \\
\hline Citizens & $\square$ & $\square$ & $\square$ & $\square$ & $\square$ & 口 & $\square$ & 口 \\
\hline Advocacy Groups & $\square$ & $\square$ & $\square$ & $\square$ & $\square$ & $\square$ & ㅁ & $\square$ \\
\hline Politicians & $\square$ & $\square$ & $\square$ & $\square$ & $\square$ & $\square$ & $\square$ & $\square$ \\
\hline Health Canada & $\square$ & $\square$ & $\square$ & $\square$ & $\square$ & 口 & $\square$ & $\square$ \\
\hline WHO & $\square$ & $\square$ & $\square$ & 口 & $\square$ & 口 & $\square$ & $\square$ \\
\hline
\end{tabular}

$3.10 \mathrm{~b}$ For each of the factors that I mentioned, please tell me now whether you think that their influence should be negligible, weak, moderate or strong.

$3.10 \mathrm{c}$ Are there any others to add to this list? Please comment. 
3.11 In your opinion, do you think that people overestimate, properly evaluate, or under estimate their risk of experiencing a side-effect when taking a pharmaceutical drug?

Overestimate the risk $\square \quad$ Properly Evaluate it $\square \quad$ Underestimate the risk

3.12 Does the public have any role to play in ensuring the safety of pharmaceutical drugs? Yes $\square \quad$ No $\square$

3.12b Please comment.

4. Anti-malarials: Use and Safety

4.1 Are you aware of any health concerns with the drug mefloquine (also sold under the name Lariam () ? $\quad$ Yes $\square \quad$ No $\square$

4.1b [If yes] please describe what you have heard regarding these health concerns.

4.1c What is your overall assessment of mefloquine (Lariam $®)$ as an anti-malarial drug?

4.2 Are you aware of any health concerns with the drug atovaquone proguanil HCI (malarone)? Yes $\square \quad$ No $\square$

$4.2 \mathrm{~b}$ [If yes] please describe what you have heard regarding these health concerns.

4.2c What is your overall assessment of malarone as an anti-malarial drug?

4.3 Are you aware of any controversy surrounding the drug mefloquine (also sold under the name $\left.\operatorname{Lariam}^{(}\right)$? $\quad$ Yes $\square \quad$ No $\square$

$4.3 b \quad$ [If yes] please comment. 
4.4 What is the effect, in general, of controversy, on the safety of pharmaceutical products? Please comment.

5. The Impact of Advocacy Groups on the Safety of Pharmaceutical Products

5.5 Have you ever heard of the group 'Lariam Action'? Yes No

5.5b If yes, please tell me in your own words, what 'Lariam Action' does.

5.6 Certain organizations or 'advocacy groups' like 'Lariam Action' are created by individuals who believe that it is important to educate others regarding the potential sideeffects associated with certain pharmaceutical drugs. How important, do you think, is work done by advocacy groups like 'Lariam Action', is it: Very Important, Somewhat Important, Neutral, Not very important, Not at all Important?

Very Important Not at all Important

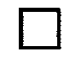

5.6b Please comment on your response to question 5.6.

5.7 How beneficial, in your opinion, is work done by groups like 'Lariam Action', is it: Very beneficial, Somewhat beneficial, Neutral, Somewhat harmful, Very harmful?

Very beneficial .very harmful

5.8b Please comment on your response to question 5.8.

6. Respondents views and request for more information 
6.1 Are there any other questions or issues that you think I should be addressing in this research project, which I have not yet touched upon?

6.2 Do you have anything further to add?

6.3 Can you think of anyone in particular whom I should be talking to about the issues raised in today's interview?

6.4 Have you any documentation on mefloquine, malaria, or the regulation of pharmaceutical drugs, which you think that I should read?

6.5 Would you be willing to participate in a focus group or conference call, in the winter of 2004 ?

Yes $\square \quad$ No $\square$ Maybe $\square$

6.6 Do you wish to be notified when the thesis has been completed? Yes

No

Conclusion

Thank you again for your participation.

Interview notes will be sent to you by e-mail for your review within one week. If I do not receive comments from you within the following month, I will assume that you are satisfied with the responses and the notes that I have taken.

Please feel free to contact me at any time, if you have anything further to add, or would like any information about the project. [Give contact information again] 


\section{Appendix D Survey of Travel Medicine Providers}

*Please note that while questions remain unchanged, formatting in the original instrument was different.

1. Your views on malaria prevention information

1.1 In general, where, or from what sources, should individuals who are planning a trip to a malaria-endemic region, get information about health and safety? Please list all that apply. (Use reverse if you require more space)

1.2 Do you feel that adequate travel health information about the risk of malaria and ways to prevent it, is available for individuals who are planning a trip to a malaria

endemic country? Yes $\square \quad$ No $\square$

$1.2 \mathrm{~b}$ Please comment. (Use reverse if you require more space)

1.3 In your opinion, do individuals, who are travelling to an area where malaria is present, overestimate, properly evaluate, or underestimate their risk of contracting malaria?

Overestimate the risk $\square \quad$ Properly Evaluate it $\square \quad$ Underestimate the risk

1.3b Please comment on your answer to 1.3 (above). 
1.4 The following is a list of sources of information. How relevant (very relevant, somewhat relevant, not particularly relevant, not at all relevant or don't know) is each one, for individuals who are preparing to travel to a country where malaria is present?

Please check the appropriate square.

\begin{tabular}{|c|c|c|c|c|c|}
\hline & $\begin{array}{l}\text { Very } \\
\text { Relevant }\end{array}$ & $\begin{array}{l}\text { Somewhat } \\
\text { Relevant }\end{array}$ & $\begin{array}{l}\text { Not } \\
\text { Particularly } \\
\text { Relevant } \\
\end{array}$ & $\begin{array}{l}\text { Not at all } \\
\text { Relevant }\end{array}$ & Don't Know \\
\hline $\begin{array}{l}\text { Health } \\
\text { Canada } \\
\text { Publications }\end{array}$ & & & & & \\
\hline $\begin{array}{l}\text { WHO } \\
\text { Publications }\end{array}$ & & & & & \\
\hline $\begin{array}{l}\text { DFAIT } \\
\text { Travel } \\
\text { Advisory }\end{array}$ & & & & & \\
\hline $\begin{array}{l}\text { Family } \\
\text { Physician }\end{array}$ & & & & & \\
\hline $\begin{array}{l}\text { Travel } \\
\text { Medicine } \\
\text { Provider }\end{array}$ & & & & & \\
\hline $\begin{array}{l}\text { Other } \\
\text { Individuals } \\
\text { who have } \\
\text { travelled to } \\
\text { the country } \\
\text { in question }\end{array}$ & & & & & \\
\hline $\begin{array}{l}\text { Past personal } \\
\text { experience }\end{array}$ & & & & & \\
\hline $\begin{array}{l}\text { Family } \\
\text { Members }\end{array}$ & & & & & \\
\hline Other: & & & & & \\
\hline Other: & & & & & \\
\hline Other: & & & & & \\
\hline
\end{tabular}

$1.4 \mathrm{~b}$ Please comment on your choices for 1.4 , above. Use reverse of this sheet if you require more space.

1.5 In your own words, how would you define the term 'malaria zone'? Please use reverse if you require more space. 
1.6 What role does a patient's personal experience and/or past history play in selecting appropriate anti-malarial precautions? Please use reverse if you require more space.

2. Your Views on the Safety of Pharmaceutical Products

2.1 In your opinion, who, or what factors influence the process of pharmaceutical drug regulation in Canada? Please list all that apply and use the reverse if you require more space.

2.2 Are you aware of the process by which a drug goes from testing to approval for sale in Canada? If so, can you describe it?

2.3 Are you aware of the process by which the safety of pharmaceutical drugs is monitored in Canada, once is has been approved for sale? If so, can you describe it? Please use reverse if you require more space.

2.4 Is the system in place to monitor the safety of pharmaceutical drugs effective in alerting Health Canada of a potentially dangerous drug?

Yes $\square \quad$ No $\square \quad$ Don't Know / Can't Say

2.4b Please comment on your answer to 2.4 .

2.5 In your opinion, what constitutes a 'safe' pharmaceutical drug?

2.6 In your opinion, do consumers overestimate, properly evaluate, or underestimate their risk of experiencing a side-effect when taking a pharmaceutical drug?

Overestimate the risk $\square \quad$ Properly Evaluate it $\square \quad$ Underestimate the risk

2.6b Please comment on your answer to 2.6 .

2.7 Does the public have any role to play in ensuring the safety of pharmaceutical drugs? $\quad$ Yes $\square \quad$ No $\square \quad$ Don't Know / Can't Say $\square$

2.7b Please comment on your answer to 2.7 .

3. Anti-malarials: Use and Safety 
3.1 What is the most commonly prescribed anti-malarial drug?

3.2a Do you have any statistics on the numbers of prescriptions sold for each of the various anti-malarial drugs in Canada? Yes $\square \quad$ No $\square$

3.2b If yes, would you be willing to share this information with me?

3.2c If no, do you know where I might find these statistics?

3.3a Are you aware of any health concerns with the drug mefloquine (also sold under the name Lariam(®)? Yes $\square \quad$ No $\square$

3.3b If yes, please describe what you have heard regarding these health concerns.

3.3c What is your overall assessment of mefloquine (Lariam $\left.{ }^{\circledR}\right)$ as an anti-malarial drug?

3.4 Have their been any changes in the status of mefloquine since it was licensed in Canada in 1993? (i.e have any new warnings been issued by Health Canada?)

3.5a Have the malaria prevention strategies used by Western travellers to malariaendemic countries changed over the past decade?

Yes $\square \quad$ No $\square$

$3.5 \mathrm{~b}$ If yes, in what ways?

3.6 What are the major challenges that you face, as a travel medicine provider, with respect to the prevention of malaria among Canadian travellers?

4. Your views on the research project and request for more information 
4.1 Do you have any comments on this survey in general?

4.2 Can you think of anyone in particular whom I should be talking to about the issues addressed in this questionnaire?

4.3 Do you wish to be notified when the thesis has been completed? Yes $\square$ No $\square$

If you wish to be notified, please insert your business card, which I will keep in a separate file from your survey responses. This is done to preserve the anonymity of your responses. 


\section{Appendix E Instruction Letter for Interview Participants}

Ph.D. Dissertation: "Exploring the Subjective Experience of Risk and Safety and its Role in the Regulation of Pharmaceutical Drugs in Canada"

Kimberly-Anne Ford

Department of Sociology and Anthropology, Carleton University, Ottawa Ontario

Tel. (613) 992-7900 Fax. (613) 995-5785 E-Mail: $k$ ford@,connectmail.carleton.ca

Dear Research Participant,

Thank you for agreeing to take part in an interview. Please find attached a consent form and a waiver of anonymity form, the latter of which you should fill out only if you wish to be identified and to waive your right to anonymity.

Please fill and sign out the(se) form(s) and return them to me in the enclosed selfaddressed-stamped envelop.

I appreciate your taking the time to contribute to this Ph.D. project.

Sincerely,

Kimberly-Anne Ford, Ph.D. Candidate. 


\section{Appendix F Consent Form for Interview Participants}

Ph.D. Dissertation: "Exploring the Subjective Experience of Risk and Safety and its Role in the Regulation of Pharmaceutical Drugs in Canada"

Kimberly-Anne Ford

Department of Sociology and Anthropology, Carleton University, Ottawa Ontario

Tel. (613) 992-7900 Fax. (613) 995-5785 E-Mail: kford@,connectmail.carleton.ca

Carleton University Ethics Committee: Co-Supervisors:

Dr. Klaus Phole (academic Chair) Dr. Florence Kellner

Department of Journalism

Tel.: (613) 520-2600 ext. 2598

Carleton University

E-Mail: flo_kellner@ccs.carleton.ca

Ottawa, Ontario

Tel.: (613) 520-2600 ext.7424

Dr. Louise De La Gorgendière

E-Mail: klaus_pohle@carleton.ca

Tel.: (613) 520-2600 2589

E-Mail.: louise_de_la_gorgendiere@carleton.ca

Introduction

The Carleton University Ethics Committee, which has approved this research project, requires that all research involve participants who are fully informed about the nature of the research and consent to participate. This "Informed Consent Form" has been designed in accordance with these requirements, to inform all participants about the nature of the project and their participation in it. It is meant to ensure that research participants are protected from any harm potentially arising from their participation in the research process.

Purpose of the Study

This study, part of the requirements of a Ph.D. in sociology, is intended to answer the following question:

With specific reference to the prevention and treatment of malaria, what role does subjective or personal experience play in the construction of medical knowledge and understandings of risk and safety?

I have received a letter of information that describes the project in detail. If I have any questions about the research project, I know that I can ask them at anytime, or contact the thesis committee (as identified above).

Research Format

I am being asked to participate in an interview that will involve the following:

Open-ended and closed-ended interview questions, to elicit information on the process of pharmaceutical regulation in Canada in general and the safety of the drug mefloquine in particular. Each interview will be conducted over the telephone (or in person if I am located in the Ottawa area) and will last up to one hour. I will be sent typed interview notes and given the opportunity to make any changes or additions to my statements. 
Anonymity/Confidentiality

My words, in the form of quotations, may be used in writing up the results of the research. At the beginning of my interview, I will be asked whether I wish to remain anonymous. At that time, I can sign a form stipulating that I wish to waive my right to remain anonymous; otherwise, I understand that my identity will be kept confidential. If I chose to remain anonymous, a letter-number code will be assigned to my interview, and only this code will appear in the published results. It is my understanding that any documents containing information that could reveal my identity will be kept securely, in a locked file cabinet and/or in password-protected files, and that every effort will be made to safeguard my identity.

Right of Withdrawal

I can refuse to answer any question(s) and/or withdraw from the study at any time. In addition, I will be given the opportunity to review the notes from my interview before they are used. I may, at that time, demand that the interview notes be destroyed and not used in the study if I feel that they are inaccurate, or for any other reason. If, however, I do not return the notes or contact the researcher within 30 days of receiving them, it will be assumed that they are accurate and may be used in the dissertation.

\section{Signatures}

\section{Participant:}

I have been informed of what the above-described research entails, and on this basis, agree to participate in the study. I understand that my signature does not in any way constitute a waiver of my rights, and that I may at any time or for any reason withdraw from the study.

Name:

Signature:

Date:

Please indicate the following:

What is the best way to reach you to schedule the interview?

Researcher:

I certify that this form and its attached "Project Description" cover letter provide a complete and accurate description of the aims and processes of this research project.

Name: Kimberly-Anne Ford

Signature:

Date: 


\section{Appendix G Waiver of Anonymity Form for Interview Participants}

Ph.D. Dissertation: "Exploring the Subjective Experience of Risk and Safety and its Role in the Regulation of Pharmaceutical Drugs in Canada"

Kimberly-Anne Ford Department of Sociology and Anthropology, Carleton University, Ottawa Ontario Tel. (613) 992-7900 Fax. (613) 995-5785 E-Mail: kford@.connectmail.carleton.ca

I, __ have been interviewed by Kimberly-Anne Ford for the (print your name)

"Exploring the Subjective Experience of Risk and Safety and its Role in the Regulation of Pharmaceutical Drugs in Canada" project.

I have chosen not to remain anonymous. Kimberly-Anne Ford, Carleton University, and any publications which use material from this research project have my permission to publicly identify me as indicated below and use the transcript of the interview with me (after I have had the opportunity to review and modify it) as an accurate representation of what I have said.

You may identify me by my (please fill in all information that applies to you):

Name:

Title:

Organization:

Signature:

Name:

Title:

Date: 


\section{Appendix H Letter of Information for Survey Participants}

Ph.D. Dissertation: "Exploring the Subjective Experience of Risk and Safety

and its Role in the Regulation of Pharmaceutical Drugs in Canada"

Kimberly-Anne Ford

Department of Sociology and Anthropology, Carleton University, Ottawa Ontario

Tel. (613) 992-7900 Fax. (613) 995-5785 E-Mail: kford@connectmail.carleton.ca

Wednesday, March $24^{\text {th }}, 2004$

Dear [TMP name],

You are being asked to fill out a survey for a Ph.D. research project that is being conducted in the Department of Sociology and Anthropology, at Carleton University. The aim of this thesis is to explore how knowledge on risk and safety is socially constructed, using the case study of the risk of malaria and the use of mefloquine as an anti-malarial drug. The thesis also investigates the process of pharmaceutical regulation in Canada, and looks, in particular, at how personal experience impacts upon this process. My dissertation aims to answer the following question:

With specific reference to the prevention and treatment of malaria, what role does subjective or personal experience play in the construction of medical knowledge and understandings of risk and safety?

To answer this question, I am conducting telephone interviews with individuals who are involved in the regulation of pharmaceutical drugs in Canada. I am also conducting email surveys with individuals who have traveled to malaria-endemic countries. Finally, I am conducting a survey of travel medicine providers.

You are being asked to fill out the enclosed survey. There are 26 questions for you to fill out; this should take you approximately 30 minutes. In this survey, you will be asked questions about the sources of information on malaria and on mefloquine that are available for travellers planning a trip to a malaria-endemic country. You will be asked about the process of pharmaceutical regulation in Canada. You will also be asked about the precautions that you recommend to safeguard travellers from malaria infection.

It is important that you know that I will make every effort to guarantee your privacy and confidentiality. I will be the only person to have access to the data files and the contact information used during this research project. Moreover, there are no personal identifiers included on the survey itself. If you have any questions about this project, feel free to contact me, or a member of my dissertation committee, or the Carleton University Ethics Board (all contact information is provided below). 
I sincerely hope that you will take the time to fill out this survey. If you decide to do so, once you have completed it, please return it in the self-addressed stamped envelope provided for this purpose.

Thank you for your time and consideration.

Regards,

Kimberly-Anne Ford, Ph.D Candidate

Department of Sociology and Anthropology

Carleton University, Ottawa Ontario 


\title{
Appendix I Letter to the Workplace Safety Insurance Board
}

\author{
National Defënce \\ Défense nationale \\ Nayional Delence Headquarters \\ Ottawa, Ontario \\ Ouartier genorarai de la Détense nationale \\ Ottawa (Ontario) \\ K1A OKR \\ KIA OK2 \\ 300000067-5-001 (PMO QOL D/PD) \\ 8 June 2001
}

Workplace Safety and Insurance Board

200 Front Street West

Toronto, Ontario M5V 3J1

To whom it may concern:

Ms Kimberley-Anne Ford is a civilian Defence Scientist (DS-03) in the employ of the Department of National Defence (DND). Ms. Ford is directly employed by the Project Management Office for Quality of Life (PMO QOL). Her duties include the collection of qualitative data through the conduct of focus groups and interviews among personnel at $\mathrm{CF}$ deployment sites.

As part of her duties Ms Ford was required to undertake the immunization protocols to permit her to travel to Africa for the conduct of focus groups aimed at Canadian Forces' members deployed to missions in that area of the world. The anti-malaria drug mefloquine formed part of the prescribed suite of immunizations. The treatment protocol for mefloquine requires that it be taken orally one week prior to departure and four weeks after return from Africa. Prior to the trip, during the week of 5-9 March 2001, Ms. Ford and two other participants in the African site visit received this drug at the National Defence Medical Center. The site visit was conducted without incident from 15 to 18 March 2001. Ms. Ford to continued taking the drug after returning to Canada and, on April $7^{\text {th }}$, she experienced a severe psychological reaction to mefloquine and had to be involuntarily committed to the Psychiatric Unit of the Ottawa Civic Hospital. Ms Ford returned home April $11^{\text {th }}$ with on-going psychological symptoms of her experience with mefloquine. The physician's first report, WSIB Form 8, is enclosed.

It was not until the middle of April that the nature and extent of Ms. Ford's injuries could be determined by her employer, and later still before her condition would permit a visit to progress completion of the necesssary forms and reports. Once Ms. Ford's situation was understood, her employer took steps to place her on "Injury-on-Duty Leave with Pay" in accordance with Article 18.18 of the Defence Scientist Employment Agreement. An excerpt of the pertinent portions of the Agreement is enclosed. Ms. Ford has been on "Injury-on-Duty Leave with Pay" since May $7^{\text {th }}, 2001$. As Ms. Ford has been paid in full during ber period of disability it is believed that any compensation for lost time in the workplace will be paid to her employer, DND.

$1 / 2$

\section{Canadă \\ Printed on recycled paper - Imprimé sur du papler recycié}


Due to the unusual nature of this injury and the absence of clear guidelises withiz the Department for how to report a workplace absence of this type, it has taken some time for PMO QO' to compile the necessary DND and WSIB foms. It is believed, however, that the recent addition to the file of WSID Form $T$ (enclosed) completes the package you requite to progress the necessary alministrative procecures. Should you need, towever, to speak with Ms. Ford's employer, the point of contact in the PMO QOL is Ms. Ford's supervisor,

Colonel

co: CF T.ggal Advisor

(Note: Identifying information has been removed to protect the identity of the author) 


\section{Appendix J Excerpt from the Product Information Sheet (2004), Full Mefloquine and Product Insert (1997) and Pharmacy Print-Out (2001)}

\section{Roche}

February 4, 2004

\section{INFORMATION FOR THE PATENT (excerpt)}

What is the most important information I should know about 'Lariam'?

1. Take 'Lariam' exactly as prescribed to prevent malaria. Malaria is an infection that can cause death and is spread to humans through mosquito bites. If you travel to parts of the world where the mosquitoes carry the malaria parasite, you must take a malaria prevention medicine. 'Lariam' is one of a small number of medications approved to prevent and to treat malaria. If taken correctly, 'Lariam' is effective at preventing malaria but, like all medications, it may produce side-effects in some patients.

2. 'Lariam' can rarely cause serious mental problems in some patients. The most frequently reported side-effects with 'Lariam', such as nausea, difficulty sleeping, and bad dreams are usually mild and do not cause people to stop taking the medicine. However, people taking 'Lariam' occasionally experience severe anxiety, feelings that people are against them, hallucinations (seeing or hearing things that are not there for example), depression, unusual behavior, or feeling disoriented. There have been reports that in some patients these side-effects continue after 'Lariam' is stopped. Some patients taking 'Lariam' think about killing themselves, and there have been rare reports of suicides. It is not known whether 'Lariam' was responsible for these suicides.

If you use 'Lariam' to prevent malaria and you develop a sudden onset of unexplained anxiety, depression, restlessness or irritability, or confusion (possible signs of more serious mental problems), or you develop other serious side-effects, including a persistently abnormal heart beat or palpitations, contact a doctor or health care provider. It may be necessary to stop taking 'Lariam' and use another malaria prevention medicine instead. If you can't get another medicine, leave the malaria area. However, be aware that leaving the malaria area may not protect you from getting malaria. You still need to take a malaria prevention medicine. 

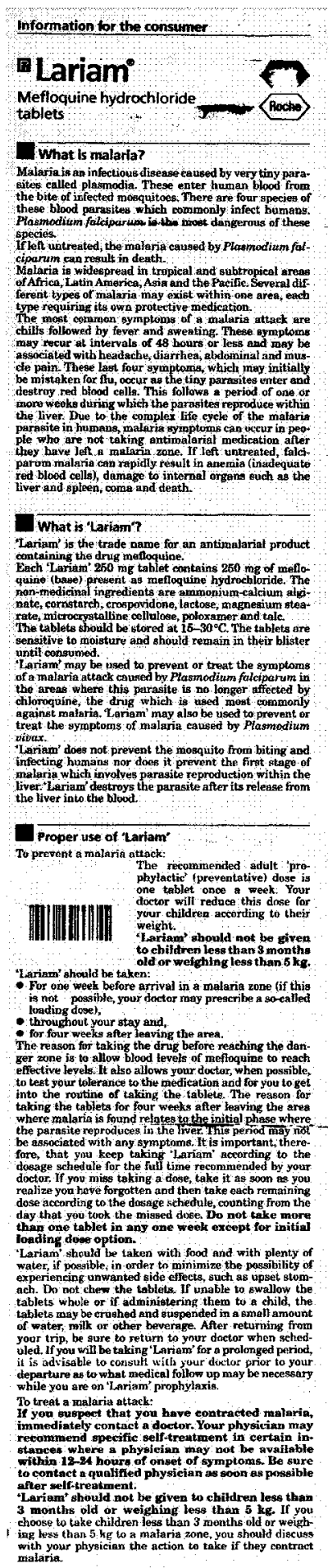

General precautions with 'tariam' 'Tariam' has been prescribed for the prevention or treatthe trip for which it was prescribed Your doctor ho form of maluria found in the regions to which you are

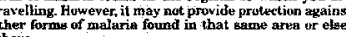

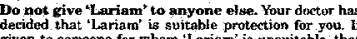
person may not receive appropriate antimalarial prot
tion in the area of destination nad in addition, may be risk of experiencing advest
of the reach of thildren.
2966215 CDN 9807.1072

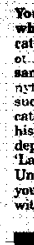
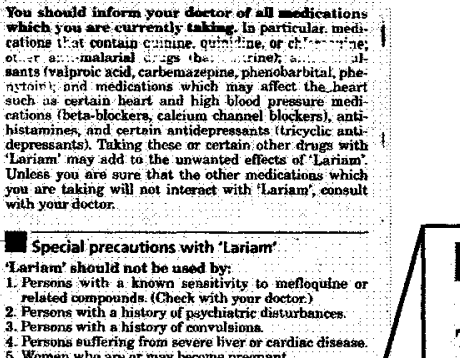

What are the possible unwanted effects of Lariam'?

The following unwanted effects have been reported to occur with Lariam! nausea, vomiting, dizziness, lightKeadedness or loss of balance, headache, sleepiness, inability to sleep, abnormal dreams, loose stools or diarrhea, and abdominal pain. In rarer cases, loss of appetite abnormal heart beat, itching of the skin or skin rash, hair loss, eyesight problems, muscle pains, convulsions, and disturbances of mood (depressed mood, mental confusion, anxiety states) may occur. Because many of these symptoms accompany malaria, it is often difficult to tell whether the symptoms are due to malaria or are unwanted effects of 'Lariam'. When 'Lariam' is used as malaria prevention, these events usually subside within a short period of time after drug administration. If these adverse events are not severe in nature and are tolerable, it is in your best interest to con tinue 'Lariam' prophylaxis since the consequences of contracting malaria are cause for greater concern.

It is best to avoid alcoholic drinks during treatment with 'Lariam'.

You should not operate vehicles or other hazardous machinery or engage in any other activity requiring your full attention until you know how you react to this medicine. If you experience unexplained anxiety, depression, restlessness, irritability, or confusion, stop taking 'Lariam' and consult a doctor immediately. 


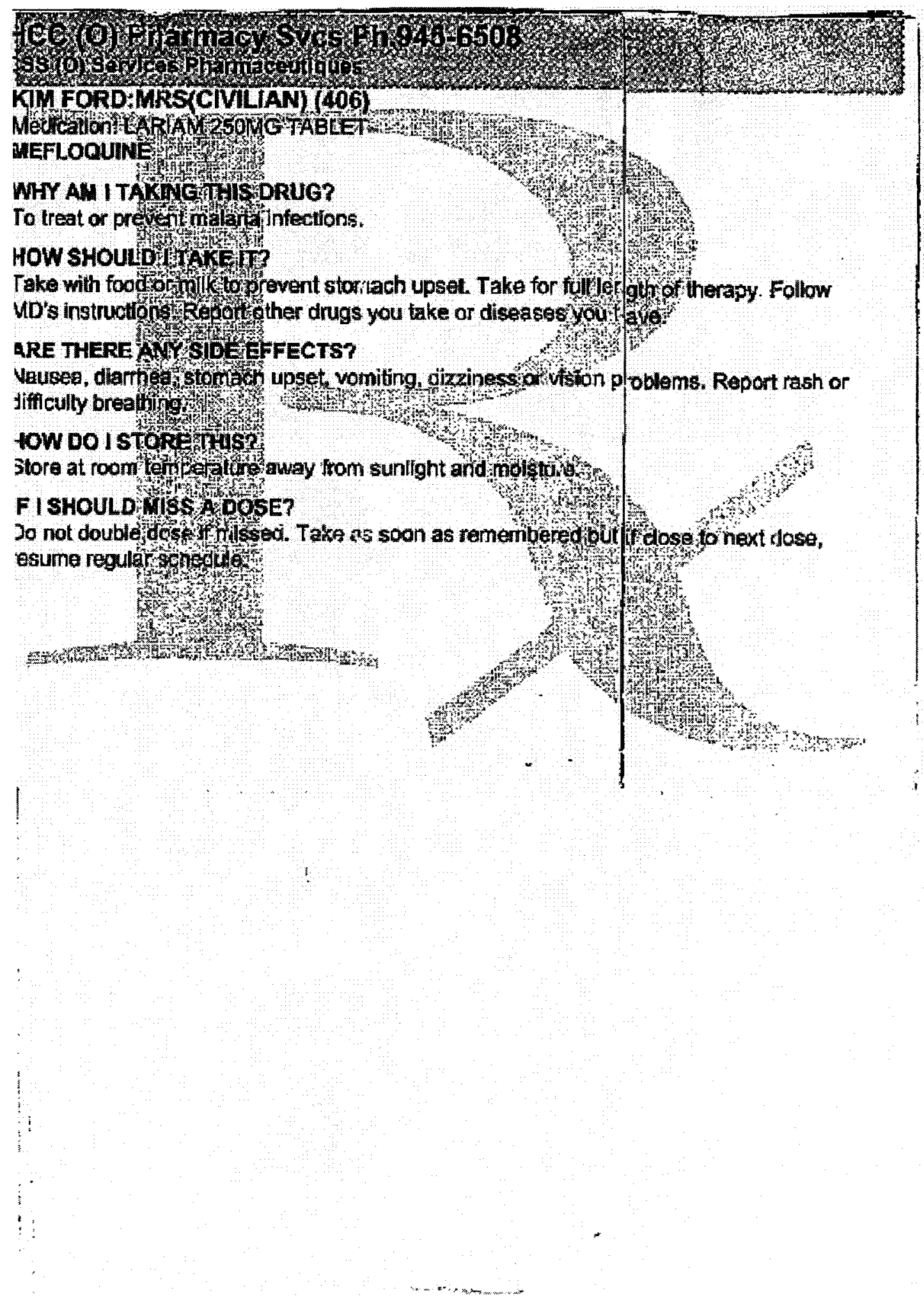




\section{Appendix K Letters of Confirmation of Diagnosis (2)}

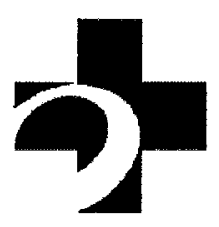

\section{The Ottawa | LHôpital \\ Hospital I dottawa}

$$
0|-04-1|
$$

$$
\begin{aligned}
& \text { To Whan dt Mey Coricen } \\
& \text { ne: Kumbenly Jad } \\
& \text { DOB } 22-10-18
\end{aligned}
$$

Rleas be adruid thet the a bove named

wan achuntted ti losputat ender my care

\begin{tabular}{|c|c|c|}
\hline 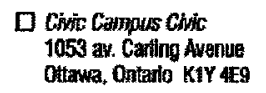 & 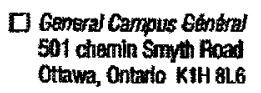 & 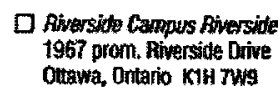 \\
\hline
\end{tabular}

fam 01-04-0 t to 01-04-11. I belueve

that the achurion was pricypitatio by

side effeth of ha ant malariat mudveduen: 
April 16, 2001

To Whom it May Concem,

\section{RE: KIM FORD}

For medical reasons the above mentioned patient is unable to work for a period of one month. At which time she will be re-evaluated. 


\section{Appendix $\mathrm{L} \quad$ Characteristics of Canadian Mefloquine}

\section{Bloggers}

\begin{tabular}{|c|c|c|c|c|}
\hline Blogger \# & Blog Date & Side-effect ${ }^{*}$ & $\begin{array}{l}\text { Self or } \\
\text { other** }\end{array}$ & $\begin{array}{l}\text { Reaction } \\
\text { Symptomes }\end{array}$ \\
\hline 1 & $11-13-03$ & $\mathrm{~N}$ & - & - \\
\hline 2 & $11-09-03$ & $\mathrm{Y}$ & $\mathbf{S}$ & Nausea \\
\hline 3 & $10-26-99$ & $Y$ & $\mathbf{S}$ & Nightmares, got malaria \\
\hline 4 & $10-21-99$ & $\mathbf{Y}$ & Daughter & Vomiting, diarrhoea \\
\hline 5 & $10-29-99$ & N? & - & - \\
\hline 6. & $10-07-99$ & $\mathrm{Y}$ & $\mathrm{S}$ & Under treatment, serious \\
\hline 7. & $09-30-99$ & $\mathrm{Y}$ & $\mathrm{S}$ & Sleep disturbances ringing in ears, high blood pressure \\
\hline 8. & $09-24-99$ & $Y$ & $\mathrm{~S}$ & Serious cognitive impairment \\
\hline 9. & $09-13-99$ & $\mathrm{Y}$ & Daughter & $\begin{array}{l}\text { Lariam toxicity, Heart palpitations, cold sweat, panic, } \\
\text { lasted at least } 4 \text { months }\end{array}$ \\
\hline 10. & 06-02-99 & $\mathrm{Y}$ & $\mathrm{S}$ & $\begin{array}{l}\text { severe and persistent muscular discomfort in low back } \\
\text { and abdomen }\end{array}$ \\
\hline 11. & $07 / 23-99$ & $\mathrm{Y}$ & $\mathrm{S}$ & Panic, hives \\
\hline 12. & $05-13-99$ & $\mathrm{Y}$ & Wife & Wife,pregnant \\
\hline 13. & $03-25-99$ & $\mathrm{Y}$ & $\mathrm{S}$ & "Still having effects" (8 yrs later) \\
\hline 14. & $03-03-99$ & $\mathrm{Y}$ & $\mathrm{S}$ & "Thought I was Crazy!" \\
\hline 15. & $01-04-99$ & $\mathrm{Y}$ & $\mathrm{S}$ & - \\
\hline 16. & $12-02-98$ & $\mathrm{~N}$ & $\mathrm{~S}$ & - \\
\hline 17. & - & - & $\mathbf{S}$ & - \\
\hline 18. & - & $\mathrm{N}$ & $\mathrm{S}$ & Doesn't take anti-malarial drugs \\
\hline 19. & - & $\mathrm{Y}$ & $\mathrm{S}$ & One dose only no details \\
\hline 20. & 08-06-98 & $\mathrm{Y}$ & $\mathrm{S}$ & Bad experience in 1991 \\
\hline 21. & - & - & - & - \\
\hline 22. & $07-09-98$ & $\mathrm{Y}$ & $\mathrm{S}$ & "Thought I was Crazy!" \\
\hline 23. & - & $\mathrm{Y}$ & $\mathrm{S}$ & - \\
\hline 24. & - & $\mathrm{N}$ & $\mathrm{S}$ & - \\
\hline 25. & - & - & - & - \\
\hline 26. & $04-05-98$ & $\mathrm{Y}$ & $\mathrm{S}$ & Loss of skin on hands + feet 63 male \\
\hline 27. & $03-30-98$ & $\mathrm{Y}$ & Friend - died & neuropathy \\
\hline 28. & - & $\mathbf{N}$ & - & - \\
\hline 29. & $10-27-97$ & $Y$ & $\mathrm{~S}$ & Sleep disorders palpitations \\
\hline 30. & $01-21-98$ & $\mathrm{Y}$ & $\mathrm{S}$ & Hallucinations \\
\hline 31. & $10-27-97$ & $\mathrm{Y}$ & $\mathrm{S}$ & Glad I'm not the only one! \\
\hline 32. & - & $\mathrm{Y}$ & $\mathrm{S}$ & Depression, anxiety, anger \\
\hline 33. & Feb 2001 & $\mathrm{Y}$ & $\mathrm{S}$ & 'Nasty vertigo' \\
\hline 34. & $12-08-00$ & $\mathrm{Y}$ & $\mathrm{S}$ & Anxiety, panic, heart palpitations, Weight loss \\
\hline 35. & - & $\mathrm{N}$ & $\mathrm{S}$ & - \\
\hline 36. & $10-15-00$ & $\mathrm{Y}$ & $\mathrm{S}$ & Irrational behaviour \\
\hline 37. & $10-04-00$ & $\mathrm{Y}$ & $\mathbf{S}$ & Hallucinations, seizures. \\
\hline 38. & $08-30-00$ & $Y$ & $\mathrm{~S}$ & Saw 10 M.D.s, Anxiety, skin probs, fatigue, urticaria \\
\hline 39. & $08-27-00$ & $\mathrm{Y}$ & $\mathrm{S}$ & nightmares \\
\hline 40. & $08-03-00$ & $\mathbf{Y}$ & $\mathrm{S}$ & "messed up" wrote a song about it \\
\hline 41. & - & - & - & - \\
\hline 42. & - & $\mathrm{N}$ & $\mathrm{S}$ & - \\
\hline 43. & $03-16-00$ & $\mathrm{Y}$ & $\mathrm{S}$ & "Only a zillion!" \\
\hline 44. & $02-07-00$ & $Y$ & $\mathrm{~S}$ & Malaria symptoms but no malaria \\
\hline 45. & $01-28-00$ & $\mathrm{Y}$ & $\mathrm{S}$ & "completely lost it" said he would report it. \\
\hline 46. & $01-11-00$ & $\mathrm{Y}$ & $\begin{array}{l}\text { Daughter of } \\
\text { friend }\end{array}$ & "Bad side-effects" \\
\hline 47 & $12-15-99$ & $\mathrm{Y}$ & $\mathrm{S}$ & - \\
\hline 48. & $12-14-99$ & $\bar{Y}$ & $\mathrm{~S}$ & No descript \\
\hline 49. & - & - & - & - \\
\hline 50 . & $08-09-98$ & $\mathrm{~N}$ & - & - \\
\hline
\end{tabular}

* Indicates whether or not blogger is reporting a side-effect

** Indicates whether blogger experienced the relationship or whether they are reporting a side-effect experienced by someone else (if later is the case, relationship is also indicated) Bold: Indicates that the reaction was serious enough to alter daily activities Bold and Underline: Indicates that the reaction was life threatening, resulted in prolonged disability, and/or required hospitalisation 


\section{References}

Abraham, Charles, Stephen Clift, and Peter Grabowski. 1998. "Cognitive Precursors of Adherence to Malaria Prophylaxis Regimens on Return from a Malarious Region: a Prospective Study." Social Science and Medicine 48: 1641-1654.

Administracion Nationales de Laboratorios e Intitutos de Salud. 2005. "Malaria o Paludisme." http://www.anlis.gov.ar/consulta/infecciosas/malaria/malaria.htm (last accessed on July 17, 2006).

Ali, S. Harris. 1999. "The Search for a Landfill Site in the Risk Society." Canadian Review of Sociology and Anthropology 36 (1): 1-19.

-. 2002. "Dealing With Toxicity in the Risk Society: the Case of the Hamilton, Ontario Plastics Recycling Fire." Canadian Review of Sociology and Anthropology 39 (1): $29-48$.

-. 2004. "A Socio-Ecological Autopsy of the E. Coli O157:H7 Outbreak in Walkerton, Ontario, Canada." Social Science and Medicine 58 (12): 2601-12.

Atwood, Margaret. 1990. Cat's Eye. London: Little, Brown and Company. Auditor General of Canada. 1999. "1999 Report of the Auditor General of Canada." Auditor General of Canada, Ottawa.

Barrett, P J, P D Emmins, P D Clarke, and D J Bradley. 1996. "Comparison of adverse events associated with use of mefloquine and combination of chloroquine and proguanil as antimalarial prophylaxis: postal and telephone survey of travellers." British Journal of Medicine 313: 525-528.

Bate, Roger and Richard Tren. 2001. Malaria and the DDT Story. London: The Institutes of Economic Affairs. 
Beck, Ulrich. 1992. Risk Society Towards a New Modernity. London: Sage.

—. 1999. World Risk Society. Cambridge: Polity Press.

Benjamin, Mark and Dan Olmsted. 2002a. "Suicide Attempts from FDA Database." http:/www.upi.com/print.cfm?StoryID=20052002-102050-2048r (last accessed on February 05, 2003).

—. 2002b. "UPI Investigates: Lariam and suicide." United Press International. http://www.upi.com/print.cfm?sturyID=20052002-054200-9601r21/05/02 (last accessed on March 03, 2003).

—. 2003. "Navy Coverup Alleged on Side-effects." United Press International. http://www.upi.com/view.cfm?StoryID=20030907-042825-2777r (last accessed on March 10, 2004).

Bergson, Henri. 1911. Creative Evolution. Translated by A. Mitchell. New York: Random House.

Berkes, Fikret, Johan Colding, and Carl Folke. 2000. "Rediscovery of Traditional Ecological Knowledge As Adaptive Management." Ecological Applications 10 (5): 1251-1262.

Bijker, Wiebe E and John Law, ed. 1992. Shaping Technology/Building Society: Studies in Sociotechnical Change. Cambridge Massachussetts: The MIT Press.

Biondi, Lorenzo. 1994. "'Lariam' (mefloquine) IND - Safety Monitoring Study with Limited Distribution of 'Lariam'." Hoffmann-La Roche: Ottawa.

Blackburn, Simon. 1994. Dictionary of Philosophy. Oxford: Oxford University Press. Bourdieu, Pierre. 2004. Science of Science and Reflexivity. Translated by Richard Nice. Chicago: University of Chicago Press. 
Brashers, Dale E., Stephen M. Haas, Renee S. Kingle, and Judith L. Neidig. 2000. "Collective AIDS Activism and Individuals' Perceived Self Advocacy in Physician-Patient Communication." Human Communication Research 26 (3): $372-402$.

Bridgstock, Martin. 1998. "Controversies Regarding Science and Technology." Pp. 83107 in Science Technology and Society, edited by Martin Bridgstock, David Burch, John Forge, John Laurent, and Ian Lowe. Cambridge: Cambridge University Press.

Brown, David. 2003. "Failed Safeguards Are Blamed For Marines' Malaria Outbreak." p. 16 in Washington Post. Washington.

Brown, Peter. 1997. "Culture and the Global Resurgence of Malaria." Pp. 119-141 in The Anthropology of Infectious Disease, Theory and Practice in Medical Anthropology and International Health, edited by Marcia Inhorn and Peter Brown. Amsterdam, Netherlands: OPA Overseas Publisheres Association.

Bueckert, Dennis. 2004. "Scientist Gets Congratulatory Letter from Health Canada After Being Fired." Canadian Press. http://www.healthcoalition.ca/yourfired.pdf (last accessed on September 12th, 2005).

Cameron, Colonel S. 2001. "Surgeon General Council Meeting Issue: Is Mefloquine to Remain a Primary Antimalarial Chemoprophylactic Drug for the CF?" Ottawa: Department of National Defence. Unpublished document received through the Access to Information Program. 
Canadian Broadcasting Corporation (CBC). 1998. "Interview with Dr. J. Keystone, Mefloquine Researcher." in Newsmedia Transcripts - Documentation. Ottawa: CBC.

—. 2003. "Malaria Drug Under Scrutiny After Suicides." http://www/cbc.ca/storyview/cbc/2003/01/28/consumers/malaria_030128 (last accessed on 14 april 2003).

—. 2004a. "Faint Warning: From Coloured Tabs to Computerized Signals: How Canada Tracks Dangerous Drugs." CBC News in Depth. http://www.cbc.ca/news/adr/ (last accessed on July 19, 2006).

—. 2004b. "Health Canada Fires Three Scientists." CBC News in Depth. (last accessed on July 14,2006$)$.

-. 2004c. "Pushing for change." CBC News in Depth. http://www.cbc.ca/disclosure/archives/040217_adr/change.html (last accessed on February 17, 2004).

Canadian Pharmacists' Association (CPA). 2002. Compendium of Pharmaceuticals and Specialities -- The Canadian Drug Reference for Health Professionals. Ottawa, Canada: CPA.

Canadian Television Network (CTV). 1997. "Mefloquine Nightmare." Ottawa, Canada. Castells, Manuel. 2000. The Rise of the Network Society. Oxford: Blackwell. Centre for Disease Control (CDC). 2001. "Malaria Deaths Following Inappropriate Malaria Chemoprophylaxis ---United States, 2001." CDC. 
—. 2003. "Parasites and Health: Malaria."

http://www.dpd.cdc.gov/DPDx/HTML/Malaria.htm (last accessed on July 19, 2006).

Chevalier, Jacques. 2001. "Stakeholder Analysis and Natural Resource Management." Carleton University. http://http-server.carleton.ca/ jchevali/STAKEH2.html (last accessed on Dec 28, 2005).

Christians, Clifford. 2000. "Ethics and Politics in Qualitative Research." Pp. 133-155 in Handbook of Qualitative Research, edited by Norman Denzin and Yvonne Lincoln. Thousand Oaks, California: Sage.

Clarke, Adele E, Janet K Shim, Laura Mamo, Jennifer Ruth Fosket, and Jennifer R Fishman. 2003. "Biomedicalization: Technoscientific Transformations of Health, Illness, and U.S. Biomedicine." American Sociological Review 68 (2):161-194.

Comelles, Joseph M. 2000. "The Role of Local Knowledge in Medicine: A TransHistoric Perspective." Culture, Medicine and Psychiatry 24 (1):47-75.

Cooke, Bill and Uma Kothari. 2001. "The Case for Participation as Tyranny." Pp. 1-16 in Participation -- The New Tyranny?, edited by Bill Cooke and Uma Kothari. London: Zed Books.

Cramer, Jacqueline, Ron Eyerman, and Andrew Jamison. 1987. "The Knowledge Interests of the Environmental Movement and its Potential for Influencing the Development of Science." Pp. 89-115 in The Social Direction of the Public Sciences: Causes and Consequences of Co-Operation between Scientists and Non-Scientific Groups, vol. XI. edited by Stuart Blume, Joske Bunders, Loet 
Leydesdorff and Richard Whitley. Dordrecht, Holland: D. Reidel Publishing Company.

Croft, Ashley M. and Andrew Herxheimer. 2002. "Tolerability of Antimalaria Drugs." Clinical Infectious Diseases 34 (1):1278.

Croft, Ashley M., Dominic P. Whitehouse, C. Gordon, M Cook, and Dominic Beer. 2002. "Safety Evaluation of the Drugs Available to Prevent Malaria." Expert Opinion on Drug Safety 1 (1) :19-27.

Cummins, John. 1999a. "Letter to the Auditor General of Canada." Ottawa. http://www.johncummins.ca/mefloquine.htm (last accessed on July 19, 2006).

—. 1999b. "Lying About Mefloquine Let Me Count the Ways." Ottawa.

http://www.johncummins.ca/mefloquine.htm (last accessed on July 19, 2006).

—. 1999c. "Response on Mefloquine Question Number 138." Ottawa.

http://www.johncummins.ca/mefloquine.htm (last accessed on July 19, 2006).

—. 2002a. "Disastrous Drug Toll on Soldiers Ignored." In August 21, 2002 Ottawa

Citizen: A13.

—. 2002b. "More Concerns on the Government's Handling of Mefloquine." Ottawa. http://www.johncummins.ca/mefloquine.htm (last accessed on July 19, 2006).

—. 2002c. "Order Paper Question on Mefloquine." Ottawa.

http://www.johncummins.ca/mefloquine.htm (last accessed on July 19, 2006).

—. 2004. "House of Commons Debates." Government of Canada.

http://www.johncummins.ca/docs/Q-12\%20FEB\%202\%202004\%20\%20RESPONSE\%20MARCH\%2022\%202004.pdf (last accessed on September $20,2005)$ 
Defert, Daniel. 1991. "Popular Life and Insurance Technology." of in The Foucault Effect: Studies in Governmentality, edited by Graham Burchell, Colin. Gordon and Peter Miller. Hertfordshire: Harvester Weatshaft.

De La Gorgendière, Louise. 2005. "Rights and Wrongs: HIV Research in Africa." Human Organization 64 (2):166-178.

Deleuze, Gilles. 1994. Difference and Repetition. Translated by P. Patton. New York: Colunbia University Press.

Department of National Defence Canada (DND). 1997. "Report of the Somalia Commission of Inquiry on the Mefloquine Issue." Ottawa, Canada. Unpublished Document received through the Access to Information Program.

—. 2002a. "CF Experience with Mefloquine." Ottawa: Department of National Defence. Unpublished document received through the Access to Information Program.

—. 2002b. "Malaria Kills - Malaria Pills Don't: Update on Malaria Pills." Ottawa, Canada. Unpublished Document received through the Access to Information Program.

—. 2002c. "Isssue: Is Mefloquine (Mef) to Remain the Antimalarial Prophylactic Drug (AMPD) of Choice for the CF?" Ottawa, Canada. Unpublished Document received through the Access to Information Program.

Dilman, Don A. 2000. Mail and Internet Surveys. New York: John Wiley and Sons. Douglas, Mary. 1966. Purity and Danger an Analysis of Concepts of Pollution and Taboo. London: Routledge and Kegan Paul.

—. 1992. Risk and Blame: Essays in Cultural Theory. London: Routledge. 
Dreyfus, Hubert L. and Paul Rabinow. 1983. Michel Foucault: Beyond Structuralism and Hermeneutics. Chicago: University of Chicago Press.

Dunn, Jason and Kimberly-Anne Ford. 2004. Civilians in Operations: An Exploration of Research and Policies on the Deployment of Civilians into Military Operations. Ottawa, Canada: Department of National Defence. Prepared for the governments of the United States, the United Kingdom, Canada, Australia and New Zealand under The Technical Cooperation Program (TTCP). Ref.: TR-HUM-1-2004.

Eisenhower, Dwight D. 1961. "Military Industrial Complex." Pp. 1035-1040. Public Papers of the Presidents.

http://coursesa.matrix.msu.edu/ hst306/documents/indust.html (Last accessed on July 19, 2006).

Ellis, Caroly and Arthur Bochner. 2000. "Autoethnography, personal narrative, reflexivity: Researcher as subject." Pp. 733-768 in Handbook of Qualitative Research, edited by Norman Denzin and Yvonne Lincoln. Thousand Oaks California: Sage.

Ewald, Francois. 1991. "Insurance and Risk." of in The Foucault Effect: Studies in Governmentality, edited by Graham Burchell, Colin. Gordon and Peter Miller. Hertfordshire: Harvester Wheatshaft.

FAS, Federation of American Scientists. 1998. "Army Science and Technology Transfer Master Plan." FAS. http://www.fas.org/man/dod101/army/docs/astmp98/sec7a_b.htm (Last accessed on October 4, 2003).

Fekete, Jason. 2002. "Local Soldier Says Drug Triggers Anger: Mefloquine." p. A3 in Edmonton Journal. Edmonton. 
Fine, Michelle, Lois Weis, Susan Weseen, and Loonmun Wong. 2000. "For Whom?

Qualitative Research, Representations, and Social Responsibility." Pp. 107-131 in Handbook of Qualitative Research, edited by Norman Denzin and Yvonne Lincoln. Thousand Oaks, California: Sage.

Ford, Kimberly-Anne and William Hipwell. 2001. "Eros Unbound." Alternatives Journal $27(3): 16-20$.

Foucault, Michel. 1965. Madness and Civilization: A history of Insanity in the Age of Reason. Translated by R. Howard. New York: Random House.

-. 1970. The Order of Things An Archaeology of the Human Sciences. New York: Pantheon Books.

- 1972. The Archaeology of Knowledge. London: Routledge.

- 1973. The Birth of a Clinic: An Archeology of Medical Perception. Translated by A.

Sheridan. New York: Pantheon Books.

- 1977. Discipline and Punish: The Birth of the Prison. Translated by A. Sheridan.

New York: Random House.

-. 1978. The History of Sexuality: An Introduction (La Volonté de savoir), vol. 1.

Translated by R. Hurley. New York: Vintage Books.

—. 1980. Power/Knowledge: Selected Interviews and Other Writings 1972-1977, Edited by Colin Gordon. New York: Pantheon Books.

- 1985. The Use of Pleasure: The History of Sexuality - Volume Two. Translated by Robert Hurley. New York: Pantheon. 
-. 1988. "The Care of the Self: the Ethic of Care for the Practice of Freedom." Pp. 166 in The Final Foucault, edited by James Bernauer and David Rasmussen. Cambridge Massachussetts: M.I.T. Press.

—. 1991. "Governmentality." Pp. 87-112 in The Foucault Effect: Studies in Governmentality, edited by Graham Burchell, Colin. Gordon and Peter Miller. London: Harvester Wheatsheaf.

—. 1997. "The Birth of Biopolitics." Pp. $73-79$ in Michel Foucault: Ethics Subjectivity and Truth, edited by P. Rabinow. New York: New Press.

Furedi, Frank. 1997. Culture of Fear: Risk Taking and the Morality of Low Expectation. London: Cassell.

Gadd, R.E.A. 1996. "Melfoquine (Lariam)." Ottawa: Health Canada. Unpublished Document received through the Access to Information Program.

—. 1997. "Lariam (Mefloquine) - Neuropsychiatric Side-effects." Ottawa, Canada: Health Canada. Unpublished Document received through the Access to Information Program.

—. 1998. "Ministerial Inquiries Regarding Mefloquine." Ottawa, Canada: Canadian Parliament. Unpublished Document received through the Access to Information Program.

Garland, David. 2003. "The Rise of Risk." Pp. 48-87 in Risk and Morality, edited by Aaron Doyle and Richard Ericson. Toronto: University Press.

Gartner, Hana. 2002. "Fifth Estate: The Nightmare Drug." Ottawa, Canada. Transcript received through the Access to Information Program

Geertz, Clifford. 1973. The Interpretation of Cultures. New York: Basic Books. 
Giddens, Anthony. 1999. "Runaway World." in Reith Lecture Series; BBC; Lecture \#2 Risk - Reith Lectures -London School of Economics. Hong Kong: BBC; http://news.bbc.co.uk/hi/english/static/events/reith_99/week2/week2.htm (last accessed on March 10, 2004).

GlaxoSmithKline. 2002. " FDA Approves New Safety Data for Malarone ${ }^{\mathrm{TM}} . "$ GlaxoSmithKilne. http://www.gsk.com/press_archive/press_08232002.htm (last accessed on December 01 2005).

Glaser, Barnie G. and Anslem L. Strauss. 1967. The Discovery of Grounded Theory. New York: Aldine.

Gordon, Colin. 1991. "Governmental Rationality: An Introduction." Pp. 1-86 in The Foucault Effect: Studies in Governmentality. Edited by Graham Burchell, Colin. Gordon and Peter Miller. London: Harvester Wheatsheaf.

Gorman, Diane. 2002. "Health Canada's Regulatory Role in Lariam (mefloquine)." Ottawa: Health Canada. Unpublished Document received through the Access to Information Program.

Greenwood, Davydd J. and Morten Levin. 2000. "Reconstructing the Relationship Between Universities and Society through Action Research." Pp. 85-107in The Handbook of Qualitative Research, edited by Norman Denzin and Yvonne Lincoln. Thousand Oaks, California: Sage.

Gutierrez, Emily C. Zielinski and Carl Kendall. 2000. "The Globalization of Health and Disease The Health Transition and Global Change." Pp. 84-99 in Handbook of Social Studies in Health and Medicine, edited by Gary Albrecht, Ray Fitzpatrick, and Susan Scrimshaw. London: Sage. 
Hackett, L.W. 1947. Malaria in Europe: An Ecological Study. London: University Press.

Hacking, Ian. 1990. The Taming of Chance. Cambridge: Cambridge University Press.

-. 1992. "The Self-Vindication of the Laboratory Sciences." Pp. 29-64 in Science as Practice and Culture, edited by Andrew Pickering. Chicago: University of Chicago Press.

—. 1998. Mad Travelers: Reflections on the Reality of Transcient Mental Illness.

Charlottesville: University of Virginia Press.

—. 2003. "Risk and Dirt." Pp. 22-48 in Risk and Morality, edited by Aaron Doyle and Richard Ericson. Toronto: University Press.

Haggerty, Kevin. 2003. "From Risk to Precaution: The Rationalities of Personal Crime Prevention." Pp. 193-215 in Risk and Morality, edited by Aaron Doyle and Richard Ericson. Toronto: University Press.

Hall, Celia. 2002. "Suicide Warning on Malaria Pills after Cambridge Students' Death." P.5 in Telegraph (UK). London.

Health Canada. 1994. "Health Protection Board Drug Adverse Reaction Program Report of Suspected Adverse Reactions." Health Canada Health Protection Branch, Ottawa. Unpublished Document received through the Access to Information Program.

-. 1995. "Canadian Recommendations for the Prevention and Treatment of Malaria Among International Travellers 1995." Ottawa. Unpublished Document received through the Access to Information Program.

—. 1999. "Lariam (mefloquine)." Ottawa. Unpublished Document received through the Access to Information Program. 
-. 2000. "Canadian Recommendations for the treatment and Prevention of Malaria." Health Canada. http://www.phac-aspc.gc.ca/publicat/ccdr -rmtc/00vol26/26s2/ (last accessed on October 04, 2004).

—. 2000b. "Guidelines for Reporting Adverse Events Associated with Vaccine Products." Health Canada. http://www.phac-aspc.gc.ca/publicat/ccdrrmtc/00vol26/26s1/26sle_e.html (last accessed on August 01, 2006)

—. 2001. "Disease Information: Malaria." Health Canada. http://www.phacaspc.gc.ca/tmp-pmv/info/pal_mal_e.html (last accessed on November 04, 2004).

—. 2002a. "Canadian Adverse Drug Reaction Monitoring Program Form: HC/SC 4016 (04-02)." Ottawa. Unpublished Document received through the Access to Information Program.

—. 2002b. "Health Products and Food Branch Inspectorate Policy" www.hcsc.gc.ca/hpfb-dgpsa/inspectorate (last accessed November 04, 2004).

—. 2002c. "Misconceptions about Malaria and Mefloquine." Health Canada. http://www.phac-aspc.gc.ca/publicat/ccdr-rmtc/00vol26/26s2/26s2n_e.html (last accessed December 12, 2003).

—. 2006. "CADRMP Adverse Reaction Database." The Marketed Health Products Directorate. http://www.hc-sc.gc.ca/dhp-mps/medeff/databasdon/index_e.html (last accessed on July 16, 2006).

Hess, David J. 2004. "Medical Modernisation, Scientific Research Fields and the Epistemic Politics of Health Social Movements." Sociology of Health and Illness: 695-709. 
Hipwell, William T. 2001. "Taking Charge of the Bras d'Or: Ecological Politics in the "Land of Fog"." Ph.D. Thesis, Geography and Environmental Studies, Carleton University, Ottawa.

Hoffmann-La Roche. 1997. "Lariam Product Monograph." Mississauga, Ontario.

—. 2003. "Lariam Brand of Mefloquine Hydrochloride Tablets." Nutley, New Jersey: Roche Pharmaceuticals.

Holder, Martha K. 2003. "Lariam (mefloquine) info."

http://www.indiana.edu/ primate/lariam.html (last accessed on November 11, 2005).

Hughesman, Curtis. 2004. "The Buisness of Biotech." Bio Teach Reviews and Readings. http://www.bioteach.ubc.ca/Bioethics/business/index.htm (last accessed on April $25,2004)$.

Hunt, Alan. 2003. "Risk and Moralization in Everyday Life." Pp. 165-193 in Risk and Morality, edited by Aaron Doyle and Richard Ericson. Toronto: University of Toronto Press.

Icke, Graham and Richard Davis. 2000. "History of Malaria." CDC, Perth. Unpublished document received through the Access to Information Program.

Institute of Health Promotion Research (UBC), Consortium for Health Promotion Research, and The Royal Society of Canada. 1995. "Study of Participatory Research in Health Promotion: Review and Recommendations for the Development of Participatory Research in Health Promotion in Canada." The Royal Society of Canada and University of British Columbia, Vancouver B.C. 
Jackson, Peter. 2001. "Making Sense of Qualitative Data." in Qualitative Methods for Geographers, edited by Melanie Limb and Claire Dwyer Oxford: University Press.

Jones, Major R. 2002a. "Media Response on mefloquine use by Canadian Soldiers." edited by DND. Ottawa: Department of National Defence. Unpublished document received through the Access to Information Program.

—. 2002b. "Media Response Line." Ottawa: Department of National Defence.

Unpublished document received through the Access to Information Program.

—. 2002c. "Mefloquine Proposal - Private." edited by Lt Col Tremblay. Ottawa:

Department of National Defence. Unpublished document received through the Access to Information Program.

—. 2002d. "Mefloquine Proposed MRL." edited by LCol Tremblay Ottawa: Department of National Defence. Unpublished document received through the Access to Information Program.

Jones, Willaim H. 1909. Malaria and Greek History. Manchester: Manchester University Press.

Juckett, Gregory. 1999. "Malaria Prevention In Travellers." American Family Physician (May):7.

Kaplan, Robert. 2000. The Coming Anarchy: Shattering the Dreams of the Post Cold War. New York: Vintage.

Kavanagh, Capt (N) M. 2002a. "Mefloquine follow-up." Ottawa: Department of National Defence. Unpublished document received through the Access to Information Program. 
Kiernan, Nancy Ellen. 2005. "Increasing Your Survey Response Rate: Tipsheet \#74." Penn State Cooperative extension. www.extension.psu.edu/evaluation/pdf/ts74.pdf (last accessed on October 25, 2005).

Kinsman, L.Gen D.N. 1998. "Briefing Note for the DM: Mefloquine." Ottawa: Department of National Defence. Unpublished document received through the Access to Information Program.

Knuutila, Tarja. 2002. "Signing for Reflexivity: Constructionist Rhetorics and its Reflexive critique in Science and Technology Studies." Forum: Qualitative Social Research 3:1-16.

Latour, Bruno. 1983. "Give Me a Laboratory and I Will Raise the World." Pp. 141-171 in Science Observed, edited by Knorr Cetrut and M. Mulleay. Beverley Hills: Sage.

—. 1987. Science in Action. Cambridge Massachusetts: Harvard University Press.

—. 1990. "Drawing Things Together." of in Representation in Scientific Practice, edited by Micheal Lynch and Simon Woolgar. Cambridge: MIT Press.

-. 1994. We Have Never Been Modern. Translated by C. Porter. Cambridge Massachusetts: Harvard University Press.

—. 2004a. "The Last Critique." Harpers:15-20.

-.2004b. Politics of Nature: How to Bring the Sciences into Democracy. Translated by C. Porter. Cambridge Massachussetts: Harvard University Press.

Latour, Bruno and Francoise Bastide. 1986. "Writing Science -- Fact and Fiction." Pp. 51-66 in Mapping the Dynamics of Science and Technology: Macmillan. 
Lee, Shirley. 2004. "The Medicalization of Compulsive Buying." Social Science \& Medicine 58:1709-1718.

Leiss, William. 1972. The Domination of Nature. New York: George Braziller.

Leitch, Robert. 2003. "Advice for the Minister: Lariam - Mefloquine." Ottawa: Heath Canada, Health Products and Food Branch. Unpublished document received through the Access to Information Program.

Lese, Jeanne, Patrick Gregory, and Susan Rose. 2005. "Taken As Directed." produced by Susan Rose, directed by Jason Mills. Channel Three Media Works.

Lexchin, Joel. 1998. "Drug Makers and Drug Regulators: Too Close for Comfort. A Study of the Canadian Situation." Pp. 485-496 in Health and Canadian Society, edited by Carl D'Arcy, George Torrance and David Coburn. Toronto: University of Toronto Press.

—. 2003. "Re-thinking the Numbers on Adverse Drug Reactions - a Letter." CBC Marketplace - Special Report on Adverse Drug Reactions. http://www.cbc.ca/consumers/market/files/health/prescriptions.cmaj1 lletter.html (last accessed on February 17, 2004).

Lexchin, Joel and Barbara Mintzes. 2004. "Transparency in Drug Regulation: Mirage or Oasis?" Canadian Medical Association Jounral CMAJ 171:1503.

Luhmann, Niklas. 1993. Risk: A Sociological Theory. New York: Walter de Gruyter. Lupton, Deborah. 1997. "Foucault and the Medicalisation Critique." Pp. 53-74 in Foucault, Health and Medicine, edited by Alan Peterson and Robert Bunton. London: Routledge. 
Mackenzie, Col R.A.E. 1996. "Briefing Note: Concerns regarding the administration of mefloquine." Ottawa: Department of National Defence. Unpublished document received through the Access to Information Program.

-. 1997. "Briefing Note for the CDS (Chief of the Defence Staff) and MND (Minister of National Defence)." Ottawa: Department of National Defence. Unpublished document received through the Access to Information Program.

Malaria Foundation International (MFI). 1999. "FAQ's: What is the Impact of Malaria on Human Life and Health?" http://www.malaria.org/lifehealth.html (last accessed on October 04, 2003).

Maria, Ana. 1999. "SCOPA Hearing on Mefloquine." SCOPA (Standing Committee on Public Accounts), Canadian Parliament. Ottawa: Directorate of Parliamentary Affairs National Defence Headquarters. Unpublished document received through the Access to Information Program.

McDonald, Dr. P.A. 1992. "Review of Safety Report Update for the 'Lariam Safety monitoring Study'." Ottawa: Infection and Immunology Division Health Canada. Unpublished document received through the Access to Information Program.

McMullin, Ernan. 1992. "Introduction: The Social Dimension of Science." in The Social Dimension of Science, edited by Ernan McMullin. Notre Dame, Indiana: Notre Dame University Press.

McNeill, William H. 1976. Plagues and Peoples. Garden City, New York: Anchor Press. Merrifield, Juliet. 1993. "Putting Scientists in Their Place: Participatory Research in Environmental and Occupational Health." in Voices of Change: Participatory 
Research in the United States and Canada, edited by Peter Park. Westport, Connecticut: Bergin and Garvey.

Mills, C. Wright. 1956. The Power Elites. New York: Oxford University Press.

Mokhiber, Russell. 2000. "Hoffman-La Roche Tops List of Leading Corporate Criminals of Decade." Common Dreams Newswire. http://www.commondreams.org/pressreleases/september99/090299f.htm (last accessed on April 28, 2006)

Morris, David B. 1998. Illness and Culture in the Postmodern Age. Berkeley: University of California Press.

Murphy, Elizabeth. 2003. "Expertise and Forms of Knowledge in the Government of Families." The Sociological Review 51:433-462.

Nietzsche, Friedrich. 1954. "Thus Spoke Zarathustra." Pp. 103-439 in The Portable Nietzsche, edited by W. Kaufmann. New York: Penguin Books.

Overbosch, David, Herbert Schilthuis, Ulrich Bienzle, Ronald H. Behrens, Kevin C. Kain, Paul D. Clarke, Stephen Toovey, Jürgen Knobloch, Hans Dieter Nothdurft, Dea Shaw, Neil S. Roskell, Jeffrey D. Chulay, and the Malarone International Study Team. 2001. "Atovaquone-Proguanil versus Mefloquine for Malaria Prophylaxis in Nonimmune Travelers: Results from a Randomized, Double-Blind Study." Clinical Infectious Diseases 33:1015-1021.

Park, Peter. 1993. "What is Participatory Research? A Theoretical and Methodological Perspective." Pp.i- xxii, in Voices of Change: Participatory Research in the United States and Canada, edited by Peter Park Westport, Connecticut: Bergin and Garvey. 
Parliament of Canada. 1984. "Canada Health Act." in $P R B$ 94-4E.

http://www.parl.gc.ca/information/library/PRBpubs/944-e.htm (last accessed on November 07, 2005).

-. 1985. "Access to Information Act." in R.S., 1985, c. A-1.

http://laws.justice.gc.ca/en/A-1/ (last accessed on November 07, 2005).

Parsons, Talcott. 1951. The Social System. London: Routledge Kegan Paul.

Paton, Cindy. 1996. Fatal Advice: How Safes-Sex Education Went Wrong. Durham:

Duke University Press.

Pickering, Andrew, ed. 1992. Science as Practice and Culture. Chicago: University of Chicago Press.

Platt McGinn, Anne. 2003. "Combating Malaria." Pp. 62-84 in State of the World 2003 -A World Watch Institute Report on Progress Toward a Sustainable Society, edited by Linda Starke. New York: W.W. Norton and Company.

Potts, Annie. 2004. "Deleuze on Viagra or What Can a Viagra Body Do?" Body and Society 10:17-36.

Prothero, R Mansell. 1965. Migrants and Malaria in Africa. Pittsburg: University Press. Puddicombe, Stephen. 2006. "Canada in Afghanistan." CBC.

http://www.cbc.ca/news/background/afghanistan/canada.html (last accessed on 29 May).

Pugliese, David. 2002. "Soldiers Took Drug Linked to Killings." p. A1 in Ottawa Citizen. Renaldo, Sandy. 1997. "Mefloquine Use by Soldiers." in W5. Ottawa: Canadian Television Network. Transcript received through the Access to Information Program. 
Rheaume, Jacques. 1982. "La Recherche Action: Un Nouveau Mode de Savoir?" Sociologie et Societes 14:43-51.

Rose, Nicholas. 1993. "Government, Authority and Expertise in Advanced Liberalism." Economy and Society 22:283-299.

—. 1994. "Medicine History and the Present." Pp. 48-72 in Reassessing Foucault: Power Medicine and the Body, edited by Colin Jones and Roy Porter. London: Sage.

—. 2003. The Neurochemical Self and Its Anomalies. Toronto: University Press.

Rose, Nicholas and Peter Miller. 1992. "Political Power Beyond the State: Problematics of Government." British Journal of Sociology 43:172-205.

Rowlands, Barbara. 2000. "'A Better Pill for Preventing Malaria."' World Reporter. http://dgpadgap.mil.ca/scripts/showfile.asp?URL=/edgpa/Intl/010430/f02649ad.htm (last accessed on April 15, 2003).

Russell, Paul F. 1955. Man's Mastery Of Malaria. London: Oxford University Press. Ryan, Gery and H. Russell Bernard. 2000. "Data Management Analysis and Methods." Pp. 769-803 in The Handbook of Qualitative Research, edited by Norman Denzin and Yvonne Lincoln. Thousand Oaks California: Sage.

Salisbury, Lt Col D.A. 1997. "Briefing Note for the Minister of National Defence." Ottawa: Department of National Defence. Unpublished document received through the Access to Information Program.

Schlagenhauf, Patricia, Alois Tschopp, Richard Johnson, Hans D Nothdurft, Bernhard Beck, Eli Schwartz, Markus Herold, Bjarne Krebs, Regina Allwinn, and Robert Steffen. 2003. "Tolerability of Malaria Chemoprophylaxis in Non-immune 
Travellers to Sub-Saharan Africa: Multicentre, Randomised, Double Blind, Four Arm Study." British Medical Journal 327:1078.

Scott, Col. Ken. 2002a. "Mefloquine." Ottawa: Department of National Defence.

Unpublished document received through the Access to Information Program.

-. 2002b. "Mefloquine and the House of Commons." Ottawa: Department of National

Defence. Unpublished document received through the Access to Information

Program.

Seck, Jacqueline. 1999. "Question Period note: Auditor general report on Mefloquine."

Ottawa, Canada: Health Canada. Unpublished document received through the Access to Information Program.

Sheridan, Alan. 1994. Michel Foucault The Will To Truth. London: Routledge.

Singh, Illina. 2004. "Doing their jobs: mothering with Ritalin in a culture of motherblame." Social Science \& Medicine 59:1193-1205.

Skarbinski, Jacek, M. James Eliades, Louise M. Causer, Ann M. Barber, Sonja Mali, Phuc Nguyen-Dinh, Jacquelin M. Roberts, Monica E. Parise, Laurence Slutsker, and Robert D. Newman. 2004. "Malaria Surveillance -- United States, 2004."

Centre for Disease Control - Morbidity and Mortality Weekly Report. http://www.cdc.gov/mmwr/preview/mmwrhtml/ss5504a2.htm (last accessed on 29 May).

Speth, James Gustave. 2004. Red Sky at Morning: America and the Crisis of the Global Environment - A Citizen's Agenda for Action. New Haven: Yale University Press. 
SurfAid. 2005. "We Save Lives." Surf Aid.

http://www.surfaidinternational.org/site/pp.asp?c=ekLPK4MOIsG\&b=260621 (last accessed on May 9, 2006).

Szasz, Thomas. 2004. "Pharmacracy in America." Society: 54-58.

The Committee to Advise on Tropical Medicine and Travel (CATMAT). 2006. "About CATMAT." Health Canada. http://www.phac-aspc.gc.ca/tmp-pmv/catmatccmtmv/index.html (last accessed on November 07, 2005).

Tremonti, Anna Maria. 2004. "Lariam and Suicide Among Soldiers." in The Current. Ottawa: CBC. Transcript received through the Access to Information Program. Turner, Bryan S. 1987. Medical Power and Social Knowledge. London: Sage.

—. 2000. "The History of the Changing Concepts of Health and Illness: Outline of a General Model of Illness Categories." Pp. 9-23 in Handbook of Social Studies in Health and Medicine, edited by Gay Albrecht, Ray Fitzpatrick and Susan Scrimshaw. London: Sage.

Vaillancourt, Major R. 1997. "Questions and Answers: Acquisition and Use of Mefloquine in Somalia." Ottawa: Department of National Defence. Unpublished document received through the Access to Information Program.

Van Rassel, Jason. 2004. "Brinks bandit freed on parole." p. 1 in Calgary Herald. Calgary.

Van Riemsdijk, Melanie M., Miriam C. J. M. Sturkenboom, Lolke Pepplinkhuizen, and Bruno H.Ch. Stricker. 2005. "Mefloquine Increases the Risk of Serious Psychiatric Events During Travel Abroad: A Nationwide Case-Control Study in the Netherlands." Journal of Clinical Psychiatry 66:199-204. 
Venkatacharya, Hari A. 1993. "Letter Regarding Mefloquine." Ottawa: Health Canada. Unpublished document received through the Access to Information Program.

Vertinsky, Ivan B. and Donald A. Wehrung. 1990. "Risk Perception and Drug Safety Evaluation." Health and Welfare Canada, Ottawa Canada.

Vidich, Arthur J. and Stanford M. Lyman. 2000. "Qualtative Methods: Their History in Sociology and Anthropology." Pp. 37-84 in Handbook of Qualitative Research, edited by Norman Denzin and Yvonne Lincoln. Thousand Oaks, California: Sage.

Wasylycia-Leis, Judy. 1999. "Edited Hansard." Parliament of Canada.

http:/www.parl.gc.ca/36/1/parlbus/chambus/house/debates/187_1999-03-

02/han187_1905-e.htm (last accessed on May 31,2006).

Wheale, Peter. 1984. "Health and Medicine." Pp. 102-123 in People, Science and Technology: A Guide to Advanced Industrial Society, edited by Charles Boyle, Peter Wheale, and Brian Surgess. Sussex: Wheatsheaf Books Ltd.

Wheatley, Elizabeth E. 2005. "Disciplining Bodies at Risk: Cardiac Rehabilitation and the Medicalization of Fitness." Journal of Sport and Social Issues 29:198-221.

World Health Organization (WHO). 2000. "WHO Expert Committee on Malaria Twentieth Report." WHO, Geneva.

—. 2002. "RBM: 2001-2010 United Nations Decade to Roll Back Malaria." WHO. http://www.doh.gov.za/issues/malaria/red_reference/rbm/factsheets/factsheet5.pdf (last accessed on October 04 2004).

—. 2004. "US\$1.5 Billion TO US\$2.5 Billion Needed Annually." World Health Organization (WHO). http://www.afro.who.int/press/2004/pr20041102.html (last accessed on May 29 2004). 
Williams, Greer. 1969. The Plague Killers. New York: Charles Scribner's Sons.

Woolgar, Steven. 1981. "Interests and Explanation in the Social Study of Science." Social Studies of Science 11:365-394. 